\title{
The Great Emancipator? \\ The Impact of the Birth-Control Pill on Married Women in English Canada, 1960-1980
}

by

Jessica Haynes

A thesis submitted to the Faculty of Graduate and Postdoctoral Affairs in partial fulfillment of the requirements for the degree of

Doctor of Philosophy

in

History

Carleton University

Ottawa, Ontario

(C) 2012

Jessica Haynes 
Library and Archives

Canada

Published Heritage

Branch

395 Wellington Street

Ottawa ON K1A ON4

Canada
Bibliothèque et

Archives Canada

Direction du

Patrimoine de l'édition

395 , rue Wellington

Ottawa ON K1A ON4

Canada
Your file Votre référence

ISBN: 978-0-494-93656-6

Our file Notre référence

ISBN: $978-0-494-93656-6$
NOTICE:

The author has granted a nonexclusive license allowing Library and Archives Canada to reproduce, publish, archive, preserve, conserve, communicate to the public by telecommunication or on the Internet, loan, distrbute and sell theses worldwide, for commercial or noncommercial purposes, in microform, paper, electronic and/or any other formats.

The author retains copyright ownership and moral rights in this thesis. Neither the thesis nor substantial extracts from it may be printed or otherwise reproduced without the author's permission.
AVIS:

L'auteur a accordé une licence non exclusive permettant à la Bibliothèque et Archives Canada de reproduire, publier, archiver, sauvegarder, conserver, transmettre au public par télécommunication ou par l'Internet, prêter, distribuer et vendre des thèses partout dans le monde, à des fins commerciales ou autres, sur support microforme, papier, électronique et/ou autres formats.

L'auteur conserve la propriété du droit d'auteur et des droits moraux qui protege cette thèse. $\mathrm{Ni}$ la thèse ni des extraits substantiels de celle-ci ne doivent être imprimés ou autrement reproduits sans son autorisation.
In compliance with the Canadian Privacy Act some supporting forms may have been removed from this thesis.

While these forms may be included in the document page count, their removal does not represent any loss of content from the thesis.
Conformément à la loi canadienne sur la protection de la vie privée, quelques formulaires secondaires ont été enlevés de cette thèse.

Bien que ces formulaires aient inclus dans la pagination, il n'y aura aucun contenu manquant. 


\begin{abstract}
$\underline{\text { Abstract }}$
Beginning in 1961, Canadian women could take a pill and, provided they did so reliably, achieve almost perfect control of their fertility. The pill is rightly understood by many to be one of the most important discoveries of the twentieth century. It is often credited with unleashing a sexual revolution among single women, permitting many of them to engage in premarital sex. However, the experience of married women, for whom the pill was intended, has often been overlooked. Particularly in Canada, the historical scholarship on the pill, which is at present rather limited, focuses on unmarried women. Drawing primarily on oral testimony, my thesis explores the complex impact of the pill on English-Canadian women who started it in the 1960s when married or engaged. By tracing a woman's journey on the pill from the moment she heard about it to some of its more long-term ramifications, I demonstrate that the pill was deeply significant, if not always in positive ways, in the lives of married, Canadian women.
\end{abstract}




\section{Acknowledgements}

I must first express my deep gratitude to the many women who gave generously of their time and spoke candidly about the experiences with the birth-control pill in the 1960s and 1970s. Quiet simply, this project would not have been possible without them. I also wish to thank my supervisor, Dominique Marshall, for her steadfast help and advice. Marilyn Barber, who served as a committee member for my thesis, was a wonderful resource as I learned about and used oral history. My thesis examination board also included Kate Fisher, Hugh Armstrong and Susanne Klausen, all of whom provided invaluable and very constructive feedback on my work. This project benefited greatly from the financial support of Carleton University and the Social Science and Humanities Research Council of Canada.

In the past five years, my family and friends have heard a great deal about contraception and the pill. They always responded with heartening interest and enthusiasm. Most particularly, my husband never lost faith in me or the importance of this project, even on days when I did. Finally, my daughter, who is two years old as I write this, provided much needed perspective and joy during the writing process. She is lucky enough to grow up in a world where birth control is much safer and more effective than in the 1950s and 1960s. Hopefully, by the time she truly appreciates that, there will be even better options. 


\section{$\underline{\text { Table of Contents }}$}

Abstract . ii

Acknowledgements $\quad$ iii

Table of Contents $\quad$ iv

List of Appendices vi vi

1. Introduction 1

History of Birth Control and Family Planning in Canada 3

$\begin{array}{lr}\text { Population Control } & 8\end{array}$

$\begin{array}{ll}\text { The Development of the Pill } & 14\end{array}$

Postwar Canada: Families, Authority and Medicine $\quad 18$

Memories and Representations of the 1960s 23

$\begin{array}{ll}\text { Historiography of Birth Control } & 27\end{array}$

$\begin{array}{ll}\text { Methodology } & 41\end{array}$

Organization of the Thesis $\quad 50$

2. Moving Towards the Pill: The News, The Appeal and The Man's Role 52

How Did Women Hear about the Pill? 53

The Appeal of the Pill $\quad 59$

Husband's Role in Choosing the Pill $\quad 71$

$\begin{array}{ll}\text { Conclusion } & 81\end{array}$

3. Getting on the Pill 83

Did A Ring Matter? Attitudes Regarding Premarital Sex and the Pill 83

What's Age Got to Do With It? 92

The Letter of the Law $\quad 93$

$\begin{array}{ll}\text { Regional Barriers } & 94\end{array}$

$\begin{array}{lr}\text { Too High A Price } & 95\end{array}$

Asking for the Pill $\quad 101$

The Initial Appointment: Discussing Side Effects 108

$\begin{array}{ll}\text { The Need for a Physical? } & 118\end{array}$

$\begin{array}{ll}\text { Check-Ups? } & 124\end{array}$

Appearance and Brand of the Pill 129

$\begin{array}{lr}\text { Forgetting the Pill } & 132\end{array}$

$\begin{array}{ll}\text { Conclusion } & 138\end{array}$

4. Experiencing Side Effects 140

$\begin{array}{ll}\text { The Downside of the Pill: Side Effects } & 140\end{array}$

$\begin{array}{ll}\text { Dealing with Side Effects } & 157\end{array}$

$\begin{array}{ll}\text { Conclusion } & 177\end{array}$

5. Hearing About Side Effects $\quad 179$

$\begin{array}{lr}\text { Friends and Family } & 179\end{array}$ 
The Role of the Media

How Did Women Respond to Reports of Side Effects? 196

Conclusion

6. The Impact of the Pill 205

A Sexual Revolution? 206

The Pill: A Boon to Sexuality? 214

Family Size $\quad 224$

Beyond the Bedroom Door: The Specter of Pregnancy, The Marital 234

Dynamic, and Female Careers

Religion: The Battle within the Catholic Church

244

Religion: The Lingering Unease in Christian Science 259

$\begin{array}{ll}\text { Conclusion } & 261\end{array}$

7. Conclusion 263

Appendix 1

Appendix 2

Bibliography 287 


\section{$\underline{\text { List of Appendices }}$}

Appendix 1- Interviewees and Ethics Clearance Form

Appendix 2- List of Surveys and Studies Consulted on the Pill and Contraception, 1962-1993, Principally focused on Canada, Britain, England, Wales and the United States 


\section{Chapter 1-Introduction}

“...it was my liberation, my freedom, my ability to pursue my profession."”

"It definitely has restricted my freedom."

Here, two married Canadian women of the first generation of users reflect on the very different experiences they had with the pill. Their responses highlight several important findings about the contraceptive. First, it had a profound, if complicated, impact upon married women. Too often the attention, both academic and otherwise, has focused exclusively on the repercussions of the pill on the lives of single women. The assumption is that married women were in a much more comfortable situation and would be better able to handle an unplanned pregnancy, should it arise. While I wish in no way to minimize the very difficult road many unwed pregnant women were forced to travel before the pill, my thesis argues that the lives of their married counterparts could also be seriously disrupted by the arrival of another child, imperiling their health, career and relationships. In addition, historians have pointed out that single women often had restricted access to the pill, particularly in the early 1960s. However, a wedding or engagement ring did not necessarily guarantee a prescription for the pill. Barriers, such as income and the doctor's attitude, sometimes still presented themselves. My thesis will explore the pill's effect on the lives of married women, providing a voice to a group that has often been silent.

The above quotations also dramatically articulate, as my thesis will demonstrate, that pill use by Canadian, married women did not follow a single path or narrative. In the 1960 s, the pill was lauded as the "Great Emancipator" which freed women "from the

\footnotetext{
${ }^{1}$ Interview with Judy Meyer, October 8, 2009, 21.

${ }^{2}$ Interview with Ellen Jackson, October 23, 2009, 28.
} 
tyranny of pregnancy-the oldest, the most natural and thus the harshest tyranny of all."3 However, in reality, it proved not to be that simple. Though some found it incredibly freeing, having a positive influence well beyond the confines of the bedroom, it was not the case for everyone. Some, like Jackson, discovered that side effects could be so problematic that the pill actually sabotaged their freedom and choices. A few also found that the pill trapped them in a new moral dilemma as they struggled to reconcile its use with their religion.

Married women were not alone in their birth-control decisions and experiences. They were surrounded by friends, family, husbands, doctors and the ever-present media. Though women on the pill, as they do now, bore the brunt of the consequences of its use, this did not mean husbands and male partners were disinterested or disengaged. In fact, as I will discuss in this thesis, many were involved in the decision to both take and later drop the pill. A few even steered their wives or fiancées towards it or pressured them to stay on despite side effects. Even more than husbands, doctors were key players during women's years on the pill. The new contraceptive had to be prescribed by a doctor, necessitating a relationship which may not have existed before. My thesis will explore the dynamic between the doctor and the pill user beginning with the initial appointment. Particularly as women navigated their side effects, they had opportunities to be more assertive with the medical profession.

Before analyzing women's experiences on the pill, this introduction will provide information on the history of family planning in Canada, population control, the development of the pill, postwar society, and the 1960s. An understanding of these

\footnotetext{
${ }^{3}$ Douglas Marshall, "The Surprising Social Revolution We've Started with The Pill," Maclean's March 1967, 20.
} 
topics is necessary to make sense of the results of my research. I will also discuss the relevant historiography and the methodology of my project.

\section{History of Birth Control and Family Planning in Canada}

In 1892, at a time when birth control information was seen as obscene, the Canadian Criminal Code was amended, making it illegal to "offer to sell, advertise, publish an advertisement of or have for sale or disposal any medicine, drug or article intended or represented as a means of preventing conception or causing abortion. ${ }^{\text {,A }} \mathrm{A}$ similar law had been enacted in the United States in $1873 .{ }^{5}$ Canadian doctors, at least, were pleased with the law as, in the nineteenth century, they tended to assert that birth control was unnatural and injurious. Indeed, "Abstinence or restraint, intercourse only within prescribed periods, and prolonged nursing were about the only forms of birth control countenanced by physicians." ${ }^{6}$ Despite this medical condemnation and the legislation, Canadian fertility continued to decline, indicating an increasing use of birthcontrol methods. By the late nineteenth century, Canadians wishing to limit their families could use withdrawal, the most popular method, as well as abortion, some form of rhythm or even condoms. The 1930s witnessed an increase in the sale of female birth control such as douches and pessaries. Letters from Canadians to British birth-control advocate Marie Stopes in the mid-1930s indicated a belief "that birth control, by ending

\footnotetext{
${ }^{4}$ The Criminal Code, 1892, 55 and 56 Vict (1892), s 179. Quoted in Angus McLaren and Arlene Tigar McLaren, The Bedroom and The State: The Changing Practices and Politics of Contraception and Abortion in Canada, 1880-1980 (Toronto: McClelland and Stewart, 1986), 9; Brenda Margaret Appleby, Responsible Parenthood: Decriminalizing Contraception in Canada (Toronto: University of Toronto Press, 1999), 4.

${ }^{5}$ McLaren and McLaren, 9; Andrea Tone, Devices and Desires: A History of Contraceptives in America (New York: Hill and Wang, 2001), 3-4.

${ }^{6}$ Wendy Mitchinson, The Nature of Their Bodies: Women and Their Doctors in Victorian Canada (Toronto: University of Toronto Press, 1991), 135, 146, 149-150. Mitchinson implies that eugenics, to be discussed below, may also have informed medical opposition to contraception. She says there was a "concern about birth control...being used by the 'better' classes."
} 
the terrible anxiety of becoming pregnant, would restore sexual pleasure to their marriages and strengthen the marital bond." "7 Very similar sentiments would be expressed by women and pill advocates in the 1960s.

Despite the apparent widespread use of birth control, in contravention of the law; the Canadian birth-control movement remained quite small into the 1960s. In the 1920s, the first supporters of birth control in Canada were socialists and socialist feminists. With the Depression, others, who often had eugenic sympathies, became interested in the birth-control cause. Most notably, rubber manufacturer A.R. Kaufman started providing birth-control information and sterilizations to the employees he had been forced to lay off in $1929 .{ }^{8}$ He expanded his involvement with his Parents' Information Bureau (PIB), based in Kitchener, which, though at first favouring diaphragms, soon began mailing many more contraceptive jellies and condoms. Kaufman also employed nurses to conduct home visits and discuss birth control. It is important to note that "The services of the PIB were restricted to poor married couples." In 1936, Dorothea Palmer, one of the nurses, was arrested in Eastview and charged. She was ultimately acquitted on the basis that her activities were in "the public good." Kaufman continued his PIB and, in a 1962 interview on CBC, said the Bureau had assisted about 220,000 women over the course of its existence. The PIB may have been particularly valued because, as Kaufman

\footnotetext{
${ }^{7}$ McLaren and McLaren, 11-12, 17-23, 24 and 26.

${ }^{8}$ Linda Revie, "More Than Just Boots! The Eugenic and Commercial Concerns behind A.R. Kaufman's Birth Controlling Activities," Canadian Bulletin of Medical History 23, 1 (2006), 125 and 120. In 1930, the Eugenics Society of Canada was established, with Kaufman as Treasurer. Revie argues in her article that Kaufman "became involved in birth control because he was a eugenicist and because he wanted to capitalize on the manufacture of contraceptives."
} 
confirmed, it provided free or at least discounted birth control. He added that it was, after the Palmer case, never again bothered by legal difficulties. ${ }^{9}$

The first Canadian birth-control clinic actually opened not in Kitchener, home of the PIB, but in Hamilton in 1932. Here the movement was spearheaded by an upperclass woman, Mary Hawkins, who had ties to prominent American birth-control activist Margaret Sanger. The clinic primarily provided, after seeing a note from a doctor, diaphragms to married women who had at least two children. ${ }^{10}$ Hamilton birth-control activists were also, like Kaufman, at least partly influenced by eugenic concerns and argued that contraception "would reduce the incidence of venereal disease, tuberculosis, mental deficiency, and, as a result, the tax burden of the middle class."11

Thus, both the PIB and the Hamilton clinic limited access to birth control based on marital status. As I will discuss in Chapter 3, this inequity continued to exist in many birth-control services into the 1960s. Within five years, there were other clinics in Toronto and Windsor. By the end of the 1930s, birth control was considered much more respectable, distanced from its earlier associations with radicalism. ${ }^{12}$ However, services remained patchy and, for some, unsatisfactory into the 1950s. For example, Gilles and Rita Breault, a working-class Quebec couple, faced with their own birth-control dilemma,

\footnotetext{
${ }^{9}$ Revie, 123, 131, 133-134; McLaren and McLaren, 58, 66, 92, 96-97, 102, 105-108, 109-111, 116-117 ; "Looking Back on the Birth Control Movement," Close-Up, CBC Show, broadcast November 11, 1962, interviewer George Reynold, http://www.cbc.ca/archives/categories/health/reproductive-issues/the-birthcontrol-pill/looking-back.html; McLaren and McLaren explain that only those who could afford it, a tiny minority of PIB clients, were charged for their first supply of birth control. In his 1962 interview, Kaufman states that, though everyone paid a registration fee of $\$ 2$, the initial birth control was still almost always free and, thereafter, discounted. He also emphasized at this time that he made no profit from the activities of the PIB. In her article, however, Revie claims that, at least in the 1930 s, he definitely made a profit with diaphragms which his company manufactured for 23 cents and sold for $\$ 1-\$ 3$. Direct quotation in above paragraph from Revie, 131.

${ }^{10}$ McLaren and McLaren, 99-100; Catherine Annau, "Promoting Prophylactics: The Birth Control Society of Hamilton's Very Public Profile," Ontario History LXXXX, 1 (Spring 1998), 49-52.

11 McLaren and McLaren, 102.

${ }^{12}$ Ibid., 92 and 12-13.
} 
learned about a woman's natural cycle and began to share this information with other couples. They formed the Service de régulation des naissances (Seréna) in 1955. Ten years later, Seréna, described by McLaren and McLaren as a "grassroots Catholic movement," ran its own clinic in Quebec and also went out into francophone communities in this province as well as in Ontario and New Brunswick. While it may have been very useful in some respects, the organization had its limitations as it only taught the rhythm method, a contraceptive strategy permitted by the Catholic Church. ${ }^{13}$ Canadians in the 1950s could also get birth control from hospitals but only under very restrictive conditions. Ultimately, as Chatelaine writer Gerald Anglin explained in 1953, "birth control education in Canada is left largely to family physicians." have been a problem for some. According to a pharmacist, whose experiences were included in a 1953 Chatelaine article, the vast majority of Protestant doctors he worked with at the time were willing to prescribe birth control if a patient asked for it. He did not, however, state if patients who requested and received birth control were married. In addition, in order to get birth-control information or devices from a doctor, one had to be able to afford to visit one, as a general practitioner points out in the same article. ${ }^{15}$ Perhaps the Parents' Information Bureau remained a chief source of birth control for Canadians into the 1960 s, as suggested in a 1965 Chatelaine article. ${ }^{16}$ While access may have been uneven, there was certainly a continuing desire for birth control in the 1950 s.

\footnotetext{
${ }^{13}$ Marie-Paule Doyle, "Serena Canada: Twenty Years of Family Planning Action," in Family Planning and Social Work (Ottawa: Health and Welfare Canada, 1976), 30-31; McLaren and McLaren, 131; Constance Mungall, "Birth Control in Canada Today," Chatelaine 38, 4 (April 1965), 20. Religion, particularly Catholicism, is discussed in more detail in Chapter 6.

${ }^{14}$ Gerald Anglin, "The Pill That Could Shake the World," Chatelaine 26, 10 (October 1953), 100-101. Anglin compares this situation to the United States where, according to him, hospitals and governments were much more involved with family planning.

${ }^{15}$ Ibid., 101-102.

${ }^{16}$ Mungall, 18.
} 
One doctor, quoted in Chatelaine magazine in 1953, confirmed that "There is no doubt that most people today believe in proper spacing of children, and more and more we find that young women come to us when they are about to be married for a proper understanding of birth control techniques."17 The nature of these methods will be discussed more in Chapter 2.

The 1960s witnessed some important developments for the family planning movement in Canada, including the establishment of Planned Parenthood of Toronto in 1962 by George and Barbara Cadbury. ${ }^{18}$ By 1965 , hospitals seemed to be more liberal and open in dispensing birth control, despite the illegal nature of such activities. ${ }^{19}$ In a 1962 television interview, Planned Parenthood's Mrs. Cadbury discussed the need to amend Canada's birth-control laws and said "I speak for all the normal parents of Canada, Protestant and Catholic, who don't want to have the twenty-four or twenty-five children that might easily come to them in the course of a normal married life."20 While Kaufman's PIB was never again involved in a prosecution after 1936, this did not mean the law was entirely toothless. Indeed, "in the early 1960 s, a Toronto pharmacist was convicted of selling condoms through the mail.,21

Meanwhile, efforts to legalize birth control continued throughout the decade and were successful in 1969. Many factors explain the decriminalization of contraception at

\footnotetext{
${ }^{17}$ Anglin, 101.

${ }^{18}$ Raymond Boutin, "A History of the Family Planning Movement in Canada," in Family Planning and Social Work (Ottawa: Health and Welfare Canada, 1976), 19-20.

${ }^{19}$ Mungall, 20.

20 "Looking Back on the Birth Control Movement," http://www.cbc.ca/archives/categories/health/reproductive-issues/the-birth-control-pill/looking-back.html; http://www.cbc.ca/archives/discover/programs/c/close-up/close-up-aug-8-1960.html Close-Up, a television show on the CBC, was on the air from 1957 to 1963.

${ }^{21}$ Christabelle Sethna, "The University of Toronto Health Service, Oral Contraception, and Student Demand for Birth Control, 1960-1970," Historical Studies in Education 17, 2 (2005), 270.
} 
this time. Perhaps most notably and simply, the public wanted it. ${ }^{22}$ Gallup Polls indicate a dramatic shift in views. In 1952 , only $48 \%$ of the Canadian population endorsed birth control. Nine years later, that number had jumped to $55 \%$ and, by 1965 , to $66 \%$. A 1975 Gallup Poll found that only $11.7 \%$ still believed that birth control was morally wrong. ${ }^{23}$ The appearance of the pill itself "led members of the Planned Parenthood Federation of Canada, along with doctors and businessmen interested in the scientific and financial advantages of oral contraceptives, to lobby politicians for the reform of the Criminal Code."24 Doctors reversed their position on birth control and "were willing to come forth to defend fertility control because it was now obviously employed by the majority of the population, because their American and British counterparts were supporting it, and because the invention of the intrauterine device (IUD) and the contraceptive pill had made birth control worthy of scientific interest."25 Members of the government, in turn, were receptive because they knew that Canada could not become more involved in international family planning efforts while it still had the 1.892 law on the books. Following legalization, federal funding became available for family planning services. Notably, "in 1970 the Family Planning Division of the national Department of Health and Welfare was established to help fund the programs of the Planned Parenthood Federation at the local and provincial levels."26

Population Control

\footnotetext{
${ }^{22}$ Appleby, 4 and 6; Christabelle Sethna, "A Bitter Pill: Second Wave Feminist Critiques of Oral Contraception," in Canada: Confederation to the Present, eds. Bob Hesketh and Chris Hackett (Edmonton: Chinook Multimedia Inc., 2001), http://chinookmultimedia.com/poccd/registered/web papers/case studies5.php.

${ }_{23}$ "An Increasing Number of People Favor Birth Control," Gallup Report, February 13, 1965, 1-2; Canadian Gallup Poll, June 1975, \#377.

${ }^{24}$ Sethna, 2001..

${ }^{25} \mathrm{McL}$ aren and McLaren, 133.

${ }^{26}$ Ibid., 135.
} 
Indeed, the population control movement would also prove crucial in the fight to legalize contraception in Canada. ${ }^{27}$ This interest in managing and regulating populations predates the twentieth century. In 1798, Thomas Malthus, an Anglican curate, wrote his famous essay reflecting on what he perceived to be a pressing social problem. He claimed that "since the amount of food increased arithmetically, that is at a fixed rate (a statement since proven incorrect), the potentially geometric rate of population growth had to be controlled." Malthus suggested that populations were limited by both deaths and the prevention of births. In the latter case, Malthus emphasized postponing marriage and abstaining from sex. Ironically, given the later influence of his work on both population control and birth control, Malthus felt contraception was repugnant. ${ }^{28}$ This attitude was religiously motivated and likely reflected the fact that the Anglican Church did not approve of artificial birth control until 1930. However, neo-Malthusians, who became most influential in subsequently shaping Malthusian ideas, did not share this opposition and were actually enthusiastic proponents of contraception. ${ }^{29}$

Along with neo-Malthusians, eugenicists were much involved in nineteenth- and early twentieth- century discussions involving population growth and control. ${ }^{30}$ Eugenics built upon Darwinian principles of evolution and surfaced in late nineteenth-century Britain. ${ }^{31}$ It became popular in Canada, as well as other countries, and remained so for

\footnotetext{
${ }^{27}$ Sethna, 2001; Appleby, 201.

${ }^{28}$ Elizabeth Siegel Watkins, On the Pill: A Social History of Oral Contraceptives 1950-1970 (Baltimore: The Johns Hopkins University Press, 1998), 15; Appleby, 162.

${ }^{29}$ Linda Gordon, The Moral Property of Women: A History of Birth Control Politics in America (Chicago: University of Illinois Press, 2007), 41-42; Appleby, 162. Gordon labels neo-Malthusians anticlerical. Perhaps their hostility to religion explains why they did not share Malthus' view on contraception.

${ }^{30}$ Lara V. Marks, Sexual Chemistry: A History of the Contraceptive Pill (New Haven: Yale University Press, 2001), 16-17.

${ }^{31}$ Ibid., 17; Wendy Kline, Building a Better Race: Gender, Sexuality and Eugenics from the Turn of the Twentieth Century to the Baby Boom (Berkeley: University of California Press, 2001$), 3$.
} 
much of the twentieth century. ${ }^{32}$ Both neo-Malthusians and eugenicists were troubled by statistics suggesting that better educated and wealthier individuals were having fewer children while their poorer counterparts continued to have many. They urged "fitter" groups to have larger families while simultaneously looking for ways to curtail the fertility of those perceived to be inferior. ${ }^{33}$ Initially, eugenicists "opposed contraception on the grounds that it was employed by the very families who should have been encouraged to reproduce. It thus contributed directly to the differential birth rate-the unfit having large families and the fit having small families." However, by the 1920s, it had become clear that the "fit" groups in society could not be persuaded to give up fertility control and, thus, some eugenicists began to emphasize the need for universal access to contraception. ${ }^{34}$ The reconciliation of eugenics to contraception was no doubt furthered by birth-control advocates who, in the 1910s and 1920s, began to utilize eugenic rhetoric and emphasize their shared goals. ${ }^{35}$

While eugenicists were concerned about the quality of a nation's populace as well as general declines in birthrates, after 1945 there was growing anxiety about possible excess in the planet's inhabitants. ${ }^{36}$ World population did appear to be increasing substantially, jumping from 1.6 billion to 3 billion between 1900 and $1960 .{ }^{37}$ Some

\footnotetext{
${ }^{32}$ Angus McLaren, Our Own Master Race: Eugenics in Canada, 1885-1945 (Toronto: McClelland and Stewart, 1990). On American eugenics, see Rebecca M. Kluchin, Fit to Be Tied: Sterilization and Reproductive Rights in America, 1950-1980 (New Brunswick: Rutgers University Press, 2009); Alexandra Stern, Eugenic Nation: Faults and Frontiers of Better Breeding in Modern America (Berkeley: University of California Press, 2005).

${ }^{33}$ Marks, 16-17, Kline, 2; Kluchin, 2.

${ }^{34}$ McLaren, 78 and 81.

${ }^{35}$ Linda Gordon, Woman's Body, Woman's Right: A Social History of Birth Control in America (New York: Penguin Books, 1976), 279-284.

${ }^{36}$ Gordon, 2007, 280; Gordon, 1976, 279, 391, 395-396. Gordon argues that many eugenicists, at least in the United States, actually morphed into population controllers and that this new discourse took over birthcontrol organizations.

${ }^{37}$ Elaine Tyler May, American and the Pill: $A$ History of Promise, Peril, and Liberation (New York: Basic Books, 2010), 36.
} 
individuals in Western countries were particularly concerned that the unchecked growth of underdeveloped nations would lead to regional poverty and make these areas vulnerable to the lure of Communism. ${ }^{38}$ If much of the leadership of the population control movement was American, it had a broader reach. ${ }^{39}$ For instance, in 1952 , Margaret Sanger helped set up the International Planned Parenthood Federation. ${ }^{40}$

Certainly, Canadians were aware of and influenced by concerns about overpopulation. According to a 1953 article in Chatelaine magazine, millions of people had read the 1948 book by Dr. William Vogt entitled Road to Survival. Dr. Vogt, who was later appointed director of the Planned Parenthood Federation of America, conveyed in his book a sense of urgency, asserting that overpopulation had already caused many starvation deaths. He advocated the curtailing of populations and the sensible preservation of crucial resources. ${ }^{41}$ In addition to the menace of Communism which could prey on the Third World, population control experts "warned [Canadians] that domestic population growth would double rapidly. The consequences would be felt in crowded cities, water and air pollution, housing shortages and inadequate hospitals, schools and transportation."

Fuelled by these dire predictions of both domestic and international chaos, population control rhetoric continued to percolate in Canada throughout the $1960 \mathrm{~s}$. The Population Bomb, a 1968 best-selling book by American biology professor Paul Ehrlich, may have contributed to keeping the ideas in the public mind. He asserted that food

\footnotetext{
${ }^{38}$ Sethna, 2001; Christabelle Sethna, "The Evolution of the Birth Control Handbook: From Student PeerEducation Manual to Feminist Self-empowerment Text, 1968-1975," Canadian Bulletin of Medical History 23, 1 (2006), 99.

${ }^{39}$ May, 41.

${ }^{40}$ Marks, 27.

${ }^{41}$ Anglin, 103

${ }^{42}$ Sethna, 2006, 98-99.
} 
supplies could not possibly keep up with the demands of teeming populations and advocated a somewhat extreme and harsh solution. Ehrlich urged that "Populations determined to be able to survive alone would receive food aid [from developed nations]; others would be left to starve or survive independently. ${ }^{, 43}$ In the late 1960s, Ehrlich helped found the Zero Population Growth movement which focused on the domestic arena and pressured Americans to only have two children. ${ }^{44}$ Testifying to the popularity and prevalence of population control ideas, many different Canadians drew on this rhetoric to justify the legalization of birth control in $1969 .^{45}$

Several Canadians may have used population control to change the law and many were possibly alarmed by the grim future painted in the work of Vogt and later Ehrlich. This did not mean they embraced these ideas with abandon. For example, early editions of McGill University's Birth Control Handbook, published in 1968 and 1969, seemed to accept that birth control could help stem overpopulation. However, the third edition, also published in 1969, was much more critical of this discourse, suggesting it had racist undertones. The editors went even further in subsequent versions, blaming Third World problems on American capitalism and denouncing Paul Ehrlich and his Zero Population Growth. ${ }^{46}$

Even in the early $1950 \mathrm{~s}$, before it was produced or available, the birth-control pill was perceived to be a potential solution to the problem of overpopulation. In 1953, Chatelaine magazine announced that a pill capable of preventing conception was on the

\footnotetext{
${ }^{43}$ May, 44; Matthew Connelly, Fatal Misconception: The Struggle to Control World Population (Cambridge: Belknap Press of Harvard University, 2008), 258-259; Sethna, 2006, 101. Direct quotation in above from Sethna.

${ }^{44}$ May, 44-45.

${ }^{45}$ Sethna, 2006, 99.

${ }^{46}$ Ibid., 99-101; May, 44.
} 
horizon. The article, by Gerald Anglin, went on to say that "Some thoughtful men believe...that such a pill could save the world from a threat they consider greater than the atom bomb-the threat of world over-population which is already taking a staggering toll in human life and misery. ${ }^{, 47}$ Certainly, Margaret Sanger and her associate Dr. Gregory Pincus, two developers of the pill, were concerned about this issue. ${ }^{48}$ Indeed, "The pill was intended primarily as a family-planning aid for married, not single, women in the First World and as a population-control tool in the Third. ${ }^{, 49}$ How influential was the discourse of population control on individual views and choices? Historian Elaine Tyler May points out that many, like the editors of the Birth Control Handbook, were not necessarily sold on population control. ${ }^{50}$ A Canadian Gallup Poll from March of 1960 devoted to general issues seems to confirm this. Of those polled, $53 \%$ claimed they had never even heard about the "population explosion" and of those who had, only $18.6 \%$ were concerned. ${ }^{51}$ However, this may have changed as the decade wore on. A 1971 survey of married women in Halifax found a majority of respondents, across all socioeconomic groups, believed that global populations were unsupportable. ${ }^{52}$ The reaction of individuals to this rhetoric will be further analyzed in Chapter 6 .

\footnotetext{
${ }^{47}$ Anglin, 17; Valerie Korinek, Roughing It in the Suburbs: Reading Chatelaine Magazine in the Fifties and Sixties (Toronto: University of Toronto Press, 2000), 44-45. According to Korinek, by at least 1952 Anglin was a managing editor of the magazine.

${ }^{48}$ Sethna, 2001. This work will be discussed below.

${ }^{49}$ Christabelle Sethna, " 'Chastity Outmoded!' The Ubyssey, Sex, and the Single Girl, 1960-1970" in. Creating Postwar Canada: Community, Diversity, and Dissent, 1945-1975, edited by Magda Fahrni and Robert Rutherdale (Vancouver: UBC Press, 2008), 293.

${ }^{50}$ May, 50.

${ }^{51}$ Canadian Gallup Poll, March 1960, \#281. This particular poll covered a range of topics, including women's fashion, believes concerning an afterlife, use of credit and divorce. The record does not indicate who commissioned the poll.

${ }^{52}$ Virginia K. Elahi, "A Family Planning Survey in Halifax, Nova Scotia," Canadian Journal of Public Health, 64 (November/December 1973), 519. Elahi actually found that the pervasiveness of this idea was inversely related to socio-economic status, causing her to conclude "it is possible that those with a higher education are more critical of the information they receive about the world population situation." See Appendix 2 for details on this survey.
} 


\section{The Development of the Pill}

The birth-control pill first became available in Canada in 1961. Knowledge of hormones and the female reproductive system had advanced considerably in the first half of the twentieth century. In the 1950s, it became possible to synthesize progesterone and, by 1957, two American drug companies had done so. G.D. Searle was at the forefront of this research and employed Gregory Pincus as a consultant. ${ }^{53}$ Pincus, a biologist who had once taught at Harvard University, specialized in mammalian sexual physiology. In 1944, he had co-founded the Worcester Foundation for Experimental Biology to "strengthen ties between practical medicine and biology through pharmaceutical science." The foundation particularly focused on research into steroids. ${ }^{54}$ However, in late 1950 or early 1951 , he was introduced by Dr. Abraham Stone to someone who would have a profound effect on his life and career. ${ }^{55}$

Margaret Sanger had been an outspoken birth-control advocate for much of the twentieth century. Growing up, she saw the detrimental effects of repeated pregnancies on her mother who had eleven children and suffered from tuberculosis, dying untimely at the age of fifty. Sanger's views about the need for reliable birth control were further enforced by her work as a nurse in New York City. ${ }^{56}$ Throughout the 1920s, Sanger, and the American Birth-Control League she had founded, opened clinics to provide contraception. During these years, Sanger worked tirelessly to promote the diaphragm. ${ }^{57}$ However, "in the late 1940s, Sanger became increasingly dissatisfied with the diaphragm

\footnotetext{
${ }^{53}$ Watkins, $21-22$ and 24.

${ }^{54}$ Marks, 55; Watkins, 20; Tone, 209. Direct quotation from Tone.

${ }^{55}$ Marks, 54; Gordon, 2007, 181. Dr. Stone was affiliated with the Planned Parenthood Federation of America and worked as the director of the Margaret Sanger Research Bureau. The Bureau had opened in 1923 as "a birth control clinic that would serve also as a center for the medical study of contraception." ${ }^{56}$ Marks, 51-52.

${ }^{57}$ Tone, 118, 122-132.
} 
and spermicidal jelly method of contraception...because it appealed to a limited audience of women worldwide. Millions of women lacked the sanitary facilities necessary for hygienic use of the diaphragm; others disliked the intimate physical contact it required." 58 Now, she wanted a contraceptive pill, a possibility that had occurred to her decades earlier. ${ }^{59}$ Above all, Sanger envisioned a world in which women would be able to control their fertility without having to rely on the cooperation of men. ${ }^{60}$ In the early $1950 \mathrm{~s}$, she met Gregory Pincus and convinced him to turn his attention and expertise towards developing a contraceptive pill. ${ }^{61}$

Following this meeting, "Pincus initiated investigations into the effects of progesterone and synthetic progestins on ovulation and fertilization." To facilitate his work, G.D. Searle supplied Pincus with several hormone compounds as did other drug companies, including Syntex. He found in both rabbits and rats that ovulation was inhibited. The results also concluded that two products, "Searle's norethynodrel and Syntex's norethindrone...[were] the most promising antifertility compounds. ${ }^{, 62}$ Thus, this early research was supported in part by drug companies. However, while Searle may have provided him with the synthetic hormones as well as some money, the company did not finance his project until much later. ${ }^{63}$ As one can imagine, developing a contraceptive pill was not a cheap undertaking. Though Pincus benefited from Planned Parenthood Federation of America support in the early 1950s, their contributions only allowed him to carry out animal studies and were by no means sufficient to meet his

\footnotetext{
${ }^{58}$ Watkins, 14.

${ }^{59}$ Ibid.; May, 18.

${ }^{60}$ Marks, 52-53.

${ }^{61}$ Watkins, 20-21; Marks, 54.

${ }^{62}$ Watkins, 25, 27-28.

${ }^{63}$ Ibid., 25.
} 
research goal of developing a contraceptive pill. ${ }^{64}$ Luckily for him, and the many women eager for a birth-control pill, he soon had other sources of revenue, thanks again to the intervention of Margaret Sanger.

Sanger persuaded her friend and very wealthy heiress, Katherine Dexter McCormick, to almost single-handedly finance Pincus's work. McCormick threw her considerable resources behind Pincus. Ultimately, she would contribute approximately $\$ 2$ million to the project. ${ }^{65}$ Consequently, the production of the pill owes a great deal to Margaret Sanger and Katherine McCormick.

With this support in place, Pincus could continue his work. When it was time for human trials, Pincus recruited an obstetrician-gynecologist, Dr. John Rock, to become part of the project. Dr. Rock had made a name for himself treating infertility. He injected women who had trouble conceiving with progesterone and estrogen. He hoped that "the temporary cessation of ovulation would give the womb a forced sabbatical, enabling it to be more effective once regular, unimpeded functions resumed" and indeed, after discontinuing this treatment, some were able to get pregnant, a result that gynecologists labeled the "Rock rebound." W6 With Pincus, Rock administered norethindrone and norethynodrel to fifty infertile women in 1954 and 1955 . He was chiefly interested in whether these compounds could create the "Rock rebound" effect. However, as part of this project, he was able to confirm to Pincus that they successfully prevented ovulation. ${ }^{67}$

\footnotetext{
${ }^{64}$ Marks, 55-56.

${ }^{65}$ Tone, 214.

${ }^{66}$ Watkins, 28-29; Tone, 216.

${ }^{67}$ Watkins, 29; Tone, 217-218.
} 
Before proceeding with a large-scale clinical trial, Pincus and Rock had to select one product. Ultimately, norethindrone was excluded because of some concerns it could lead to masculinization. In addition, "the long-standing relationship between Pincus and Searle surely played some role in the decision. Furthermore, Searle's compound benefited from the accidental contamination of norethyndrel with a tiny amount of estrogen...This combination actually reduced breakthrough bleeding during the cycle of treatment. ${ }^{, 68}$ The chosen compound would be marketed under the name Enovid. ${ }^{69}$

Requiring a large group of participants, Pincus turned to Puerto Rico. This site was attractive to him because, amongst other reasons, "he thought working there would allow him to avoid the press and premature publicity; because overpopulation contributed to poverty in Puerto Rico; and because he believed Puerto Rican women to be tractable and unlikely to protest. ${ }^{.70}$ It was also helpful that Pincus and Rock already had contacts at the University of Puerto Rico School of Medicine, and that a family planning movement, complete with birth-control clinics, was already well established on the island. Finally, the female population was "keen for contraception and most were semiliterate or fully illiterate, and had large families. They were therefore considered perfect models for testing whether the pill could be used for women around the world, particularly in places where population problems were thought to be at their worst."

\footnotetext{
${ }^{68}$ Watkins, $30-31$.

${ }^{69}$ Marks, 75 .

${ }^{70} \mathrm{Ibid}$., 101; Gordon, 2007, 287. Direct quotation from Gordon.

${ }^{71}$ Gordon, 2007, 287; Watkins, 31; Marks, 101. Direct quotation from Marks. Marks added that Puerto Rico was quite accessible from the United States, which would facilitate supervision of the trials, and that "many of its medical practitioners were American trained.".
} 
By 1958, 830 women in Puerto Rico as well as Haiti had participated in trials, making them among the earliest users of Enovid. ${ }^{72}$ The scientists concluded that it was very effective but even then there were reports of side effects including nausea, headaches and dizziness, suggesting a potentially troubling pattern. ${ }^{73}$ Regardless, in 1960, the American Food and Drug Administration approved Enovid for birth-control use and Canadian authorities did likewise in $1961 .^{74}$ Within eight years, an estimated 500,000 Canadian women were taking the pill. ${ }^{75}$ A 1971 survey in Halifax confirmed the pill's rapid dominance of the birth-control market, at least among married women. Of the respondents using contraception, $49.4 \%$ relied on the pill. Rhythm, IUDs and condoms were much less popular alternatives. ${ }^{76}$ Thus, a large number of Canadian married women, whose personal experiences have not been studied, were relying on the pill by the early 1970s. The following sections will contextualize their birth-control decisions by considering Canadian society in the postwar period and the 1960 s.

\section{Postwar Canada: Families, Authority and Medicine}

In May of 1945, my grandfather stepped off a train in Ottawa and into the arms of my grandmother. He had been gone a long time, serving as a flight navigator and then spending four years in a German Prisoner of War camp. Engaged since 1940, they quickly married in July and moved to an apartment in Ottawa on Somerset Street. In 1947, they had their first child and, four years later, bought a new house in the developing suburbs off Carling and Broadview Avenues. At the time, my great-

\footnotetext{
${ }^{72}$ Watkins, 32. Watkins mentions trials in Haiti but does not say why this site was chosen. One assumes it shared some of the characteristics of Puerto Rico, such as poverty and overpopulation.

${ }^{73}$ Ibid., 31-32.

${ }^{74}$ Sethna, 2001; Tone, 226; Sethna, 2008, 293. The FDA had already, in 1957, approved Enovid, as well as norethindrone, to treat gynecological conditions. Though not giving a precise date, Sethna says in her 2008 article that similarly "the pill was introduced into Canada in the late 1950 s, first as a menstrual regulator." ${ }^{75}$ Sethna, 2001.

${ }^{76}$ Elahi, 516 and 517.
} 
grandmother wondered why they wanted to live there, in an area that was neither town nor country and lacked many amenities. However, the house and neighbourhood met their long-term needs and they stayed there happily, welcoming my mother in 1951.

The experiences of my grandparents mirrored that of many other young couples in postwar Canada. At the end of World War Two, following decades of social and economic upheaval, they were often eager to get on with their lives. They married, had children and bought homes in very high numbers. The Canadian baby boom was soon in full swing with births climbing from "just over 300,000 at war's end to 372,000 by 1947 , and to more than 400,000 by $1952 ., 77$ Many of these young families made their homes in the ever-growing suburbia, attracted by the space and plethora of single-family dwellings. Indeed, by 1960 , over one million Canadians had moved to the suburbs. In light of the baby boom and the popularity of these areas, it is not surprising that both suburbs and postwar society itself became very child-centric. ${ }^{78}$

The parents of the baby boomers, possibly bolstered by a wave of economic prosperity and the advances of modern medicine which protected the young from death and disease, had high expectations for their children's lives. However, society made its own demands of the postwar family. ${ }^{79}$ During the early Cold War, the family was not only to provide emotional comfort and joy but was expected to contribute to the struggle against Communism by bolstering the economy and raising the next generation of democratic Cold War warriors. Ultimately, "This strategy contributed to the fear that the

\footnotetext{
${ }^{77}$ Doug Owram, Born at the Right Time: A History of the Baby Boom Generation (Toronto: University of Toronto Press, 1996), 7-9, 6, 56 and 4.

${ }^{78}$ Jessica Haynes, "The Legacy of Scientific Motherhood: Doctors and Child-Rearing Advice in the 1960s and 1970s in English Canada," (Master's Thesis, Department of History, Carleton University, 2007), 50; Owram, 55, 59 and 5.

${ }^{79}$ Owram, $x, 51$ and 32 .
} 
survival of the middle-class family in Western countries and democracy were inextricably linked."80

During the early Cold War, it was easy to embrace moral certainty. In Western countries, there was a strong consensus about the evils of Communism and the need to rally against it. However, beginning in the late 1950 s, cracks began to appear in this foundation. Significantly, countries newly released from colonialism seemed to be freely choosing Communism as their new governing system. This made it more difficult to position Communism as anathema to democracy. Particularly, Cold War rhetoric did not provide a convincing rationale for the protracted conflict in Vietnam. Dissent with Cold War tactics was expressed by groups, such as the Combined Universities Campaign for Nuclear Disarmament, in Canada as well as the United States. Domestically, there were more signs of growing unease. First, anti-Americanism resurfaced in political discourse with a vengeance during the 1963 Canadian federal election. Disillusionment with the United States may also have been strengthened by the suppression, which seemed contrary to democratic values, of the American Civil Rights movement. Indeed, "the most important impact of the civil-rights movement was the way it legitimized resistance to governmental authority." All these developments contributed to a more general critique of authority articulated during the $1960 \mathrm{~s}^{81}$

Medicine, during this period, came under particular scrutiny. ${ }^{82}$ Just as Communists had been easily cast as the villains in the early postwar years, doctors had been made to play the part of heroes. Indeed, in the 1950s, Western medicine had been riding high, buoyed by the recent discoveries of polio vaccines and antibiotics. People

\footnotetext{
${ }^{80}$ Haynes, 48.

${ }^{81}$ Owram, 161-167; May, 117-118; Watkins, 73. Direct quotation in above from Owram, 167.

${ }^{82}$ May, 126-127; Watkins, 73.
} 
watched with relief, as dreaded childhood diseases and dangerous infections were practically vanquished. In fact, "by mid-century the dramatic success of the biomedical paradigm had created great prestige for medical researchers and practitioners, public adulation for the profession, and heightened expectations of new triumphs." Statistics from the first half of the twentieth century, showing a decline in infant mortality and an increasing life expectancy, were used to confirm the achievements of medicine. ${ }^{83}$

The celebration, however, would be short-lived as it soon became clear that medicine was not infallible nor did it necessarily hold the solutions to all health problems. First, antibiotics proved insufficient as bacteria adjusted. Furthermore, medicine continued to have few weapons to fight chronic and dangerous diseases, like cancer. ${ }^{84}$ Critics also "began to draw attention to the fact...that more of the improvement in health over the past century had arisen from factors such as enhanced food supplies and better sanitation than from interventions by orthodox biomedicine." ${ }^{, 85}$ Medical care and the medical profession were characterized as, amongst other things, impersonal and paternalistic. ${ }^{86}$ Finally, the credibility of medicine was seriously undermined by the thalidomide tragedy which played out in the early 1960s. Thalidomide was a tranquilizer

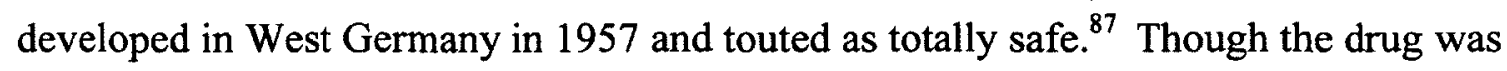
marketed to treat many problems, thalidomide was "recommended for pregnant women

\footnotetext{
${ }^{83}$ Allan M. Brandt and Martha Gardner, "The Golden Age of Medicine?" in Roger Cooter and John Pickstone, eds., Medicine in the Twentieth Century (Amsterdam: Harwood Academic Publishers, 2000), 23-5, 29 and 22.

${ }^{84}$ Ibid., $30-31$.

${ }^{85}$ Mike Saks, "Medicine and the Counter Culture," in Medicine in the Twentieth Century, 116.

${ }^{86}$ Watkins, 73 and 104.

${ }^{87}$ Jacalyn Duffin, History of Medicine: A Scandalously Short Introduction Second Edition (Toronto: University of Toronto Press, 2010), 117-118; Barbara Clow, "An Illness of Nine Months' Duration': Pregnancy and Thalidomide Use in Canada and the United States," in Women, Health, and Nation: Canada and the United States since 1945, edited by Georgina Feldberg et. al. (Kingston: McGill-Queen's University Press, 2003), 47; The Insight Team of the Sunday Times, Suffer the Children: The Story of Thalidomide (London: André Deutsch Limited, 1979), 29-30, and 96.
} 
both to combat severe morning sickness and as a sedative." ${ }^{\text {88 }}$ Sadly, they discovered when their babies were born that it could cause devastating birth defects. ${ }^{89}$

The North American women's health movement (WHM) was one manifestation of this new criticism and skepticism towards the medical profession. The movement, which began in the 1970 s, the second half of the period covered by this study, produced popular publications like Our Bodies, Ourselves and set up clinics, stressing the need for women to become knowledgeable about their bodies and challenge medical hegemony. ${ }^{90}$ A 1976 feminist resource handbook from the Ottawa women's centre articulated many of the movement's principles in stating

It is our bodies, our selves that are being mistreated. But control and selfdetermination start with knowledge and we have an advantage. No matter how many degrees after a doctor's name, if that doctor is male, he can never know how menstruation, childbirth or menopause feel. We do. We are the authorities. We should make deliberate attempts to learn about our bodies but always being frank and openly skeptical of male experts and authorities. $^{91}$

Ultimately, the WHM urged women to cast off their passive role in health care by participating in activities like knowledge sharing and self-help gynecology. ${ }^{92}$

Historians of Canada and of other Western countries have noted the connections between the pill and the women's health movement. ${ }^{93}$ As American historian Elizabeth

\footnotetext{
${ }^{88}$ Trent Stephens and Rock Brynner, Dark Remedy: The Impact of Thalidomide and Its Revival as a Vital Measure (Cambridge: Perseus Publishing, 2001), 16; Marks, 289-290, note 2.

${ }^{89}$ The Insight Team, 113.

${ }^{90}$ Marina Morrow, "Our Bodies, Ourselves in Context: Reflections on the Women's Health Movement in Canada," in Women's Health in Canada: Critical Perspectives on Theory and Policy, edited by Marina Morrow, Olena Hankivsky and Colleen Varcoe (Toronto: University of Toronto Press, 2007), 42; Kathleen McDonnell, "The Women's Health Movement in Canada: New Directions," Canadian Dimension 13, 7 (May 1979), 30.

${ }_{91}$ Ottawa Women's Centre, Ottawa Women's Resource Handbook, 1976, 26, University of Ottawa Archives, Canadian Women's Movement Archives Fonds, Box 91.

${ }^{92}$ Claudia Dreifus, "Introduction," in Seizing Our Bodies: The Politics of Women's Health, edited by Claudia Dreifus (New York: Vintage Books, 1977), xxx; Sheryl Burt Ruzek, The Women's Health Movement: Feminist Alternative to Medical Control (New York: Praeger Publishers, 1978), 9 and 53; Linda Light and Nancy Kleiber, Caring for Ourselves: An Alternative Structure for Health Care (1978), 10-11 and 112; A Vancouver Woman's Health Booklet (Press Gang Publishers, 1972), 40 and 78-9.
} 
Siegel Watkins explains, "The feminist critique of medicine grew from several sources of dissatisfaction, but the controversy over the safety of the pill and the importance of informed consent in its use served as a catalyst for the growth of the women's health movement." Watkins goes on to say that the stirrings of this critique were evident in the doctor's office where women struggled to get information from the medical profession about the pill's safety. ${ }^{94}$ This will be discussed in more detail in Chapter 4 . Certainly in engaging with their doctors and becoming active consumers of health care, Canadian pill users were achieving a significant goal of the women's health movement. ${ }^{95}$ Also, as I will discuss in Chapter 2, one woman used the discourse of the WHM when discussing the appeal of the pill.

Memories and Representations of the $1960 \mathrm{~s}$

There is a growing and very interesting body of literature on postwar Canadian society and the 1960s. However, sometimes the baby boomers and their youthful experiences dominant. This is the case with historian Doug Owram's important book, Born at the Right Time: A History of the Baby Boom Generation. While Owram provides some interesting insights into the generation which won World War Two and produced the baby boom, he is quite explicitly writing, as he says in preface, a biography of the

\footnotetext{
${ }^{93}$ Sethna, 2001; Sethna, 2006, 98.

${ }^{94}$ Watkins, 3 and 101-102.

${ }^{95}$ However, it is important not to overstate the influence of the pill in changing women's interactions with the medical profession. While oral contraceptives clearly had an impact, which I will explore further in Chapters 3 and 4, historian Wendy Mitchinson argues that Canadian women in the first half of the twentieth century, well before the pill, demonstrated agency in dealing with doctors. She says, "Although limited by circumstances in their lives, by societal mores, and by the unequal power relationships they had with physicians, individual women did exert their will." This could take many forms, including deciding to see a doctor in the first place and refusing treatment they did not want. Wendy Mitchinson, "Problematic Bodies and Agency: Women Patients in Canada, 1900-1950," in On The Case: Explorations in Social History (Toronto: University of Toronto Press, 1998), 281 and 275-278. See also, Mitchinson, "Agency, Diversity, and Constraints: Women and Their Physicians, Canada, 1850-1950," in The Politics of Women's Health: Exploring Agency and Autonomy by The Feminist Health Care Ethics Research Network (Philadelphia: Temple University Press, 1998), 122-149; Mitchinson, 1991.
} 
Canadian baby boom generation. Therefore, much of his coverage of the $1960 \mathrm{~s}$ is through their eyes. While he acknowledges that not all baby boomers were radical or even politically engaged, he also describes the 1960 s by saying "Hippies and dope, free love, flower power and women's liberation, Vietnam, the Kennedys and Trudeau, university protest, and the Beatles-the decade has few rivals as an age of change and excitement." He adds that in Canada radical rhetoric permeated the 1960 s and that the concerns of young people, who were so demographically dominant, took precedence. ${ }^{96}$ Such statements tend to perpetuate certain images of the 1960 s and further the idea that, as a decade, it belonged to baby boomers. ${ }^{97}$

Nevertheless, there are some notable books and articles which discuss the wider Canadian social context, going beyond the baby boomers and their activities. In her very interesting book, Mary Louise Adams examines norms surrounding sexuality in English Canada in the 1940 s and 1950 s. To track these discourses, she particularly looks at how the sexuality of young people was understood and managed. ${ }^{98}$. Veronica Strong-Boag and Mona Gleason write about the Canadian postwar family, focusing on the nature of suburbs and the influence of psychology respectively, whereas while Owram discusses suburbs, families and sexuality, it is again from the baby boom perspective. ${ }^{99}$ Finally, Valerie Korinek's book, Roughing It in the Suburbs, analyzes the shifting content of Chatelaine magazine in the 1950 s and 1960s. Korinek argues that Chatelaine had an important "role in disseminating second-wave feminist messages to a mass audience of

\footnotetext{
${ }^{96}$ Owram, ix, 160, $x$ and 311.

${ }^{97}$ For a similar stance, see also Myrna Kostash, Long Way From Home: The Stories of the Sixties Generation in Canada (Toronto: James Lorimer, 1980).

${ }^{98}$ Mary Louise Adams, The Trouble with Normal: Postwar Youth and the Making of Heterosexuality (Toronto: University of Toronto Press, 1997), 3-4.

${ }^{99}$ Veronica Strong-Boag, "Home Dreams: Women and the Suburban Experiment in Canada, 1945-1960," Canadian Historical Review 72, 4 (1991): 471-504; Mona Gleason, Normalizing the Ideal: Psychology, Schooling, and the Family in Postwar Canada (Toronto: University of Toronto Press, 1999).
} 
Canadian women." 100 She is also interested in the engagement of readers, who, according to a 1969 study, were primarily married people ranging in age from 35 to $44 .^{101}$ Their voices, preserved in letters, provide very important insight into the lives and views of Canadians who were not part of the baby boom.

In the last few years, scholars have begun to explore even more different facets of the postwar Canadian social landscape. For instance, in Creating Postwar Canada, edited by Magda Fahrni and Robert Rutherdale, essay topics include interracial adoption, consumerism, fast food, the role of the father and nationalism as well as a nuanced study of premarital sex by Christabelle Sethna and one on drug use by Marcel Martel. ${ }^{102}$ Another collection, published in 2009 , includes essays on the Canadian context but considers the 1960 s as a global phenomenon. ${ }^{103}$

Despite the existence of increasingly nuanced academic analyses, public memory of the 1960 s still often associates the decade with an unruly youth culture. Owram, discussing the period with his students in the 1990s, found that many negatively connected it to hippies and drugs. ${ }^{104}$ Those who were married and had children in the 1960 s also often shared these associations, if not always in a disparaging way. When asked, many of the women interviewed for this doctoral study commented that people today, or popular culture, tended to emphasize the politics, music, drugs, sexual

\footnotetext{
${ }^{100}$ Korinek, 9.

${ }^{101}$ Ibid., 65-66.

${ }^{102}$ Creating Postwar Canada: Community, Diversity, and Dissent, 1945-1975, edited by Magda Fahrni and Robert Rutherdale (Vancouver: UBC Press, 2008). See also The Sixties: Passion, Politics, and Style, edited by Dimitry Anastakis (Montreal and Kingston: McGill-Queen's University Press, 2008).

${ }^{103}$ New World Coming: The Sixties and the Shaping of Global Consciousness, edited by Karen Dubinsky, Catherine Krull, Susan Lord, Sean Mills and Scott Rutherford (Toronto: Between the Lines, 2009).

${ }^{104}$ Owram, xi.
} 
liberation, Beatniks, hippies, or free love of the $1960 \mathrm{~s} .{ }^{105}$ Some even seemed to personally remember the decade that way. ${ }^{106}$ However, how accurate is this portrayal, particularly for the early years of the decade? Though Owram finds stirrings of change and rebellion in the late 1950s, many of the more radical shifts he discusses, including a transformation of sexual values and the emergence of the "hippie," either began or occurred, according to him, only in the mid-1960s. ${ }^{107}$ Additionally, as I will discuss in Chapter 3, many single women did not enjoy unfettered access to the birth-control pill in the 1960s, complicating further the image of the entire decade as one of enthusiastic social metamorphosis.

Indeed, many interviewees who lived through this period articulate a sense of detachment from the apparent upheaval of this decade because of their age or life situation. ${ }^{108}$ Some say that they were simply busy raising their children. ${ }^{109}$ For example, Johnson associated the 1960 s with the Beatles, but she was quick to say that "as a married person with young children I kind of wasn't into that sort of flower child thing."110 Campbell agreed that, as a married woman, she had a much different experience of the 1960s than her younger siblings whom she called "flower children."111

\footnotetext{
${ }^{105}$ Email correspondence from Ruth Wright, July, 2009, 4; Interview with Olivia Taylor, August 6, 2009, 14; Interview with Susan Brown, August 7, 2009, 20; Interview with Margaret Wilson, August 12, 2009, 25; Jackson, 35; Interview with Betty Shevchenko, November 9 and 10, 2009, 25; Interview with Beth Reid, November 18, 2009, 30; Interview with Heather Anderson, December 3, 2009, 15; Interview with Evelyn Scott, December 12, 2009, 18; Interview with Vivian Koch, January 21, 2010, 24; Interview with Cynthia Young, February 8, 2010, 22; Interview with Caroline Morrison, March 9, 2010, 32-33; Interview with Emma Edwards, April 12, 2010, 43; Interview with Isabelle Lowe, April 27, 2010, 36.

${ }^{106}$ Interview with Eileen Stewart, August 18, 2009, 30; Interview with Yvonne Wilkins, September 30, 2009, 34; Interview with Joan Walker, October 15, 2009, 24-25; Interview with Anne Ryan, October 27, 2009, 20-22; Interview with Annie Beck, November 6, 2009, 29; Interview with Claire Moore, November 17, 2009, 33; Interview with Cheryl Clarke, November 12, 2009, 30.

${ }^{107}$ Owram, 160, 218, 190 and 249.

${ }^{108}$ Wilkins, 34-35; Beck, 30; Moore, 33; Shevchenko, 26; Koch, 24; Young, 23; Morrison, 32-33.

${ }^{109}$ Interview with Jane Lynch, October 6, 2009, 36; Anderson, 15; Scott, 18.

${ }^{110}$ Interview with Linda Johnson, July 17, 2009, 14.

${ }^{111}$ Interview with Deborah Campbell, February 9, 2010, 23.
} 
Other women concur that how many people remember or think about the 1960s does not jive with their experiences, describing themselves or their group of friends as more moderate, conservative, or simply already tied to their homes or families. Many support these claims by pointing to the fact that they never experimented with drugs or had promiscuous sex lives. ${ }^{112}$

Other Canadian women I spoke to, rather than emphasizing that they were not "hippies," go further and question the very nature of the revolutionary 1960s. They claim in fact that society remained conservative until later in the 1960s or even into the 1970 s when it experienced dramatic changes in clothing, music, and behaviour. ${ }^{113}$ These views complement the more recent historiography, and suggest that there were many ways to experience the 1960s in Canada. Not everyone was a hippie, not everyone was young and not everyone was equally affected by the social changes occurring, which may have happened more in the mid- to late-1960s.

\section{Historiography of Birth Control}

Much more work on both contraception in general and the pill specifically has been carried out in Britain and the United States than in Canada. For many historians in the field, Linda Gordon's 1976 Woman's Body, Woman's Right remains pivotal as it is one of the first to detail the history of the birth-control movement in the United States in the nineteenth and twentieth centuries. As an active feminist with a Marxist background, Gordon connects the trajectory of this movement to larger developments in society, like the growth of capitalism. Thus, "Both the suppression and then the legalization of birth

\footnotetext{
${ }^{112}$ Taylor, 14-15; Wilson, 25; Jackson, 35; Reid, 30-31; Interview with Susan Walsh, November 24, 2009 , 14; Lowe, 36-37.

${ }^{113}$ Interview with Katherine Quinn, August 14, 2009, 15-16; Interview with Olivia Klein,October 20, 2009, 42-43; Interview with Cora Stefánsson, November 23, 2009, 19.
} 
control were developments in the struggle between the sexes and the changing economic organization of society." 114 For this project, Gordon draws on a wide range of sources, including newspapers, marriage manuals and medical journals. She examines three different incarnations of the birth-control movement: voluntary motherhood in the late nineteenth century; birth control from 1910 to 1920 and planned parenthood in the 1940s. ${ }^{115}$ According to Gordon, each of these stages expressed the class interests of different groups of women. Thus, voluntary motherhood advocates were more likely from independent farm, artisanal, commercial and professional families while birthcontrollers in the 1910s spoke more for the working class. ${ }^{116}$ Other scholars of contraception share Gordon's interest in class dynamics, as will be explored below. Another debate in the literature, tackled by Gordon, considers whether or not the means to control fertility existed before the desire to use them. On this question, Gordon argues that, based on the antiquity of some birth-control methods, "the burden of involuntary childbearing was not the result of lack of technology but of the suppression of technology." "117 Gordon's book, though one of the first to look at contraception, focuses more on the nineteenth and early twentieth centuries.

Published twenty-five years later, Andrea Tone examines the evolution of the modern American birth-control industry and market from 1873 to the 1970s. Rather than focusing on physicians, lawmakers and activists as other historians, like Gordon, have done, her Devices and Desires is the "story of what it was like to make, buy, and use contraceptives during a century when the contraceptive industry was transformed from an

\footnotetext{
${ }_{114}^{114}$ Gordon, 1976, vi and xiv.

${ }^{115}$ Ibid., xv.

${ }^{116}$ Ibid., xvi-xvii.

${ }^{117}$ Ibid., 46.
} 
illicit trade...to one of the most successful legitimate businesses in American history." "118 To analyze this shift, Tone draws on diverse sources, including newspapers, court records and the Planned Parenthood Federation of America papers. The first part of her book focuses more on the nineteenth century and the development of the modern condom. She then moves into an analysis of the pill. With the advent of the pill, contraception became medicalized in a way that did not happen with the diaphragm or condom. ${ }^{119}$ Doctors now devoted more time in their days to contraceptive advice and women on the pill had to come in for regular medical check-ups. ${ }^{120}$ However, despite this increased medical control of the industry, Tone stresses the agency of American women who were anxious for access to the pill and continued to use it even when they knew of or suffered from some of its side effects. ${ }^{121}$ She says further that women often demanded the pill from their physicians who had to prescribe it or lose business, a concern in situations where doctors worked in a fee-for-service system. ${ }^{122}$ According to Tone, "doctors' recollections from this era suggest that many physicians felt pressured by women to prescribe oral contraceptives, not the other way around. As consumers, women were never just pawns of the reorientation of medical practice; they were its driving force."123

The question of female agency comes up in many books on contraception. This may largely be because of the continuing debate over the safety of the pill. By the late 1960 s, accusations were swirling that the pill had been inadequately tested before its release to unsuspecting women who then suffered a myriad of side effects and who might

\footnotetext{
118 Tone, xvi.

119 Ibid., 203.

${ }^{120}$ Ibid., 240-1.

${ }^{121}$ Ibid., 234 and 245.

122 Ibid., 241.

${ }^{123}$ Ibid.
} 
also have exposed themselves to untold long-term risks. Earlier feminist scholarship sometimes reflects this indictment of medicine and the pharmaceutical industry but this began to change in the 1980 s and more recent work, like Tone's, strives for a balanced and nuanced analysis of both the approval of the pill and women's role in acquiring it. ${ }^{124}$ Historian Elizabeth Siegel Watkins, in her book on the social history of the birth-control pill in the United States, agrees with Tone that women were demanding the pill and that "Women who came to their physicians with specific requests for oral contraceptives no longer passively received medical care, but were transformed into active participants."125 My thesis contributes to this discussion by considering the agency of Canadian women in getting the pill and staying on it, often despite personally experiencing, or hearing about, serious side effects. Siegel Watkins' sources include newspapers, magazines, the papers of Gregory Pincus and records from the American Food and Drug Administration. Her work contains a very important analysis of the interaction of American women and their doctors regarding the pill, the role of the media in the dissemination of information on the pill and the development of the pill.

In 2010, coinciding with the fiftieth anniversary of the pill's American release, Elaine Tyler May published her book, America and the Pill: A History of Promise, Peril, and Liberation. May's book provides some important insights into the impact of the contraceptive, particularly on married women. Perhaps most pertinent for my argument, May asserts that the pill actually had more significance for them than their single counterparts. She says "The ability to plan and space the birth of children

\footnotetext{
${ }^{124}$ Barbara Seaman, The Doctors' Case Against the Pill (New York: Peter H. Wyden, Inc., 1969); Watkins, 5-6. ${ }^{125}$ Watkins, 51.
} 
allowed...[married women] to take advantage of educational and professional opportunities that unexpected pregnancies precluded."126

May's book also includes information on the pill's development. However, this narrative had already been well covered by historians like Siegel Watkins in 1998 and Lara V. Marks in 2001. Marks particularly charts the evolution of the science behind the pill. She argues that, despite later and enduring criticism, the pill was tested in keeping with the standards of the time, which were much more lax before the thalidomide tragedy. In stating that "the original developers of the pill have been unfairly accused of experimenting on women as though they were guinea pigs," Marks is contributing to the trend in the scholarship, discussed above, which rejects the casting of women as hapless victims. She also distinguishes her book on the birth-control pill by placing its development and subsequent use in an international context with a particular focus on the United States and Britain. ${ }^{127}$ To perform this analysis, Marks uses an impressive array of sources, including interviews (some with doctors), records from the Food and Drug Administration and medical journals. While Marks makes a valuable contribution to the historiography on the birth-control pill, her book lacks an explicit discussion of her theoretical stance, even in reference to the oral interviews she, and others working on her behalf, conducted.

In addition to Marks' book, interesting literature has been produced strictly on the British context. Most pertinent for my project are books by Hera Cook and Kate Fisher. Hera Cook examines the period from 1800-1975. Her use of surveys on sex and fertility reflects her interest in the sexual experiences, practices and negotiations of ordinary men

\footnotetext{
${ }^{126}$ May, 79.

${ }^{127}$ Marks, 4, 114, 2-3.
} 
and women. ${ }^{128}$ However, these sources do not allow her to capture some of the complexities of reproductive decision-making, as Fisher does. Cook claims that in the early twentieth century, birth-control methods were very inefficient and that success in preventing pregnancy depended largely on luck and a couple's willingness to sacrifice some physical pleasure. On the whole, Cook is rather pessimistic about birth control in England before World War Two. She concludes: "By the 1930s, those women and men who had co-operative partners, self-discipline, an adequate income, and private washing facilities could, by using a spermicidal pessary, and a douche and either a condom, rubber cap, or diaphragm, obtain a high level of protection from pregnancy." 29 Under these restrictive conditions, Cook argues that withdrawal continued to be the most common method but that the fertility decline was actually due to high levels of abstinence and sexual repression. $^{130}$

According to Cook, the pill offered British women for the first time a highlyeffective female method of birth control. Cook asserts that the pill, thus, had an even greater societal impact in Britain than in the United States where female methods, such as the diaphragm, had been popular throughout the 1950s. ${ }^{131}$ Cook draws on Kate Fisher's doctoral thesis on birth control, discussed below, to argue that most English women rejected female-controlled methods, like the diaphragm, because to use them would mean becoming more active sexual agents. ${ }^{132}$ However, Cook does not really try to explain why losing their image of sexual passivity seemed to bother English women more than

\footnotetext{
${ }^{128}$ Hera Cook, The Long Sexual Revolution: English Women, Sex and Contraception 1800-1975 (Oxford: Oxford University Press, 2004), 4-5.

${ }^{129}$ Ibid., 142.

${ }^{130}$ Ibid., 142 and 161 .

${ }^{131}$ Ibid., 272.

${ }^{132}$ Ibid., 114-115.
} 
their American counterparts. Finally, she asserts that a revolution in sexual attitudes took place in the 1960s. She says "The force which propelled the cultural transformation of attitudes to sexual behaviour forwards was the transformation of conception and pregnancy from an uncontrollable risk to a fully chosen outcome of sexual intercourse." $" 133$

In many ways, Kate Fisher complicates existing literature on British contraception, including Cook's The Long Sexual Revolution. Fisher's book examines birth-control methods in Britain from 1918 to 1960 through oral testimony. Fisher confirms that "Although many did try appliance methods [such as condoms and caps], the extent to which they were disliked has been underestimated." She also fundamentally challenges some of the other assumptions of the historiography. Most particularly, Fisher argues that women were not, as many historians have supposed, in control of contraceptive decision-making. In fact, young men of all classes in the 1930s and 1940s, saw birth control as the responsibility and duty of the husband. Indeed, according to oral narratives, "contraception was viewed by both men and women as part of a male world: whether birth control was used, to what extent, and when, was left in the hands of the husband." 134 Most wives in the first half of the twentieth century clung to an image of sexual innocence and passivity which they associated with respectability. ${ }^{135}$ In addition, despite the assertions of historians like Waily Secombe, Fisher found that many couples from 1918-1960 continued to use traditional methods of contraception, especially withdrawal. These men and women claimed that withdrawal, unlike appliance methods,

\footnotetext{
${ }^{133}$ Cook, 339.

${ }^{134}$ Kate Fisher, Birth Control, Sex, and Marriage in Britain, 1918-1960 (Oxford: Oxford University Press, 2006), 109, 111, 137-138, 191.

${ }^{135}$ Ibid., 66 and 212 . In pursuing her interest in the gendered nature of contraceptive attitudes, Fisher draws on literature on gender as well as sexuality.
} 
was convenient and inexpensive. Perhaps more importantly, it enabled them to enjoy sex naturally and spontaneously. ${ }^{136}$ This testimony is revealing in light of Cook's analysis. While Cook affirms that withdrawal was very popular as a birth-control method in this period, she tends to depict it more negatively and suggests it entailed a loss of sexual pleasure. ${ }^{137}$ Fisher argues further that, rather than adopting a firm view of family size in these decades as some scholars have claimed, most couples believed that no birth-control method was perfect and should only be used to roughly limit family size. Family limitation was rarely rationally or even explicitly discussed between spouses and they retained a certain fatalistic view that children would inevitably arrive. ${ }^{138}$ Thus, Fisher challenges many of the previous claims about birth-control methods in the twentieth century. She concludes that, with the introduction of the pill, "the increasingly significant role played by women in determining contraceptive strategy by the 1960 s did not represent the culmination of their active attempts to limit the size of their families over the previous half-century. Rather, these developments were novel, and represented a sharp break with previous contraceptive practice."139

Fisher's use of oral interviews is of great importance to my own work. Her book is primarily the product of interviews conducted with 193 men and women. The first interviews were done for her $\mathrm{PhD}$ thesis, completed in 1997, and involved 58 people from south Wales and 46 from Oxford. She later added interviews with people from Hertfordshire and Blackburn. ${ }^{140}$ Fisher found her informants primarily through

\footnotetext{
${ }^{136}$ Fisher, 187.

${ }^{137}$ Cook, 142.

${ }^{138}$ Fisher, 76-7 and 96.

139 Ibid., 243.

${ }^{140}$ Ibid., 18-19. Fisher explains that the interviews were conducted by herself, Simon Szreter and James Mark.
} 
community centres and organizations. She uses unstructured oral interviews to interrogate some of the existing scholarly assumptions about birth-control behaviour in the twentieth century. ${ }^{141}$ She also skillfully embeds the findings from this testimony in larger social discourses and trends. For example, many of those interviewed asserted that they were largely ignorant of reproduction and birth control. Rather than dismiss these claims in light of the proliferation of literature and clinics in the 1920s, Fisher considers how these protestations of ignorance were linked to the inaccessibility of much of the information on birth control. ${ }^{142}$ Thus, because oral testimony is available, Fisher can, unlike other authors on contraception, determine what couples actually knew rather than what information was published. As my own research demonstrates, just because something was available in print or other media, did not mean that everyone had equal access to it, read it or absorbed the message.

Fisher also ties contraceptive behaviour into the larger gender dynamics of marriage. According to her findings, men were expected to be the responsible heads of the household, which meant both protecting their wives' health as well as ultimately determining the size of the family. Throughout my thesis, I also explore the role of the husband in contraceptive decisions as well as the impact of the pill on marital dynamics.

In the Canadian context, literature on contraception, though limited, is important. Angus McLaren is perhaps the best-known and most-cited historian. In his 1986 book, The Bedroom and the State: The Changing Practices and Politics of Contraception and Abortion in Canada, 1880-1980, co-written by Arlene Tigar McLaren, McLaren traces the availability and use of contraception in Canada in the nineteenth and twentieth

\footnotetext{
${ }^{141}$ I will discuss Fisher's interview techniques in more detail in my section on methodology.

${ }^{142}$ Fisher, 42.
} 
centuries. ${ }^{143}$ McLaren and McLaren argue that, starting in the nineteenth century, "The birth rate was brought down, not because of any technological breakthrough, but because more couples intent on limiting their fertility conscientiously employed traditional methods." ${ }^{.144}$ In this way, they enter the debate among historians of contraception over the effectiveness and accessibility of birth control, where Linda Gordon, as previously mentioned, agrees that birth-control technologies and information were always available and, when prohibited by society, were used clandestinely, ${ }^{145}$ and where others, such as Hera Cook, contend that withdrawal, a traditional method, was neither widely know nor terribly effective. ${ }^{146}$ Moving through the twentieth century, McLaren and McLaren discuss Canadian campaigns for birth control spearheaded by industrialist A.R. Kaufman. They provide valuable information on the leaders of the movement for legalized birth control in Canada in the interwar period. They also, like Gordon, effectively highlight the class interests of those involved. For example, Kaufman, a eugenicist, wished to limit the reproduction of the working classes. ${ }^{147}$ However, The Bedroom and the State, despite its subtitle, provides limited information on the post-World War Two period and even less on the 1960 s to the 1980 s.

Brenda Margaret Appleby's 1999 book Responsible Parenthood: Decriminalizing Contraception in Canada provides a very interesting analysis of events leading to the legalization of birth control in this country. She particularly examines the submissions of

\footnotetext{
${ }^{143}$ McLaren and McLaren; Angus McLaren and Arlene Tigar McLaren, The Bedroom and the State: The Changing Practices and Politics of Contraception and Abortion in Canada, 1880-1997 Second Edition (Oxford: Oxford University Press, 1997). In the second edition, McLaren and McLaren include a new chapter covering the period 1980 to 1997 . The rest of the book is virtually unchanged. I will primarily draw on the first edition, unless otherwise indicated.

${ }_{144}$ McLaren and McLaren, 22.

${ }^{145}$ Gordon, 1976, 47.

${ }^{146}$ Cook, 89.

${ }^{147}$ McLaren and McLaren, 105.
} 
groups, including the Canadian Bar Association, the Canadian Medical Association, and the Canadian Catholic Conference, in 1966 to the House of Commons' Standing Committee on Health and Welfare which was charged with considering "four bills proposing amendments to the Criminal Code in regard to conception prevention." ${ }^{148}$ In addition to the committee records, Appleby uses articles from the Canadian Medical Association Journal. Her book provides important insights into the discourse of family planning, the Catholic position on birth control and the process by which contraception became decriminalized in Canada.

Recent research on the pill by historian Christabelle Sethna is more pertinent to my work. She wrote, in 2001, a very interesting overview of the development of the pill and its reception in Canada, touching upon side effects, access to the contraceptive, and the women's health movement. Her sources include The Gallup Report, newspapers and magazines. ${ }^{149}$. Additionally, in a 2005 article, which draws on university records and the student newspaper, she outlines the struggle of unmarried students for the pill at the University of Toronto. In the early 1960s, the university Health Service resisted prescribing the pill to single women as they feared both legal and parental criticisms. ${ }^{150}$ However, both the Students' Administrative Council and the student paper The Varsity became more vocal in demanding the pill. In this article, Sethna convincingly proves that, even though the pill was available in Canada after 1961, it was not accessible to single women. Cook and Siegel Watkins affirm that this was also the case in Britain and the United States. ${ }^{151}$ In a second article, Sethna tracks the evolution of the McGill

\footnotetext{
${ }^{148}$ Appleby, 6-7.

${ }^{149}$ Sethna, 2001.

${ }^{150}$ Sethna, 2005, 270-1.

${ }^{151}$ Cook, 279-280; Watkins, 135.
} 
University Birth Control Handbook from a student peer-education manual to a feminist text which pre-dated the famous American book Our Bodies, Ourselves. Using the manual itself, as well as interviews, newspapers and the records of the McGill Students Union Collective, Sethna outlines how the Students' Council at McGill formed the Birth Control Committee which, in 1968, produced the first edition of the Birth Control Handbook. It contained information on birth control and anatomy and was distributed widely across North America. Sethna demonstrates persuasively that in subsequent editions the manual took on controversial topics, such as the Therapeutic Abortion Committees. The editors worried that these committees could block access to legal abortions. $^{152}$

Diane Gervais and Danielle Gauvreau's 2003 article also looks at contraception in post-World War Two. Drawing primarily on the 1971 Quebec fertility survey and interviews, the authors discuss family limitation in Quebec from 1930 to 1960 . They interviewed forty-five people, including priests, physicians and women, all of whom were Francophone, Catholic and based in the Montreal region of the province. For her 2005 and 2006 articles, Sethna also interviewed a few physicians but their testimony was used sparingly to supplement her other sources. ${ }^{153}$ In the Canadian context, Gervais and Gauvreau are the only ones to speak directly to priests on the sensitive topic of contraception. Former priests were contacted through the Archdiocese of Montreal while the Collège des médecins was used to reach retired, willing doctors, "most of whom were obstetricians and general practitioners." Gervais and Gauvreau do not provide very much insight into how they conducted interviews other than to state that "Filtering informants"

\footnotetext{
${ }^{152}$ Sethna, 2006, 97 and 100.

${ }^{153}$ Sethna, 2005, 274-275 and 284-285; Sethna, 2006, 94 and 103.
} 
responses to the interview questions was minimal. The interviewer intervened only to bring the discussion back to the main topics." This suggests an unstructured discussion. Gervais and Gauvreau found that, despite papal ambivalence over contraception, many priests and couples believed that the rhythm method was acceptable. ${ }^{154}$ However, a lot of doctors interviewed thought this method was too difficult for couples. In turn, the couples "found themselves in a moral dilemma, torn between the physical desire they felt for one another, their desire to limit the size of their families, and their desire to live in a proper Christian way."155 Gervais and Gauvreau discovered that many priests thought the pope would approve the use of the birth-control pill by married couples in 1968 . Though discovering a spectrum of opinions on contraception, Gervais and Gauvreau conclude that religion, in this case Catholicism, coloured many of the views. ${ }^{156}$ The authors persuasively demonstrate that doctors and priests were often caught between professional guidelines on birth control and their desire to help couples. Women, in turn, and according to the doctors interviewed, often demanded the birth-control pill, a finding consistent with the American context as discussed by Tone and Siegel Watkins.

Historians have, to varying degrees, tackled the question of religion in the history of contraception. The influence of religious views on contraceptive policy and decisionmaking also comes up in several books. Gordon says that when the pill first became available in the United States, American Catholics believed by a 3:2 ratio that the Church should accept oral contraception. Tone concurs that Catholic women often defied the

\footnotetext{
${ }^{154}$ Diane Gervais and Danielle Gauvreau, "Women, Priests, and Physicians: Family Limitation in Quebec," Journal of Interdisciplinary History 34, 2 (Autumn 2003), 299-300, 303. For reasons they do not explain, the majority of gynecologists were not interested in being interviewed. Gervais and Gauvreau also mention interviews with men and women that were conducted but apparently not included in this analysis.

${ }^{155}$ Ibid., 304.

${ }^{156}$ Ibid., 313.
} 
Church's prohibition on the pill and other forms of contraception. According to Siegel Watkins, this happened to such an extent in the United States that, by 1976, Protestant and Catholic wives were using the pill in equal numbers. ${ }^{157}$ In the British context, Fisher finds as well that the religion of the people she interviewed did not always determine contraceptive choices. She says that, with the exception of Catholic couples, respondents rarely brought up religion at all when discussing birth-control use. ${ }^{158} \mathrm{McLaren}$ and McLaren provide some intriguing pages on the Catholic response to contraception in Quebec. According to them, in the first half of the twentieth century, some Catholics were concerned that birth control was part of a "broader eugenic movement launched by upper-class Protestant Canadians that had as its goal the control of the fertility of the Catholics and the lower classes." McLaren and McLaren demonstrate, using journals and books, that Catholic opinion remained divided on contraception. In particular, many felt that the pill should be acceptable as it only improved upon the rhythm method by regulating a woman's reproductive cycle. ${ }^{159}$ As in Britain and the United States, Christabelle Sethna confirms that Canadian Catholics in the 1960s were increasingly favourable towards contraception. ${ }^{160}$ However, her articles say little on how religious views affected the contraceptive choices of individual women. This remains the primary focus of Gervais and Gauvreau in their examination of the views of Francophone, Catholic women, priests and physicians.

My work adds to both this international and Canadian literature. First, there is surprisingly little written about contraception in Canada. While McLaren and McLaren's

\footnotetext{
${ }^{157}$ Gordon, 2007, 288; Tone, 237; Watkins, 63.

${ }^{158}$ Fisher, 150.

${ }^{159}$ McLaren and McLaren, 130-132.

${ }^{160}$ Sethna, 2005, 286.
} 
book is very interesting and a necessary starting point for any research on this subject, it is, as noted above, focused on the nineteenth and early twentieth centuries. Christabelle Sethna has started the very important task of considering the impact of the pill, however, most of her work concerns single women. With the exception of Gauvreau and Gervais, there has been very little analysis of the effect of the birth-control pill on married women. Also, their article is unique in considering how religion affected birth-control decisions. My thesis represents the first significant examination of the impact of the pill on married, English-Canadian women.

\section{Methodology}

Not all voices are recorded equally in the historical record. Sometimes discerning the perspective of women can be challenging and historians have to be prepared to consider a range of sources. McLaren and McLaren uncovered much about the birthcontrol experiences of Canadians, predominantly Protestant, urban, middle-class, English-speaking, married women, in letters written to Marie Stopes in the 1930 s. $^{161}$ Similarly, I draw on letters to Chatelaine magazine. However, I found only a limited number of them and, additionally, letters are static, lacking the capacity to provide more relevant information. Consequently, this thesis relies a great deal on fifty-three oral interviews I conducted with Canadian women from June of 2009 to April of 2010. As Fisher says, particularly given the lack of other sources, "Oral history...allows the historians to examine birth control practices from within the context of a whole life and on the interviewee's own terms."162

\footnotetext{
${ }^{161}$ McLaren and McLaren, 24-28.

${ }^{162}$ Fisher, 12-13.
} 
Unlike Fisher, Gervais and Gauvreau, I chose to focus exclusively on women since my study was specifically on the pill which directly impacted only the female half of the population. I did discuss the male role in contraception but primarily as remembered by their wives. Whenever possible, I included male voices from other sources. Future studies, particularly if looking at other forms of contraception (such as sterilization), might want to conduct interviews with men and women. Additionally, as Gervais and Gauvreau demonstrate, it could be interesting to ask physicians directly about their experiences prescribing the pill in the 1960s and 1970s.

The women I interviewed, born between 1918 and 1950, had a broad range of experiences on the pill which they all began taking some time in the 1960s. Total length of time on the pill varied extensively. At one extreme, a woman I interviewed only took the contraceptive for a month because of side effects. Others stayed on for years, sometimes without interruption. All informants were raised in Canada, with a few immigrating as young children. I decided to limit my study to English Canada, fully aware that French Canadian women may have had to come to terms with a very different cultural milieu when negotiating pill use. Unfortunately, this decision meant that some stories could not be told in my thesis but await further research. ${ }^{163}$ I did decide to include a woman with an Acadian background because, though her parents spoke French at home, they did not encourage their children to do so and, in fact, felt Acadians were disdained. This woman grew up in a largely Anglophone town where she did not think there were many Acadians. She had a Catholic education and cannot speak French.

\footnotetext{
${ }^{163}$ Gervais and Gauvreau provide in their article an interesting preliminary glimpse into the interactions of Francophone women with contraception.
} 
Interviewees lived across the country during their years on the pill. Though many called Ontario home, others were on the pill in Alberta, Manitoba, British Columbia, Quebec, New Brunswick and Nova Scotia. Some women also moved within Canada, resulting in a pill experience which spanned provinces. I decided to include the testimony of a Canadian woman who actually started the pill in England in about 1961. Because she returned to Canada within a year or so and continued to take it, I thought her testimony was still very valuable. I also chose to include four women, Green, Stevens, Klein and Evans who first went on the pill in Canada but then lived outside the country for a time. Their testimony, particularly if they were only gone for a short time and then had additional years on the pill in Canada, still reflects the Canadian experience in terms of such topics as choosing a birth-control option, access to the pill, side effects, and initial appointments.

In regard to ethnicity, many reported that their families had been in Canada for generations. As one might expect, given the composition of the country for much of the twentieth century, many reported their families originally hailed from the British Isles. ${ }^{164}$ However, others also had roots in Germany, Austria, Poland, Iceland, Ukraine, Hungary and the United States. As I will discuss particularly in Chapter 5, pill use had an added dimension for women who were practicing Catholics in the 1960s since their Church disapproved of all artificial contraception. In my sample, I spoke to nine such women who had a variety of reactions to the Church's position. Finally, the women I

\footnotetext{
${ }^{164}$ Historical Statistics of Canada: Section A-Population and Migration, Table A125-163 Origins of the population, census dates, 1871-1971, Statistics Canada website, http://www5.statcan.gc.ca/access acces/archive.action?l=eng\&loc=A125 1.63-eng.csv. The 1961 Census confirmed that a large proportion of the Canadian population, almost eight million, had originated in Britain. The total sample was over 18 million. While other European ethnic groups exceeded nine million, this number included French Canadians so, among English Canadians, the subject of my study, one can conclude that in 1961, those of British origins were still predominate.
} 
interviewed filled a variety of occupational positions during their years on the pill including homemakers, teachers, and public servants. ${ }^{165}$ Gervais and Gauvreau state that the eight women included in their 2003 article were housewives, social workers and nurses. ${ }^{166}$ Without additional information, it is difficult to ascertain their precise socioeconomic statuses. In her book, Fisher asserts more explicitly that "the social and economic positions of respondents varied." However, her larger and first set of interviews was mostly with working-class individuals. ${ }^{167}$ In contrast, the majority of my respondents could be characterized as middle-class. I will particularly consider the influence of class and income in Chapter 3.

Given the paucity of sources which provide insight into the experiences of Canadian married women on the pill, these interviews were vitally important for the viability of my project. Finding informants proved to be much more challenging than I originally anticipated. Somewhat naively, I assumed that I could simply put up welldesigned posters in libraries, community and seniors centers and women would be eager to participate. In making this assumption, I underestimated the reticence individuals might naturally feel in contacting a stranger and discussing a sensitive topic like birth control. Thus, early on the project I had to diversify and change my approach. In order to find informants, I tried many different avenues, some more fruitful then others. The Canadian Federation of University Women was generous enough to inform its members of my project in the summer of 2009 when I was struggling to find interested parties. Personal contacts and word of mouth remained vitally important throughout the entire

\footnotetext{
${ }^{165}$ For full details on the ethnic backgrounds, occupations, religions and other information pertaining to these women, see Appendix 1.

${ }^{166}$ Gervais and Gauvreau, 299.

${ }^{167}$ Fisher, 3-4 and 14.
} 
project. Sometimes one woman would discuss her interview with her friends who then contacted me. I sent numerous small articles or notices to websites including Carleton University, the Older Women's Network, and the Canadian Women's Health Network. In October of 2009 , I had a small article printed in a local newspaper and did an interview on CBC Radio. Finally, in February of 2010, I did a short presentation at a senior's center which was covered by a local newspaper. All of these sources, as well as a few others, helped me find participants. To further introduce myself to people and, hopefully, alleviate any concerns about myself or my project, I set up a modest website to which I could direct interested parties. ${ }^{168}$

The interviews, which usually lasted between one to two hours, were conducted over the telephone or in person. ${ }^{169}$ For both, I found an interview guide, which evolved over the course of the project, helpful but generally pursued an open-ended discussion to facilitate a comprehensive and relaxed experience. In her book, Fisher advocates unstructured interviews which were "flexible enough to accommodate respondents who held differing ideas about the appropriateness of talking about sexual issues with a relative stranger." ${ }^{, 170}$ In the interviews for her book, Fisher also says questions were posed in different ways depending upon the sensibilities of the respondents. ${ }^{171}$ Though I attempted in my interviews to be appropriately discrete and tactful, I also found that some women appreciated a more frank and explicit conversational style. Given the rather

\footnotetext{
${ }^{168} \mathrm{https}: / /$ sites.google.com/site/thepillincanada/home

${ }^{169}$ In a few cases, I did follow-up interviews and also contacted some respondents in 2012 for basic information such as religious practices when on the pill.

${ }_{170}^{170}$ Fisher, 15.

${ }^{171}$ Ibid., 16.
} 
sensitive nature of the topic, I have also assigned pseudonyms to all participants, whether or not they requested it. ${ }^{172}$

Oral history has expanded in the last four decades and has become the subject of much academic debate. Some historians still question the validity of evidence obtained through oral testimony. First, they articulate a preference for evidence like "documents that remain the same over time even if interpretations of them shift." However, all historians are trained to treat any source critically and it has long been recognized that material such as newspapers and diaries are often biased, selective and even factually wrong. ${ }^{173}$ Second, oral history involves working with human memory, which can be incomplete and changeable. This reality has caused some historians to question the merits of the methodology. ${ }^{174}$ In 1979, oral historian Alessandro Portelli, to answer these and other criticisms, asserted that "memory is not a passive depository of facts, but an active process of creation of meanings." 175 Consequently, the "subjectivity of memory...[provides] clues not only about the meanings of historical experience but also about the relationships between past and present, between memory and personal identity, and between individual and collective memory." ${ }^{.176}$ My interviews, conducted decades after the events in question, demonstrate how women navigate these dynamics. For example, as I have already discussed in this chapter, my interviewees considered their

\footnotetext{
${ }^{172}$ Raymond M. Lee, Doing Research on Sensitive Topics (London: Sage Publications, 1993), 98 and 102. Lee suggests it is better to use unstructured interviews when looking into sensitive topics, such as sexuality. He also asserts that confidentiality can help establish a framework of trust necessary in this sort of interview.

${ }_{173}$ Donald A. Ritchie, Doing Oral History: A Practical Guide Second Edition (Oxford: Oxford University Press, 2003), 26-27.

174 "Part 1-Critical Developments: introduction," The Oral History Reader Second Edition, edited by Robert Perks and Alistair Thomson (New York: Routledge, 2006), 3; Valerie Raleigh Yow, Recording Oral History: A Guide for the Humanities and Social Sciences Second Edition (New York: Altamira Press, 2005), 20.

${ }^{175}$ Alessandro Portelli, "What Makes Oral History Different," Reprinted in The Oral History Reader, 32 and 37.

176 "Part 1-Critical Developments: introduction," The Oral History Reader, 3-4.
} 
personal experiences of the 1960s in light of a larger cultural narrative regarding this decade.

Using oral history to examine sexual or contraceptive practices has its own specific challenges. First, some historians may question whether or not it is worthwhile to ask older women about their birth-control experiences, given the passage of time. As Fisher acknowledges in her book, "It is undeniable that it is difficult for individuals to remember precise details of contraceptive choices, debates, and practices so long after their childbearing years."177 However, "[Psychological] research indicates that much is forgotten in the first twenty-four hours. More is forgotten during the next three to five years. But after that, constituents of a memory may remain intact for fifty years or more." Oral historian Valerie Raleigh Yow adds that older adults actually recount the past better than their more youthful counterparts. ${ }^{178}$ This may be because they reach a point of " 'life review' in which early memories are remembered with renewed clarity." 179 Indeed, I was often surprised at how much my informants remembered and were willing to share. Like Fisher, I received "testimony...[which] was remarkable for its apparent frankness...Many took their role as participants in academic history seriously, endeavoured to be honest, and apologized when unable to remember a specific detail."180 This common attitude, as well as the in-depth nature of the interviews, alleviated any concerns that participants might try to significantly misrepresent or fabricate their experiences. $^{181}$

\footnotetext{
${ }^{177}$ Fisher, 24.

${ }^{178}$ Ritchie, 27; Yow, 38.

${ }^{179}$ Fisher, 24, note 86 .

${ }^{180}$ Ibid., 17.

${ }^{181}$ Ibid., 16.
} 
There is a growing and relevant literature on women's oral history. Beginning in the 1970 s, feminists embraced oral history as a way to recover the experiences of women which were often not included in other sources. ${ }^{182}$ At the same time, feminist social scientists "mounted a critique of interview relationships based on supposed 'detachment' and objectivity."183 They argued that these ideals were impossible to achieve and in fact camouflaged unequal power relations. ${ }^{184}$ In addition, as Kristina Minister asserted in a 1991 article, "for girls, communication is the opportunity for establishing equality and intimacy in relatively small and private groups; for boys, communication is the site for contesting dominance in hierarchically structured groups that are public and relatively large." $" 185$ In consequence, Minister and other feminists called for a more collaborative and equal process in which women would interview women. ${ }^{186}$ But Joan Sangster would critique these feminist goals and states that, still, "feminist research is inevitably enmeshed in unequal, intrusive and potentially exploitative relationships, simply by virtue of our position as researchers and that of other women, with less control over the finished product, as 'subjects' of study."187

As I carried out my interviews, I was conscious of the power dynamics inherent in what I was doing. Many of my informants were educated, married, white women and, as such, they had a great deal in common with me. I would frequently share personal information with them, unsolicited or not, in order to create a rapport and a sense of

\footnotetext{
182 Joan Sangster, "Telling Our Stories: Feminist Debates and the Use of Oral History," Women's History Review 3, 1 (1994), 5.

${ }^{183}$ Ibid., 11.

${ }^{184} \mathrm{Ibid}$.

${ }^{185}$ Kristina Minister, "A Feminist Framework for the Oral History Interview," in Women's Words: The Feminist Practice of Oral History, edited by Sherna Berger Gluck and Daphne Patai (New York: Routledge, 1991), 30.

${ }^{186} \mathrm{Ibid} ., 32$ and 35.

${ }^{187}$ Sangster, 11.
} 
reciprocity since they were telling me so much about their lives. In doing so, I was trying, as Minister advised, to place our interaction on a more equal level. ${ }^{188} \mathrm{My}$ success in this effort was perhaps best confirmed by an informant who said, at the end of our interview, that it had been more like friends talking. ${ }^{189}$ Though I was happy to have put her at ease, inwardly I cringed somewhat, knowing that, as Sangster pointed out, our relationship was still unequal because I would assume the dominant role in interpreting and using what she had confided.

Post-structuralism has also had a pervasive impact on women's oral history. In 1998 , British historian and student of oral history, Penny Summerfield, asserted that in post-structuralism "The meanings within language are cultural constructions collectively generated, historical deposits within the way we think, which constitute the framework within which we act." However, rather than simply interpreting language as confining and deterministic, Summerfield proposes that historians consider the fruitful question of relations between experience and discourse. For her, oral history analysis must include "not only the voice that speaks for itself, but also the voices that speak to it, the discursive formulations from which understandings are selected and within which accounts are made." 190 Though my thesis does not offer a systematic discourse analysis, I do try, like Summerfield, to reflect on how women's experiences have been mediated by prevailing discourses on sexuality and reproduction. For example, Chapter 6 includes an analysis of how child-bearing women in my sample responded to and negotiated the discourse surrounding population control.

\footnotetext{
${ }^{188}$ Minister, 35 .

189 Brown.

${ }^{190}$ Penny Summerfield, Reconstructing Women's Wartime Lives: Discourse and Subjectivity in Oral Histories of the Second World War (Manchester: Manchester University Press, 1998), 11-12 and 15.
} 
To supplement and contextualize the oral interviews, I drew on a range of other primary sources, including the $\mathrm{CBC}$ Digital Archives for coverage on the pill. I examined Chatelaine magazine's issues as well as its unpublished records held at the Archives of Ontario. A very interesting source for historians, "Chatelaine was by far the most popular women's magazine in Canada. In 1968, Chatelaine had a circulation of over 900,000 compared to Family Circle, the most popular American women's magazine, which had only 410,275 Canadian sales per issue." contraception in the 1960s, with the exception of Appleby in her book on the legalization of birth control, have only used the Canadian Medical Association Journal sparingly. I found it to be helpful in providing insight into medical opinion on the pill as well as studies of side effects. American journalist Barbara Seaman's 1969 book remains very important for anyone interested in women's experiences on the birth-control pill. ${ }^{192}$ Prior to the book's publication, Seaman wrote articles for women's magazines, including a column in Brides magazine on marriage that she co-authored with her husband, a psychiatrist, and "dozens of articles...about issues related to women's health and wellbeing." 193

\section{Organization of the Thesis}

After covering the important background on Canadian society and the development of the pill in Chapter 1, the next chapter explores some of the steps involved in a married (or engaged) woman's progression to the pill, such as hearing about the new contraceptive, the appeal of the pill and the husband (or fiancé's) involvement in

\footnotetext{
${ }^{191}$ Jessica Haynes, "Help for All Parents? Child-Rearing Advice in English Canada in the 1960s and 1970s," Histoire Sociale/Social History 44,1 (May 2011), 56.

${ }^{192}$ Seaman.

${ }^{193}$ May, 130; Watkins, 103-104.
} 
choosing the pill. However, even once a woman decided to try the pill and had the support of her male partner, it was often not that simple. Chapter 3 discusses some of the barriers involved in getting the pill, including marital status, income, and medical attitudes. This chapter then proceeds to analyze a woman's experience on the pill, beginning with the initial appointment. Side effects, the subject of Chapters 4 and 5 , were also a large component of the reality of pill use in the 1960s and 1970s. Finally, Chapter 6 looks at the impact of the pill on larger aspects of the lives of married, Canadian women, namely sexuality, family size, careers and religion. 


\section{Chapter 2-Moving Towards the Pill: The News, The Appeal and The Man's Role}

A married woman's decision to go on the pill in the 1960s involved multiple steps. First, she had to hear about this new contraceptive. Traditionally, doctors informed their patients of and recommended specific medications. However, with the pill, women could learn about it through other sources, unconnected to the medical profession, such as the media, friends, family members and work or education. Armed with the knowledge they acquired through these channels, women could then potentially broach the topic of the pill with their doctors. Thus, the discussions of the pill in both private and public settings may have empowered women in their interactions with physicians.

Not all married women who heard about the pill were interested in taking it. Those who were frequently emphasized that the appeal of the pill was linked to its effectiveness and convenience. This may have been particularly true for those married women who had previous experience with other methods. Their stories of contraceptive failures, leading to unexpected pregnancies and disrupted sex lives, demonstrate why the pill became so popular among Western women. Even women I interviewed who had never personally tried other birth control, like the diaphragm, were aware of the reputation of other methods as unpleasant, inconvenient and fallible. These negative impressions may have influenced them to become pill users in the first place. Perhaps other women did not choose to try the pill because they were more satisfied with existing contraceptives.

Once a woman wanted to try the pill, she usually discussed the option with her fiancé or husband. While some historians have speculated that female-controlled 
methods, like the pill, made contraception a female responsibility, this does not seem to have been the case with married, Canadian women. Though some couples did have this view, for many others men were part of the decision-making on the pill. Their involvement could be limited to simply approving the woman's choice or more actively encouraging or discouraging the pill.

\section{How Did Women Hear about the Pill?}

As I will discuss in more detail in Chapter 3, the pill dramatically altered the patient-doctor relationship. Before its arrival, it was not common for patients to ask their doctors to prescribe specific medications, ${ }^{1}$ With the pill, many women did just that. However, before they could start taking the pill or even seek it out, women had to know that it existed. If, in 1961 the pill was available in Canada, this did not mean that all women realized this immediately. In the 1960 s, women heard about the pill from a variety of sources, including the media, friends, doctors and family members. ${ }^{2}$

Their recollections demonstrate that knowledge of the pill permeated many forums, both public and private, and definitely extended beyond the doctor's office. ${ }^{3}$ While some pill users recalled specifically where and when they first heard about it, others stressed that it was simply general knowledge and was widely discussed,

\footnotetext{
${ }^{1}$ Lara V. Marks, Sexual Chemistry: A History of the Contraceptive Pill (New Haven: Yale University Press, 2001), 7.

${ }^{2}$ Elizabeth Siegel Watkins, On the Pill: A Social History of Oral Contraceptives 1950-1970 (Baltimore: Johns Hopkins University Press, 1998), 41; Andrea Tone, Devices and Desires: A History of Contraceptives in America (New York: Hill and Wang, 2001), 239. The existing literature as well as women in my sample do not discuss learning of the pill through public health channels. In Canada, this may have been because disseminating information on contraception was illegal until 1969.

${ }^{3}$ Wendy Mitchinson, "Problematic Bodies and Agency: Women Patients in Canada, 1900-1950," in On The Case: Explorations in Social History (Toronto: University of Toronto Press, 1998), 270. Mitchinson demonstrates that, in the first half of the twentieth century, women similarly could learn about general health issues from many sources, including magazines and friends. She says "Physicians frowned on these information networks and advised women not to listen to friends and relations but to depend on their doctors for information that would be medically scientific." I am not sure if doctors in the 1960s and 1970s had similar attitudes about contraceptive knowledge. Further research into this question would be interesting.
} 
particularly in the media. ${ }^{4}$ For example, Wilkins, who learned of the pill sometime during her fourth pregnancy in 1962, thought she read about it and people talked about it. $^{5}$ Other women were similarly a little vague about their own experiences and suggested a number of possible sources, including the doctor, the media and friends. ${ }^{6}$

As one might expect, the media was often credited with creating awareness of the pill as a new contraceptive. While Mason, Taylor and Smith thought maybe they had found out about the pill through newspapers and the press ${ }^{7}$, other pill users were more certain. $^{8}$ Sometimes more specific publications were mentioned as possibly introducing women to the birth-control pill. Quinn asserted that she probably first heard about the pill in Chatelaine magazine which she started reading in her late teens. She said that the magazine often had articles on women's health issues. ${ }^{9}$ Stefánsson concurred that Chatelaine had a lot of content on the pill and birth control in general. Stefánsson's mother subscribed to it and, though Stefánsson did not remember specifically, the magazine, as well as possible conversations with friends, seemed to her a likely source for her introduction to the pill. ${ }^{10}$ Similarly, Moore thought she might have talked with

\footnotetext{
${ }^{4}$ Interview with Julia Hall, June 29, 2009, 2; Interview with Rose Murray, October 28, 2009, 7-8; Interview with Lydia Stevens, November 20, 2009, 6; Interview with Cheryl Clarke, November 12, 2009, 5-6, 8. Also, in my sample, some women could not remember when or how they heard about the pill.

${ }^{5}$ Interview with Yvonne Wilkins, September 30, 2009, 14-15.

${ }^{6}$ Interview with Penelope Dobos, July 7, 2009, 3; Interview with Heather Anderson, December 3, 2009, 5; Interview with Cynthia Young, February 8, 2010, 5; Interview with Ellen Carter, February 12, 2010, 6-7; Interview with Emma Edwards, April 12,2010, 7; Interview with Susan Brown, August 7, 2009, 6. Edwards, for example, was in university in the early 1960s and knew a woman there who went on the pill. She also assumed it was in the news.

${ }^{7}$ Interview with Caroline Mason, July 29, 2009, 3; Interview with Olivia Taylor, August 6, 2009, 4-5; Interview with Catherine Smith, July 9, 2009, 12 .

${ }^{8}$ Interview with Ruth Wright, July 8, 2009, 3; Interview with Claire Macdonald, March 11, 2010, 31-32. Macdonald also mentioned discussions with friends.

${ }^{9}$ Interview with Katherine Quinn, August 14, 2009, 2. Quinn was born in 1941 (1) so she would have been in her late teens in the late 1950s and early 1960s. For more on Chatelaine's coverage of the birth-control pill, see Chapters 4 and 5.

${ }^{10}$ Interview with Cora Stefánsson, November 23, 2009, 4. Stefánsson referred to Chatelaine as a strong feminist magazine in the 1960s. This is precisely the argument Valerie J. Korinek makes in her Roughing
} 
friends and read about the pill in magazines such as Cosmo or Glamour. ${ }^{11}$ Finally, Campbell mentioned that Time magazine had pages on science and she may have first heard about the pill through reading it. ${ }^{12}$ Therefore, in the 1960 s the media, including women's periodicals, may have played an important role in introducing Canadian women to the pill. These sources provided information quite independently from the medical profession.

Female friends and family were also important vehicles for disseminating information about the pill. ${ }^{13}$ Arsenault, for instance, thought she may have heard about the pill initially from one of her sisters. ${ }^{14}$ Lynch much more clearly remembered a specific conversation with her sister-in-law which took place in 1962 . Lynch had two children at the time and had just suffered a miscarriage. This third pregnancy had happened despite her conscientious use of a diaphragm. Her husband's sister, who was on the pill, spoke glowingly of it and asked if Lynch had heard of it. She had not but promptly went to her doctor to get it. ${ }^{15}$ Somewhat more unusually, Ryan vividly recalled first learning about the pill, possibly in the early 1960 s, from her father who was a pediatrician. They were going to visit her brother, who was married with two children, when her father stopped to pick up something at the drugstore. When Ryan inquired, he rather reluctantly and briefly explained that it was this new pill, intended for her sister-in-

It in the Suburbs: Reading Chatelaine Magazine in the Fifties and Sixties (Toronto: University of Toronto Press, 2000).

${ }^{11}$ Interview with Claire Moore, November 17, 2009, 14, 17-18; Korinek, 4-5. Korinek notes that Cosmo (Cosmopolitan) was one of the most popular magazines in North America in the 1950s and 1960s.

${ }^{12}$ Interview with Deborah Campbell, February 9, 2010, 12.

${ }^{13}$ Kate Fisher, Birth Control, Sex, and Marriage in Britain, 1918-1960 (Oxford: Oxford University Press, 2006), 60-61 and 63. In contrast, Fisher found that the British women she studied did not talk about birth control with each other but instead relied on their husbands for this information. She cites an article on Italian and Jewish women in the United States to confirm that they "[also] had difficulty finding out about birth control and did not discuss it." For more on women's discussions concerning the pill, see Chapters 4 and 5.

${ }_{14}^{14}$ Interview with Jane Arsenault, March 2, 2010, 6-7.

${ }^{15}$ Interview with Jane Lynch, October 6, 2009, 25-6. 
law. He told her the pill would prevent pregnancy. ${ }^{16}$ Therefore, in the 1960 s, news of the pill could spread through family members and provide the impetus for women to seek out the contraceptive.

In the 1960s, as now, women did discuss birth control with their friends.

Sometimes through these conversations, again unmediated by the medical profession, women learned about the pill. Both Macdonald and Walker, for instance, recalled group discussions regarding the pill. For Macdonald, the topic of birth control came up as friends prepared to get married. Especially in the early 1960 s, these conversations centered around the diaphragm but, by 1963 when Macdonald got married, her group of friends had shifted their interest to the pill. Macdonald felt it was through these conversations, as well as press reports, that she first learned of the pill. ${ }^{17}$ Walker also heard of the pill through friends. In her case, they discussed birth control after one friend got pregnant and had an abortion. ${ }^{18}$ Therefore, friends as well as the media and family, introduced some women to the pill in the 1960s. These informal discussions represent yet another way that women could learn about the pill without ever setting foot inside a doctor's office.

Canadian women could also hear about the pill through their education and work. Doyle first learned of the existence of the pill in 1959 or 1960 when she did a year of nursing training. ${ }^{19}$ Galli, who trained and worked as a nurse in the early 1960 s before getting additional degrees, also speculated that she probably heard about the pill through

\footnotetext{
${ }^{16}$ Interview with Anne Ryan, October 27, 2009, 1, 4-5.

${ }^{17}$ Macdonald, 3-6, 31-32.

${ }^{18}$ Interview with Joan Walker, October 15, 2009, 5-6. Abortion, though beyond the scope of this thesis, did come up in the interviews. Several women had personally had abortions at one time or another. The use of this procedure by married, Canadian women deserves further study.

${ }^{19}$ Interview with Eleanor Doyle, November 30, 2009, 2-3.
} 
nursing. ${ }^{20}$ Finally, Beck worked as a secretary in the department of obstetrics and gynecology of a hospital from 1960 to 1963 . She first heard about the pill during these years as it was a common topic of conversation around the office. ${ }^{21}$ Thus, for these women awareness of the pill was tied to their training or work in medical settings. However, for them, as for those pill users who heard through the media, friends or family, knowledge of the pill was not dependent on the information conveyed by one's personal physician. This represents a shift as, even into the 1950s, most Canadians relied on their doctors for contraceptive information. ${ }^{22}$

Indeed, it was still possible, though not common, for women to learn about the pill through this more traditional channel. Wood went on the pill in 1967 but, about three years before that, a doctor had broached the topic of the pill as a remedy for her amenorrhea. ${ }^{23}$ Wilson also initially heard about the pill from her family doctor. She had just had her first child, in 1965 , and the doctor asked if she planned on another baby very soon. She replied that she rather hoped not and he suggested the pill. ${ }^{24}$ Likewise, Stewart thinks her family doctor, Dr. R., must have told her about the pill and suggested she try it in the early $1960 \mathrm{~s}^{25}$ Stewart had had two children close together in 1957 and $1958 .^{26}$ Finally, Johnson, who went on the pill in 1963, heard about it from her obstetrician. She had, following her first pregnancy, developed a blood clot and was

\footnotetext{
${ }^{20}$ Interview with Diane Galli, December 8, 2009, 2-3, 4.

${ }^{21}$ Interview with Annie Beck, November 6, 2009, 3, 10, 11 and 27.

${ }^{22}$ Gerald Anglin, "The Pill That Could Shake the World," Chatelaine 26, 10 (October 1953), 101.

${ }^{23}$ Interview with Emily Wood, July 6, 2009, 3 and 5; http://www.merriamwebster.com/medlineplus/amenorrhea. Amenorrhea is defined as the "abnormal absence or suppression of menstruation."

${ }^{24}$ Interview with Margaret Wilson, August 12, 2009, 6, 7-8.

${ }^{25}$ Interview with Eileen Stewart, August 18, 2009, 7-8, 23.

${ }^{26}$ Ibid., 7.
} 
advised not to get pregnant again for at least a year. ${ }^{27}$ It is interesting that the women who learned about the pill through doctors seemed, with the exception of Wilson, to have had medical reasons to take it (i.e. amenorrhea, back-to-back pregnancies or a blood clot). Perhaps these conditions made physicians more likely to bring up the topic of birth control.

Thus, women in the 1960 s heard about the pill from a variety of sources. While some pill users explain that it was simply "in the air," others more specifically credit the media, family, friends, education and work experience or doctors. Notably, husbands were not mentioned. This makes these Canadian women different from their earlier British counterparts who, "presented themselves as having been almost entirely dependent on their husbands for birth control information." 28 Further, my analysis has shown that, despite the impressions of some that the pill was all over the media, there was no single way that women initially heard about it. Though some I spoke to do remember media coverage, others have vivid recollections of illuminating conversations with friends, doctors and, in one case even, their father. These accounts highlight how birth control became an acceptable topic in both the private and public sphere. Women who tried the pill could learn about it through an intimate conversation with their best friend or through reading a newspaper report. They did not need to rely totally on a doctor for information about the pill. With the knowledge they acquired through various sources, women may have felt more empowered in approaching their doctors for prescriptions.

\footnotetext{
${ }^{27}$ Interview with Linda Johnson, July 17, 2009, 7-8.

${ }^{28}$ Fisher, 60, 57-58. Interestingly, Fisher says that men had far better access to and knowledge of contraceptive information than women. Indeed, "Men were far more likely to find out about contraception before marriage, and many more men discussed methods of birth control with friends or colleagues." Fisher also mentions that many men read the work of birth-control advocate Marie Stopes.
} 
The evolution of women into active consumers of health care will be discussed in more detail in Chapters 3 and 4.

The Appeal of the Pill

As Canadian women considered their birth-control options in the 1960 s and heard about the pill, what was the appeal of this new contraceptive? For many, the answer was obvious: "freedom from the fear of pregnancy, convenience, and total control over contraception." 29 Women in my sample largely confirm this assertion, often placing the most emphasis on effectiveness and convenience. ${ }^{30}$ This section will first consider those women who had experience with birth control before the pill and, thus, were in a position to personally appreciate the disadvantages of other methods. I will then analyze why, drawing again on the testimony of former pill users, Canadian women with no previous contraceptive history also chose the new method. How did they perceive the pill in relation to other methods? Why were they happy to avoid condoms or diaphragms?

According to a 1965 Chatelaine article, of the two and a half million fertile and married women in Canada, seventy to eighty percent used some form of birth control. ${ }^{31}$ Married women in Canada did have access to other forms of birth control both prior to and after the pill's arrival, including the sponge, the diaphragm, the IUD and the condom. They could also rely on rhythm, withdrawal or abstinence. ${ }^{32}$ However, women often found these methods problematic for a variety of reasons. Of most concern, was the fact

\footnotetext{
${ }^{29}$ Elaine Tyler May, American and the Pill: A History of Promise, Peril, and Liberation (New York: Basic Books, 2010), 58; Tone, 234-235. Tone also comments that women valued the effectiveness, convenience and control offered by the pill.

${ }^{30}$ Canadian Gallup Poll, March 1967, \#323; Canadian Gallup Poll, May 1970, \#341. Canadian Gallup Polls confirm the widespread impression that the pill was efficacious. In 1967 and $1970,88.8 \%$ and $85.9 \%$ of those polled thought so.

${ }^{31}$ Constance Mungall, "Birth Control in Canada Today," Chatelaine 38, 4 (April 1965), 18.

${ }^{32}$ Ibid.; Watkins, 11; Hera Cook, The Long Sexual Revolution: English Women, Sex and Contraception 1800-1975 (Oxford: Oxford University Press, 2004), 135-139, 142; Marks, 187; May, 4; Robert Jütte, Contraception: A History, trans. Vicky Russell (Cambridge: Polity Press, 2008), 201 and 207.
} 
that they did not, despite diligent use, always prevent pregnancy. The pill was very effective, providing nearly 100 per cent protection against pregnancy when taken daily, and perceived as such by married women in the $1960 \mathrm{~s} .{ }^{33}$ Women who had experienced an unplanned pregnancy while using other birth-control methods particularly valued this reliability.

Women in my sample reported contraceptive failures with a variety of methods, some more prone to mishaps than others. ${ }^{34}$ For example, withdrawal was still used even into the 1950s and 1960s. ${ }^{35}$ Lynch was married in 1957 and her husband practiced withdrawal at first. Lynch hoped it would work but instead she got pregnant quickly and had her first child in $1958 .^{36}$ Johnson, married in 1960 , also quickly became pregnant. In her case "we used a spermicide called Delphen and I think there's a baby in every tube because we lasted six weeks. And I became pregnant." 37 After this child was born, Johnson developed a blood clot in her leg and was advised by her obstetrician to go on the pill so she would not get pregnant again right away. When asked why she agreed to try the pill, Johnson alluded to its glowing reputation for effectively preventing pregnancies. $^{38}$

\footnotetext{
${ }^{33}$ Christabelle Sethna, "A Bitter Pill: Second Wave Feminist Critiques of Oral Contraception," in Canada: Confederation to the Present, eds. Bob Hesketh and Chris Hackett (Edmonton: Chinook Multimedia Inc., 2001), http://chinookmultimedia.com/poccd/registered/web_papers/case_studies5.php. However, it is important to note that at least one woman in my sample got pregnant on the pill despite, according to her, conscientious use.

${ }^{34}$ It is worth noting that pill users, as a group, may report more problems with other methods as those who were happy with, for example, condoms or a diaphragm, may have never tried the pill.

${ }^{35}$ May, 4.

${ }^{36}$ Lynch, 12, 3 and 20.

${ }^{37}$ Johnson, 15 and 4.

${ }^{38}$ Ibid., 7-8, 13.
} 
The appeal of condoms increased in the late 1950s when they became thinner and pre-lubricated. ${ }^{39}$ Also, in the 1960 s, a spermicide on the surface of the condom increased its reliability. ${ }^{40}$ Nevertheless, then as now, condoms could and did fail to prevent all pregnancies. For instance, Wilkins, after getting pregnant on a diaphragm, tried condoms and, though she used them consistently, she got pregnant for a fourth time and her daughter was born in $1962 .^{41}$ When asked why she then tried the pill, Wilkins, emphasizing its effectiveness, replied "So I wouldn't ever have to be pregnant again. I wouldn't ever have to be terrified that I might get pregnant. ${ }^{, 42}$

In the 1950s, "the most effective method of birth control was a diaphragm used in combination with spermicidal jelly." This device had to be fitted by a doctor. ${ }^{43}$ However, despite its effectiveness and their conscientious use, several women in my sample reported that they got pregnant while using diaphragms. ${ }^{44}$ For example, Smith got a diaphragm before her marriage in June of 1959. She hoped to postpone children as her husband was still in law school but instead they had three children in two and a half years while relying on the diaphragm. She went on the pill in 1962 because the diaphragm was obviously not working for her. ${ }^{45}$ Similarly, Lynch, discussed above, switched to a diaphragm after her daughter was born in February of 1958. However, she quickly became pregnant again either because the diaphragm failed or she did not position it properly. After her second daughter was born just a year later, Lynch went back to the diaphragm and was even more careful with it. However, she got pregnant

\footnotetext{
${ }^{39} \mathrm{Cook}, 137-139$. Before this time, condoms had to be lubricated by the user.

${ }^{40}$ Jütte, 202.

${ }^{41}$ Wilkins, 13-15.

${ }^{42}$ Ibid., 29.

${ }^{43}$ Watkins, 11.

${ }^{44}$ Interview with Vivian Koch, January 21, 2010, 3-4, 6; Interview with Lucy Williams, October 8, 2009, 10.

${ }^{45}$ Smith, $1,2,4,5,9,11$ and 17.
} 
again in 1962 , miscarried and then went on the pill. ${ }^{46}$ Wilkins also experienced disappointing failures with a diaphragm. In her case, "I think I wasn't knowledgeable enough about my body to put it in properly." She added that one was supposed to get the diaphragm refitted after having a baby but she did not. As a result of these problems, Wilkins had two unplanned children in 1960 and $1961 .^{47}$

Therefore, some women, before accessing the pill, suffered unplanned pregnancies because of failures or difficulties with the existing birth control. ${ }^{48}$ The birth of an unexpected or additional child was often very disruptive to their lives. Other women, while not actually experiencing such occurrences with these methods, may have worried constantly about this happening to them and were, therefore, also drawn to the reputed effectiveness of the pill.

Women, perhaps surprisingly, still relied on the rhythm method in the 1950 s and 1960s. This method could involve avoiding sex in the more fertile days in a woman's cycle determined by simply calculating them from the last menstrual period, measuring body temperature and/or cervical mucus changes. ${ }^{49}$ The rhythm method, and other forms of periodic abstinence, was the only contraception strategy approved of by the Catholic Church. ${ }^{50}$ However, it is worth noting that non-Catholics also used it, sometimes in combination with other methods. For instance, Meyer, after trying a diaphragm,

\footnotetext{
${ }^{46}$ Lynch, 20, 22, 24-25.

${ }^{47}$ Wilkins, 6, 9, 12 and 14 .

${ }^{48}$ In discussing pregnancies that were not intended, interviewees do not usually speak of them as "planned" or "unplanned." For instance, when asked if she had decided to get pregnant, Williams simply replies "No. But I did get pregnant." More often, I am the one who labels conceptions as "unplanned" which likely reflects my own discursive position. I will more fully explore family planning rhetoric in Chapter 6. ${ }^{49}$ Jütte, 204-205; Diane Gervais and Danielle Gauvreau, "Women, Priests, and Physicians: Family Limitation in Quebec, 1940-1970," in Journal of Interdisciplinary History 34, 2 (Autumn 2003), 301-302. Wilhelm Hildebrand, a Catholic priest, made the intriguing discovery in the 1930 s that body temperature increased when a woman ovulated.

${ }^{50}$ Gervais and Gauvreau, 301-302; Marks, 218.
} 
condoms and an IUD, then limited sex to certain times of the month, possibly in conjunction with condoms. For her, and possibly given this history, the pill was appealing because "it was almost fool-proof, the chances of getting pregnant were very slim."51 Carter, who used the rhythm method before her marriage in 1968, also remembered she was anxious about this method. ${ }^{52}$ After fearing a pregnancy, the pill appealed to her because it was very effective and would mean no more worrying. ${ }^{53}$

Withdrawal, condoms and even a diaphragm could also provoke anxiety among women. Wilson, for example, had used withdrawal before her wedding and for a month or so after it. She admitted that this method made her worry all the time about getting pregnant. She did hope to start her family quickly though and her son was born in 1965 . At this time, she went on the pill at her doctor's suggestion, who "said it was ninety percent or ninety-nine percent effective which I was very relieved then because I remember thinking, oh, I don't have to worry anymore."54 Ryan and Stewart both commented that condoms were not as reliable as the pill. ${ }^{55}$ Ryan had used condoms with her fiancé before their 1966 wedding but wanted something more secure once they were married. ${ }^{56}$ Stewart stated that condoms could break and, though she never had an unplanned pregnancy while using them, she was interested in the pill when her doctor told her it was $99 \%$ effective. $^{57}$

Thus, married, Canadian who first tried the pill in the 1960 s, some of whom had had unplanned pregnancies while using other methods, very much valued the

\footnotetext{
${ }^{51}$ Interview with Judy Meyer, October 8, 2009, 4-6, 7, 9-11, 12.

${ }^{52}$ Carter, 4-6. Carter thinks they may also have used douches and condoms before marriage.

${ }^{53}$ Ibid., 9.

54 Wilson, 4-8.

${ }^{55}$ Hall, 1.

${ }^{56}$ Ryan, 5-6, 9.

${ }^{57}$ Stewart, 7-9.
} 
effectiveness and reliability of the birth-control pill. Meanwhile, the convenience of the pill was also important for those who had had experience with other contraception, especially the diaphragm. As Marks explained, "Many women chose the pill precisely because it involved no fiddling around and they could feel more 'natural' during the sex act." W8 Williams, for example, used a diaphragm after she was married in 1959. Not only did she get pregnant on it, as discussed above, but she "found it awkward to put in, I found it mostly embarrassing that you decided ahead of time that you were going to have sex...I hated it." ${ }^{, 59}$ Because she hated it, Williams then tried an IUD which came out by itself after a few months. Despite this failure, Williams emphasized again the convenience factor, saying "it was certainly very nice in the sense that you didn't have to make any preparations to have sex, it could happen...at any time of the day or night. You didn't have to say, well excuse me I have to run out and put in my diaphragm." Having exhausted these options, Williams turned to the pill. ${ }^{60}$ Hall had a similar experience with the diaphragm. She was married in 1961 and used a diaphragm for the first few years. She tried the pill "because I didn't like using the diaphragm. The diaphragm was messy and awkward and not...terribly spontaneous." For her, the pill was just much easier. ${ }^{61}$ Dawson, who had tried both condoms and the diaphragm, agreed that the pill was simpler than a diaphragm. She explained that sometimes she would put the diaphragm in and then find out her husband was not interested in sex that night. She would then have to take it out. For her, the pill allowed for a more spontaneous sex life. ${ }^{62}$ Lynch, who used a diaphragm for several years, mentioned that the pill was the most secure method but

\footnotetext{
58 Marks, 193.

${ }^{59}$ Williams, 6-7.

${ }^{60}$ Ibid., 11-12.

${ }^{61}$ Hall, 1. Hall added that she had the impression condoms were not as reliable.

${ }^{62}$ Interview with Charlotte Dawson, November 5, 2009, 22-23.
} 
also concurred that "[The pill] freed you up from that diaphragm and buying the jelly and being refitted for the diaphragm, you know, every year you had to go back to the doctor and have it refitted to be sure it was correct and that you inserted it properly, that it was covering the cervix and...it made life a lot easier. ${ }^{, 63}$ She added that the diaphragm interrupted sex. ${ }^{64}$ Therefore, women who had previously used a diaphragm appreciated that the pill was easy to use and facilitated sexual spontaneity. ${ }^{65}$

Some pill users I interviewed also emphasized that condoms were unpleasant and inconvenient. ${ }^{66}$ Murray, who had used condoms and possibly withdrawal before her marriage in 1966, chose to go on the pill rather than continue with condoms because "the pill's a little nicer...[condoms are] a little messy and not too spontaneous."67 Evans had also used condoms with her future husband but likewise chose to go on the pill shortly before their wedding. She said 'I didn't like condoms...I didn't like the time that it took to get them on and then having to take them off after and you're there and the bliss of the moment is obscured because you have to do something...So I thought the pill would be a whole lot easier. Which it was." Evans added she felt condoms may have decreased sensation. ${ }^{68}$ Condoms, then, as well as diaphragms, were perceived to diminish both enjoyment and spontaneity.

\footnotetext{
${ }^{63}$ Lynch, 20, 24-25, 31.

${ }^{64}$ Ibid., 25.

${ }^{65}$ Fisher, 169-170. The valuation of spontaneity was not limited to Canada in the 1960s. Fisher looks at British couples, most of whom got married in the 1930s, and found that, as mentioned in Chapter 1, many liked withdrawal because they "believed that good sex should be uncontrived, spontaneous, and "natural." ${ }^{66}$ In this characterization of condoms, it is important to remember that I only spoke to pill users. Women who never went on the pill and preferred methods like the condom would probably speak of it in more favourable terms.

${ }^{67}$ Murray, 6-7, 9 .

${ }^{68}$ Interview with Hazel Evans, December 1, 2009, 2-3, 5.
} 
When asked why they decided to try the pill, some women with previous birthcontrol experience gave equal weight to effectiveness and convenience. ${ }^{69}$ For instance, Beck had experience with foam, possibly condoms and a diaphragm before going on the pill in 1965. While she never had an unplanned pregnancy with these methods, she still chose the pill because it was the most reliable. ${ }^{70}$ She also felt that it was less intrusive on one's sex life. ${ }^{71}$ Earlier in the interview, she had commented that the foam was messy and the diaphragm had to be cleaned. ${ }^{72}$ Koch used a diaphragm in her first marriage, which started in 1952 . However, she quickly became pregnant. In addition, she found it inconvenient and was uncomfortable inserting it. Thus, when she next needed contraception, in 1961 and during her second marriage, she chose the pill for both effectiveness and convenience. ${ }^{73}$ Campbell was likewise motivated by these two factors. She was married in 1959 and had experience with foam, rhythm and a diaphragm. She decided to try the pill in 1964 because she had the impression it was more effective than these other methods as well as less messy. ${ }^{74}$ Reid echoed many of these sentiments. Prior to her 1967 wedding, she and her fiancé used condoms but she never liked the sensation. She chose the pill because of the "guarantee which they were practically offering was that you weren't going to get pregnant and...it's a nice clean way to take care of birth control." Reid added that the pill made it possible to predict your period. ${ }^{75}$

\footnotetext{
${ }^{69}$ Interview with Evelyn Scott, December 12, 2009, 21-22, 3 and 7; Edwards, 4-7; Galli, 6-8 and 23.

${ }^{70}$ Beck, 6, 8-13, 19.

${ }^{71}$ Ibid., 20.

${ }^{72}$ Ibid., 8.

${ }^{73}$ Koch, 3-6, 11 and 14

${ }^{74}$ Campbell, 3-4, 6-7, 9-11, 19 and 25.

${ }^{75}$ Interview with Beth Reid, November 18, 2009, 5-6, 21 and 8.
} 
Thus, most former pill users, when discussing its appeal in the 1960s, stressed convenience and/or reliability. ${ }^{76}$ Obviously, these were very important factors in freeing sex lives and preventing unplanned pregnancy. But, as Margaret Sanger had envisioned, the pill also had the potential to give women much more control over their reproductive lives, a characteristic that was very attractive to some women, particularly if their husbands were not cooperative about family planning. For example, one American woman, married to a lawyer, reported to Barbara Seaman:

I certainly can't count on Evan to use precautions. I can't even count on him to give me enough time to use a diaphragm. The IUD? Well, I don't know whether they have proven them reliable enough yet. Besides, Evan is just the type who might pull it out for a joke. Some men do that, you know. ${ }^{77}$

While Claire Moore apparently had a much more helpful husband, she also emphasized control when discussing the pill. Moore was married in 1957 and had children in 1958, 1959,1961 and 1964. She also suffered a miscarriage in 1967. Of these five pregnancies, two were unplanned. Until she went on the pill in about 1968, Moore relied on the rhythm method. She found the pill appealing because it meant she "would have control of my own body...I don't have to worry about anything else."78 Her answer, with its emphasis on autonomy over her body, evokes the women's health movement, discussed in Chapter 1. It is interesting that more women do not use this language. Perhaps in Moore's case, her choice of words has something to do with her espousal of

\footnotetext{
${ }^{76}$ Though beyond the scope of my thesis, it would be interesting to know how women who never tried the pill would describe the method. Pill users might be particularly positive about the contraceptive as they would need to justify their choice both at the time and in retrospect.

${ }^{77}$ Barbara Seaman, The Doctors' Case Against the Pill (New York: Peter H. Wyden, Inc., 1969), 59-60.

${ }^{78}$ Moore, 2, 3, 6-7, 10, 12-14, 17, 19-20 and 32. Moore added that for her the pill also meant both sexual freedom and freedom from having more children. Earlier in the interview, she alluded to another disadvantage of thythm, saying that it removed any spontaneity and "made sex the pits because you have to watch a calendar."
} 
feminism in the 1960s which she does confirm, when asked, likely influenced her attitudes about the pill. $^{79}$.

Therefore, though other contraception was available, it was clearly not satisfactory for all married women. The pill, for women who had tried other birth control, was primarily appealing because it was reliable and easy to use. Women who used the pill as their first method were drawn to it for the same reasons. ${ }^{80}$ Many likewise highlighted its effectiveness at preventing pregnancy. ${ }^{81}$ Women often expressed the sentiment that the pill was as close to one hundred percent effective as possible. ${ }^{82}$ For example, Quinn, who started the pill about three months before her wedding in 1967, chose the pill because "it seemed like the most hundred percent, it's not quite a hundred percent, I know, but it seemed like the most reliable form of birth control and also something that you have some control over in terms of taking it responsibly each day. Macdonald agreed that the pill was appealing because "it was understood to be a hundred percent effective if you took it as prescribed. ${ }^{184}$ Arsenault, who abstained from sex for five months after the birth of her son in 1966 then went on the pill, had a similar impression of its efficacy. She said "It know it was easy and it was safe but the big thing

${ }^{79}$ Generally, my interviewees do not discuss feminism (or use its rhetoric) in reference to reproduction or birth control. Possibly these particular women, some of whom felt alienated from the social changes of the 1960s, as discussed in Chapter 1, also felt second-wave feminism did not resonate with this part of their lives.

${ }^{80}$ Wright, 2; Interview with Isabelle Lowe, April 27, 2010, 4 and 9-10. In this group, there were a couple women who used another method for a brief time before using the pill exclusively. However, this was either to give the pill time to become effective (Wright) or the other method was not used in a clear or consistent fashion. For example, Lowe started on the pill in 1967 and had sex before that with no birth control except a vague understanding of her menstrual cycle. I do not think such knowledge constitutes the use of the rhythm method. I have also included one woman, cited in Chatelaine magazine, whose birth control background I do not know.

${ }^{81}$ Interview with Elizabeth Thompson, June 11, 2009, 19; Interview with Jean Watson, November 3, 2009, 10.

${ }^{82}$ Mason, 4-5; Quinn, 4.

${ }^{83}$ Quinn, 4.

${ }^{84}$ Macdonald, 14. 
was it was sure. No mistakes. You didn't get pregnant. And I still believe to this day when women tell me the pill didn't work for them, I think, oh no, that's not true, you've made a mistake." ${ }^{, 55}$ Thus, women who had not used other birth-control methods, often chose the pill because they believed it was the most effective contraceptive.

This group of women, inexperienced with other birth control, also had the impression the pill was much easier and more convenient than other methods. Brown, who started the pill in 1966 before her wedding, said of the diaphragm "how nice that you wouldn't have to use that...and that you could be spontaneous and oh yeah I knew lots of advantages, I was quite excited to be on...[the pill]." ${ }^{, 86}$ Young, married and starting the pill in 1965 , never even considered other options as the pill "just seemed the easiest, the best thing to do." pill in the spring of 1969 and said the pill was easy and, with no talk of side effects, it seemed like a no-brainer. She said "I mean you take a pill, you don't get pregnant...we didn't even talk about the other stuff, you just went on the pill. That was just what you did. It wasn't even I think a question. I don't think I maybe thought two seconds about it." ${ }^{, 88}$ Thus, for women who first tried the pill in the 1960 s, the method's perceived convenience was an important factor in their decision-making. In fact, the pill was so easy to use that some women took for granted it would be their choice.

\footnotetext{
${ }^{85}$ Arsenault, 3, 5 and 30 .

${ }^{86}$ Brown, 3, 4, 5 and 9. Brown thinks she may have used condoms or rhythm in a previous relationship but, given that she was not sure on this point, I decided to include her among the women with no meaningful birth-control experience before the pill.

${ }^{87}$ Young, 3-4, 7.

${ }^{88}$ Stefánsson, 5 and 6.
} 
Sometimes women with no prior birth-control experience gave equal significance to convenience and effectiveness when choosing the pill. ${ }^{89}$ For example, Taylor started the pill in 1966 and got married the following year. She said "there was a lot of good reports out [about] how well it worked and...it seemed to be the easiest way, the most convenient way to prevent having a family immediately." ninety-nine point nine percent sure and it was convenient." ${ }^{\text {91 }}$ Clarke and Lowe stressed effectiveness but also alluded to the pill's impact on sex itself. ${ }^{92}$ Clarke, who started the pill a few months before her wedding in 1967 , noted that, unlike the pill, condoms and diaphragms created a sense of barrier. ${ }^{93}$ Lowe more explicitly stated that these other methods disrupted sex. ${ }^{94}$ Summarizing the arguments for the pill, Ellen Jackson explained that it "was probably the most effective method and one of the simplest methods. It certainly wasn't as messy as a diaphragm, certainly more effective than rhythm. IUDs seemed to...anything I'd heard, people had seemed to be having some problems with them." 95

Given the birth-control options available to married couples by the mid-twentieth century, some people may have wondered if the pill would be necessary or appealing. However, upon closer inspection, other available methods were, or were perceived to be, prone to failures and aggravation. Obviously, pill users who had suffered unplanned pregnancies while relying on diaphragms, condoms or other methods were very interested

\footnotetext{
${ }^{89}$ Anderson, 11; Interview with Alice Richards, December 7, 2009, 7; Stevens, 4-7; Phyllis Holman in Mildred Istona, "Is There a Young Marriage Revolution? Part 2," Chatelaine 39, 12 (December 1966), 40. In 1966, Holman was a twenty-six-year old married fashion co-ordinator with no children. I do not know if she had any experience with other birth-control methods.

${ }_{90}$ Taylor, 4.

${ }^{91}$ Interview with Olivia Klein, October 20, 2009, 10.

${ }^{92}$ Clarke, 7; Lowe, 6-7.

${ }^{93}$ Clarke, 9, 4 and 7.

${ }^{94}$ Lowe, 6-7.

${ }^{95}$ Interview with Ellen Jackson, October 23, 2009, 6.
} 
in the new contraceptive. Other women who went on the pill found these methods effective but unpalatable because they interrupted sex or diminished pleasure. Women who were just getting married or simply had not used any contraception prior to the pill emphasized the same advantages of effectiveness and convenience. However, pill users did not make their birth-control choices in isolation. The next section of this chapter will explore the involvement of the male partner in this process.

\section{Husband's Role in Choosing the Pill}

Through history, women were not always solely or even primarily responsible for birth control. If withdrawal, as Angus McLaren has claimed, remained the most popular birth-control method in Europe and North America till at least the 1930s, then obviously men were actively involved in limiting family size. ${ }^{96}$ In the 1930 s, female methods, such as the diaphragm, may have gained in popularity, but in both the United States and Britain, condoms remained the most popular method until the advent of the pill. ${ }^{97}$ Despite these facts, some historians have stated that birth control remained or became a female responsibility in the $1930 \mathrm{~s}^{98}$

Kate Fisher's 2006 book, Birth Control, Sex, and Marriage in Britain 1918-1960, is very important in exploring this apparent contradiction. Drawing on one hundred and ninety-three interviews with both men and women in England and Wales, the majority of whom married in the 1930 s, Fisher actually concludes that "in contrast to the widespread assumption that women were at the forefront of birth control practices, respondents

\footnotetext{
${ }^{96}$ Angus McLaren and Arlene Tigar McLaren, The Bedroom and the State: The Changing Practices and Politics of Contraception and Abortion in Canada, 1880-1980 (Toronto: McClelland and Stewart, 1986), 18.

${ }^{97}$ Jütte, 201; Marks, 187; Andrea Tone, "Making Room for Rubbers: Gender, Technology and Birth Control before the Pill," History and Technology 18, 1 (2002): 53; Paul Jobling, "Playing Safe: The Politics of Pleasure and Gender in the Promotion of Condoms in Britain, 1970-1982," Journal of Design History 10, 1 (1997): 55 and 58.

${ }^{98}$ McLaren and McLaren, 27; Jütte, 201.
} 
asserted that they valued male responsibility for and authority over contraception." 99 In her sample, women's sexual identity was defined by innocence and passivity. To display an obvious interest in birth control would mean abandoning this role as it would have "required them to engage with sexual information, demanded that they speak about sexual matters publicly in order to obtain appliances, entailed the awkwardness of discussing family limitation with their husbands, and compelled them to display a direct interest in coitus prior to the act." $" 100$ In this context, women seemed happy to abdicate responsibility for birth control to men and Fisher found that men often selected the method, decided when it would be used and ultimately determined the size of the family. ${ }^{101}$

While Fisher's analysis ends in 1960, she does comment that, in the second half of the twentieth century, women began to more actively engage with birth control. Unlike their counterparts in the 1930 s and 1940 s, women seemed to be more "comfortable with the active sexual identity that the Pill might imply." She suggests that the pill, accessible and separate from the sexual act, along with other factors, may have contributed to this shift in sensibility. ${ }^{102}$ Also describing this transformation, Sethna explains "Until the 1960s, coitus interruptus and condoms had been among the most common forms of birth control, especially in first-time intercourse for single males and for married couples. But, with the advent of highly effective female-dependent methods of birth control such as the pill, contraception became increasingly 'feminized'; women,

\footnotetext{
${ }^{99}$ Fisher, 3-5.

${ }^{100} \mathrm{Ibid}$., 201 and 238-9.

${ }^{101} \mathrm{Ibid}$., 200, 210 and 194.

${ }^{102}$ Ibid., 239-240.
} 
not men, were now considered mainly responsible for contraceptive use." ${ }^{103}$ A 1965 study in England and Wales involving 6300 married women confirmed that a rising proportion of women were taking charge of contraception. ${ }^{104}$ It is true that, in contrast to other methods, the pill allowed women to use birth control without the cooperation or even knowledge of their sexual partners. ${ }^{105}$

However, evidence for a total transformation in women's contraceptive behaviour is by no means straightforward. A 1967-1968 British survey of working-class women found that many, even after the introduction of the pill, still favoured male methods of birth control. This somewhat contradicts the 1965 study, cited in the above paragraph, and suggests the unevenness of changes. In addition, women who did go on the pill may have been assuming responsibility for birth control but this method, divorced from sex, also could allow them to maintain their passivity in the bedroom. ${ }^{106}$ Fisher cautions against simply assuming that, with the pill, male interest in contraception evaporated. Instead, she says "We need to examine whether gendered roles were radically reformulated so that birth control became seen primarily as a wife's job, or whether men continued to play significant roles within new forms of relationship, in which birth control was openly negotiated by partners who saw contraception as a matter of joint concern." 107 The rest of this chapter will seek to answer these questions by examining the role of Canadian husbands and fiancés in choosing the birth-control pill in the 1960s. To date, there has been very little analysis of these questions in the Canadian context.

\footnotetext{
${ }^{103}$ Sethna, 2001. Italics her own.

${ }^{104}$ Marks, 199.

${ }^{105}$ May, 4; Marks, 196.

${ }^{106}$ Marks, 195.

${ }^{107}$ Fisher, 241-2.
} 
Dr. Benjamin Schlesinger, associate professor in the School of Social Work at the University of Toronto, discussed the pivotal role of the husband in family planning in 1966. He said "The use of the pill enables the husband to share the meaning of family planning with his wife and allows the wife freedom and less anxiety about unwanted pregnancies. Studies of family planning reveal that unless the husband supports the use of the pill or any other form of contraception, very little progress can be made." ${ }^{\text {108 }}$ While Dr. Schlesinger stressed the need for male support of birth-control decisions, did men really act in this way? In the 1960 s, as before, married women did not make their birthcontrol choices alone. The opinions and wishes of their husbands or fiancés did matter to them. In the fifty-three interviews I conducted, most women remember that their partners agreed with their decision to go on the pill. However, according to the women, some men were more actively involved in contraceptive decisions while others hung back or expressed no opinion. Among those who adopted this more passive role, some were lauded for simply supporting their wives' or fiancées' right to reproductive control while others were chided for burdening women with this responsibility. ${ }^{109}$ In either case, men who were not active participants in choosing the pill tended to believe that birth control was a woman's prerogative.

\footnotetext{
${ }^{108}$ Mildred Istona, "Is There a Young Marriage Revolution? Part 1," Chatelaine 39, 11 (November 1966), 44; Istona, "Is There a Young Marriage Revolution? Part 2," 40,60 and 64. Based on his interviews with six Canadian couples in 1966, Dr. Schlesinger concluded that husbands were very interested in the pill, suggesting a level of involvement. The magazine does not explain precisely how these couples were chosen other than to say they "were selected at preliminary interviews to ensure some variety of circumstances and perspectives."

${ }^{109}$ Fisher, 241. Fisher concurs that "Some women complained that, by expecting them to be on the Pill, or to get an abortion in the case of an accident, men burdened their female partners with the sole responsibility for preventing pregnancy." See also Tone, 247 and 251.
} 
According to a number of women I interviewed, their husbands never expressed an opinion about the pill. ${ }^{110}$ For some, this was because birth control in their marriages was always, or became, a female responsibility. This seems to be in keeping with Sethna's claim that "the feminization of contraception allowed men to skirt or to abdicate entirely their contraceptive responsibilities." 111 Hall affirmed that, when she married in the early $1960 \mathrm{~s}$, birth control was seen as something a woman looked after and her husband was never really comfortable discussing such matters. ${ }^{112}$ Smith, who married in 1959 , concurred that she did not discuss birth control too much with her husband and simply felt the need to look after her own body. ${ }^{113}$ For Dawson, who married in 1945, birth control became her responsibility after her husband declared his dislike of condoms and stopped using them early in their marriage. At his urging, she then went to a doctor who advised a diaphragm. Dawson stated, after this point, her husband did not care if she used the diaphragm or took the pill, which she did in the $1960 \mathrm{~s}^{114}$ Anderson's husband was even less involved in her decision to begin the pill in 1965 , following the birth of her three children. She said "I don't think I ever discussed it with him. It was my decision."115 Similarly, Arsenault stated that birth control was her business and she did not really discuss it too much with her husband when she started the pill in 1966, after the

\footnotetext{
${ }^{110}$ Scott, 7 and 9; Hall, 7; Smith, 17; Meyer, 12; Interview with Beverley Brooks, October 19, 2009, 16; Dawson, 18; Interview with Elizabeth Kennedy, November 10, 2009, 13; Anderson, 6; Arsenault, 20 and 33.

"111 Sethna, 2001.

${ }^{112}$ Hall, 1,6 and 7 .

${ }^{113}$ Smith, 3, 12 and 16.

114 Dawson, 5-6, 12 and 18; Fisher, 58. Fisher wrote in her study of British couples, the majority of whom were married in the 1930s, that "[Birth-control] Clinics reported...men frequently found out about them and sent their wives." Perhaps, in sending her to the doctor, Dawson's husband was simply following this older pattern.

${ }^{115}$ Anderson, 2-6.
} 
birth of their son. ${ }^{116}$ Meyer and Brooks, instead of saying birth control was a female responsibility, emphasized that their husbands were content to go along with whatever they had decided. ${ }^{117}$ In summing up this attitude, Meyer said that "Whatever made me happy, made him happy."118 Thus, whether motivated by a belief in female responsibility for birth control or just a desire to be agreeable, it would seem some husbands had almost totally abdicated responsibility for contraceptive decisions by the 1960 s. This would indeed be a dramatic shift from the 1930 s when men were in charge of such matters.

However, not all men were as passive. First, many, according to the women they married, at least were pleased when their wives or fiancées went on the pill. For men, as well as women, the pill often removed the fear of unwanted pregnancy. ${ }^{119}$ As expressed by Moore, a mother of four who started the pill in about 1968, "It was my decision but I think he was relieved that he wouldn't have to worry anymore about getting pregnant." 20 While some partners seemingly just agreed the pill was a good idea when told about it, ${ }^{121}$ others took a more active role in selecting the pill for birth control. Taylor, Walker, Clarke, Edwards, and Wright all said that they discussed contraception with their husbands prior to marriage and agreed that the pill was the best option. ${ }^{122}$ For these women choosing the pill was remembered more as a joint activity. ${ }^{123}$ This seems to confirm Kate Fisher's speculation that "an increasing openness on the part of women to

\footnotetext{
${ }^{116}$ Arsenault, 3, 5, 20 and 29.

${ }_{117}$ Meyer, 12; Brooks, 16.

${ }^{118}$ Meyer, 12.

${ }^{119}$ May, 58.

${ }^{120}$ Moore, 1, 2, 10 and 27; Quinn, 4; Murray, 17; Stefánsson, 14; Doyle, 6; Richards, 10-11. Quinn, Murray, Stefánsson, Doyle and Richards also think their partners had a favourable initial opinion of the pill. ${ }^{121}$ For example, Wilson, 9; Jackson, 7; Klein, 11. Again, sometimes this diminished involvement may have been because they saw birth control as a female prerogative. On this, see Interview with Thompson, 16 and 17,21 and Klein, 45-46.

${ }^{122}$ Taylor, 4; Walker, 16; Clarke, 8 and 31; Edwards, 23-24. Taylor, Walker and Clarke were married in 1967, Edwards in 1965 and Wright in 1969.

${ }^{123}$ Stevens, 23. Stevens actually said it was a "joint decision."
} 
address issues surrounding birth control, and the end of sole male responsibility for it, made couples see birth control as a 'joint decision', and led them to newly open forms of communication about contraception which their parents' generation would have considered inappropriate. ${ }^{2124}$ Perhaps, given the above dates, this sentiment increased throughout the 1960s. Ruth Wright, who went on the pill three months before her 1969 wedding, expressed this feeling of cooperation when she said she and her fiancé "read everything we saw about the pill and other options, and we both chose the pill as the best option." ${ }^{25}$ Galli, on the pill a few months before her 1968 wedding, agreed that she and her fiancé chose the pill “in consultation together, it wasn't something I decided to go and zip off and do and then, by the way, guess what I've done?"'126

For Evans, her fiancé may have determined even more her decision to go on the pill before their 1966 wedding. Neither of them liked condoms and "I think he...probably influenced my decision to...get the pill too cause I think it's probably much more enjoyable for a man not to have to wear [a condom]." 27 Macdonald also hinted that her fiancé may have influenced her decision to go on the pill in 1963 when she said "I wouldn't eliminate the possibility of him having brought...[the pill] up in the first instance." ${ }^{128}$ Therefore, even before marriage, some men still apparently felt they were at least a little responsible for birth control. They would often participate in selecting a method and one or two may have even steered their partners toward the pill specifically.

Women who were married when they started the pill similarly remembered that their husbands were involved with birth-control decisions. For instance, Beck, already a

\footnotetext{
${ }^{124}$ Fisher, 243.

${ }^{125}$ Wright, 2; Email correspondence from Ruth Wright, July, 2009, 2. Italics my own.

${ }^{126}$ Galli, 3,5 and 9.

${ }_{127}^{127}$ Evans, 2-3 and 5.

${ }^{128}$ Macdonald, 3, 8 and 31.
} 
wife and mother when she went on the pill in 1965, emphasized that she discussed it with her husband and they decided together to follow the advice of her obstetrician. ${ }^{129}$

Likewise, Koch recalled that she and her husband agreed she should go on the pill in 1961 following a number of pregnancies. ${ }^{130}$ Morrison's husband seemed even more involved in the decision to go on the pill in 1965 , following the birth of their two children. He suggested she speak to a doctor about birth control. ${ }^{131}$ Therefore, here again, it would appear that Canadian husbands in the 1960s did not completely abandon the birth-control field to their wives.

Thus, despite the feminization of birth control described by Sethna, many of my respondents remember that their husbands or fiancés, throughout the decade, did take an active interest in their birth-control choices, either reaching the decision with them or possibly even guiding them toward the pill. Indeed, apparently some men were almost oppressive in their enthusiasm for the pill and pressured their wives to stay on it. ${ }^{132}$ I will discuss this further in Chapter 4.

While most of my respondents report that their husbands or fiancés were happy with the pill as birth control, this was not always the case. Jack Batten, in a 1969 Chatelaine article, alleged that thousands of husbands refused to allow their wives to take the pill. ${ }^{133}$ According to a Toronto gynecologist, "about ten or twelve women a year tell me that their husbands want them off the pill or don't want them to start on it...and I'm

\footnotetext{
${ }^{129}$ Beck, 11 and 21 . Her obstetrician suggested she go on the pill as she had had two pregnancies close together and he thought it would be best if she did not have another baby for at least two years.

${ }_{130}^{130}$ Koch, $10-11$ and 17.

${ }^{131}$ Interview with Caroline Morrison, March 9, 2010, 10.

${ }^{132}$ Seaman, 59. In my sample, class or economic security did not seem to significantly impact the role of the husband in choosing the pill.

${ }^{133}$ Jack Batten, "Is There a Male Conspiracy against The Pill?" Chatelaine 42, 7 (July 1969),39; Korinek, 308. Though not providing any biography of him, Korinek includes Batten in a list of "journalistic luminaries who wrote for...[Chatelaine] in the sixties."
} 
quite certain that that may be only the top of the iceberg- lots of other husbands probably feel the same way. ${ }^{.134}$ Marg Jones, a married twenty-two-year-old interviewed in Chatelaine, confirmed that she knew "one couple - no sooner was she out of the hospital, he wanted another baby. She wanted to take the pill, but he wouldn't allow it."135 Dr. Denise Pullen, who worked in family planning in Britain in the 1950s and 1960s, added that 'it was not uncommon in the early 1960 s for men to flush their wives' oral contraceptives down the toilet." 136

Some men apparently worried that the pill threatened their masculine identities as potent sexual aggressors, while others complained it gave too much responsibility and power to women. ${ }^{137}$ According to Dr. M.J. Meldman, a psychiatrist from Chicago, "many husbands see the pill- with its power to release their wives from pregnancy fears and thus to encourage them into more relaxed and even aggressive activities in bed- as a terrifying threat to their own sense of masculinity." 138 One man, interviewed in the 1960s, for instance, explained he would rather use male methods as, with the pill, "his wife could unilaterally decide to have another child merely by stopping the pill without informing him."139 It is possible that Wilkins' husband was reacting to this perceived loss of control. Wilkins, who went on the pill in 1962 after the birth of three children, recalled that her husband was suspicious of the pill's effectiveness. He was concerned that it would not work. Wilkins went on the pill despite his objections and said "well, if you really don't want to, then use a condom and I'll take the pill. So we did for awhile."

\footnotetext{
${ }^{134}$ Cited in Batten, 41.

${ }^{135}$ Istona, "Is There a Young Marriage Revolution? Part 2," 40 and 57.

${ }^{136}$ Marks, 195 and 198.

${ }^{137}$ Ibid., 198-199; May, 58.

${ }^{138}$ Cited in Batten, 41.

${ }^{139}$ Marks, 199.
} 
Wilkins reflected that her husband was very controlling and "he didn't want me to have the pill because it meant he couldn't control me anymore."140

While Wilkins' husband claimed to doubt the reliability of the pill, other husbands actually objected to it because they thought it was perhaps a little too effective in preventing pregnancy. Lynch, for instance, also went on the pill in 1962 after the birth of two children and a miscarriage. In recalling her decision to go on the pill, she said "I didn't ask permission...I did it. I'm not sure...[my husband]...was all that happy, he would have liked to have had more children. It was a little bit of a source of disagreement at times, why don't you stop taking the pill? ${ }^{141}$ Lynch added that, in their marriage, birth control was ultimately her decision. ${ }^{142}$ Similarly, Ramsey, who went on the pill in about 1967 after four children was not sure how much she discussed it with her husband. He did know she was on it and "he liked little babies so I'm not sure he was as happy about it as I was."143

While the focus of my study is the impact of the pill on Canadian women in the 1960 s, it is important to note the evolving role of men in contraceptive decision-making. It seems that, at least among those who tried the pill, by the 1960 s women had assumed primary responsibility for birth control. Nevertheless, this did not mean that men were silent, passive or invisible. As my interviews have shown, many fiancés and husbands were involved in the initial decision to try the pill. This participation could take the form of simply expressing happiness with the choice of the pill, deciding with their female

\footnotetext{
${ }^{140}$ Wilkins, 14-17, 1, 28-29.

${ }^{141}$ Lynch, 20, 25 and 28.

142 Ibid., 39.

${ }^{143}$ Interview with Mary Ramsey, October 29, 2009, 6-11, 17. However, Ramsey suggested that this was just an impression on her part and, later in the interview, stated that her husband did not really have an opinion on the pill.
} 
partners to get the pill, actually suggesting the pill or even opposing it. However, there were limits to their input. Most strikingly, the three women who suggested that their husbands may not have been overjoyed about the pill went on it anyway.

\section{$\underline{\text { Conclusion }}$}

This chapter has examined the factors involved in the decision of married, Canadian women moving towards the pill. First, they had to hear about it. Women learned of the pill through the media, friends, family members and education or work as well as doctors. My analysis has demonstrated that, with the pill, discussion of contraception became acceptable in many different forums and certainly had escaped the confines of the doctor's office. Armed with their own knowledge, gleaned from these sources, women could then approach their doctors with requests for the pill, becoming in the process much more active agents in their reproductive health. However, for a few women, doctors remained the initial sources of information on the pill. Husbands or fiancés apparently did not enlighten their female partners about this contraceptive, suggesting a shift from the dominant role they assumed in Fisher's account.

Once they heard about it, women had to evaluate whether or not the pill was right for them. Much of the appeal of the pill in the 1960s was connected to its perceived high degree of effectiveness and convenience. Both pill users who had struggled with other methods and those who had simply heard about them, valued the contraceptive for these qualities. Finally, before seeking a prescription, husbands and fiancés, while not providing the initial information about the pill, were part of the decision-making process regarding birth control in the 1960 s. While some male partners did not engage very much on the subject, others approved of the pill or even more actively steered their wives 
or fiancées towards it. A few husbands even objected to the pill, again demonstrating that men were by no means silent in the matter of birth control. 


\section{Chapter 3-Getting on the Pill}

Once a woman had heard about and decided to take the pill, either more unilaterally or in consultation with her partner or doctor, she had to acquire a prescription for it. Like today, this involved at the very least a conversation with a doctor. This chapter will discuss what occurred during this initial appointment. I will then examine some aspects of a married woman's experience on the pill, including medical check-ups and the regimen of pill use. Side effects will be discussed in great detail in Chapter 4 .

First I will outline some barriers to accessing the pill in the 1960s. While it became available in Canada in 1961, that did not mean that all women had equal access to this new contraceptive. Indeed, marital status, age, and income could act as impediments to obtaining the pill for Canadian women in the 1960s. In addition, some women were inhibited by their own unease regarding premarital sexuality. If all these obstacles were overcome, women could still encounter resistance from prescribing doctors, some of whom were concerned about the safety of the pill and some of whom simply disapproved of sex before marriage.

\section{Did A Ring Matter? Attitudes Regarding Premarital Sex and the Pill}

By mid-century, young men and women in Canada socialized by "going steady" with one partner, often until marriage. ${ }^{1}$ Despite the prevalence of these exclusive relationships, society continued to disapprove of premarital sex and hoped (some would

\footnotetext{
'Mary Louise Adams, The Trouble with Normal: Postwar Youth and the Making of Heterosexuality (Toronto: University of Toronto Press, 1997), 99; Christabelle Sethna, "The University of Toronto Health Service, Oral Contraception, and Student Demand for Birth Control, 1960-1970," Historical Studies in Education 17, 2 (2005), 268.
} 
say naively) that girls would remain virgins until marriage. ${ }^{2}$ According to Adams' study of Canadian sexual norms, in the 1950 s,

Sexual activity took place on a graduated scale that culminated in 'going all the way.' So long as a couple went up the scale in the proper order, at the proper stage of their dating relationship, the dating system could contain and sanction their intimacies. As an institution, going steady allowed both girls and boys to maintain their reputations while permitting them access to sex, in some cases, even intercourse, so long as they didn't get caught. Pregnancy was an incontestable marker of having crossed the line between normal $/ \mathrm{moral} /$ good and abnormal/immoral/bad. ${ }^{3}$

Many of my informants, born in the 1930s and 1940s, described the system they were negotiating in similar terms. For them, as for others, the 1950 s and early 1960 s was a period in which "old and new values sat uneasily juxtaposed." As historians have found, the sexual revolution, in which premarital sex became more common and acceptable, did not occur the moment the calendar flipped to $1960 .^{5}$ Rather, it was a gradual process that affected different groups of the population more than others. In my sample, some felt very much a part of these dramatic social changes while others, particularly those who married in the early 1960s, adhered to the older model of premarital sexual activity described by Adams.

When the pill was released in Canada in 1961, many still believed sexual intercourse should occur only in marriage. ${ }^{6}$ However, as discussed in Chapter 1 , an increasing number were beginning to consider birth control (presumably for married

\footnotetext{
${ }^{2}$ Doug Owram, Born at the Right Time: A History of the Baby Boom Generation (Toronto: University of Toronto Press, 1996), 257.

${ }^{3}$ Adams, 105.

${ }^{4}$ Owram, 261.

${ }^{5}$ Ibid., 262-269. I will discuss the sexual revolution, as well as the historiographical debate surrounding it, in more detail in Chapter 6.

6 "Is Pre-Marital Sex Right or Wrong? Split Opinions Among Young: Old Object," Gallup Report, April 11, 1970, p. 2. According to the Gallup Report, $57 \%$ of Canadians in 1970 still believed that premarital sex was wrong. I think one can safely assume the number would have been even higher a decade earlier.
} 
couples) acceptable. Perhaps reflecting these values, in many countries, the pill was

originally intended for married women or women engaged to be married. ${ }^{7}$ In the $1960 \mathrm{~s}$, single Canadian women had difficulty accessing the pill. ${ }^{8}$ They found that

the majority of doctors who declined to dispense the pill did so because they opposed premarital sex on moral grounds or feared the legal consequences of treating patients who fell below provincial age limits for consent to medical care without parental permission. As a result of such difficulties, single, teenaged girls often resorted to wearing phony wedding rings, lying about their birthdates, or frequenting birth control clinics that operated on a don't-ask-don't-tell policy regarding marital status, age, and parental permission.'

While women may have used such strategies to get the pill in the 1960 s, "by the early 1970s, adult women, whether married or not, had little difficulty obtaining birth-control information and prescriptions from doctors." 10 However, feminist organizations would continue to complain that Canadian teenagers still had trouble accessing birth-control services after this time. ${ }^{11}$

The women I interviewed confirmed that marital status did matter when trying to get the pill in the 1960s. The majority of married women appreciated that, in the 1960s,

\footnotetext{
${ }^{7}$ Lara V. Marks, Sexual Chemistry: A History of the Contraceptive Pill (New Haven: Yale University Press, 2001), 8 and 202; Sethna, 2005, 270.

${ }^{8}$ Sethna, 2005, 291; Christabelle Sethna, "A Bitter Pill: Second Wave Feminist Critiques of Oral Contraception," in Canada: Confederation to the Present, eds. Bob Hesketh and Chris Hackett (Edmonton: Chinook Multimedia Inc., 2001), http://chinookmultimedia.com/poccd/registered/web_papers/case_studies5.php.; Hera Cook, The Long Sexual Revolution: English Women, Sex and Contraception 1800-1975 (Oxford: Oxford University Press, 2004), 274-275, 279, 288 and 290. As Cook details, single British women could also encounter difficulty in getting the pill. Here, the Family Planning Association (FPA), which "played a pivotal role in the introduction of the pill to Britain," ran clinics and only provided the pill to married women. To serve single clients, Helen Brook opened a clinic in 1964. Only four years after that, did it then become possible for unmarried women to access contraception through the FPA clinics.

${ }^{9}$ Sethna, 2001; Sethna, 2005, 281. Sethna adds in her 2005 article that, given the resistance of university health services to meet all contraceptives needs, single members of the female student body "began flooding family planning clinics that had originally been established to dispense contraceptives to poor, married women."

${ }^{10}$ Owram, 267.

"Sethna, 2001.
} 
they were likely to have more access to the pill than their single peers. ${ }^{12}$ Some were even quite emphatic in asserting that single women could not acquire prescriptions. Among those who were more certain, Hall said that, in the 1960s, "you had to go to a doctor and get a prescription and at one point I think there was a law that said you had to be married to get it."13 While no such law existed, other women confirmed that doctors would choose not to prescribe the pill to single women. Most strikingly, Beck worked as a medical secretary in the early 1960 s for the obstetrics and gynecology department at the Victoria General Hospital in Halifax. It was definitely her impression that, during those years, a single woman would have been denied the pill. ${ }^{14}$ Watson, who started the pill in about 1962 as a married mother of three, concurred that "you heard of young girls who couldn't get the pill without asking their parents' permission through the doctor."15 Lending credence to the idea that the sexual revolution unfolded gradually and unevenly in the $1960 \mathrm{~s}$, two women who were married when they started the pill simply said that single women either were not often sexually active in the 1960 s or, if they were, they would have found it hard to admit to being so in order to get the pill. ${ }^{16}$

Many women who started the pill in the 1960 s when engaged also understood that the new contraceptive was intended for betrothed and married women or those with

\footnotetext{
${ }^{12}$ Interview with Elizabeth Thompson, June 11, 2009, 25-26; Interview with Julia Hall, June 29, 2009, 15 16; Interview with Jane Lynch, October 6, 2009, 36; Interview with Mary Ramsey, October 29, 2009, 14; Interview with Jean Watson, November 3, 2009, 20-21; Interview with Charlotte Dawson, November 5, 2009, 21; Interview with Annie Beck, November 6, 2009, 24; Interview with Betty Shevchenko, November 9 and 10, 2009, 22-23; Interview with Claire Moore, November 17, 2009, 31; Interview with Eleanor Doyle, November 30, 2009, 13; Interview with Evelyn Scott, December 12, 2009, 14; Interview with Caroline Morrison, March 9, 2010, 26; Interview with Judy Meyer, October 8, 2009, 11 and 19. Meyer was an exception. She went on the pill in the early 1960 s and did not have the impression it was intended for married women. In her answer, she alluded to the "sexual revolution" of the 1960 s.

${ }^{13}$ Hall, 15.

${ }^{14}$ Beck, 3, 10 and 24.

${ }^{15}$ Watson, 5-8, 20-21.

${ }^{16}$ Interview with Deborah Campbell, February 9, 2010, 22; Scott, 14.
} 
menstrual difficulties. Again, some recalled this impression more vividly than others. ${ }^{17}$ Reid, for instance, started the pill two months before her wedding in 1967 and stated that while 'I'm not sure about [the pill] being just for married women...I don't know that too many of the people I knew could have gone and asked a doctor to be on the birth-control pill without a ring on their finger." Reid added that she herself would not have tried to get the pill before 1967 as she would have been embarrassed to approach her gynecologist since he knew she was unmarried. ${ }^{18}$ Brown, who started the pill in 1966 , was more certain about access and said "they wouldn't give it to you, they wouldn't prescribe it...if you weren't getting married and soon. Like, I think the doctor even wanted to know when I was getting married or perhaps I just thought he would...But I do remember that was a factor in getting the pill, that you would be married." ${ }^{\text {"19 }}$ Harrison remembered even more clearly that marital status mattered when acquiring the pill. Harrison had actually heard about the pill when she was sexually active but, "nobody was able to get it if they weren't married. The doctors wouldn't prescribe it." Without adequate birth control, Harrison got pregnant and had a son in 1966. She chose not to marry the father, who had been unfaithful to her, and instead got engaged in 1967 to another man. Then, "before I got married I went to a doctor that had the reputation of being more liberal about birth control and...he said that he had seen my engagement in the paper so yes, he would give me the pill."20

\footnotetext{
${ }^{17}$ Interview with Emily Wood, July 6, 2009, 16; Interview with Olivia Taylor, August 6, 2009, 13; Interview with Rose Murray, October 28, 2009, 24; Interview with Elizabeth Kennedy, November 10, 2009, 21; Interview with Katherine Quinn, August 14, 2009, 15; Interview with Anne Ryan, October 27, 2009, 9; Interview with Mary Jones, December 3, 2009, 16-17; Interview with Diane Galli, December 8, 2009, 20; Interview with Cindy Harrison, January 25, 2010, 22.

${ }^{18}$ Interview with Beth Reid, November 18, 2009, 6, 7, 28-29.

${ }^{19}$ Interview with Susan Brown, August 7, 2009, 3-4, 17.

${ }^{20}$ Harrison, 3-6. Despite his comments, Harrison added some unmarried friends got the pill from him.
} 
Further confirming perhaps the widespread impression that the pill was designated for married or affianced women in the 1960 s, many recall that they presented themselves to the prescribing doctor as engaged. ${ }^{21}$ Edwards recalled "going to the doctor and specifically waiting until...like a month before I was married."22 Carter got the pill through the Toronto Public Health Department in about 1967 and remembered that, when she approached the public health nurse about it, "I said I was engaged to be married, I thought that would be...a good selling point and...she practically did hand-springs and said, yes, yes, you can have the pill." ${ }^{, 23}$ For Galli, who got the pill from her Catholic $\mathrm{Ob} / \mathrm{Gyn}$ in 1968, it was "probably important for both of us [that I present myself as engaged]. I didn't want him to think I was a loose woman or something like that."24 Finally, Clarke agreed that at least some groups in Canadian society would have limited the pill to married women. When she went on the pill in 1967 she was engaged and got it from her doctor. She commented that "because there was a date for the wedding, it was quite acceptable to have this conversation." 25 Therefore, women who started the pill in the 1960 s while planning their weddings were aware that their status as soon-to-be brides might have been significant in getting it.

Sometimes the respectability conferred by this position seemed to be of more concern to the woman seeking the pill than to her doctor. Intriguingly, Evans reflected that her doctor probably would have given her the pill earlier but that waiting until she

\footnotetext{
${ }^{21}$ Interview with Olivia Klein, October 20, 2009, 3, 7 and 33; Kennedy, 5, 21-22; Interview with Hazel Evans, December 1, 2009, 2, 3 and 14; Interview with Cynthia Young, February 8, 2010, 3, 4 and 21; Interview with Claire Macdonald, March 11, 2010, 3, 7 and 29; Interview with Emma Edwards, April 12, 2010, 4 and 38; Interview with Ellen Carter, February 12, 2010,3, 5 and 10; Interview with Susan Walsh, November 24, 2009, 12.

${ }^{22}$ Edwards, 38.

${ }^{23}$ Carter, 5, 10 and 33.

${ }^{24}$ Galli, 5 and 20.

${ }^{25}$ Interview with Cheryl Clarke, November 12, 2009, 4, 9, 25 and 8.
} 
could go with a ring on her finger mattered to her. ${ }^{26}$ Mason, married in 1966, and Jones, married in 1967 , also maintained that they did not think their doctors cared about their marital statuses. However, both thought that they made them aware of their wedding plans. ${ }^{27}$ It is interesting that even when women did not think their physicians cared whether they were married or not, they made a point of mentioning it. This compulsion could speak to the lingering stigma around premarital sex even at the end of the decade of "sexual revolution." In discussing wedding plans or flashing an engagement ring, these women may have been wishing to express their conformity to traditional sexual morality which emphasized premarital virginity for women.

By playing the part of the responsible but sexually contained bride, these Canadian women were recognizing that physicians often acted as the gatekeepers to pill access. $^{28}$ However, an engagement or wedding ring did not always automatically produce a prescription. Macdonald, who was married in 1963 , remembered that she and her friends knew not all doctors were comfortable prescribing the pill, regardless of marital status. Amongst themselves, they passed on the names of cooperative physicians. ${ }^{29}$ Some doctors, as will be discussed more in the next section, had genuine concerns, unrelated to marital status, about the safety of the pill. Other factors could also influence a doctor's reaction to a request for the pill. Brooks, as an engaged woman, approached her family doctor for the pill in 1969. Perhaps due to his Catholicism, he

\footnotetext{
${ }^{26}$ Evans, 14.

${ }^{27}$ Interview with Caroline Mason, July 29, 2009, 2, 5 and 15; Jones, 3 and 17.

${ }^{28}$ Wendy Mitchinson, The Nature of Their Bodies: Women and Their Doctors in Victorian Canada (Toronto: University of Toronto Press, 1991), 151. It would seem doctors had historically adopted this role with contraception in general. Discussing the Victorian period, Mitchinson says "By controlling access to information, access to birth control of any type, doctors increased their power and influence."

${ }^{29}$ Macdonald, 5.
} 
refused to prescribe it until three months before the wedding. ${ }^{30}$ Therefore, as late as 1969, Canadian women, even those planning a wedding, did not enjoy unrestricted access to the new contraceptive.

Conversely, it is also important to note that, even in the 1960 s, not all single women were denied the pill. Wilkins, though under the impression that the pill, like the diaphragm, was restricted to married or engaged women, had no problem continuing on the pill after her marriage broke down in 1964. Perhaps this was because she had been married and was the mother of three children by this point. ${ }^{31}$ However, never-married women did have ways to get the pill as well. For instance, in the mid-1960s, Dawson, a social worker, volunteered in a family planning clinic in Ottawa. ${ }^{32}$ This clinic, like others, seemed to practice a "don't-ask-don't-tell" policy regarding marital status. ${ }^{33}$ Here, single women could get the pill. ${ }^{34}$

Historians have argued, as discussed above, that women had increasing access to the pill as the 1960 s wore on. Certainly, some women who lived through the period felt there was a shift in both attitudes and actions. Wright asserted that "by the mid-1960s, any woman or girl who told her doctor she was sexually active would have felt the pill was intended for her."35 Stevens concurred that possibly when the pill first came out it was intended for married women but the situation changed during the $1960 \mathrm{~s}^{36} \mathrm{My}$ interviews also reflect that doctors in different settings were prescribing the pill to single women by the end of the 1960 s. Stefánsson went on the pill in 1969 . Though she was

\footnotetext{
${ }^{30}$ Interview with Beverley Brooks, October 19, 2009, 3-4 and 6.

${ }^{31}$ Interview with Yvonne Wilkins, September 30, 2009, 7, 9, 14, 22 and 31.

${ }^{32}$ Dawson, 14-15.

${ }^{33}$ Sethna, 2001.

${ }^{34}$ Dawson, 21.

${ }^{35}$ Email correspondence from Ruth Wright, July, 2009, 3.

${ }^{36}$ Interview with Lydia Stevens, November 20, 2009, 22.
} 
engaged, she got the name of the doctor who prescribed the pill from a single friend. ${ }^{37}$

Walsh also started the pill in 1969 as an engaged woman. While she was under the impression at this time the pill was still intended for married women, like Stefánsson, she had single friends who were on it. ${ }^{38}$ Finally, Lowe, though in a relationship with the man she would marry, was not yet engaged nor did she pretend to be when she started the pill in 1967 . She deliberately went to the university health clinic at the University of Toronto, where she was a law student, because "I seemed to feel I'd be able to get a prescription at the university health clinic which I'd never gone to before. It was the only time I ever went." Lowe thought it would be easier to get the pill through a university clinic and, though she did sense some disapproval from the doctor, ultimately she walked out with a prescription. ${ }^{39}$

Single women, as other historians have demonstrated, did not enjoy the same access to the pill when it first came out in the early 1960 s. Doctors were much more at ease with acknowledging that married or engaged women were either already having sex or would be soon and, consequently, would require birth control. Married or engaged women who took the pill in the 1960 s were often aware that their status facilitated getting

\footnotetext{
${ }^{37}$ Interview with Cora Stefánsson, November 23, 2009, 3-4, 15.

${ }^{38}$ Walsh, 5-6 and 12.

${ }^{39}$ Interview with Isabelle Lowe, April 27, 2010, 4-5, 8-9. For more on the battle over the pill on Canadian university campuses see Sethna, 2005: 265-292; Christabelle Sethna, "The Evolution of the Birth Control Handbook: From Student Peer-Education Manual to Feminist Self-empowerment Text, 1968-1975," Canadian Bulletin of Medical History 23, 1 (2006): 89-1 18; Christabelle Sethna, "Chastity Outmoded!' The Ubyssey, Sex, and the Single Girl, 1960-1970," in Creating Postwar Canada: Community, Diversity, and Dissent, 1945-1975, eds. Magda Fahrni and Robert Rutherdale (Vancouver: UBC Press, 2008). According to Sethna's 2005 article, the University of Toronto's Health Service policy in 1965 stated that "while it was recognized that contraceptive prescription will always remain a matter of individual medical judgement and decision, in general, at the University, such prescription should be limited at present to married students and to those students in their period of premarital counselling." Though ultimately deferring to medical discretion and, therefore, potentially allowing some single women, like Lowe, to access the pill, it was not until 1968 that "Health Service physicians [were authorized] to prescribe the pill on the spot to single students in the hope of preventing unplanned pregnancies and subsequent illegal abortions."
} 
the pill. Many even made a point of waiting to see a doctor until they had a ring on their finger and wedding plans in the works. While doing so may have relaxed both doctors and women in many cases, it is important to note that there were always exceptions. Some married or engaged women could still be denied the pill while single women, especially as the 1960 s wore on, found ways to get prescriptions.

\section{What's Age Got to Do With It?}

As mentioned above, some doctors were leery of prescribing the pill to young women. Sethna explains that "The treatment of minors who fell below provincial age limits for consent to medical care was another legal grey area. It was speculated that without parental notification, the gynaecological examination often required for a pill prescription and the pill prescription itself could lead technically to charges of battery or to contributing to the delinquency of a minor. ${ }^{, 40}$ However, and perhaps because the women in my sample were married or engaged, age did not seem to be an issue when accessing the pill. Only one woman, Walker, mentioned age as a factor at all and her testimony sheds interesting light on the interplay between age and marital status. In 1966, Walker was twenty and living in Montreal. Wanting the pill, she went to a doctor and said "we're...getting married but we want to save up for a while and so...with that understanding, he would let me have a birth-control prescription." Walker was sure that the doctor would not otherwise have given her a prescription, at least not without her mother's signature, since she was under twenty-one. At this point, Walker felt that her age mattered more than her marital status. In other words, in her mind, the doctor would have given her the pill once she was twenty-one, regardless of whether or not she was

\footnotetext{
${ }^{40}$ Sethna, 2005, 270-271.
} 
married. ${ }^{41}$ However, other women might not agree with this assessment. Of the fiftythree I interviewed, twelve were twenty-one-years old or younger when they first started the pill. Only Walker mentioned age as a possible barrier to pill use. However, as discussed above, several in the total sample asserted that the pill was not available to single women in the 1960 s.

\section{The Letter of the Law}

As mentioned in Chapter 1, birth control was restricted under Canadian law from 1892 to 1969 . One might assume that this legislation would have been the biggest barrier to accessing the pill or other contraception. Indeed, it may have played a role in the reluctance of some doctors to prescribe the pill for single women. ${ }^{42}$ However, doctors, as discussed above, had far fewer qualms about dispensing the new contraceptive to married or engaged women. This double standard was readily apparent to those fighting for access in the 1960s. In one attempt to highlight it, University of British Columbia student Ann Ratel provoked a firestorm of controversy when she went undercover as a married woman and got a prescription for the pill. ${ }^{43}$

Beyond the university, "Family planning was so widespread in the 1960 s that few Canadians realized that the sale and distribution of contraceptives were still theoretically illegal. ${ }^{, 44}$ Indeed, women interviewed for this thesis rarely expressed any awareness of the illegal nature of birth control. Dawson, who volunteered in a birth-control clinic, was an exception. She said "Contraception...was illegal...I don't know how you got away

\footnotetext{
${ }^{41}$ Interview with Joan Walker, October 15, 2009, 12, 4-5 and 24.

${ }^{42}$ Sethna, 2001; Sethna, 2005, 270-271.

${ }^{43}$ Sethna, 2005, 275; Sethna, 2008, 300.

${ }^{44}$ Angus McLaren and Arlene Tigar McLaren, The Bedroom and the State: The Changing Practices and Politics of Contraception and Abortion in Canada, 1880-1980 (Toronto: McClelland and Stewart, 1986), 132.
} 
with it...I had had it all those years because I had a sufficiently privileged...position that I could have it and I had a doctor who agreed with it." ${ }^{45}$ Though Dawson provides a potentially interesting explanation, alluding to class factors, I wonder if perhaps doctors did not fear the law when giving contraception to married women because, by the 1960 s, this was widely accepted as serving "the public good," which was apparently the only defence for those charged under the 1892 law. A 1961 article in Chatelaine magazine confirmed that "Although the law does not specifically exclude doctors from liability if they fit or dispense prescriptions for contraceptives, most experts believe a doctor could not be successfully prosecuted. Everything a doctor does professionally is presumably in the public good and therefore he is considered immune. ${ }^{, 46}$ Despite this blanket immunity, doctors possibly reasoned that supplying birth control for the now respectable goal of family planning was far less dangerous. It was much easier to argue that contraception in the hands of single people would increase promiscuity, a result many would decry as contrary to the public good.

\section{$\underline{\text { Regional Barriers }}$}

Into the mid-1970s, feminist organizations in Canada argued that inhabitants of rural areas were among those who had the most trouble accessing birth-control services. ${ }^{47}$ Since then, some historians have suggested that women had earlier and better access to the pill if they lived in large urban centres. ${ }^{48}$ Several women in my sample also wondered if women, particularly unmarried women, in small towns might have had more

\footnotetext{
${ }^{45}$ Dawson, 15-17.

${ }^{46}$ Ron Kenyon, "The Pill Nobody Talks About," Chatelaine 34, 11 (November 1961), 64.

${ }^{47}$ Sethna, 2001.

${ }^{48}$ Owram, 267; Marks, 201.
} 
difficulty getting the pill. ${ }^{49}$ While I can only be speculative on this question, it is worth noting that two women, who were engaged at the time and got the pill from doctors in small communities (one in southern Ontario and one in New Brunswick), had no marked difficulty in doing so. ${ }^{50}$ On the other hand, as discussed above, Brooks was denied the pill by a doctor in Windsor. ${ }^{51}$ Therefore, it seems precipitous to make generalizations about access based on the size or location of the community.

Too High A Price

A woman's class and income also influenced her access to the pill and other birth control. ${ }^{52}$ Birth-control advocates, while hesitant about single women from the middle and upper classes using the pill, had no such qualms about their poor unmarried counterparts. Indeed, during the 1960s, American "federal agencies devoted significant funds and personnel to the development of contraceptive services in low-income areas." Similar attitudes at least seemed to exist in Canada. By 1967, and "Influenced in part by the consternation American population growth experts continued to express over the illegitimate birth rate of poor women of colour, many Canadians appeared willing to provide free oral contraceptives to all women of child-bearing age on welfare." $\$ 4$

In 1968, the federal government implemented the Medical Care Act which facilitated the creation of publicly-funded health insurance. Under this act, the cost of

\footnotetext{
${ }^{49}$ Quinn, 17; Edwards, 39-40.

${ }^{50}$ Murray, 9-10; Harrison, 4-6.

${ }^{51}$ Brooks, 3. Doctor's location confirmed in follow-up telephone call April 27, 2012.

${ }^{52}$ Marks, 200-201. Marks adds that better educated women were more likely to be on the pill in both Britain and the United States in the mid-1960s.

${ }^{53}$ Elizabeth Siegel Watkins, On the Pill: A Social History of Oral Contraceptives 1950-1970 (Baltimore: Johns Hopkins University Press, 1998), 56 and 67-68. See Johanna Schoen, Choice and Coercion: Birth Control, Sterilization, and Abortion in Public Health and Welfare (Chapel Hill: The University of North Carolina Press, 2005) for a nuanced analysis of poor women's access to birth-control services in the twentieth century.

${ }^{54}$ Sethna, 2001.
} 
visiting a doctor was covered. However, prescription medications were not included. ${ }^{55}$ Therefore, throughout the 1960 s and 1970 s, the price of the pill could be a barrier for some women. ${ }^{56}$ In the United States, the annual retail price of the pill dropped from $\$ 100$ in 1960 to $\$ 25$ in 1965 but it still remained prohibitively expensive for working-class women. ${ }^{57}$ Canadian prices appeared to be comparable. At one time, in the early 1960 s, each tablet cost $₫ 55$ which, based on twenty pills per month, could work out to well over $\$ 100$ a year. $^{58}$ However, Chatelaine magazine reported that, by 1965 , the pill's price had decreased to between $\$ 20$ and $\$ 30$ for a year's supply. ${ }^{59}$

Certainly, especially in the early 1960s, price was perceived as a barrier to access. Mary S. Calderone, Medical Director of Planned Parenthood in the United States, identified this problem very soon after the FDA approved Enovid. In a letter to G.D. Searle, Calderone said "there will be many poor patients who will not be able to afford the drug in any way for whom we will have to raise funds to cover the cost." To address this issue, Searle agreed to sell the pill directly to Planned Parenthood. ${ }^{60}$ However, not all women had access to the clinics of Planned Parenthood and even the subsidized pills

\footnotetext{
${ }^{55}$ Eugene Vayda and Raisa B. Deber, "The Canadian Health-Care System: A Developmental Overview," in Canadian Health Care and the State: A Century of Evolution edited by C. Naylor (Montreal: McGillQueen's University Press, 1992), 128; Joel Lexchin, "Pharmacare: Equity, Efficiency, and EffectivenessWe've Waited Long Enough," in Medicare: Facts, Myths, Problems \& Promise, edited by Bruce Campbell and Greg Marchildon (Toronto: James Lorimer and Company Ltd., 2007), 262; Greg Marchildon, "Federal Pharmacare: Prescription for an Ailing Federation," in Medicare: Facts, Myths, Problems \& Promise, 274; Lee Soderstrom, The Canadian Health System (London: Croom Helm Ltd., 1978), 147. Though obviously not helpful to everyone, "Between 1970 and 1986, every province introduced a prescription drug plan. Most were drug subsidy programs aimed at seniors and individuals receiving social assistance." By 1978, Manitoba and Saskatchewan covered the cost of prescription medications universally.

${ }^{56}$ Andrea Tone, Devices and Desires: A History of Contraceptives in America (New York: Hill and Wang, 2001), 257.

${ }^{57}$ Ibid.

${ }^{58}$ Letter by Doris Anderson, editor, Chatelaine, in response to Mrs. Higgins, November 17, 1961, Archives of Ontario, Reference Code F138, Barcode B255348, F-4-3-A, Box 215, file February 1962 (2 of 2).

${ }^{59}$ Constance Mungall, "Birth Control in Canada Today," Chatelaine 38, 4 (April 1965), 48.

${ }^{60}$ Watkins, 40.
} 
were expensive for some. ${ }^{61}$ A Saskatoon doctor, reporting the various applications of Enovid in 1961, confirmed that, despite its success in treating gynecological problems, price was a disadvantage. ${ }^{62}$ Reflecting on this reality, in an unpublished letter to Chatelaine, Mrs. Hazel McBride, of Prince Rupert, British Columbia, wrote "I wish fervently; that everyone desiring birth-control pills, could be given them, at such low cost, that everyone could afford them." ${ }^{63}$ Other Canadian women agreed, particularly in the early 1960 s, that the price of the pill was prohibitive. Mrs. Margaret Higgins, from Willowdale, Ontario wrote rather indignantly to the editor of Chatelaine in response to a 1961 article on the pill. She said

Writer Ron Kenyon has made a rather glaring omission in stating the pros and cons of the use of Enovid as a contraceptive. ('The Pill Nobody Talks About'.) Nowhere did he mention the prohibitive price of these pills. They retail at fifty-five cents each, and since they must be taken daily for twenty days out of each month, one a day, the cost alone puts them beyond the reach of the majority of Canadian women. They say the answer to the world population explosion will be a device that is easy to use, and cheap. The Pill is simple enough to administer, but so far the cost makes it less than practical.

Editor Doris Anderson replied that, though the pill did at one point cost that much, it had since decreased to about $\$ 4$ a month. ${ }^{64}$ Readers of Chatelaine continued to be preoccupied by this issue, however, and it would seem that price could vary, as Mrs.

\footnotetext{
${ }^{61}$ Tone, 257.

${ }^{62}$ Lawrence Galton, "Here's Health: A versatile drug for menstrual disorders," Chatelaine 34, 8 (August $1961), 26$.

${ }^{63}$ Letter by Mrs. Hazel McBride, Prince Rupert, B.C., to Chatelaine, January 22, 1962, Archives of Ontario, Reference Code F138, Barcode B255348, F-4-3-A, Box 215, file January 1962 (1 of 2).

${ }^{64}$ Letter by Mrs. E.M. Higgins, Willowdale, Ontario, to Chatelaine, November 1, 1961, Archives of Ontario, Reference Code F138, Barcode B255348, F-4-3-A, Box 215, file February 1962 (2 of 2); Letter by Anderson to Higgins; "Why the pill isn't the answer," The Last Word is Yours, Chatelaine 35, 2 (February 1962), 92. In her personal response to Mrs. Higgins, editor Doris Anderson did concede that once the pill had been that expensive. However, she said the price was due to decrease. A short excerpt of this letter was printed in the February 1962 issue of Chatelaine. Here, the editors clarified that the monthly price was $\$ 4$.
} 
Anderson also pointed out in her personal response to Mrs. Higgins. ${ }^{65}$ In two 1962 letters to the magazine, married women wrote to ask for clarification on this matter and reported prices ranging from $\$ 4$ to $\$ 14$ per month. ${ }^{66}$

Price could serve as a deterrent to pill use, even when reliable contraception was desperately needed. Arsenault, recalling that the pill cost about $\$ 8$ a month, remembered that an acquaintance, pregnant with her seventh child in 1966 , claimed that she did not take the pill because she could not afford it. ${ }^{67}$ Smith, married in 1959 , had the same impression. While relying on a diaphragm, she had children in 1960, 1961 and 1962. With her husband in law school, Smith really needed to be able to work as a teacher but she was fired when she informed the school inspector of her first pregnancy. After the baby was born in April; Smith was able to get a job as a service representative at Bell. However, she quickly became pregnant again, stretching their finances further. Their situation was somewhat improved when her husband finished law school and was able to earn a modest living during his articling. The couple decided to move to British Columbia, even though he would have to repeat his year of articling, because Ontario required a full year bar admission course which did not include a salary. After moving to Victoria and having her third child in 1962, Smith went on the pill. Given her history, one might assume that Smith would be eager to take the pill as soon as it was available. However, intriguingly, she claimed that she knew about the pill in Toronto as early as 1958 but "it was $\$ 15$ a month and we thought that was too expensive. And we laugh

\footnotetext{
${ }^{65}$ Letter by Anderson to Higgins.

${ }^{66}$ Letter by Mrs. Grant Murray, Harriston, Ontario, to Chatelaine, March 2, 1962, Archives of Ontario, Reference Code F138, Barcode B255348, F-4-3-A, Box 215, file February 1962 (1 of 2); Letter by Mrs. D. Robinson, Scarborough, Ontario, to Chatelaine, January 27, 1962, Archives of Ontario, Reference Code F138, Barcode B255334, F-4-4-b, Box 220, interior Box 445, file RA-RZ.

${ }^{67}$ Interview with Jane Arsenault, March 2, $2010,19$.
} 
now, we think why did we think $\$ 15$ a month was more expensive than having children?"68

Harrison and her husband, a welder, also struggled to make ends meet. ${ }^{69}$ She started the pill in 1967 and concurred that it was expensive but "when you considered what it cost to have a child and raise it, it was worth doing without something else to...buy it." However, when Harrison and her husband separated in 1970, Harrison, who was not working outside the home at the time, went off the pill, partly because she could not afford it. ${ }^{70}$ Thus, for women like Harrison and Smith who raised their families on sometimes very limited means, the pill's price was perceived to be problematic.

However, other pill users, including those who struggled financially, said the method was not prohibitively expensive. In fact, Wilson, who went on the pill in 1966, and Carter, who went on it in about 1967 , both thought that they may have gotten it for free from their doctors initially. ${ }^{71}$ Dawson, who volunteered as a social worker in a birthcontrol clinic in the 1960s, acknowledged that the pill may have been free through the clinic. $^{72}$ Even without such arrangements, women with a limited income said the pill was not costly. Though a law student, like Smith's husband, Lowe did not think the pill was overly expensive when she started it in $1967 .^{73}$ Additionally, Morrison went on the pill in 1965. She had just had her second child and, after a brief return to the workforce,

\footnotetext{
${ }^{68}$ Interview with Catherine Smith, July 9, 2009, 1-4, 8-11, 19. Perhaps Smith heard about the pill when it was still, at least technically, only approved to regulate periods. See Chapter 1 , note 74 .

${ }^{69}$ Harrison, 1,4, 12-13. After her marriage in 1967, Harrison worked as an instructor in hairdresser and also sometimes in her father's grocery store.

${ }^{70}$ Ibid., 4-5, 12-14, 22-24.

${ }^{71}$ Interview with Margaret Wilson, August 12, 2009, 1 and 11; Carter, 3 and 20; Watkins, 101. A doctor's willingness to provide free samples of the pill may have been connected to their perceptions of the women's socio-economic status. Watkins explained in her book on the American context that some doctors were more likely to propose the pill for poor women because they perceived them to be less responsible in using barrier methods.

72 Dawson, 14-15, 24.

${ }^{73}$ Lowe, 4 and 16.
} 
stayed at home until 1970. During these years, her husband worked three different jobs to support his family. Even so, Morrison never remembered the price of the pill as an issue, possibly because they had medical plans through work which covered it. ${ }^{74}$

As one might expect, married women who tried the pill and were even more financially comfortable did not remember cost as a problem. Arsenault, while knowing some women found the pill beyond their resources, never thought it was too expensive for her. ${ }^{75}$ Similarly, Macdonald never remembered the price of the pill as an issue. Once her first child was born in 1967 , she stayed at home to raise her family. They had no problems relying on the income of her husband, a public servant, to meet their needs, including birth control. However, she did add that "I think we regarded it as...enough of an essential that we would have paid the price, whatever it was.",76

While many women focused on the price of the pill itself, it is worth noting that, even if this cost decreased, women still had to pay for the visit, ideally occurring more regularly if they were on the pill, to the doctor. ${ }^{77}$ In the mid-1960s, a Chatelaine article acknowledged the need to include doctor's fees when considering the pill and said that it cost "with an annual doctor's check and cancer test, about forty dollars a year."78 Therefore, while the McGill Daily reassured university students in 1968 that the pill itself was "a good deal cheaper than a pair of [false] mink eyelashes," those "with no or little medical insurance would certainly be unable to pay the high fees physicians could demand." ${ }^{, 79}$ Ultimately, then, as was acknowledged in the $1960 \mathrm{~s}$, the cost of the pill

\footnotetext{
${ }^{74}$ Morrison, 10-11, 22

${ }^{75}$ Arsenault, 19, 3, 16 and 29. Arsenault's husband made a good living with the Bank of Canada.

${ }^{76}$ Macdonald, 12, 22 and 27.

${ }^{77}$ Tone, 257.

${ }^{78}$ Mungall, 48.

${ }^{79}$ Sethna, 2006, 92-93.
} 
could act as a barrier for Canadian women. Nevertheless, many pill users, both workingand middle-class, did not remember it as prohibitive possibly because, like Macdonald, they simply considered it to be necessary and were willing to budget accordingly. While this was an option, it is also possible that other women may have been deterred by the price and, therefore, chose never to take the pill.

\section{Asking for the Pill}

According to historian Kate Fisher, British women, up until at least the midtwentieth century, adopted a passive sexual persona, characterized by ignorance and dissociation from birth-control matters. In fact, Fisher argues that men controlled birthcontrol decisions. However, for reasons requiring further exploration, by the time the pill appeared, women had become more comfortable assuming a role in contraception. ${ }^{80}$ Before the advent of the pill, women were also more passive in their interactions with the medical profession. They tended to defer to their doctors in matters of diagnosis and treatment. They were particularly reticent in asking about birth control. ${ }^{81}$ Some doctors, for their part, still did not consider contraception to be an area worthy of medical interest. ${ }^{82}$ The pill dramatically redefined the doctor-patient relationship. First, it medicalized birth control, bringing doctors firmly into the family planning arena and making them proponents of birth control. ${ }^{83}$ At least until the mid-1960s, many doctors especially valued that the pill was easy to prescribe and, because it required a

\footnotetext{
${ }^{80}$ Kate Fisher, Birth Control, Sex, and Marriage in Britain, 1918-1960 (Oxford: Oxford University Press, 2006), 194, 200-201, 210, 238-241. For more on this, see Chapter 2.

${ }^{81}$ Watkins, 50-51.

${ }^{82}$ McLaren and McLaren, 133.

${ }^{83}$ Tone, 203 and 241; Cook, 280; Marks, 8 and 118; Angus McLaren, $A$ History of Contraception: From Antiquity to the Present Day (Oxford: B. Blackwell, 1990), 240. In the early twentieth century, many doctors viewed birth control with suspicion and considered it "quakery." This attitude would persist in some quarters even into the 1960 s.
} 
prescription, enhanced medical authority ${ }^{84}$ More importantly, the pill emboldened women and those "who came to their physicians with specific requests for oral contraceptives no longer passively received medical care, but were transformed into active participants. ${ }^{.85}$ Into the early 1960 s, patients did not usually request specific drugs from their doctors. ${ }^{86}$ While physicians have been accused of pressuring women to go on the pill, many were actually taken aback by women's enthusiasm for the new drug and their demands for prescriptions. ${ }^{87}$ The 1970 report of the special committee to the Food and Drug Directorate (FDD) recognized the pill's profound impact on the doctor-patient dynamic. It said "Hitherto, it has been implicit that the patient accepts the judgement, expertize and experience of her doctor." However, with the advent of the pill, women had to throw off this more passive role and make informed decisions about birth control. $^{88}$

Women in my sample, both engaged and married, did visit doctors specifically to get the birth-control pill. ${ }^{89}$ In doing so, they assumed an active role in shaping their reproductive and sexual lives. They also arrived at the doctor's with a particular medical solution already in mind for their family planning dilemma. For instance, Galli remembered that she went to an obstetrician/gynecologist in 1968 and let "him know that

\footnotetext{
${ }^{84}$ Watkins, 35.

${ }^{85} \mathrm{Ibid} ., 51$.

${ }^{86}$ Marks, 7.

${ }^{87}$ Linda Gordon, The Moral Property of Women: A History of Birth Control Politics in America (Chicago: University of Illinois Press, 2007), 288; Tone, 240; Cook, 278-281; Diane Gervais and Danielle Gauvreau, "Women, Priests, and Physicians: Family Limitation in Quebec," Journal of Interdisciplinary History (Autumn 2003), 311; Marks, 116-117; Elaine Tyler May, American and the Pill: A History of Promise, Peril, and Liberation (New York: Basic Books, 2010), 1-2.

${ }^{88}$ Report of The Special Committee appointed by The Minister of National Health and Welfare to Advise The Food and Drug Directorate on all Aspects of the Safety and Efficacy of Oral Contraceptives Marketed in Canada, October 1970, Rx Bulletin, Special Issue, December, 1970, 40. This report is discussed in detail on pages 110-111 and in Appendix 2.

${ }^{89}$ Wood, 3; Mason, 5 and 15; Taylor, 5; Brown, 6; Quinn, 6; Wilkins, 15; Clarke, 8-9; Reid, 11; Walsh, 3 4; Jones, 4; Stevens, 7; Edwards, 7-8. Edwards added she also went for a general check-up.
} 
I was going to be married and that...we did not want to have any children for several years until we finished our educations and would he please give me a prescription." 90 While some simply went to their regular family physician or gynecologist for the pill, others exerted particular effort to find a cooperative doctor. For example, Macdonald, preparing for her wedding in 1963, got the name of a doctor from a friend and went to him because she understood he would prescribe the pill. ${ }^{91}$ Likewise, Lowe, who was not yet engaged, believed that a doctor at the University of Toronto's health clinic was more likely to give a single woman the pill in $1967 .{ }^{92}$ Finally, though Moore, a Catholic mother of four, asked her Catholic obstetrician about the pill, she increased the odds of his cooperation by agreeing to the premise that, in her case, the pill was being prescribed to regulate her periods. ${ }^{93}$

While most doctors were happy to comply with requests for the pill, others did express some reservations and ambivalence. In touching upon this exchange, it is important to remember that doctors were also individuals with their own complex, and sometimes unspoken, set of moral and medical agendas. Some doctors were genuinely concerned about the pill's side effects and wondered about long-term use. ${ }^{94}$ Indeed, when the pill first came out, G.D. Searle advised women not to take it for more than two years without a break. ${ }^{95}$ Though the time frame may have changed, certain doctors apparently adhered to the idea of a limit. For instance, when Kennedy got married in 1967 she got the pill from a gynecologist. He said she could stay on the pill for four

\footnotetext{
${ }^{90}$ Galli, 5.

${ }^{91}$ Macdonald, 3, 7-8.

${ }^{92}$ Lowe, 4-5, 8-9.

${ }^{93}$ Moore, 17-19.

${ }^{94}$ Gervais and Gauvreau, 311; Watkins, 39; Kenyon, 64; Mungall, 48.

${ }^{95}$ Kenyon, 64.
} 
years but then "I will be quite fierce with you if you expect to continue taking them for more than four years because we don't know enough about what's going to happen." 96

Additionally, Gervais and Gauvreau found in their interviews with Catholic, francophone doctors that "physicians reluctant to...[prescribe the pill] on moral grounds could use its medical contraindications to avoid the moral issue entirely." Thus, one doctor who started his medical career in 1954, explained that "Women might come into our office without any explanation whatsoever and say 'I want the pill!'...I didn't say, 'What about your husband, what about the religious issues, etc.' I said, 'What about the high blood pressure, cardiac insufficiency, varicose veins, etc.?"97 Similarly, when Smith asked for the pill in 1962 from her GP, he also demurred initially, emphasizing medical concerns. He said "oh, Mrs....[Smith] I can't really fully...recommend that because they haven't been fully tested." ${ }^{.98}$ In stressing medical complications, doctors may have been trying to reassert their authority over female patients who were uncharacteristically active in their approach to the pill. ${ }^{99}$

If this was the case, Smith was not daunted or deterred. By then, she had had three children while using a diaphragm, and responded to her doctor that "I'll be dead at this rate anyway so I think I'll have the pill, thanks." ${ }^{100}$ Possibly from reading accounts in the press, Smith felt confident that the pill had been adequately tested and she ultimately got it at this time, overruling her doctor's qualms. ${ }^{101}$ Klein's long-time family doctor also had concerns about putting her on the pill in 1964. Knowing there was a

\footnotetext{
${ }^{96}$ Kennedy, 5 and 8.

${ }^{97}$ Gervais and Gauvreau, 311.

${ }^{98}$ Smith, 11; Watkins, 101. Watkins confirms that some doctors advised against the pill and, citing Seaman, that some were genuinely concerned about the safety of it.

${ }^{99}$ Gervais and Gauvreau, 312.

${ }^{100}$ Smith, 2, 10-11.

${ }^{101}$ Ibid., 19 and 11.
} 
family history of depression and alcoholism, he worried that the hormones in the pill would affect her psychologically. However, he appreciated that she needed to be able to work as a teacher at least until her husband finished school. Ultimately, he gave her the pill. $^{102}$ While the doctors approached by Smith and Klein may have had legitimate medical concerns regarding the pill, Brooks' family doctor, a Catholic, may have been pushing another agenda. He refused to prescribe the pill until three months before her 1969 wedding. While not explicitly stated, Brooks was sure it was because he had a strong moral position against premarital sex. ${ }^{103}$

Therefore, my interviews do confirm that large numbers of women were actively seeking out the pill in the 1960 s. Many of them made appointments specifically to get the pill and some demanded it even in the face of medical uncertainty. However, women also describe the survival of a more traditional relationship in which they were guided by the doctor's advice on health matters, including birth control. These women recalled that, rather than demanding the pill, they either asked for a medical opinion or enquired more generally about contraception. ${ }^{104}$ Evans, for instance, started the pill before her wedding in 1966. She made an appointment with a doctor and asked his advice about taking the pill. He replied, "Oh everyone's taking the pill now, and it's been proven, the studies have been done, everything's fine." 105 Campbell also thought she would have asked her doctor, the obstetrician/gynecologist who delivered her children, about the pill in 1964 as "the way I was brought up...you try and find the best doctor for your purposes and you

\footnotetext{
${ }^{102}$ Klein, 7-9.

${ }^{103}$ Brooks, 3, 4 and 6.

${ }^{104}$ Interview with Eva Green, June 23, 2009, 1-3; Morrison, 10 and 13.

${ }^{105}$ Evans, 2, 3 and 5.
} 
ask them for...their advice and then you take it." ${ }^{\prime 106}$ Placing the decision about contraception even more in medical hands, Jackson remembered that, in 1968, she went to a doctor 'and said 'I'm getting married. What do you recommend?'. And that was when they put me on the pill for the first time." ${ }^{107}$ Thus, these women relied more heavily on medical advice than others who came to the doctor's office already knowing they wanted the pill. In this behaviour, they conformed more to the traditional doctorpatient dynamic in which the patient deferred to medical wisdom. ${ }^{108}$

This was even more the case for women who did not initiate conversations with their doctors about the pill. Rather, the doctors themselves broached the subject and the women took their advice. Stewart, for instance, had had two children in 1957 and 1958. Her husband in particular felt their family was complete so when her family doctor suggested she try the pill, she replied "yes, if you think it's wise, I'll go on it." ${ }^{\text {"109 }}$ Wilson was even more relieved when she heard about the pill from her doctor in 1966 , following the birth of her son. Her family doctor "asked...if I was planning on having another baby right away and I said...I'd like to not...and this was all very embarrassing to actually talk to a doctor about...And he said, well, there's this new method that has come out and it's just a pill and...I'd like to try it. And he gave me a sample pack and a prescription." Since Wilson thought she would have to go back to using withdrawal as birth control, she was quite happy with this conversation. ${ }^{110}$ Her embarrassment also suggests that some women were still not comfortable discussing such matters as sex or contraception, even with a doctor. Possibly for this reason, they remained more reserved in interacting with

\footnotetext{
${ }^{106}$ Campbell, 9-12.

${ }^{107}$ Interview with Ellen Jackson, October 23, 2009, 3 and 5.

${ }^{108}$ Watkins, 116.

${ }^{109}$ Interview with Eileen Stewart, August 18, 2009, 7-9 and 23.

${ }^{110}$ Wilson, 1, 7-8.
} 
the medical profession and were more likely to simply accept medical advice about the pill.

Among doctors who retained more of a controlling interest over contraceptive decisions, some could be a little insistent if they thought that the pill, by preventing pregnancy, would safeguard the general health and well-being of their patients. Thompson went on the pill in 1967 after the birth of her second child. Since her two children were only seventeen months apart, her obstetrician/gynecologist, who had followed her during both pregnancies, advocated the pill as a way to ensure her body had a break from procreation for awhile. Thompson appreciated this advice and did go on the pill at this time. ${ }^{111}$ Similarly, Beck's first two children were born in 1963 and 1965, also seventeen months apart, and her obstetrician urged her to go on the pill and avoid another pregnancy for at least two years. ${ }^{112}$

While some women fought their doctors to get on the pill, others resisted when it was suggested to them. For instance, Williams had tried an IUD, even though the pill was available, because she had doubts about the pill's long-term effects. When the IUD fell out in about 1962, however, her obstetrician, while acknowledging that the pill was new and relatively unknown, advised she try it. She ultimately did at this time, despite her reservations. ${ }^{113}$ Doyle also had concerns about the pill. When she first heard about it in about 1959, during her nursing training, she was horrified that women would take drugs in this way. By 1963, she had two children, born fifteen months apart, and was still not completely comfortable with the pill as birth control. Nevertheless, her obstetrician, who had delivered both children, was quite insistent that she go on the pill as he argued it

\footnotetext{
111 Thompson, 15-16 and 28.

${ }^{112}$ Beck, 10-11.

${ }^{113}$ Interview with Lucy Williams, October 8, 2009, 8, 9, 11-12 and 14.
} 
was unhealthy to have too many children too closely spaced. He reassured her about the pill's safety and, after speaking to him, as well as possibly asking friends and reading up on the pill, Doyle overcame her fears and did take it. ${ }^{114}$ Thus, doctors into the $1960 \mathrm{~s}$ sometimes advised women to take the pill in order to protect their health from repeated pregnancies. They did this particularly if the women had had children close in age. In doing so, they were met with a range of reactions, from relief to suspicion. This suggests again that not all women passively accepted medical advice in the 1960s.

In discussing the American context, historian Elizabeth Siegel Watkins argues that the pill radically redefined the doctor-patient relationship. Suddenly, women became actively involved in managing their own reproductive health. ${ }^{115}$ Though, as Mitchinson demonstrates, women were doing this in nineteenth-century Canada, as I mention in Chapter 1, the pill certainly seems to have furthered this trend. Many women did ask doctors specifically for the pill, sometimes going to extra effort to ensure a positive response. However, it is important to note that the metamorphosis of women into active health consumers in the 1960 s was by no means complete. While some did approach their doctors with explicit demands for pill prescriptions, others more deferentially sought medical advice on the pill or birth control in general. Sometimes, doctors still took a leading role in contraceptive decision-making and brought up the topic themselves, even urging women to consider the pill. However, patients were under no obligation to do so and some resisted this advice, again demonstrating assertive behaviour and changes in the doctor-patient dynamic.

The Initial Appointment: Discussing Side Effects

\footnotetext{
${ }_{114}^{11}$ Doyle, 2-3, 4-6.

115 Watkins, 51.
} 
As I will discuss in much more detail in Chapter 4, women taking the birthcontrol pill in the 1960 s did experience side effects. Researchers running the first clinic trials of Enovid in Puerto Rico reported that women suffered from bloating, weight gain, nausea, vomiting, stomach pain, headaches, rashes and dizziness. ${ }^{116}$ Some women could also have debilitating migraines, depression or even life-threatening blood clots.

However, at least initially, not all doctors were equally well-informed about adverse effects. Early reports were likely to appear in specialty medical journals and not all doctors kept up with such publications. In addition, the "physicians who prescribed the oral contraceptives, mostly obstetrician-gynecologists and general practitioners, were not the ones who received and treated patients with symptoms of adverse health effects. Instead, a woman went to an ophthalmologist if she experienced vision problems, a psychiatrist if she felt depressed, or a neurologist if she had a stroke."117 This situation made the connection between the pill and its side effects less obvious. However, even after reports of side effects began to circulate more publicly throughout the $1960 \mathrm{~s}$, the medical community was divided over the benefits and risks of the pill. ${ }^{118}$ As I discussed above, some Canadian doctors were clearly not in favour of prescribing the pill for all their patients. Nevertheless, definitive proof linking the pill to multiple adverse effects remained elusive. Without such evidence, many doctors were hesitant to suspend pill prescriptions. ${ }^{119}$ Finally, in 1967 the British Medical Journal published a report showing a clear increased risk of blood clots among pill users. These findings were then

\footnotetext{
${ }^{116}$ Sethna, 2001; Gordon, 287; Marks, 101 and 195. Problems like nausea, dizziness, headaches and vomiting afflicted "in the first few months 17 per cent of the subjects."

${ }^{117}$ Watkins, 80-81 and 102.

118 lbid., 80 and 75-79, 96.

${ }^{119}$ Ibid., 96 and 101.
} 
corroborated by a 1969 American FDA study as well as Canadian studies which showed clots were possible. ${ }^{120}$

Despite the delay in achieving definitive proof, throughout the 1960s, increasingly vocal critics of the pill, such as American journalist Barbara Seaman, asserted that the pill had not been adequately tested, that it had numerous and problematic side effects and that women were not properly informed about it. Seaman in particular asserted that "the number of test subjects and the duration of the Puerto Rican field trials had been insufficient to presume the long-term safety of the pill. Yet doctors and drug companies continued to keep women in the dark about the pill's adverse side effects." Such charges led to American Senate hearings on pill safety, under Senator Gaylord Nelson, in early 1970. ${ }^{121}$ In response to these events, the Canadian Medical Association declared in February of 1970 that the pill should not be totally pulled from the market but that "each doctor had to weigh carefully the benefits of virtually 100 per cent effective contraception against possible side effects for each patient. For example, the pill was not to be recommended to those with a history of diabetes or thrombosis." 122 The Canadian government, also responding to heightened alarm over side effects, announced the creation of a committee of its own in January of 1970 to make recommendations to the Food and Drug Directorate regarding the safety and effectiveness of the pill. Dr. R.A.H. Kinch, an obstetrician/gynecologist, chaired the all male, all medical, seven-member special committee. Their report, which contained a comprehensive overview of the

\footnotetext{
${ }^{120}$ Watkins, 89-90; Tone, 244; See for example, Editoral, "Oral Contraception and Thromboembolic Disease," Canadian Medical Association Journal 98, 23 (June 8, 1968), 1117-1118.

${ }^{121}$ Sethna, 2001.

${ }^{122}$ Sethna, 2005, 288.
} 
existing data on side effects, was published in October of $1970 .{ }^{123}$ A second report, by a bigger committee now including two female doctors, was released in $1975 .{ }^{124}$ Three years later, the committee, by then renamed the Special Advisory Committee on Reproductive Physiology to The Health Protection Branch, again produced a report on the pill. ${ }^{125}$

The Nelson hearings focused a lot on informed consent and, just as they were concluding, the American Food and Drug Administration announced it would henceforth compel drug companies to include a patient insert with the pill outlining side effects. After heated protest from the industry and doctors, the latter claiming this insert usurped their role in communicating with their patients, the FDA settled on a much shorter patients disclaimer which limited discussion to blood clots and was only seven sentences long. ${ }^{126}$ The Canadian Medical Association also objected to the inclusion of a short patient insert, suggested by the special committee in 1970 . The committee acknowledged that women must be informed about the pill and participate in contraceptive decisionmaking. To these ends, it recommended an insert which would instruct women to "contact your doctor at least once a year...[and] immediately if you develop severe or persistent headache, blurred vision, pain in the calves of the legs, pain in the chest,

\footnotetext{
123 “Canadian Medical News-Health Minister Announces: Seven-doctor Committee Studies Safety of Oral Contraceptives," Canadian Medical Association Journal 102, 3 (February 14, 1970), 236; Report of The Special Committee, 1970; "Hazards of the Oral Contraceptive," Medical News Special Supplement, Canadian Medical Association Journal 102 (May 30, 1970), 1193; "Association News Special Supplement: The Canadian Medical Association comments on the Food and Drug Committee Report 'Hazards of the Oral Contraceptive,"' Canadian Medical Association Journal 103, 13 (December 19, $1970), 1415$.

${ }^{124}$ Report of the Special Committee Appointed by The Minister of National Health and Welfare to Advise the Health Protection Branch on All Aspects of the Safety and Efficacy of Oral Contraceptives Marketed in Canada, Second Report, February 1975, Rx Bulletin Volume 6, Supplement 1 (1975). See Appendix 2 on these reports.

${ }^{125}$ Report of The Special Advisory Committee on Reproductive Physiology to The Health Protection Branch (Ottawa: The Branch, 1978).

${ }^{126}$ Watkins, 117-118, 121-122, 124; Tone, 250.
} 
menstrual irregularities, or other unusual symptoms." ${ }^{, 27}$ This hardly represented a comprehensive overview of all possible side effects or explicitly told women to ensure they received yearly check-ups. Nevertheless, according to the CMA, a document like this would "create additional unnecessary patient concern, self-diagnosis, and may in fact detract from already inadequate patient education." The CMA emphasized the need for conscientious doctors to discuss the pill with his or her patient. Once this had taken place, the doctor could then provide printed material with the above information. ${ }^{128}$ Despite these protestations, a patient insert, which was virtually identical to that proposed by the government committee in 1970 , was in use by at least $1975 .{ }^{129}$ Subsequently, "More detailed warnings followed in 1977 . The new warnings, which spoke specifically to the risk of heart attacks for pill takers over 30 who smoked cigarettes, also recommended that women over age 40 not take the pill.,"130 A patient insert in the 1978 special committee report also included the cautions that the pill could diminish milk supply in a breast-feeing mother, that a woman should postpone conception for at least three months after discontinuing the pill and that, in the event of surgery, a woman should be sure to let her doctor know she was taking the pill. ${ }^{131}$

While the next chapter will analyze women's interactions with side effects, here I would like to discuss whether or not Canadian doctors in the 1960s were telling women

\footnotetext{
${ }^{127}$ Report of The Special Committee, 1970, 38; "Association News Special Supplement: The Canadian Medical Association comments on the Food and Drug Committee Report 'Hazards of the Oral Contraceptive," Canadian Medical Association Journal 103, 13 (December 19, 1970), 1417.

128 "Association News Special Supplement: The Canadian Medical Association comments on the Food and Drug Committee Report 'Hazards of the Oral Contraceptive," Canadian Medical Association Journal 103, 13 (December 19, 1970), 1417-1418.

${ }_{129}$ Report of The Special Committee, 1975, 44-45.

${ }^{130}$ Sethna, 2001.

${ }^{131}$ Report of The Special Advisory Committee on Reproductive Physiology to The Health Protection Branch, 15.
} 
of possible problems when first prescribing the pill. ${ }^{132}$ In considering the amount of information conveyed, it is important to remember that, with the pill, at least initially, "Physicians controlled not only pill prescriptions, but also knowledge about those pills, and many divulged only selected portions of that information 'in the patient's best interest." "133 Additionally, doctors prescribing the pill may not have known about all side effects, particularly in the early 1960s. Even when they were aware, doctors disagreed on the safety of the pill. And finally, some doctors believed that women who were informed of all possible adverse effects would be needlessly frightened or develop psychosomatic symptoms. $^{134}$

With these factors in mind, it is not surprising that some doctors in the $1960 \mathrm{~s}$ did not discuss potential side effects with women when first prescribing the pill (or at all). A Gallup Poll of American women, reported in early 1970, confirmed that $2 / 3$ of pill-users had never been informed by their doctors about possible health problems associated with the pill. ${ }^{135}$ Similarly, some Canadian women do not remember anything at all being

\footnotetext{
${ }^{132}$ Pharmacists do not seem to be remembered as significant figures in the discussion of side effects. This may have been because, beginning in the late nineteenth century, their professional activities began to change, and some would say diminish, significantly. With the establishment of pharmaceutical companies at this time, many pharmacists stopped making their own medications. Consequently, they henceforth defined themselves as a profession by their ability to compound drugs. In post-World War Two Canada, however, "More and more prescriptions were being filled with manufactured pre-fabricated products, primarily tablets and capsules, while pharmacists were being called on to compound fewer prescriptions." With their role shifting once again, pharmacists, in the 1950 s and 1960 s, were suffering something of a professional identity crisis as the public rather dismissively considered them "pourers and counters." See Stephen Dove, "The Reconstruction of Pharmacist Authority in British Columbia: 1965-1968," (Master's Thesis, Department of History, University of Victoria, 2010), 18, 24, 37-38, 40, 42, 44-45, Accessed Online through the Canadian Academy of the History of Pharmacy Website, hitt://www.cahp.ca/documents/Masters\%20Thesis\%20Submission \%20Copy\%20August $\% 2018$.pdf. Throughout the early 1960s, pharmacists started to become more focused on the patient but this process may have been somewhat uneven. See, Glen J. Pearson, "Evolution in the practice of pharmacy-not a revolution!" Canadian Medical Association Journal 176, 9 (April 24, 2007), http://www.cmaj.ca/content/176/9/1295.full\#ref-1

${ }^{133}$ Watkins, 116.

${ }^{134}$ Barbara Seaman, The Doctors' Case Against the Pill (New York: Peter H. Wyden, Inc., 1969), 11 and 72.

${ }^{135}$ Watkins, 115 and 158 , note 51.
} 
mentioned when they began the pill. ${ }^{136}$ Wilson, for instance, said that her family doctor did not mention side effects when he put her on the pill in 1966. She suggested that perhaps side effects were not understood then. ${ }^{137}$ Evans added that she did not remember the doctor outlining any adverse effects associated with the pill when she went on it in 1966. On the contrary, he reassured her that studies had been completed on the pill and everything was fine. ${ }^{138}$ This judgment seems overly optimistic, or perhaps simply illinformed, given the increasing reports of blood clots and other problems. Clarke's family physician, who gave her the pill in 1967 , was similarly enthusiastic about the contraceptive and did not discuss side effects with her. ${ }^{139}$

Pill users also sometimes clearly remember that doctors did not mention the particular side effects or complications that would be most relevant to their subsequent experiences. Brooks said that, at the very least, her family doctor did not forewarn her about the side effects she did experience (nausea, tender breasts, anxiety) when he put her on the pill in $1969 .^{140}$ Likewise, Richards, who started the pill in 1965 , said no one warned her about migraines which she did experience on the pill. ${ }^{141}$ Reid and Ryan also suffered from migraines while on the pill and do not think their doctors warned them of this particular side effect when they started in 1967 and $1966 .{ }^{142}$ Even more

\footnotetext{
${ }^{136}$ Wood, 4 and 6; Shevchenko, 12; Moore, 21; Walker, 7 and 11; Williams, 12 and 14. However, Williams did have fears about the long-term safety of the pill which she brought up with her doctor. It is worth noting that Shevchenko first got the pill from a clinic in England suggesting that doctors there may also have been remiss.

${ }^{137}$ Wilson, 1, 7-9.

${ }^{138}$ Evans, 2-3, 5-6.

${ }^{139}$ Clarke, 4, 8-9, 13-14. Interestingly, Clarke added that there may have been an insert with the pill which discussed side effects. However, such patient inserts were not included in the pill package in Canada until the 1970s.

${ }^{140}$ Brooks, 3, 6-7.

${ }^{141}$ Interview with Alice Richards, December 7, 2009, 29, 7-9.

${ }^{142}$ Reid, 5-6, 8-9 and 11; Ryan, 3 and 9-12; Seaman, 105. In Seaman's book, Mrs. McK had a similar experience. Her doctor gave her a booklet when prescribing the pill that referred to nausea but not the debilitating headaches and other problems she endured on the pill.
} 
significantly, Jackson, who first went on the pill in 1968 and suffered a stroke while on it in 1973 , was definitely never told that smoking while on the pill was a bad idea. She was a smoker at the time. ${ }^{143}$ Therefore, women who started the pill even in the mid- to late1960s were sometimes not advised about side effects. It did not seem to matter in this regard if they got the pill from their own family doctor or a physician with whom they had less history. The paucity of information conveyed to women demonstrates the diversity of practice within the medical community. While some doctors were more forthcoming, as I will discuss below, others may have been reserved about sharing knowledge with patients or were simply poorly informed of possible side effects.

In the 1960s, some doctors prescribing the pill did explain that adverse effects were possible. ${ }^{144}$ Women encountered such physicians throughout the 1960 s, suggesting that even in the early years of pill use, some doctors were aware of side effects and choosing to pass this information on to patients. However, doctors were not always expansive in these discussions. This is illustrated in an unpublished letter to Chatelaine magazine from 1962. Mrs. Mae Douglas wrote to enquire about a Chatelaine article on the birth-control pill, Enovid. She recounts that "Two weeks ago my doctor...put me on these pills as I don't want any more children...He told me very little about these pills

\footnotetext{
${ }^{143}$ Jackson, 3, 6 and 16; Arsenault, 33. Similarly, Arsenault never remembers a doctor telling her, when she was on the pill, that smoking was especially problematic.

${ }^{144}$ It is important to note that some women also did not remember this part of the initial appointment. In fact, of my fifty-three interviews, twenty-one were not sure or did not remember if the doctor discussed side effects when first prescribing the pill. This group of women contained both those who went on to personally suffer side effects and those who did not. One of them, Wilkins, remarked that, while she did not remember what her doctor told her about the pill, she didn't "know whether I would have cared." This statement speaks to women's willingness to risk adverse effects, a phenomenon I will explore more in Chapters 4 and 5. Additionally, some doctors may have so effectively conveyed the risks of the pill that their patients chose not to try it.
} 
except to say I might feel a little sick for a while \& to stop them during menstruation."145 Though Mrs. Douglas' doctor was quite vague, other women recall that their doctors specifically listed nausea, bloating, weight gain, or breast tenderness as possible side effects. ${ }^{146}$ Doctors might also have mentioned that the pill could affect menstruation. ${ }^{147}$ Thus, these doctors were clearly educated about some of the pill's side effects at least and were willing to share information with their patients.

Doctors in the 1960 s also warned their patients about potentially more disruptive issues. In doing so, they did not seem to feel that pill users would be unnecessarily frightened. As I discussed in the previous section, Klein's family doctor was concerned the pill would affect her psychologically. ${ }^{148}$ Jones and Stewart, who both suffered from headaches while on the pill, were warned by a gynecologist and family doctor respectively that this could happen. Perhaps Jones was seen to be at particular risk because she had always been prone to migraines. ${ }^{149}$ Taylor, who started the pill in 1966 , thinks that her family doctor might have talked about phlebitis, particularly since she was a smoker. ${ }^{150}$ If so, her experience was different from that of Jackson, discussed above, who received no such warning even though she went on the pill two years later. Similarly, in 1967, a general practitioner warned Harrison that along with bloating, nausea, and increased blood pressure, the pill could also in rare cases lead to a stroke. Since Harrison, unlike Jackson and Taylor, was not a smoker, he saw no need for

\footnotetext{
${ }^{145}$ Letter by Mrs. Mae Douglas, Edmonton, Alberta, to Chatelaine, April 24, 1962, Archives of Ontario, Reference Code F138, Barcode B255331, F4-4-b, Box 219, interior Box 442, file DA-DE, 1962.

${ }^{146}$ Reid, 11; Ryan, 10-11; Klein, 9-10; Galli, 10; Harrison, 8; Young, 8.

${ }^{147}$ Interview with Penelope Dobos, July 7, 2009, 3; Carter, 15; Young, 8.

${ }^{148}$ Klein, 7-9.

${ }_{149}$ Jones, 4-5, 8-10; Stewart, 7-9.

${ }^{150}$ Taylor, 2 and 5 .
} 
concern. ${ }^{151}$ In discussing the more serious side effects, these doctors were acknowledging that this information should be shared with women on the pill.

Finally, a couple of pill users also maintained that they acquired information in the 1960s from the pill packaging about side effects. ${ }^{152}$ Quinn in particular, though not discounting the possibility that a doctor spoke to her about side effects, which she says were well understood at the time, thought that the package also mentioned the risks of blood clot or stroke when she started in $1967 .{ }^{153}$ Today in Canada, along with information on the bottle or package itself, prescription medications usually come with an insert detailing instructions for use and any known side effects. However, this may not have been the case for all medications in the $1960 \mathrm{~s}^{154}$ In fact, the birth-control pill, as mentioned above, only first came with a patient insert in the early 1970 s. ${ }^{155}$ However, possibly because of the prevalence of such inserts today, some women who took the pill in the 1960 s remember or assume that their pill prescriptions were accompanied by a similar document. ${ }^{156}$ Stefánsson, who started the pill in 1969 , said that the doctor gave her a little booklet with information on side effects. ${ }^{157}$ Similarly, Doyle began the pill in 1964 and recalled that printed material accompanied the pill and outlined side effects. ${ }^{158}$

In the 1960 s, the medical community was divided over the birth-control pill. Especially at first, the evidence about the pill's side effects was uncertain. Also, not all

\footnotetext{
${ }^{151}$ Harrison, 4-5 and 8.

${ }^{152}$ Hall, 24; Quinn, 13.

${ }^{153}$ Quinn, 4, 8, 7 and 13.

${ }^{154}$ Report to The Special Committee, 1970, 38. The 1970 report, which recommended a patient insert for birth-control pills, stated that such information was already included with things liked insulin. Thus, such pamphlets were not unheard of by 1970 but may have been limited to certain medications.

${ }_{155}$ Sethna, 2001.

${ }^{156}$ Campbell, 13-15, 9-11; Doyle, 6-7. Campbell added that her gynecologist, Dr. S., who may also have been Reid's doctor, must have gone over potential side effects with her when she started the pill in 1964 as she knew enough to contact him when she did experience problems. This is the only case in my sample where two women likely got the pill from the same physician.

${ }^{157}$ Stefánsson, 4 and 7.

${ }^{158}$ Doyle, 6-7. Doyle added that her obstetrician may have discussed side effects with her as well.
} 
doctors kept abreast of the relevant literature and the debate over the pill's safety.

Finally, among those who were well-informed, some maintained that too much

knowledge could upset patients. In light of these impediments to the full disclosure of risks, it is not surprising that some married Canadian women report a lack of discussion about side effects when they started the pill. Their ignorance may have been compounded by the absence of a patient insert until the early 1970 s. Without this sort of document, the discussion of side effects was very much left to the doctor's discretion. That being said, some physicians chose to communicate side effects, including serious problems like strokes, to their patients. In doing so, they were acknowledging that women could benefit from this knowledge.

The Need for a Physical?

In the 1960s, as now, the birth-control pill could only be obtained through a doctor's prescription. ${ }^{159}$ From its introduction, doctors were expected to perform medical examinations when prescribing the pill. ${ }^{160}$ A 1965 article in Chatelaine magazine affirmed that "[The pill] can be bought only on prescription, usually after an internal examination and a cancer test." ${ }^{\text {161 }}$ A 1966 report from the World Health Organization urged doctors to take a full medical history and perform an examination of a woman's breasts, abdomen and cervix when prescribing the pill. If possible, they were also encouraged to do cervical smears, and check both weight and blood pressure. ${ }^{162}$ The

\footnotetext{
${ }^{159}$ Kenyon, 64.

${ }^{160}$ Marks, 124 and 117.

${ }^{161}$ Mungall, 49; Sethna, 2005, 271. Sethna specifies that a gynecological examination was often required before a woman could get a prescription for birth-control pills in the $1960 \mathrm{~s}$.

${ }^{162}$ Marks, 124-125; "Clinical Aspects of Oral Gestogens: Report of a WHO Scientific Group," World Health Organization Technical Report Series, No. 326 (Geneva: World Health Organization, 1966), 3. This report was the product of the scientific group, comprising doctors and professors from around the world, who met from November 30 to December 6, 1965 in Geneva. The report acknowledged that "use of oral agents as well as other methods, for fertility control has increased at such a rapid pace in certain areas of
} 
1970,1975 and 1978 reports of the Canadian special committee affirmed that doctors should have or acquire information about both personal and family medical history and conduct a comprehensive examination of women seeking the pill. ${ }^{163}$

How fully did medical practice comply with these ideals? Not surprisingly, the evidence points to a diversity of practices. Somewhat alarmingly, a 1967-1968 British survey found that $64 \%$ of physicians did not perform a physical examination when offering advice on birth control. ${ }^{164}$ However, some apparently did, particularly pelvic examinations, when prescribing the birth-control pill. Gervais and Gauvreau, in their interviews with Francophone physicians who practiced in Montreal between 1940 and 1970, found that most did insist on a complete physical examination when prescribing the pill. One said, "[W]hen people asked for the pill, it was at least appropriate to perform a physical examination, a Pap test." ${ }^{\text {"165 }}$ A 1969 letter published in Chatelaine magazine expounded on the supposed prevalence and benefits of this procedure:

Most doctors now insist that women have the Papanicolaou test before they prescribe...[the pill]. Cell abnormalities shown up by this 'smear test' can indicate the possibility of cancer, sometimes five years in advance of its more crippling, and often killing, onslaught. Cancer treated at this stage is almost 100 percent curable. This is one other important fact which should be considered...when judging the effects of the pill. ${ }^{166}$

\footnotetext{
the world that the time seemed propitious to make an evaluation of work accomplished." See Appendix 2 on this and other studies.

${ }_{163}$ Report of The Special Committee, 1970, 9; Report of The Special Committee, 1975, 12-13; Report of The Special Advisory Committee on Reproductive Physiology to The Health Protection Branch, 4 and 6.

${ }^{164}$ Cook, 273-274. This number may have been particularly troubling given the doctor's apparent propensity to provide the pill. The same survey reported that "if asked for contraceptive advice, 83 per cent of doctors discussed the pill, [and] 60 per cent prescribed no other method."

${ }^{165}$ Gervais and Gauvreau, 300 and 311-313.

${ }^{166}$ Letter by Joan Bird, Nova Scotia, Chatelaine 42, 9 (September 1969), 124.
} 
In my interviews, almost always in response to my question, some women did report that their doctors performed a physical examination when initially prescribing the pill. ${ }^{167}$

Several confirm that this consisted of or included a pelvic examination. ${ }^{168}$ One of them, Edwards, believed that the doctor gave her this sort of examination both because she was getting married, which implied increased sexual activity, and going on the pill. ${ }^{169}$ Arsenault, who started the pill in 1966 , stated more emphatically that one had to have a total physical, which she did, including a pelvic examination and a blood pressure check, when beginning the pill. ${ }^{170}$ Jackson's doctor would seem to have agreed with this assessment as he told her he routinely sent all his patients to a clinic for a full physical. He did this with her when prescribing the pill in $1968 .{ }^{171}$ Harrison, who first went on the pill in 1967, also remembered that the doctor checked her blood pressure, and did urine and blood tests. Interestingly, Harrison did not receive an internal examination at this appointment because she had had recent checks following the birth of her son. ${ }^{172}$

Therefore, some women remember that an examination, especially a pelvic exam, may have occurred specifically because they were starting the pill. However, others, like Harrison, had internal examinations or pap smears for different reasons. In these cases, the doctors' rationales for performing such checks are less clear. Pregnancy, and its aftermath, was often a period in which women had more doctors' visits. For example, Wilson, who started the pill after the birth of her son, thought a physical examination

\footnotetext{
${ }^{167}$ It is important to note that not all interviewees remembered whether or not their initial appointment included an examination. Those who did not have a clear memory on this point were Mason, Quinn, Ryan, Murray, Ramsey, Shevchenko, Scott, Koch, Macdonald and Lowe.

${ }^{168}$ Brown, 6; Klein, 10; Kennedy, 8; Walsh, 5; Jones, 4; Galli, 9; Edwards, 8-9. Stefánsson and Stevens think this was the case for them as well. Stefánsson, 6-7 and Stevens, 8.

${ }^{169}$ Edwards, 9.

${ }^{170}$ Arsenault, 3, 5 and 9-10.

171 Jackson, 3,5 and 6.

${ }^{172}$ Harrison, 4-5 and 8-9.
} 
would have taken place during this appointment because it was her six-week check-up following the birth. ${ }^{173}$ Morrison had the same experience. She added that her family doctor, while not asking her any questions or performing any procedures obviously connected to starting the pill, would have known her health history. ${ }^{174}$ Miscarriages were also occasions in which women were examined by their doctors. Lynch miscarried in 1962 and went to her doctor to ask about the pill. During this single appointment, she thought he most likely did a post-miscarriage examination and prescribed the pill. ${ }^{175}$ Similarly, Moore suffered a miscarriage in 1967 and affirmed that her doctor, a gynecologist, would have given her a physical at this time. However, Moore added that she had yearly gynecological examinations with this doctor who also checked her heart rate and other vital signs. ${ }^{176}$ By 1964 , when she got married, Klein was also getting regular pap smears and noted that she was due for one when she went to her family doctor for the pill. ${ }^{177}$ Finally, Williams thought her obstretrician may have performed an examination when he put her on the pill in about 1962 as he almost always did a pap smear and palpitated her internal organs when she came for an appointment. ${ }^{178}$ Therefore, some women, in the 1960s, were already undergoing gynecological check-ups which were not necessarily associated with the pill. While this was sometimes connected to a pregnancy, it was not always the case.

However, not all doctors, even into the late 1960s, were as conscientious in conducting physical examinations. Indeed, despite the WHO guidelines noted above, a

\footnotetext{
${ }^{173}$ Wilson, 9.

${ }^{174}$ Morrison, 10, 12 and 16-17.

${ }^{175}$ Lynch, 25-28.

${ }^{176}$ Moore, 14, 17 and 26-27. Moore also implied that, since she started the pill in about 1968, she might have had another physical with her gynecologist after the post-miscarriage appointment.

${ }^{177}$ Klein, 3, 7, 8 and 10.

${ }^{178}$ Williams, 14-15.
} 
1967-1970 British investigation "revealed that only 36 per cent of women who first received oral contraceptives from a general practitioner had been given a medical examination at the time. This was a much lower percentage than women receiving their pill from a family planning clinic, where the proportion was 97 per cent. ${ }^{\text {"179 }}$ Canadian women usually received the pill from private physicians, either gynecologists or family doctors. ${ }^{180}$ Given the above statistics on British GPs, it is not surprising that at least some doctors encountered by Canadian women in the 1960 s did not perform a physical examination before prescribing the pill. Perhaps this omission sometimes occurred because the doctor had a history with or knowledge of the patient which made he or she happy to prescribe the pill without an accompanying physical check-up. For instance, Dr. R., general practitioner of Stewart, prescribed the pill for her in the early 1960s. According to her, she did not, as a young woman, have regular physicals and had no specific examination before starting the pill. She added that the doctor probably assumed everything was fine to start the pill as she had had her children recently. ${ }^{181}$ Brooks also had a history with her family doctor and, likewise, did not think he gave her any kind of examination before prescribing the pill three months ahead of her 1969 wedding. ${ }^{182}$ Finally, Clarke, who started the pill in 1967, also got it from her family physician. He did not perform any examination and Clarke explained that she was a healthy young woman. ${ }^{183}$ This sentiment, that healthy young people did not need or have regular

\footnotetext{
${ }^{179}$ Marks, 125-126.

${ }^{180}$ In my sample only Shevchenko, who was in England when she started the pill, got it from a family planning clinic.

${ }^{181}$ Stewart, 7-8 and 22-23.

${ }^{182}$ Brooks, 3, 6-7.

${ }^{183}$ Clarke, 4, 8-9 and 12.
} 
physicals, was also expressed by Stewart. It perhaps points to the variation in health care standards in Canada.

Therefore, some doctors, who had a history with a particular patient and may have been privy to relevant medical information, did not apparently conduct a physical examination before prescribing the pill. However, neither did some doctors meeting a woman for the first time. Evans, for instance, did not get a pelvic examination when she went, for the first time, to her sister's doctor in order to get the pill in $1966 .{ }^{184}$ Likewise, Walker approached a general practitioner for the pill in 1966 or 1967 and was able to get a prescription without any physical examination. ${ }^{185}$ This suggests that not all doctors who were prescribing the pill were necessarily conscientious about doing so in the 1960 s. Conducting some sort of physical examination before writing a prescription would have been prudent since the pill worked systemically on the body. In addition, by at least 1969, various physical contraindications for pill use were well-known. For example, "Most doctors do not think it advisable to give the pill to patients...with noticeable varicose veins." "186 While some physicians could argue they were well versed in their patient's health through routine or obstetrical care, others encountered women for the first time and prescribed the pill with no examination. This again demonstrates that, as with disclosing side effects, Canadian women who went on the pill in the 1960 s were

\footnotetext{
${ }^{184}$ Evans, $2-3$ and 6.

${ }^{185}$ Walker, 4, 7-8, 10-12. Walker was actually already pregnant and never ended up taking this prescription. After her baby was born in 1967 , she went to a different doctor for the pill and could not remember if this second doctor did an examination.

${ }^{186}$ Seaman, 42 and 218 . I decided to focus more on physical examinations but the World Health Organization report from 1966, discussed above, also recommended that doctors take a full medical history before prescribing the pill. Seaman adds that many doctors were hesitant to give the pill to women with a history of blood clots or migraine headaches. Furthermore, she states that "Conscientious doctors not only question a patient about depressive tendencies but also about any family history of depression before putting her on the pill."
} 
subject to a spectrum of medical care. There were no guarantees that the doctor they approached for the pill would perform a thorough or even cursory medical examination.

\section{Check-Ups?}

In addition to an initial examination, theoretically, women on the pill needed regular check-ups. ${ }^{187}$ The birth-control pill, unlike medications to treat disease, was administered to healthy women over an undefined period of time. ${ }^{188}$ It also acted systemically which made it very different from other birth-control methods, like the condom or the diaphragm. ${ }^{189}$ The 1966 World Health Organization (WHO) report recommended that women on the pill have check-ups every six months. As well as monitoring any potential problems with this new drug, these appointments allowed doctors "the opportunity of carrying out preventive check-ups they could not otherwise have done because of women's reluctance to come forward for such tests."190 The need for regular follow-ups was also echoed in the 1970 and 1975 reports of the special committee to the FDD. Here, committee members were a little less stringent than the WHO, suggesting that doctors see pill users again within six months but then subsequently once a year would suffice. ${ }^{191}$ Thus, the pill facilitated, in many cases, more regular contact between women and the medical profession. ${ }^{192}$ Nevertheless, doctors varied in their attentiveness to women on the pill. ${ }^{193}$ Indeed, a 1965 article in Chatelaine magazine reported that, while most Canadian doctors asked women on the pill to come

\footnotetext{
${ }^{187}$ May, 5; Tone 241-242.

${ }^{188}$ Marks, 117.

${ }^{189}$ Tone, 241-242.

${ }^{190}$ Marks, 124-125.

${ }^{191}$ Report of The Special Committee 1970, 37; Report of The Special Committee 1975, 43. This recommendation also appeared in the 1978 Report of The Special Advisory Committee on Reproductive Physiology to The Health Protection Branch, 6.

${ }^{192}$ Tone, 240-241.

${ }^{193}$ Marks, 117.
} 
back for a check-up after six months, others were writing prescriptions for a year's supply of the pill. ${ }^{194}$

Some Canadian women who started the pill in the 1960 s maintain that their doctors did monitor their experience through regular check-ups. Many thought they had annual check-ups or pap smears because they were on the pill. ${ }^{195}$ As Jackson stated "the doctor recommended at my age and with the medication that it was a good idea to have an annual pap smear done."196 Some doctors apparently did more than "recommend" and made the yearly prescription renewal contingent on having a physical examination. ${ }^{197}$ For example, after being on the pill for a year, Young got a call from the pharmacy in 1966 telling her to see her doctor for a pap test. She had never had one before and understood it was definitely connected to getting a new prescription for the pill. ${ }^{198}$ As Brown explained, "that was one good thing about the pill. You needed your prescription [and]...they didn't give it to you without a pap test so you did get a pap test every year, which was good." 199 Lynch, who started the pill in 1962, also thought that her doctor said, "you're on the pill now, you have to have a pap smear." Lynch began having yearly

\footnotetext{
${ }^{194}$ Mungall, 49.

${ }^{195}$ Jackson, 11-12; Arsenault, 17, 21-22; Galli, 10-11; Edwards, 4, 13-15; Harrison, 13-16. Arsenault's testimony is perhaps, though not necessarily, contradictory, demonstrating the sometimes difficult nature of oral history. First, she agrees that her doctor did bring her in for check-ups so he could keep an eye on her pill use. However, when asked again a moment later, she clarifies that she always had yearly physicals, including a pap smear, which were not because of the pill. Rather than omitting her testimony, I included Arsenault in both this footnote and note 208. Galli thought the pill was at least one reason for her annual appointments while Edwards thought the check-ups may have even been every six months at first. She started the pill in 1965 through a gynecologist. Finally, though Harrison maintained that her yearly physicals in the early 1970s were not occurring because she was on the pill, she then implied that she regularly saw the doctor because of her rising blood pressure. This problem was associated with the pill and, therefore, one could argue that her doctor was monitoring her reacton to the contraceptive.

${ }^{196}$ Jackson, 11.

${ }^{197}$ Thompson, 18; Brown, 9; Young, 7.

${ }^{198}$ Young, 4, 7, 9 and 11.

${ }^{199}$ Brown, 9.
} 
pelvic examinations and would get the pill prescription then. ${ }^{200}$ Wilkins, who was on the pill from 1962-1973, affirmed that, by at least 1970, she was getting regular physical examinations because she was on the pill. According to her, getting the birth-control pill became dependent upon going in for such appointments. Interestingly, especially in light of others' experience, Wilkins said this procedure evolved over time and was not in place when she first started the pill. ${ }^{201}$ Thus, some Canadian doctors were or became conscientious about bringing in pill users for check-ups.

As well as mandating regular visits, some doctors also insisted that they would only renew the pill prescription for so long, often setting a limit of four or five years. ${ }^{202}$ In her 1969 book, Barbara Seaman explained that "More and more doctors were manifesting their concern by attempting to make sure that pill-users would not stay on...indefinitely or at too advanced an age." ${ }^{203}$ While Lynch's doctor did not refuse to continue prescribing the pill after five years, he did raise the subject at this time. However, Lynch, fearing another pregnancy, would not countenance coming off the pill. ${ }^{204}$ Similarly, after being on the pill for five or six years, a doctor suggested that Evans consider taking a break from the contraceptive. Unlike Lynch, Evans decided to come off the pill at this time. ${ }^{205}$ Morrison's doctor also suggested she take a break from the pill but, in her case, she had been on for even longer, about fifteen years. Like Evans, Morrison made the decision to discontinue the pill altogether. ${ }^{206}$ Other doctors informed

\footnotetext{
${ }^{200}$ Lynch, 25, 32-33 and 40.

${ }^{201}$ Wilkins, 15, 22 and 24-25

${ }^{202}$ Kennedy, 5; Quinn, 10. Quinn had the impression five years was about the limit for pill use and thought she may have gotten this message from her doctor as well as the media.

${ }^{203}$ Seaman, 141.

${ }^{204}$ Lynch, 37-38.

${ }^{205}$ Evans, 9-10 and 15-16.

${ }^{206}$ Morrison, 24.
} 
their patients they would not prescribe the pill after age forty. ${ }^{207}$ In imposing limits based on time or age, these doctors were demonstrating an awareness of a patient's history with the pill and a desire to be cautious in its use.

Other women also had annual check-ups or pap smears, but do not remember that these were explicitly, or only occurring, because they were on the pill. ${ }^{208}$ Rather, such appointments were often recalled as a routine part of health care. ${ }^{209}$ For instance, Klein and Williams were having regular pap smears even before starting the pill and Stefánsson still had them yearly once off of it. ${ }^{210}$ Kennedy's gynecologist wanted her to come back for yearly physicals and did seem cautious about the pill. However, Kennedy thought those yearly appointments were not just because of the pill but "what you do...ladies have to have their insides looked at, they have to have a pap smear...I don't even know now when the pap smear actually started but it seems to me that it was done right from the beginning."211 Like Kennedy, Macdonald did not feel her yearly pap smears were connected to the pill but rather were "the right and proper thing to do as preventive health." ${ }^{212}$ Therefore, some women, while receiving regular medical attention, do not recall that these visits took place because they were on the pill.

\footnotetext{
${ }^{207}$ Thompson, 28 and 17-19; Smith, 14-16.

${ }^{208}$ Wilson, 19; Moore, 26-27; Clarke, 23-24; Reid, 25; Watson, 20; Arsenault, 22; Campbell, 9, 20-21 and 26. Though Clarke specified her check-ups might have been biannual with one doctor I think she actually meant every two years rather than twice a year. She also did not have regular check-ups during her first time on the pill (see below). Campbell remembered regular check-ups with her gynecologist but was only on the pill for about a month, making it hard for her to comment on any particular monitoring of her pill use.

${ }^{209}$ Beck, 25; Walker, 22-23; Lowe, 20-22 and 24. However, Lowe added that, in the absence of a yearly physical, she had the impression some sort of follow-up would have been needed to get a renewal of her pill prescription.

${ }^{210}$ Meyer, 17; Klein, 10; Williams, 24; Stefánsson, 10, 12-14.

211 Kennedy, 8 and 11.

${ }^{212}$ Macdonald, 12, 14-15, 20-21. When first on the pill, from 1963-1966, Macdonald did not have followup appointments. After the birth of her daughter in 1967, Macdonald went back on the pill for about sixteen months. This time, she thought she probably did have annual physicals.
} 
There are also women who do not remember any regular check-ups during their years on the pill. In some cases, this could be because they were on the pill for one to two years or less. ${ }^{213}$ Richards, for example, though on and off the pill several times from the mid-1960s to the mid-1970s, probably only once took it for more than a year at a time. She did not think she had yearly check-ups during that time, though she did not completely rule out the possibility. Richards added that she did go in for care during her multiple pregnancies and because of migraines. ${ }^{214}$ If a woman was only on the pill for a short time, a doctor might not have seen the need to routinely monitor her experiences on it.

However, others with more sustained exposure to the pill also reported a lack of subsequent, regular appointments. ${ }^{215}$ Morrison, who was on the pill from 1965 to about 1980 , thought she only had a full medical examination every five years or so and a pap smear, which were not presented as more necessary because she was on the pill, every three to five years. ${ }^{216}$ Similarly, Anderson, who was on the pill from 1965 into the 1980 s, did not really recall any yearly physicals or pap smears until the 1980 s. $^{217}$ Evans, who took the pill for five or six years, said she just went in to get refills and did not have check-ups. The doctor she saw for two of those years, who had initially prescribed the

\footnotetext{
${ }^{213}$ Clarke, 23-24; Dawson, 12 and 15; Scott, 6 and 13; Interview with Vivian Koch, January 21, 2010, 16, 17 and 21; Carter, 16-18. However, Koch and Clarke did see doctors to discuss the side effects they experienced with the pill. For more on this, see Chapter 4.

${ }^{214}$ Richards, 23-24, and 6. Richards started the pill in 1965 after the birth of her first child and was on it on and off until the mid-1970s. During these years, she had four more pregnancies. For more on her migraines, see Chapter 4.

${ }^{215}$ Smith, 14-15 and 18; Macdonald, 14-16. On Macdonald, see Note 212.

${ }^{216}$ Morrison, 10, 24, 18 and 21-22.

${ }^{217}$ Interview with Heather Anderson, December 3, 2009, 5-6 and 8-11.
} 
pill, may have asked if everything was alright with the medication. ${ }^{218}$ This absence of medical supervision was not in accordance with the recommendations of the report by the WHO or that of the special committee to the FDD and affirms again that there was a wide spectrum of medical care provided to women on the pill. Stefánsson's experiences illustrate this point well. Starting in 1973, she went to a gynecologist in Ottawa who gave her the pill and performed regular pap smears. However, prior to this time, she lived in Toronto and had a much less attentive doctor who did not do physical examinations. She characterized him as a "quack" who just wrote prescriptions "without any care or thought whatsoever."219

Thus, beginning with the initial appointment, doctors in Canada varied in the care they provided to women on the pill. This confirms Siegel Watkins' finding about the United States in the 1960s and 1970s that "When women compared notes on their experiences with doctors and contraceptive advice, they discovered a variety of opinions, recommendations, and practices." 220 At one extreme, the attentive physician might, when prescribing the pill, outline many potential side effects and perform a thorough physical examination. He or she would then conscientiously monitor a woman's experiences with the pill on a regular basis. However, as I have shown, less careful doctors who did not examine women, discuss risks associated with the pill or follow-up at all, also existed in Canada in the 1960s.

Appearance and Brand of the Pill

\footnotetext{
${ }^{218}$ Evans, 8-9 and 15. While on the pill, Evans also lived in Germany for two years where she went to a Canadian military doctor. This confirms that a number of doctors, in different contexts, apparently did not see the need to monitor her on the pill.

${ }^{219}$ Stefánsson, 4, 8-10 and 13-14.

${ }^{220}$ Watkins, 102.
} 
The first birth-control pill, Enovid, became available in Canada in 1961.

According to an article in Chatelaine magazine, it was "about half the size of a typical headache tablet and bright pink in color." 221 Early versions of the pill came in bottles. In this format, women could easily forget whether or not they had taken a pill on a particular day. Tired about worrying over this very question, David P. Wagner, a product engineer working for Illinois Tool Workers, designed a container to help his wife remember her daily pill. After applying for a patent in July of 1962, he shared his designs with the pharmaceutical companies, approaching both G.D. Searle and Ortho Pharmaceutical. He had heard the latter was developing its own contraceptive pill. Indeed, when OrthoNovum was launched in 1963, it came in the "Dialpak" which drew enough on Wagner's designs to warrant compensation for him from the company. Other manufacturers soon copied the model with their own memory aids. ${ }^{222}$ Henceforth "Instead of getting a vial of undifferentiated pills, women could get the Dialpak, permitting them to check at a glance if they had taken their daily tablet.,223

Calendar packs were available in Canada by 1964 and dial packages by at least $1965 .{ }^{224}$ Also, by the mid-1960s, lower dose and sequential versions of the pill, in which women took estrogen for the first part of the month and then progestogen, were for sale. ${ }^{25}$ From the beginning, pill packages were designed to be discrete. David Wagner made this explicit in his patent when he stated that "his Pill dispenser would fit into a case 'indistinguishable' from a lady's cosmetic 'compact,' so that it could be carried

\footnotetext{
${ }^{221}$ Kenyon, 31.

${ }^{222}$ Patricia Peck Gossel, "Packaging the Pill," in Manifesting Medicine: Bodies and Machines, eds. Robert Bud, Bernard Finn, and Helmuth Trischler (Amsterdam: Harwood Academic, 1999), 106-108 and 113.

${ }^{223}$ Ibid., 106-107; Tone, 258.

224 “"The Magic Pill," This Hour has Seven Days, CBC Television Show, broadcast October 11, 1964, The CBC Digital Archives Website http://archives.cbc.ca/health/reproductive issues/clips/2956/; Mungall, 49. ${ }^{225}$ Constance Mungall, "The Pill and Its Side Effects Today," Chatelaine 39, 11 (November 1966), 117.
} 
among her personal effects or in her purse, "without giving a visible clew [sic] as to matters which are of no concern to others',"226

A surprising number of Canadian women remember which brand, and even which dose, of contraceptive pill they took in the 1960s. Again and again the name Ortho or Ortho-Novum came up, often unprompted. ${ }^{227}$ An additional woman recalled that it was "Ortho-something.,"228 No other contraceptive pill, even the popular Ovral, was remembered by name. Ortho-Novum was available in Canada by August of $1962 .^{229}$

Women who remember the appearance of the pill often state that it came in a disc, dial, compack or other memory aid packaging. ${ }^{230}$ No one, not even women who started it in the early 1960 s, specifically recalled it coming in a bottle even though the first patient compliance package, the Dialpak, was not introduced until 1963. This perhaps speaks to the pervasive association of the Pill with such packaging as well as the generic and unremarkable appearance of the medication in its earliest forms. Sometimes, the packaging itself was considered a positive feature of the Pill. As Brown said, "I thought the little compack thing that it came in was so nice. I showed that to people."231 Quinn agreed that the pill disc was a "cute little thing.,"232

\footnotetext{
${ }^{226}$ Gossel, 115 .

${ }^{227}$ Follow-Up Interview with Susan Brown, December 11, 2009, 3; Quinn, 11; Klein, 23; Jackson, 10 and 14-15; Ryan, 15; Reid, 26; Anderson, 8; Jones, 10; Harrison, 9-10 and 15; Young, 10; Arsenault, 18; Macdonald, 12-13 and 21-22; Thompson, 23. Thompson was an exception. She thought Ortho-Novum sounded familiar when I mentioned it as a possible brand.

${ }^{228}$ Stewart, 11.

${ }^{229}$ Hyman Solomon, "6 Die, Warn Against Birth Control Pill," The Toronto Star, August 8, 1962, 42; Deidra Clayton, "The rising cost of birth control pills," The Financial Post, December 30, 1978, 16; Report, 1960, 7. Clayton's article describes Ovral, produced by Wyeth Ltd., and Ortho-Novum as top brands. The 1970 report by the special committee on oral contraceptives listed fifteen brands, of varying doses, for sale in Canada.

${ }^{230}$ For example, Thompson, 21; Quinn, 7 and 11; Wilkins, 23; Klein, 13; Murray, 16; Dawson, 18; Walsh, 12; Evans, 7; Scott, 12; Koch, 15-16; Campbell, 15; Arsenault, 8; Lowe, 13.

${ }^{231}$ Brown, 5.

${ }^{232}$ Quinn, 7 and 11.
} 
The colour of the Pill and its package was also appropriately soft and feminine. Enovid, the first birth-control pill, was a pink tablet. ${ }^{233}$ Additionally, in the 1960 s, pill "compacts" were made in "pastel colours with cameo and floral designs pressed into their surfaces." ${ }^{\text {234 }}$ Sometimes, colour is featured very prominently in memory. Many women who took the pill in the 1960s associated it, or its packaging, with the colour pink. ${ }^{235}$ Purple was also mentioned by a number of women in connection to the pill. ${ }^{236}$ The appearance of the pill, including its colour and discrete disc or compack, may have increased its appeal even more.

Forgetting the Pill

Katie Johnson: What happens if you forget [the pill]?

John Rock: Ahh, if you forget one pill, then that's too bad. If you forget two pills, then you get the same result that...one would get at the end of the three weeks. Withdrawal of the hormonal support of the lining of the womb in which case, there'd be a little...menstruation.

Johnson: Do you automatically become pregnant if you forget to take a pill? I've heard that.

Rock: Well, it requires more than cessation of the pill to become pregnant. And it requires more than an egg. But...no, ovulation would not occur inevitably if one just missed a couple of pills...[It] takes a little bit longer than that...unless they were missed at just the right time...

Johnson: How many women can remember to take a pill every morning?

Rock: Well, I...I don't know the exact figures but I...gather from what I hear from the...pharmaceutical houses and what I read in the newspapers, that something like...oh two and a half to three million women in the United States are doing it. Now how many...women in England and Europe and elsewhere remember to take it every day, I don't know. But...I'm pretty sure about the figures in the United States.

\footnotetext{
${ }^{233}$ Kenyon, 31 and 62.

${ }^{234}$ Gossel, 115.

${ }^{235}$ Brooks, 19; Jackson, 10; Reid, 26; Anderson, 8; Young, 17-19; Carter, 18.

${ }^{236}$ Klein, 13; Ramsey, 11-12; Reid, 26; Stefánsson, 7-8; Young, 17-19.
} 
Johnson: You don't have any figures on how many women forget? Just out of human nature.

Rock: Oh yes...well, we did in the early days. Ahh, but it wouldn't be more than five or ten percent and they'd only forget for two or three days. ${ }^{237}$

In this excerpt of a 1964 interview of Dr. John Rock, American developer of the pill, discussed in Chapter 1, on the Canadian program This Hour Has Seven Days, the interviewer, Katie Johnson, seemed preoccupied with the belief that women could not possibly remember to take a pill every day. Advertisements for oral contraceptives in medical journals in the late 1960 s certainly reinforced the perception that women would forget. ${ }^{238}$ However, was this an actual problem?

Patient compliance with the pill regimen was an issue in the early clinical trials of the pill. In one study in Haiti, over twenty percent of the women forgot to take at least some of the pills. ${ }^{239}$ Thus, forgetting the pill may have been a real problem, particularly in the early years of pill use. However, even after the introduction of the Dialpak and other memory aids, "A 1965 study of 5,600 women cited psychological difficulties such as worry about forgetting to take the Pill every morning, and a general dislike of taking a pill every day, among the reasons women switched to other methods of contraception."240 Belying the findings of this study, some women in my sample reported that they had no problems remembering to take the pill. ${ }^{241}$ An additional number specified that they did not think it was, or remember it being an issue, or at least not a usual one for

\footnotetext{
237 "The Magic Pill," The CBC Digital Archives Website http://archives.cbc.ca/health/reproductive_issues/clips/2956/

${ }^{238}$ Gossel, 115.

${ }^{239}$ Ibid., 112.

${ }^{240}$ Ibid., 115 .

${ }^{241}$ Dobos, 7; Wilkins, 23-24; Meyer, 18; Jackson, 11; Beck, 14 and 28; Kennedy, 11; Moore, 27; Evans, 7; Anderson, 8; Richards, 24; Harrison, 18; Williams, 16;
} 
them. ${ }^{242}$ As discussed above, most women I interviewed remember that the pill came in a disc, compack or other packaging which helped them remember to take it. ${ }^{243}$ In addition, some women also used memory aids such as putting the pill in a certain location and/or incorporating it into their daily routine. ${ }^{244}$ For instance, Arsenault was told to put her pill package in the coffee pot so she would see it every morning. Using this system, she never remembered missing a pill though she may have taken them late on occasion. When this happened, Arsenault thought she probably blamed her husband's interference in, for instance, making coffee and possibly moving her Dialpak. ${ }^{245}$ Clarke decided, after initially keeping her pills in the medicine cabinet, to put them with her underwear so she would not forget to take them. ${ }^{246}$

Even methodical users might have an occasional lapse. ${ }^{247}$ Particularly a change in routine could lead to a problem. Thompson, for instance, who was on and off the pill for about twelve years, once left the pills at home when going to visit family with her husband and children. Somewhat frantically, they phoned their pharmacist in Ottawa and he was able to contact a colleague in Toronto who then provided her with the pills. Thompson's testimony, particularly her use of pronouns, reveals something interesting about her husband's role in pill-taking. She says, in recounting this event, that " $I$ forgot to take my birth-control pills. And so...we were able to phone the pharmacist." ${ }^{248}$ Thus, apparently it was Thompson's responsibility to remember the pill but she felt her husband was involved in rectifying her unusual lapse. She confirmed in a follow-up interview that

\footnotetext{
${ }^{242}$ Walsh, 7-8; Jones, 10; Campbell, 19; Macdonald, 13; Lowe, 30.

${ }^{243}$ Hall, 22; Wilson, 10; Quinn, 7; Murray, 16; Dawson, 18-19; Reid, 25-26; Morrison, 20.

${ }^{244}$ Stewart, 15; Lynch, 30-31; Murray, 16; Stefánsson, 8.

${ }^{245}$ Arsenault, 30-31.

${ }^{246}$ Clarke, 22.

${ }^{247}$ Young, 13, 16 and 10; Morrison, 10, 24 and 20.

${ }^{248}$ Thompson, 16, 21-23.
} 
her husband did not ever remind her to take the pill, explaining that "I'm the one with the memory."249 I will discuss further how some husbands were involved in this way below. Smith, though admitting that "it was just a pain trying to remember all the time", also ran into particular difficulty when going away on a trip. In her case, they had to turn the car around so she could get her pills. ${ }^{250}$ Walker, also on the pill for more than ten years, asserted that she only ever missed maybe two pills and, like Smith and Thompson, this probably occurred because she was away from home. ${ }^{251}$

Finally, some women, confirming Johnson's suspicions, did frequently have trouble remembering their daily pill. ${ }^{252}$ Carter, for instance, took the pill for nine months and remembered that "when I was taking it, it was a big concern to me cause I would forget...to take the pill and then I'd think, well I guess I have to take two now. I think I was told to do that or something." Carter was not sure where she got this information but, if she realized she had forgotten, she might take the two pills to avoid pregnancy. ${ }^{253}$ Scott, on the pill for six to eight months, confirmed that remembering the pill "was probably one of the annoyances about it...I think I managed to remember but I think it wasn't easy to remember." ${ }^{254}$ Thus, even with memory aid packaging, taking the pill every day, regardless of sexual activity, was a problem for some women. This difficulty with the pill regimen further complicates its image as a perfect or nuisance-free contraceptive.

\footnotetext{
${ }^{249}$ Follow-Up Interview with Elizabeth Thompson, November 30, 2009.

${ }^{250}$ Smith, 13 and 14-15. Smith took the pill for about fourteen years.

${ }^{251}$ Walker, 7, 13 and 21.

${ }^{252}$ Ramsey, 11; Watson, 13; Koch, 18; Edwards, 37.

${ }^{253}$ Carter, 16-17, 8 and 19.

${ }^{254} \mathrm{Scott}, 6$ and 13.
} 
While the pill was obviously a contraceptive method controlled and used by women, husbands could have a role in reminding their wives to take the pill daily. In doing so, men were again demonstrating their continued involvement with birth control, as discussed in more detail in the previous chapter. For example, Brown, who took the pill for approximately three years before her first child and then maybe a year between her two children, recalled that her husband reminded her "every night to take my pill, I took my pill at bedtime every night and he made sure I took it.".255 Brown was glad for his assistance as she did not want to forget either. ${ }^{256}$ Edwards, on and off the pill over about six years, reported that, while she mostly remembered to take the pill herself, her husband would also help by reminding her. ${ }^{257}$ Thus, some men participated in contraception by helping their wives remember to take the pill.

While some husbands apparently had no problem with this level of involvement, others would not have welcomed it, as illustrated in a 1966 Chatelaine article. For this two-part piece, a group of Canadian couples were asked about a variety of topics by Dr. Benjamin Schlesginer, associate professor in the School of Social Work at the University of Toronto. Men and women were interviewed separately. When asked about the pill's impact on husbands, the following revealing exchange took place between three of the men:

Bob Dawson, twenty-nine years old and the father of three children: "My wife has a tendency of not being too well organized-so she forgets. It's still up to her to remember."

\footnotetext{
${ }^{255}$ Brown, 10, 13, 22-23 and 7.

256 Ibid., 7.

${ }^{257}$ Edwards, 4, 11-12, 22, 23, 26 and 37-38. Edwards said she forgot the pill maybe a couple of times. Edwards' husband was also involved with her pill experience because she discussed the troubling side effects she experienced with him, a subject discussed in the next chapter.
} 
Gordon Atkins, twenty-three years old with no children: "But it's up to you too."

Dawson: "Do you go to bed every night, and say, 'Did you take the pill?"” Atkins: "Yes, I do."

Don Holmon, twenty-eight years old with no children: "I don't. I assume my wife has a little intelligence."

In answering another question, Peter Jones, a twenty-three year old with one child, added that "I assume my wife is taking the pill. Maybe once a month I might check with her."258 Quinn confirmed that she did not think her husband reminded her to take the pill. $^{259}$ Perhaps some men, as Holmon implies above, felt that prompting their wives to take the pill would be an insult to their intelligence. They may also have thought; as discussed in Chapter 2 , that contraception in general was a female responsibility.

The spousal relationship could also, apparently, have an adverse effect on a woman's adherence to the pill regimen. According to Drs. Cornelius B. Bakker and Cameron R. Dightman, psychiatrists from the University of Washington in Seattle, "when there is marital discord, these women who 'forget' their pill often do it as a revengeful act against the husband."260 Mrs. D. Harrison wrote a letter in response to this article and indignantly rejected the idea that a woman would get pregnant out of spite. However, she did allow that a husband could negatively influence his wife's pill-taking by saying "I can bet you it was the husband who made her forget; in making so many demands for her attention she had no time to think of herself."261 Ultimately then, a husband could exert

\footnotetext{
${ }^{258}$ Mildred Istona, "Is There A Young Marriage Revolution? Part 1," Chatelaine 39, 11 (November 1966), 44 and Mildred Istona, "Is There a Young Marriage Revolution? Part 2," Chatelaine 39, 12 (December $1966), 40,58$ and 60.

${ }^{259}$ Quinn, 19.

260 "What's New in Health: Who Forgets the Pill?" Chatelaine 38, 5 (May 1965), 16.

${ }^{261}$ Letter by Mrs. D. Harrison, "Pregnant For Spite?" Chatelaine 38, 8 (August 1965), 68.
} 
some influence on his wife's pill-taking, either helping or hindering her. Either way, he was actively involved with birth control. However, some men clearly felt this sort of participation was inappropriate and were more content to leave the task of remembering the pill to their wives.

\section{Conclusion}

Getting on the pill was not necessarily straightforward in the 1960s. Many of the women interviewed for this thesis had the impression that it was more difficult or even impossible for single women to access the pill during this decade. They often waited until they were engaged before going to the doctor's. Age, income and the doctor's attitude could also be impediments. In addition, before the pill, a woman might have been reluctant to approach a doctor for birth control and likely would not have asked a physician for a particular prescription. The pill began to change this dynamic though the shift was by no means complete. Some women still more dutifully asked for a medical opinion or followed advice to take the pill when it was offered.

In the 1960 s, the medical community was conflicted on many questions related to the pill. For instance, what side effects were possible? Was it a good idea to communicate known risks to women going on the pill? Perhaps reflecting the lack of consensus on these issues, not all Canadian doctors discussed side effects with women before they started the pill. This left some women poorly informed of the risks they assumed by taking the pill. Compounding the potential danger of the pill, not all doctors seemed to perform a medical examination when prescribing the pill, nor did they institute regular follow-ups to monitor experiences on the pill. Though conscientious doctors did exist, clearly interactions with the medical profession were inconsistent. 
In addition to dealing with doctors, part of a woman's experience on the pill had to do with the practical aspects of taking it. Perhaps surprisingly, many women remember tactile details of their pill use, such as packaging and colour. These factors may have made the pill both more appealing and easier to take. Nevertheless, despite memory aid packaging, such as the Dialpak, some women who took the pill in the 1960s did have trouble remembering it every day. The need to take it consistently could, therefore, diminish its overall appeal.

The next chapter will continue the exploration of women's experiences on the pill by examining in detail the question of side effects. 


\section{Chapter 4-Experiencing Side Effects}

\section{The Downside of the Pill: Side Effects}

When it was first released and through much of the 1960s, the pill was lauded as a liberator of women, freeing them from, amongst other things, the health hazards of too many pregnancies. However, the side effects experienced by so many women cast a pall, which proved difficult to dispel, over science's latest triumph. ${ }^{1}$

The birth-control pill, like most drugs, has side effects for some people. In the original human trials of the pill, which began in 1956, Puerto Rican women complained of bloating, weight gain, nausea, vomiting, stomach pain, headaches, rashes and dizziness. ${ }^{2}$ Barbara Seaman, an American journalist, also listed in her influential 1969 book The Doctors' Case Against the Pill "depression, weight gain, swollen breasts, acne, arthritis, vaginal infections, and even a reduction in libido."3 Some researchers concluded that side effects rendered the pill nonviable. ${ }^{4}$ Despite these concerns, the pill became available to women all over the world. Many did experience and complain about side effects.

This chapter will focus on the pill's side effects in the 1960s and 1970s. The numerous and pervasive problems potentially associated with its use reached far beyond the bedroom door and are crucial in understanding the pill's influence on women's lives.

\footnotetext{
${ }^{1}$ This chapter does not discuss every possible side effect mentioned by the women I interviewed. As shown in Appendix 1, for instance, acne and tender breasts also occurred in my sample. I decided to focus on the most common and/or influential issues.

${ }^{2}$ Christabelle Sethna, "A Bitter Pill: Second Wave Feminist Critiques of Oral Contraception," in Canada: Confederation to the Present, eds. Bob Hesketh and Chris Hackett (Edmonton: Chinook Multimedia Inc., 2001), http://chinookmultimedia.com/poccd/registered/web_papers/case_studies5.php; Linda Gordon, The Moral Property of Women: A History of Birth Control Politics in America (Chicago: University of Illinois Press, 2007), 287.

${ }^{3}$ Sethna, 2001.

${ }^{4}$ Gordon, 287-8; Suzanne White Junod and Lara Marks, "Women's Trials: The Approval of the First Oral Contraceptive Pill in the United States and Great Britain," Journal of the History of Medicine and Allied Sciences 57, 2 (April 2002), 142.
} 
As well as discussing the actual side effects suffered by women, I will analyze how they dealt with these problems, including their interactions around such issues, with the medical profession, their partners, friends and family.

By analyzing women's experience of side effects, it is also possible to understand the varied and complex nature of the pill's influence. Unlike other means of contraception, the pill is a medication that works systemically in the body. As such, its potential impact on health and well-being is far-reaching. While some women had no noticeable side effects and a few even felt that the pill came with positive additional benefits beyond contraception, many more were not so lucky. Their stories complicate the image of the pill as a revolutionary, problem-free contraceptive. They also demonstrate that, while the pill may have been unobtrusive during sex, it could, on the flip side, have an impact well beyond that of the condom or the diaphragm. Almost all side effects manifested themselves on a continuum, ranging from mild to more debilitating. The degree to which a woman was affected influenced her decisions about the pill. It is also true that women could experience the same side effect and react to it differently. While some were able to, or chose to, tolerate them, others were driven off the pill, concluding that its promise of effectiveness and convenience were simply not worth it. Finally, some women were unlucky enough to experience more than one serious or disruptive problem during their time on the pill. The first section of this chapter will begin by briefly discussing those who were untroubled by side effects before moving into an analysis of the more problematic aspects of pill use.

Of the fifty-three women I interviewed for this thesis, twelve reported that they did not experience or remember any particular side effects while on the pill. As Williams 
expressed it, "I thought [the pill] was a wonderful thing." A few women even felt that

the birth-control pill had beneficial side effects. Some, like Emily Wood, speculated that

the pill may have increased their libidos ${ }^{6}$ while others reported that the pill helped

regulate their menstrual cycles and decrease their periods. ${ }^{7}$ A study by Dr. William G.

Francis, a gynecologist at the Grace Hospital in Toronto, cited in the April 1965 issue of

Chatelaine magazine, confirmed that many women reported shorter and more regular

periods. ${ }^{8}$ Thirty-five, out of 150 , added that they thought they enjoyed sex more.

Suggesting an even broader impact on her life, Lynch found that the pill actually

decreased the migraines that had plagued her during her two pregnancies. ${ }^{9}$

Thus, for some women, the pill had benefits apart from contraception.

Nevertheless, many more remember negative side effects, complicating the pill's status

as a problem-solving, miracle drug. While some were perceived as minor

\footnotetext{
${ }^{5}$ Interview with Lucy Williams, October 8, 2009, 15.

${ }^{6}$ Interview with Emily Wood, July 6, 2009, 15. Other sources have outlined this experience. See Lara V. Marks, Sexual Chemistry: A History of the Contraceptive Pill (New Haven: Yale University Press, 2001), 209; C.A. Douglas Ringrose, "The Emotional Responses of Married Women Receiving Oral Contraceptives," Canadian Medical Association Journal 9223 (June 5, 1965), 1208. Ringrose sent questionnaires to one hundred married women taking norethindrone $2 \mathrm{mg}$. with mestranol $0.1 \mathrm{mg}$. In this sample, $22 \%$ reported an increase in their libidos. See Appendix 2 for information on this and other studies cited in this thesis.

${ }^{7}$ Interview with Judy Meyer, October 8, 2009, 14; Interview with Jane Lynch, October 6, 2009, 15, 29-30; Interview with Jane Arsenault, March 2, 2010, 8; Interview with Isabelle Lowe, April 27, 2010, 13-14; Interview with Annie Beck, November 6, 2009, 28; Interview with Mary Jones, December 3, 2009, 11 ; Interview with Ellen Carter, February 12, 2010, 15; Interview with Lydia Stevens, November 20, 2009, 89.

${ }^{8}$ Constance Mungall, "Birth Control in Canada Today," Chatelaine 38, 4 (April 1965), 48-9. Francis "studied 150 women who took the pills for an average of ten menstrual cycles each." He found that "eighty-five percent were very happy with them. Their periods were more regular, shorter, decreased in flow, and preceded by less tension." This is not the only study to report shorter periods. See, for example, K.M. Crocker, M.D. and W.D. Stitt, M.D., "Ovulation Inhibitors," Canadian Medical Association Journal 90, 12 (March 21, 1964), 713-716. Crocker and Stitt looked at 185 women, ranging in age from 19 to 44, using Ortho-Novum. In this study, as well as that of Ringrose, cited above, the Ortho-Novum was provided by the drug company, Ortho Pharmaceutical (Canada) Ltd. As discussed in Chapter 1, pharmaceutical firms gave Dr. Pincus compounds to test in his efforts to develop a contraceptive pill, suggesting this may have been common practice. Further research into the involvement of the Canadian drug industry in clinical trials of contraceptives would be useful. For details of these and other studies, see Appendix 2. ${ }^{9}$ Lynch, 16, 21, 25, 30.
} 
inconveniences, others were more problematic. Generally, many women were strongly motivated to remain on the pill and often tenaciously endured a variety of issues.

According to American historian Andrea Tone, in the 1960s, a majority of women who went on the pill remained on it because they felt its advantages offset its risks. ${ }^{10}$ Indeed, "many women were prepared to put up with very debilitating side-effects because of the benefits that the pill promised."11

While Wood, above, claimed that the pill may have increased her sex drive, other women reported a decrease in their libidos. ${ }^{12}$ Elizabeth Thompson, for one, identified this as a problem because she felt a good sexual relationship is important in a marriage. ${ }^{13}$ Olivia Klein went even further and blamed the break-up of her first marriage on, in part, the loss of sexual desire she experienced while on the pill. ${ }^{14}$

Nausea, especially initially, was a common occurrence. ${ }^{15}$ Eva Green likened it to morning sickness and said, for her, it only lasted a few months. ${ }^{16}$ This nausea, along with other symptoms of early pregnancy such as dizziness, headaches, swollen feet, breast discomfort and weight increase could "hit a woman first when starting the pill."17

\footnotetext{
${ }^{10}$ Andrea Tone, Devices and Desires: A History of Contraceptives in America (New York: Hill and Wang, 2001), 245; Elizabeth Siegel Watkins, On the Pill: A Social History of Oral Contraceptives 1950-1970 (Baltimore: Johns Hopkins University Press, 1998), 101.

${ }^{11}$ Marks, 208.

${ }^{12}$ Interview with Elizabeth Thompson, June 11, 2009, 22; Interview with Emma Edwards, April 12, 2010, 18-19, 22-23; Interview with Caroline Morrison, March 9, 2010, 18, 25; Interview with Olivia Klein, October 20,2009, 13; Marks, 134 and 209; Ringrose, 1208. Ringrose notes that, in his sample of 100 married women, thirteen reported a drop in libido while taking oral contraception. Of these thirteen, six also had other side effects.

${ }^{13}$ Thompson, 22.

${ }^{14} \mathrm{Klein}, 23$. The pill's role in sexuality will be discussed in more detail in Chapter 6 which explores the multi-faceted impact of the contraceptive.

${ }^{15}$ Junod and Marks, 143; Interview with Margaret Wilson, August 12, 2009, 10; Interview with Beverley Brooks, October 19, $2009,7$.

${ }^{16}$ Interview with Eva Green, June 23, 2009, 3.

${ }^{17}$ Constance Mungall, "The Pill and Its Side Effects Today," Chatelaine 39, 11 (November 1966), 118. The study by Drs. Crocker and Stitt found that 17 of 185 women who began two-milligram Ortho Novum discontinued it because of these "pseudopregnancy" symptoms.
} 
Stevens found the nausea particularly disruptive and thought it once interrupted her work day. ${ }^{18}$ While she stayed on the pill for three years, ${ }^{19}$ other women decided to go off the pill because of persistent nausea. ${ }^{20}$ In Francis' study, cited above, for example, twelve of the 150 women discontinued pill use because of nausea, vomiting and bleeding. ${ }^{21}$ For these women, these symptoms were not inconsequential and clearly negated the pill's attractive properties.

Women could also experience bloating and weight gain on the pill. ${ }^{22}$ However, some did not seem to remember these as major issues. ${ }^{23}$ Summing up this attitude, Brown stated "it wasn't a major problem and I guess I expected a little bit of edema."24 Even more positively, one Chicago housewife, quoted in the Saturday Evening Post, dismissed the issue saying "Oh, I know, I've put on a little weight since I started on the pill...but I think it's just from contentment."25

Other women recalled these same side effects as more significant. Weight gain alone could be troubling. Beck, for instance, found it disconcerting that she gained twenty-five pounds on the pill and could not seem to lose it. When her doctor switched her to another pill, she at least stopped gaining weight. ${ }^{26}$ Canadian women were not alone in suffering from these sorts of problems, as evidenced in the work of American historian Andrea Tone. She interviewed Elizabeth Linden, a mother of three, who started

\footnotetext{
${ }^{18}$ Stevens, 9-10.

${ }^{19}$ Ibid., 11.

${ }^{20}$ Junod and Marks, 143.

${ }^{21}$ Mungall, 1965, 49.

${ }^{22}$ Tone, 233 and 235.

${ }^{23}$ Wood, 16; Interview with Penelope Dobos, July 7, 2009, 4 and 3; Morrison, 17 and 34; Interview with Susan Brown, August 7, 2009, 23.

${ }^{24}$ Follow-Up Interview with Susan Brown, December 11, 2009, 1.

${ }^{25}$ Steven M. Spencer, "The Birth Control Revolution," Saturday Evening Post, January 15, 1966, 21. Cited in Tone, 235.

${ }^{26}$ Beck, 13,15 and 19.
} 
on the pill in 1960 , and was plagued by headaches, bloating and weight gain. Linden told Tone "I remember that I was very uncomfortable on...[the pill] at first, that it was terrible...[however] I never stopped...I was afraid that if I went back to another method of birth control, then we'd get pregnant. ${ }^{\text {27 }}$ Unlike Linden, Harrison's bloating became an issue over time and was accompanied by increasing blood pressure and migraines. As a whole, these problems caused her to go off the pill in $1975 .{ }^{28}$ Thus, like nausea, bloating and weight gain were tolerated by some women, especially if mild, but also could be enough for others to stop taking the pill.

The pill could also affect menstrual cycles and fertility both while women were on it and when they went off. According to Barbara Seaman, journalist and author of The Doctors' Case Against the Pill, the contraceptive could cause "lighter periods, heavier periods, missed periods and spotting or staining." ${ }^{, 29}$ As mentioned above, many found that the pill regulated or made their periods lighter. According to Jones, "my periods were not irregular but they were very, very heavy and it helped control the bleeding." 30 However, not all women appreciated this side effect. Taylor was disconcerted when her periods stopped altogether and got the doctor to change the pill so this wouldn't keep happening. Once he did, she had regular periods. ${ }^{31}$ The pill could disrupt a woman's reproductive system in other ways. A few actually thought they remembered somewhat heavier periods on the pill ${ }^{32}$ whereas Koch reported more persistent heavy bleeding

\footnotetext{
${ }^{27}$ Tone, 233-234 and 343, note 2 . Linden is a pseudonym.

${ }^{28}$ Interview with Cindy Harrison, January $25,2010,10,13,14$ and 17.

${ }^{29}$ Barbara Seaman, The Doctors' Case Against the Pill (New York: Peter H. Wyden, Inc., 1969), 203.

${ }^{30}$ Jones, 11 .

${ }^{31}$ Interview with Olivia Taylor, August 6, 2009, 5-6.

${ }^{32}$ Interview with Jean Watson, November 3, 2009, 11 ; Dobos, 4; Interview with Cynthia Young, February 8, 2010, 8-9.
} 
which forced her off the pill. ${ }^{33}$ Problems with periods while on the pill were not limited to bleeding. Wright stated that "I had terrible ...[cramping] with my periods when I first started on the pill. The doctor changed my prescription after about 6 months to the pills where you had 3 weeks of one type and the last week on the other, and reduced the dosage strongly from the usual. I did not consider going off the pill, because the side effects were relieved with the different prescription." ${ }^{34}$

As discussed in Chapter 2, many women valued the effectiveness and reliability of the pill as a contraceptive. However, they also planned to start or complete their families at some point in the near future. They hoped to go off the pill and get pregnant quickly. Though, by and large, the pill facilitated such choices and planning, a few women felt it adversely affected their fertility. Diane Galli went on the pill in 1968, before her wedding. After approximately five years, her doctor informed her that, due to the pill, her ovaries had shrunk and, if she wanted to have children, she should go off for a couple of months. She did so and; apparently, her ovaries rebounded. She then resumed pill use for about a year before deciding to get pregnant. ${ }^{35}$ This particular, and somewhat alarming, problem was not mentioned by anyone else in my sample or in the secondary literature. While Galli and the majority of the women in my sample had no trouble getting pregnant after the pill, a few women reported difficulties with their fertility post-pill. ${ }^{36}$ Most seriously perhaps, Ruth Wright struggled with infertility for years before conceiving her son. She wondered "if I would have gotten pregnant more easily and been able to have more than one child if I had never gone on the pill. With 20-

\footnotetext{
${ }^{33}$ Interview with Vivian Koch, January 21, 2010, 12 and 17.

${ }^{34}$ Email correspondence from Ruth Wright, July, 2009, 3.

${ }^{35}$ Interview with Diane Galli, December 8, 2009, 5, 10-13.

${ }^{36}$ Edwards, 10, 12-13; Stevens, 13.
} 
20 hindsight, I can now say that if I had believed that the pill could cause infertility or difficulties getting pregnant, I wouldn't have used it. But...I don't remember any warnings about the pill impacting fertility."37 A 1966 article in Chatelaine confirmed that sometimes the pill could delay ovulation for a few months..$^{38}$ In her book on the pill, Barbara Seaman discussed cases of post-pill sterility which lasted much longer and even suggested the condition could be permanent for some women. ${ }^{39}$ Thus, the pill could, somewhat ironically and unfortunately, continue to prevent conception even when pregnancy was desired. In this way, it had an unexpected but significant effect on women's lives.

Recurrent yeast infections were also a problem which forced some women to go off of the pill or, at least, change their prescriptions. ${ }^{40}$ Jackson found that her occasional yeast infections got much worse when she was on the pill for about two years. After a number of treatment attempts failed, it was recommended that she go off the pill for three months so the infections could be cleared up. Jackson did so and, though using a contraceptive foam, got pregnant during this period. ${ }^{41}$ Seaman affirms in her 1969 book that such infections were common among pill users. ${ }^{42}$ Again, yeast infections, though not life-threatening, were certainly irritating and disruptive for women and represent yet another example of the pill's pervasive impact.

Headaches, as mentioned at the start of the chapter, were among the side effects reported by Puerto Rican women taking the first pill. Canadian women involved in early

\footnotetext{
${ }^{37}$ Wright, email, 3.

${ }^{38}$ Mungall, 1966, 120.

${ }^{39}$ Seaman, 145-150.

${ }^{40}$ Brooks, 8 and 10.

${ }^{41}$ Interview with Ellen Jackson, October 23, 2009, 3, 8-9, 12.

${ }^{42}$ Seaman, 20.
} 
clinical trials also said they experienced headaches. ${ }^{43}$ In the 1960 s, migraines were also associated with the pill. For instance, two doctors, in 1967 and 1968, wrote to the Canadian Medical Association Journal reporting that women on the pill, with no previous history, developed these severe headaches. ${ }^{44}$ Migraines have the potential to seriously disrupt one's work and home life. Many women complained of headaches on the pill which could range from mild annoyances to debilitating migraines. Stevens remembered headaches, as well as weight gain, bloating and nausea caused by her pill use. Though she "accepted [side effects were ]...the price you paid for convenience...and security," Stevens did become anxious after three years to get off the pill since she did not feel optimum. ${ }^{45}$ Other women, while finding the headaches in particular more disruptive and intrusive in their lives, also chose to stay on the pill. A surprising number of women either tolerated or attempted to tolerate serious migraines because they valued the pill as birth control. Jones, for example, had always had migraines and they continued on the pill. She first went on the pill in about 1966 and began to experience regular headaches after about a year. Thereafter, every couple of months, she would get a particularly bad migraine and would have to spend time in a darkened, quiet room. At the time, she was fairly certain that the pill was contributing to this problem but she stayed on until 1971 when she wanted to get pregnant. She then resumed pill use between her two children and for a brief time after her daughter was born in 1973. The

\footnotetext{
${ }^{43}$ See for example, Morris P. Wearing, "The Use of Norethindrone $(2 \mathrm{mg})$ with Mestranol $(0.1 \mathrm{mg})$ in Fertility Control: A Preliminary Report," Canadian Medical Association Journal 89, 6 (August 10, 1963), 240. This study began in January of 1962 and tracked 62 patients taking Ortho-Novum. See Appendix 2 for information on other studies.

${ }^{44}$ Letter by P.E. Hoogewerf, "Migraine and Oral Contraceptives," Canadian Medical Association Journal 97, 16 (October 14, 1967), 978-979; Letter by Martin S. Kazdan, "Migraine and Oral Contraceptives," Canadian Medical Association Journal 98, 3 (January 20, 1968), 175. For more details on these cases, see Appendix 2.

${ }^{45}$ Stevens, 9-10 and 14.
} 
headaches always came back and, in 1973, having completed her family, she went off the pill and her husband had a vasectomy. ${ }^{46}$ Ryan also persisted on the pill for six years despite experiencing migraines. She did eventually go off because of the headaches. ${ }^{47}$

Like Jones and Ryan, Stewart experienced headaches on the pill but doggedly persisted in using it. Stewart tried the pill on and off for a period of about two years in the early sixties, and experienced headaches as well as pain in her legs. She said, "I could hardly walk when it was time for my period to come...I can't tell you exactly how long I took [the pill]...but I had the worst headaches, oh my goodness, that was terrible. But I'd have a headache when it was time for my period to come." Stewart found the headaches, as well as the effect on her mood, to be discussed below, very disruptive. The headaches and leg aches came predictably each month before her period and she knew the pill was the cause. She had never experienced either problem before and both were quite debilitating. The headaches forced her to stay in bed and she had to apply heat or rub her legs to ease the pain. ${ }^{48}$ Ultimately, Stewart had to stop taking the pill because of her side effects.

Reid similarly put up with a great deal to stay on the pill. She had never had migraines before the pill but they hit her very hard while on it. She can "remember having to have someone drive my car home from South Carleton in the middle of the day because I couldn't see and I had to leave. I mean my stomach would...I would throw up and throw up and throw up. The migraine would be so bad and the light would be so

\footnotetext{
${ }^{46}$ Jones, 4, 7, 8-10, 14, 15.

${ }^{47}$ Interview with Anne Ryan, October 27, 2009, 12 and 17.

${ }^{48}$ Interview with Eileen Stewart, August 18, 2009, 7, 8, 18-19, $21-22$.
} 
bright." For her, as for Stewart, the headaches came predictably at certain times in her menstrual cycle. ${ }^{49}$

A similar pattern is described in a 1966 Chatelaine article which recounts that "two patients of Dr. Ian Rose, of Kamloops, B.C. developed wracking headaches on the second or third day after they stopped the pill at the end of a cycle...and the headaches continued on and off until two or three days after they began the pill again for the next cycle." ${ }^{50}$ Reid recalled that her gynecologist told her the headaches were caused by the pill and that she should go off it. However, Reid did not because she valued the spontaneity and security offered by the pill as birth control. She stayed on the pill for three years, until she wanted to get pregnant. ${ }^{51}$ Though she never went back on the pill again, Reid continued to have headaches with her periods. ${ }^{52}$ Finally, Richards had several side effects but, like other women, she found the migraines to be the worst. With them, she was nauseous and had an aura. Richards was on the pill three or four times in the 1960s and 1970s and always had migraines which seemed to start each time after a few months on the pill and worsen. She connected them to the pill even if, as I will discuss in the next section, her family doctor in the mid-1960s, did not. Ultimately, her doctor told her she should not be on the pill because of her migraines and she went off for good. $^{53}$ Jones, Ryan, Stewart, Reid and Richards were remarkably tenacious in continuing on the pill despite its profound effect on their health and well-being. They

\footnotetext{
${ }^{49}$ Interview with Beth Reid, November 18, 2009, 8 and 14.

${ }^{50}$ Constance Mungall, 1966, 39, 119.

${ }^{51}$ At one point, eager to stop the migraines, Reid did try an IUD but it came out within minutes of insertion.

${ }^{52}$ Reid, 9,14 and 18.

${ }^{53}$ Interview with Alice Richards, December 7, 2009, 7-10, 12 and 19; http://www.merriamwebster.com/medlineplus/aura. An aura is "a subjective sensation (as of voices or colored lights or crawling and numbness) experienced before an attack of some nervous disorders (as epilepsy or migraine)." Richards does not specify how her aura manifested.
} 
were willing to endure very bad headaches because they so valued the pill as a contraceptive.

In contrast, other women had migraines too but they chose not to tolerate this side effect for as long. ${ }^{54}$ Harrison had no side effects at all when she was first on the pill in about 1967 . Nor did she have any problems when she resumed pill use after her daughter was born in 1968. However, beginning in 1971, her doctor noticed that her blood pressure was increasing. Accompanying this trend, Harrison developed migraines and bloating. At the time, her doctor said the migraines might be because of her high blood pressure and the pill. Harrison had never had migraines before and decided to go off the pill in $1975 .^{55}$ Thus, not all women reacted the same way to the same side effect. While some endured headaches or migraines, others were more willing to give up the pill.

In the $1960 \mathrm{~s}$, there were reports that the pill, rather than alleviating pre-menstrual tension, irritability and nervousness as some of its promoters promised, could actually cause depression or other psychological problems. ${ }^{56}$ However, some doctors were, at first, unconvinced by these claims because they often saw women experiencing mood fluctuations during the normal course of menstruation, pregnancy and menopause. According to Marks, and based on medical testimony from the Nelson hearings, women themselves were often unsure while "Others who recognized feeling more tired, depressed and irritable as a result of the drug continued to take it because they felt its contraceptive benefits outweighed its disadvantages." $" 57$ Several women interviewed did feel that the pill had an adverse effect on their mood. This once again demonstrates the

\footnotetext{
${ }^{54}$ Interview with Charlotte Dawson, November 5, 2009, 12-13.

${ }^{55}$ Harrison, 10, 12, 17 and 13.

${ }^{56}$ Seaman, Chapters 15 and 16 . In these chapters, Seaman's sources include interviews with women and doctors (including psychiatrists) as well as articles from medical journals.

${ }^{57}$ Marks, 133-134.
} 
pill's ability, as a medication, to influence a woman's life in ways quite unconnected with sexuality and reproduction. Again, as with physical side effects, psychological problems could range from mild to severe. At one end of the spectrum, for example, Brown wondered if the pill might have made her more emotional in the early years of her marriage. $^{58}$

Other women were more certain that the pill had a definitive and negative impact on their psyches. ${ }^{59}$ A study by Britain's Medical Research Council, cited in a 1968 issue of Chatelaine magazine, found that about ten percent of women who went on the pill became depressed. ${ }^{60}$ In my sample, Edwards remembered that she felt more moody and a little depressed during her first time on the pill from 1965-1967. She noticed an improvement in her mood when she went off the pill to get pregnant and, when she resumed pill use after her son was born in 1968, her depression seemed more pronounced. During her third time on the pill in 1970, following the birth of a daughter, Edwards again experienced adverse changes in her mood. At this time, she made the decision to go off the pill. ${ }^{61}$ Unlike Edwards, Beck chose to remain on the pill for a few years despite its "dampening effect" on her mood. This impact did lessen when she was switched to a tricyclic pill. ${ }^{62}$

For some women, the pill had a more immediate and detrimental impact on their psyches and they, like Edwards, were driven off it. Wood, for example, experienced sadness and irritability. She said, "I was Dr. Jekyl and Mr. Hyde...I described it as

\footnotetext{
${ }^{58}$ Brown, 4 and 10.

${ }^{59}$ Richards, 7 and 9.

${ }^{60}$ Earl Damude, "What's New: Health," Chatelaine 41, 4 (April 1968), 18. However, in this study, ninety percent reported an improvement in their mental states.

${ }^{61}$ Edwards, $10,17-18$ and 22.

${ }^{62}$ Beck, 12, 13, 15, 18-19.
} 
having like the devil inside me...making me just feel horrible and mean...crabby...out of control." Wood noted she did not feel this way when off the pill. ${ }^{63}$ Describing a similar effect, Eileen Stewart asserted that on the pill she was in a bad mood all the time. Indeed, she "hated everybody and everything." Stewart also suffered headaches and leg pains while on the pill, as described above, but she emphasized the impact on her mood was as, or perhaps even more, troubling to her. She said "I knew that it was driving me crazy. I had to get off it." ${ }^{, 64}$ An unnamed woman, cited in a 1966 Chatelaine article, echoed Stewart. She said "I couldn't stand myself, my husband, or my children." This particular woman was reportedly much happier when she returned to a diaphragm. ${ }^{65}$ Thus, for some women, the pill's advantages were offset by its adverse effect on mood and temperament.

Unfortunately, it was not uncommon for women on the pill to be plagued by nausea, headaches, bloating and even mood disturbances, as I have discussed. This analysis of side effects would be quite enough to demonstrate how the pill, more than other contraceptives, reached beyond the bedroom and into every corner of a woman's life. However, there are a few other problems which were or may have been associated with the pill and, though not as common, contribute to this argument. As with nausea and headaches, these problems existed on a continuum, ranging from bothersome to debilitating. At one end, Macdonald was disconcerted by her difficulty with breastfeeding. She had resumed pill use in 1967 after the birth of her daughter and did not realize that the hormones in the pill could decrease her milk supply. Only when she mentioned her struggles with nursing to her doctor, did he tell her about the pill's impact

\footnotetext{
${ }^{63}$ Wood, 15,4 and 6.

${ }^{64}$ Stewart, 9,10 and 15.

${ }^{65}$ Mungall, 1966, 120.
} 
on breast-feeding. Interestingly, Macdonald chose to continue taking the pill and switched to formula feeding rather than giving up the pill so she could more successfully breast-feed. $^{66}$

While Macdonald was irritated by her difficulty breast-feeding, Campbell was much more disconcerted as the pill immediately caused debilitating fatigue, dizziness and faintness. In her words, "I really felt so wiped out and...sort of faint and dizzy...I mean I can remember being at the cottage and having to lean against the wall to get along to the bathroom and my mother having to keep an eye on the kids. Well, you can't go on like that." Due to these symptoms, she promptly went off the pill and never tried it again. ${ }^{67}$ Obviously, the pill had a significant and negative effect on her ability to function as a mother.

Finally, Clarke also had a more atypical side effect which shaped, in some ways, her life as a newly-married woman. She began taking the pill in 1967 , shortly before her wedding. Within days, she developed bladder control issues, specifically some leakage and a frequent need to urinate. ${ }^{68}$ Her doctor diagnosed a possible bladder infection but when the symptoms persisted he sent her to an urologist who declared that she was simply a nervous bride. Following her wedding, and in a new city, a second doctor and a second urologist again failed to find anything wrong. The latter particularly upset her by insisting her problems were psychological in nature. Since no doctor ever mentioned it, it did not occur to Clarke that her bladder control issues might be linked to the pill. She

\footnotetext{
${ }^{66}$ Interview with Claire Macdonald, March 11, 2010, 17-19.

${ }^{67}$ Interview with Deborah Campbell, February 9, 2010, 11, 12 and 18; Mungall, 1965, 49. In Francis' study of 150 women, five stopped taking the pill "because of complaints like depression, fatigue or dizziness."

${ }^{68}$ I did not come across a discussion of this particular problem in my reading of the Canadian Medical Association Journal, Barbara Seaman's book or the secondary literature. However, this does not mean it was not a side effect of the pill. Perhaps it was simply not that common or well-known in the 1960s.
} 
continued to take it and suffered these side effects until she went off to get pregnant in 1968. Then, about six months later, she read in the newspaper that the brand of pill she had been on was being removed from the market because of the very side effects she had endured. ${ }^{69}$ Thus, Clarke took the pill every day not knowing that it was casting something of a pall over her life as a young, married woman.

In the 1960s, blood clots were perhaps the most serious, publicized problem associated with pill use. They could lead to permanent disability and even death. ${ }^{70}$ By 1961, G.D. Searle, the maker of the first birth-control pill Enovid, had "amassed 132 reports of thrombosis and embolism in pill takers and a record of 11 deaths possibly attributable to the pill." ${ }^{\text {"11 }}$ Possibly to show concern and transparency, Searle sponsored "a one-day conference at the American Medical Association headquarters in Chicago in September 1962." Thirty doctors and scientists, including Pincus and Rock, were to determine if, based on the available data, the pill caused thromboembolism. Ultimately, the group decided that the "evidence did not indicate a causal relationship between Enovid and thromboembolism." ${ }^{, 72}$ Nevertheless, cases would continue to be reported throughout the $1960 \mathrm{~s} .{ }^{73}$ However, "These preliminary warnings and concerns about the safety of the pill were swiftly eclipsed in 1961 and 1962 when the worldwide scandal over thalidomide broke."74 Additionally, it was at first difficult to confirm an association between the pill and an increased risk of blood clots. Only in 1967 did a report published

\footnotetext{
${ }^{69}$ Interview with Cheryl Clarke, November 12, 2009, 10, 14, 11 and 22.

${ }^{70}$ Seaman, Chapters 6 and 7.

7 Sethna, 2001.

${ }^{72}$ Watkins, 80-82.

${ }^{73}$ Ibid., 82; Gordon, 332; Letter by Michael J. Brindle, M.D. and I. Nigel Henderson, "Vascular Occlusion of the Colon Associated with Oral Contraception," Canadian Medical Association Journal 100, 14 (April $12,1969), 681-2$. In one example, Brindle and Henderson describe the case of Mrs. D.Q., a presumably married woman, who was on Enovid and presented with an unusual colon condition, probably caused by a venous thrombosis. The writers speculate about the role of Enovid in her case.

${ }^{74}$ Junod and Marks, 154. For more on thalidomide, see Chapter 5.
} 
in the British Medical Journal persuasively make this link. ${ }^{75}$ A report on the pill by the American Food and Drug Administration, released in 1969, confirmed that women who took the pill were four and a half times more likely to develop thromboembolism. ${ }^{76}$

As I will discuss in the next chapter, many of my informants did hear in the 1960 s or 1970s about the increased risk of blood clots while on the pill and a few even personally knew women who had suffered strokes. Two women had such problems themselves. The first, Doyle, had been on the pill with no major issues from 1964 to 1967. She resumed pill use again after the birth of her third child in 1968 but had to stop in the spring of 1974 when she developed a blood clot. She had to go on blood thinners and her doctor advised her to go off the pill. The clot was resolved at this time. ${ }^{77}$ Perhaps because of the nature of the clot and the fact that it was addressed without issue, Doyle does not seem to consider this a major event in her life.

Ellen Jackson was not so lucky in her experience with a blood clot. In 1973, Jackson was a twenty-three-year-old married woman with a young son. She had been on the pill before, from 1968-1971, and had gone off because of persistent yeast infections (see above). After her son was born in 1972, Jackson resumed pill use with seemingly no problems. However, thirteen months later, in July of 1973, she woke up with a terrible headache and suffered a significant stroke later in the day. Initially, she was paralyzed on the right side of her body and had very blurry vision. Jackson was in the hospital for two and a half weeks. Though her mobility returned within a few hours, she was ultimately left with no right peripheral vision in either eye. Doctors told her immediately she could

\footnotetext{
${ }^{75}$ Watkins, 89; Elaine Tyler May, America and The Pill: A History of Promise, Peril, and Liberation (New York: Basic Books, 2010), 128; Marks, 141-144.

${ }^{76}$ Watkins, 90.

${ }^{77}$ Interview with Eleanor Doyle, November 30, 2009, 7 and 13.
} 
never drive, have more children or take the birth-control pill again. ${ }^{78}$ The impact of this stroke on her life will be discussed more in Chapter 5 but obviously the pill and its side effects had far-reaching consequences for her. No convenience or reliability afforded by the pill could compensate her for what it took away.

With side effects ranging from lighter periods to blood clots, it becomes clear there was no single or monolithic experience of the pill for Canadian women in the 1960s and 1970s. While some remember only a very effective contraceptive, most women report at least one problem or issue. It may have only been a minor inconvenience or, for the less fortunate, a major disruptive event which had significant repercussions on their lives. Nevertheless, the extent and range of side effects demonstrates that the birthcontrol pill was by no means the perfect contraception. While it may not have intruded upon sexual activity as much as the condom or diaphragm, these other methods did not come with side effects which could potentially follow women throughout their lives. Dealing with Side Effects

In the previous chapter, I discussed whether or not doctors warned their patients or discussed in any way the possibility of side effects when initially prescribing the pill. However, once women did experience problems, how did they deal with them? American historians provide some insight into this question but there is little literature on Canadian women. I have already mentioned that some women chose not to endure these disturbances. ${ }^{79}$ In fact, according to a 1966 article in Chatelaine, approximately one quarter of a million Canadian women "have taken oral contraceptives for one to six months and then stopped. Some of them stopped to have children but, for most, the

\footnotetext{
${ }^{78}$ Jackson, 14-15, 16, 17, 19, 21 and 22.

${ }^{79}$ Marks, 208-209. Marks found the same thing in her study.
} 
unpleasant side effects of the pill outweighed the obvious advantages." ${ }^{.80}$ This section will now turn to a deeper analysis of how women dealt with and understood side effects, beginning with their interactions (or lack thereof) with the medical profession before turning to any discussions with friends, family or their husbands.

By the early 1960s, "the [pharmaceutical] industry had acknowledged that all pharmaceutical preparations had some side effects, [however] these were typically considered unavoidable nuisances. ${ }^{, 81}$ Despite this recognition from the manufacturers of at least the possibility of problems with drugs in general, during the $1960 \mathrm{~s}$ and into the 1970s, the medical community was engulfed in a debate over the safety of the pill and its side effects. ${ }^{82}$. In part, the debate over side effects began during the pill's early human trials when issues such as vomiting, nausea, dizziness and headache were considered by clinicians as "psychogenic." ${ }^{83}$ There was also initial resistance within the medical community to the idea that the pill, promoted as enhancing female sexuality, could actually have a detrimental effect on a woman's libido. This particular issue was not taken seriously until 1970 . While at least certain side effects became more acknowledged in the 1960 s, some doctors were concerned that full disclosure of them to patients would result in imagined problems, particularly given the lingering stereotype of women as prone to emotional disruptions. ${ }^{84}$ Indeed, "Those considered to be anxious and worried

\footnotetext{
${ }^{80}$ Mungall, 1966, 117-118. This article also says that, in 1966, there were almost one million Canadian women on the pill. It is hard to determine exact proportions as Mungall does not provide a date range for the quarter of a million going off the pill but it would seem that if one million remained on it in 1966, more women must have found it acceptable than not. In my sample, one woman did discontinue the pill after only a month or so because of side effects.

${ }^{81}$ Jordan Goodman, "Pharmaceutical Industry," in Medicine in the Twentieth Century, eds. Roger Cooter and John Pickstone (Amsterdam: Harwood Academic Publishers, 2000), 151-152.

${ }^{82}$ Sethna, 2001; Watkins, 73-102; Seaman.

${ }^{83}$ Marks, 133; http://www.merriam-webster.com/medlineplus/psychogenic. Psychogenic is defined as "originating in the mind or in mental or emotional conflict."

${ }^{84}$ Marks, 133-135; Seaman, 11 .
} 
were thought liable to exaggerate anything that was slightly wrong and were therefore not recommended to be prescribed the pill., ${ }^{, 85}$ In addition, doctors disagreed over the actual risks posed to women. While some began to shy away from the pill, others continued to be comfortable prescribing it. ${ }^{86}$

Reflecting this uncertainty over side effects, as discussed in Chapter 3, the federal government established a committee to examine the safety and effectiveness of the pill and communicate its findings to the Food and Drug Directorate. Its 1970 report discussed the existing research on a comprehensive range of potential side effects. Though the committee agreed that some concerns, like those surrounding blood clots, were substantiated by studies, it found itself unable to confirm any conclusive link between the pill and cancer. Ultimately, the committee concluded that "on a lifetime basis, the total mortality or risk to life presented by the use of various methods of birth control is lower for oral contraceptives than other means of contraception or no contraception." 87 Subsequent reports by this committee in 1975 and 1978 continued to consider the pill's side effects, highlighting the unresolved nature of the question. ${ }^{88}$ Therefore, one must place the interactions of Canadian pill-users and their doctors within this context of the ongoing medical debate over side effects.

Additionally, the pill itself had changed the doctor-patient dynamic, as discussed in Chapter 3. Partly thanks to the existence of the pill, women now more openly asked

\footnotetext{
${ }^{85}$ Marks, 133.

${ }^{86}$ Seaman, $21-23$ and 31.

${ }^{87}$ Report of The Special Committee appointed by The Minister of National Health and Welfare to Advise The Food and Drug Directorate on all Aspects of the Safety and Efficacy of Oral Contraceptives Marketed in Canada, October 1970, Rx Bulletin, Special Issue, December, 1970, 40-43.

${ }^{88}$ Report of the Special Committee Appointed by The Minister of National Health and Welfare to Advise the Health Protection Branch on All Aspects of the Safety and Efficacy of Oral Contraceptives Marketed in Canada, Second Report, February 1975, Rx Bulletin Volume 6, Supplement 1 (1975), 14-37; Report of The Special Advisory Committee on Reproductive Physiology to The Health Protection Branch, March 1978, 69.
} 
their physicians about contraception and even requested the pill, sometimes quite forcefully. In doing so, they became more active consumers of health care, rather than passive patients. ${ }^{89}$ The existing literature shows that, in this role, and given reports of side effects, women began to solicit more information from their doctors about the pill. Often this led to "frustrating interactions...in the absence of definitive data on the health effects of the pill. ${ }^{, 90}$ Also, some doctors, concerned about preserving their authority, resisted sharing knowledge on demand with patients. ${ }^{91}$ Therefore, a discussion about side effects in the doctor's office must also be understood in light of women's new assertiveness with the medical profession.

Historians, in Canada or elsewhere, have not examined these interactions extensively. Thus, my sample provides a unique opportunity to do so. Most who developed side effects did seek medical advice or at least raised the issue with their doctors. However, a few did not. Stevens, for example, experienced bloating, weight gain, headaches and nausea during her first episode on the pill from 1964-1967. She "accepted that was the price you paid for convenience...and security" and never complained to a doctor. She suggests that people did not do this as much at the time and, somewhat in jest, says that "you were attune to suffering more than we are now." Perhaps as well she did not want to be labeled a difficult or demanding patient. ${ }^{92}$ Mason,

\footnotetext{
${ }^{89}$ See Chapter 3. However, as mentioned in Chapter 1 , it is important not to present this as completely novel behaviour. Wendy Mitchinson's interesting work demonstrates that Canadian women in the nineteenth century were actively engaged in their own health care.

${ }^{90}$ Watkins, 100-102; May, 5 and 130.

${ }^{91}$ Watkins, 102, 116-117 and 125 . However, Watkins points out that women could also ignore or reject the warnings of concerned physicians. For an example of this dynamic, see pages 166-167.

${ }^{92}$ Stevens, 4, 9-10 and 12. For more on doctors' attitudes towards patient concerns, see Chapter 5.
} 
on the other hand, did not connect the side effect she had (vaginal dryness) with the pill and, therefore, never mentioned it to a doctor either. ${ }^{93}$

Physicians, both gynecologists and family doctors, who were approached by women about side effects generally did try to help them. Often, this would take the form of adjusting the dosage or type of birth-control pill in an attempt to alleviate side effects. ${ }^{94}$ As Junod and Marks explain, "Investigators worldwide soon learned that a much lower does of hormones would effectively suppress ovulation just as well as the higher dose. Moreover, the lower doses produced fewer side effects (other than bleeding)." In my sample, Wright, once on the pill, had pain with her period. So, after about six months, she returned to her gynecologist who "changed the prescription to the one that was...seven days of a different hormone. I mean it was three weeks of one and one week of another. And...it was a lower dosage and she told me that it would solve the problems of the pain and it did so then from there on it, I didn't worry about it."96 Thus, Wright was quite satisfied with her doctor's response in this case. Similarly, Taylor was concerned because, after going on the pill, her periods ceased altogether. She waited several months and then returned to her family doctor because the lack of any menstruation made her uneasy. According to her, "[the doctor] said, well, let's change the pill that you're taking and he gave me a different one and it worked just fine."97

\footnotetext{
${ }^{93}$ Interview with Caroline Mason, July 29, 2009, 5. At some point, Mason must have decided the vaginal dryness was linked to the pill because she disclosed it to me when I asked about any problems with the contraceptive during the interview.

${ }^{94}$ Many women remember that such adjustments were made but are unclear on whether it was the dosage or brand that was changed. Report of the Special Committee, 1975, 13-14. The 1975 report mentioned that the pill might need to be modified in the event of amenorrhea (absent periods) or vaginal bleeding. By 1970, fifteen brands, with varying doses, were available in Canada. See Report of The Special Committee, 1970,7 .

95 Junod and Marks, 143; Tone, 246.

${ }^{96}$ Wright, email, 3; Interview with Ruth Wright, July 8, 2009, 5.

${ }^{97}$ Taylor, 5-6.
} 
Beck had more mixed results when her prescription was switched to a tricyclic variety. In her case, as discussed above, she had experienced weight gain and an adverse effect on her mood. After her doctor tried a different prescription, she felt much better but was still unable to lose the twenty-five pounds she had gained. Nevertheless, she chose to put up with the side effects and stayed on the pill for two years. ${ }^{98}$ Thus, some women who approached their doctors with complaints could find at least some relief when the doctor changed the pill. These particular physicians obviously understood that side effects were possible and could sometimes be alleviated with a different formulation or dose.

Other women were less impressed or satisfied with this medical strategy to deal with side effects. A woman, presumably American, writing to the Ladies' Home Journal in 1967 recounted that "I took the pills for a year and a half. In this... [time] I switched to three different kinds because I got sick...I would call my doctor and tell him I thought the pills were making me sick, so he would switch me to another pill."99 Telling a similar story, Brooks said, after repeated visits to him, she was not sure her family doctor knew what he was doing when he kept switching the pill to alleviate her side effects which included nausea, tender breasts and yeast infections. However, she did admit that her issues seemed to diminish when the pill was altered. Brooks chose to stay on the pill for approximately five years. ${ }^{100}$ Edwards' gynecologist also prescribed a different brand of pill when she went on after the birth of her son, cognizant that she had had some issues the first time. Despite this course of action, Edwards again experienced depression and

\footnotetext{
${ }^{98}$ Beck, 13 and 19.

99 "Our Readers Talk Back about the...Birth Control Pills," Ladies' Home Journal, November 1967, 161. Cited in Watkins, 99.

${ }^{100}$ Brooks, 7-8, 10 and 19.
} 
diminished libido. ${ }^{101}$ Koch also found medical efforts unsuccessful. She experienced persistent bleeding during her time on the pill in the early 1960s. When she went back to her obstetrician/gynecologist, who had prescribed the pill, he did try to adjust it to find "a pill that...[she] could take without it causing a lot of bleeding." Ultimately, these efforts failed and Koch went off the pill after about a year. ${ }^{102}$

Like Koch, other women went off the pill due to side effects. ${ }^{103}$ For them, doctors could be helpful by advising or supporting this course of action. ${ }^{104}$ In doing so, they were implicitly acknowledging both the reality of and disruption associated with the pill's side effects. They were not alone in this admission. Indeed, in 1970 the special committee to the FDD advised that the pill should be discontinued for a number of valid medical reasons, including rising blood pressure, depression, any signs of phlebitis, or migraines. ${ }^{105}$ Sometimes doctors followed these recommendations. For instance, Wood was very irritable while using it and thought she did discuss her experiences with a doctor who, in turn, took her off the pill after about a year and a half. She then noticed an immediate difference in her mood and was quite relieved. ${ }^{106}$ Jackson was advised to go off the pill both times she was on it but for very different reasons. First, in 1971, she was told to go off the pill for three months so her yeast infections could be cleared up. Then, after resuming pill use following the birth of her son, she suffered a stroke in the summer of 1973. Both her neurologist and family doctor insinuated her stroke was connected to the pill but she "almost got the impression no one wanted to say yes definitely because

\footnotetext{
${ }^{101}$ Edwards, 10, 17-21.

${ }^{102}$ Koch, 12, 13, 16 and 17.

${ }^{103}$ Watkins, 77.

${ }^{104}$ Klein, 24-25, 27-28; Doyle, 13 and 7; Watson, 12 and 14. Watson also mentioned she had trouble remembering to take the pill.

${ }^{105}$ Report of The Special Committee, 1970, 10.

${ }^{106}$ Wood, 4 and 6.
} 
they were concerned about a lawsuit." It was, however, made very clear to her that she should immediately go off the pill and never take it again. ${ }^{107}$

Doctors also played a critical role in managing the side effects which seemed to get worse over time. Richards was on the pill several times throughout the 1960 s and in 1974. Because of problems with other contraceptives, she kept trying the pill even though she had migraines and other side effects. Finally, in the mid-1970s, the migraines started occurring frequently and her doctor advised her to stop the pill "because by then they were a little more aware of possible effects, long-term effects."108 Similarly, Harrison was on and off the pill a few times between 1967-1975. She had no problems with it initially but, after 1971, her family doctor noticed that her blood pressure was increasing, accompanied by bloating and migraines. This doctor regularly monitored her blood pressure and suggested the pill might be the cause. Because of her migraines, Harrison was even sent for an eletroencephalogram (EEG) which confirmed she was at higher risk for a blood clot or stroke. Ultimately, with her blood pressure increasing, Harrison went off the pill in 1975 and had a tubal ligation. ${ }^{109}$ Thus, medical opinion on evolving side effects had a large role to play in both Richards and Harrison's decisions to go off the pill.

Doctors' offices could be helpful in ways other than adjusting the dose or taking women off the pill. Sometimes, this meant simply providing information about side effects when questions or concerns arose. For instance, Wilson phoned her doctor's

\footnotetext{
${ }^{107}$ Jackson, 8-9, 14, 16, 23 and 22; Seaman, 71, 83 and 94-95. I have not come across any cases in which Canadian women (or their families) sued the drug industry over the pill and its side effects. Such litigation was definitely pursued in the United States, as Seaman reveals in her 1969 book. For example, the widower of Julie Macauley, who I will discuss in Chapter 6, unsuccessfully sued the drug company which had made the pill his wife was taking when she died of an embolism.

${ }^{108}$ Richards, 21 and 22.

${ }^{109}$ Harrison, 10, 13-14, 16, 18-19.
} 
office about her nausea on the pill. The nurse said this could happen and would likely pass. ${ }^{110}$ For Ryan, a nurse was also directly involved in her experience with side effects. During one of her migraines, which she got on the pill, a nurse she knew observed that one pupil was much more dilated than the other and suggested she "see someone." Ryan then went to a neurologist and he confirmed that the headaches were likely due to the pill and, though he did not specifically advise her to go off, Ryan decided to anyway. ${ }^{11}$ Edwards' gynecologist was also helpful in providing information about at least one problem associated with the pill. When Edwards went off the pill for the first time to get pregnant in 1967, she did not ovulate for nine months. Her doctor, the same one who had prescribed the pill, said delayed ovulation was probably a result of the contraceptive. He suggested she monitor her body temperature to increase her chances of conception. ${ }^{112}$ Finally, and somewhat uniquely, we have seen how Galli's doctor actually informed her of a side effect of which she could not be and was not aware. After about five years on the pill, her doctor informed her that, due to the pill, her ovaries had shrunk and she should go off the pill for a few months if she wanted to have children in the future. Galli remembers him as a generally conscientious doctor. ${ }^{113}$ Thus, a good majority of doctors, and their staff, were responsive to women's experiences with the pill's side effects. This confirms once again that at least a segment of the Canadian medical profession was fully aware that the pill, unlike condoms or diaphragms, came with these sort of drawbacks.

Less frequently, in a couple of cases, doctors adopted a less active but still supportive stance when approached by women who had already made the decision to go

\footnotetext{
110 Wilson, 10.

111 Ryan, 12-13 and 17.

112 Edwards, 10, 13 and 16.

${ }^{113}$ Galli, 10-11.
} 
off the pill. For example, Shevchenko, plagued by less energy and dizzy spells, chose to go off the pill on her own but remembered that her doctor seemed pleased with her decision when informed. ${ }^{114}$ Likewise, Campbell recalled that her doctor was helpful when she did not want to continue on the pill due to extreme fatigue and dizziness. He then put in an IUD for her. ${ }^{115}$ In supporting a woman's decision to go off the pill, perhaps these doctors were reflecting an awareness of the unresolved medical debate regarding pill safety.

Despite the influential role of the doctor in negotiating side effects, it is important not to minimize women's own agency as patients. While some of my informants emphasized the doctor made the decision about whether or not they continued on the pill, others were more assertive in claiming the principal role in managing their own side effects. In doing so, they did not always agree with their doctors and sometimes ignored their advice. This independent behaviour, sometimes bordering on defiant, demonstrates how the pill helped women become engaged with their own contraceptive needs and health care. For example, Reid was advised by her gynecologist, by coincidence likely the same one Campbell used, to go off the pill because of her persistent migraines. She was reluctant to do so but, at one point, because the headaches were quite bad, she sought alternatives and agreed to Dr. S.'s suggestion of an IUD. However, when the IUD came out within minutes of insertion, Reid went back to the pill, despite her doctor's advice. ${ }^{116}$ An American woman, cited in Seaman, also defied her doctor when he asked her to come off the pill in the late 1960s because of a concern over cancer. She countered:

\footnotetext{
${ }^{114}$ Interview with Betty Shevchenko, November 9 and 10, 2009, 10-11, 15, 19.

${ }^{115}$ Campbell, 11, 20,16 and 18.

${ }^{116}$ Reid, 9, 11-12, 13-14.
} 
Look, I don't care if you promise me cancer in five years, I'm staying on the pill. At least I'll enjoy [the] five years I have left. For the first time in eighteen years of married life I can put my feet up for an hour and read a magazine. I can watch my favorite TV program without having to catch up on my ironing at the same time. I can usually get a full night's sleep because there is no baby to feed or toddler to take to the toilet. If you refuse to give me the pill, I'll go get it from someone else. ${ }^{117}$

Thus, while other women, like Reid, disagreed with their doctors, she was the only one I spoke to who persisted in pill use in the face of both side effects and medical advice. More commonly, women with side effects chose to discontinue the pill without consulting or listening to a doctor. In doing so, they rejected the need to defer to medical opinion and again showed the independent decision-making associated with active patients. Walsh, for example, unhappy with possible bloating and headaches, was on the pill for about a year and thought she did discuss her side effects with her doctor.

However, she did not recall him giving her any specific advice on this matter and thought she made her own decision to go off the pill. ${ }^{118}$ Thus, in her account and memory, the doctor's role is not substantial. Stewart remembered that her family doctor, Dr. R., was more involved in her decision to go off the pill. Suffering from irritability, migraines and leg aches, Stewart went on and off the pill over a two year period in the early 1960 s, each time hoping the side effects would not return. Her doctor did validate her experience by saying "I understand a lot of people do have headaches, some people don't have any, some people have other problems, some people do have leg aches as well." However, he seemed to feel that she should put up with these side effects, as others did. Stewart disagreed and would "go off them for awhile and the doctor said are you sure you want to

\footnotetext{
${ }^{117}$ Marks, 208. Originally cited in Barbara Seaman, The Doctors' Case against the Pill, (Alameda, California, 1995), 19.

${ }^{118}$ Interview with Susan Walsh, November 24, 2009, 6 and 7.
} 
do this? It's either that or go crazy...[Stewart] said." Ultimately, Stewart decided to go off the pill for good. ${ }^{119}$

While Dr. R. at least acknowledged that Stewart was experiencing side effects due to the pill, other physicians did not make the connection between the pill and the symptoms of the women or think to warn about possible problems. This group included family doctors, gynecologists and other specialists, indicating that less informed, helpful and forthcoming practitioners could be found in several branches of medicine. Some doctors, like those encountered by Clarke, dismissed side effects as psychosomatic or trivial. A perceived lack of support from the medical profession could be very upsetting. ${ }^{120}$ For example, Macdonald was annoyed when problems arose while breastfeeding her first child in 1967 and the "[family] doctor wasn't smart enough to point out the connection or didn't know the connection [in advance of the problem]." He only informed her that her milk supply was insufficient due to the pill once she was already experiencing difficulty. Macdonald "resented that he had not thought to make the connection [with the pill] for me prior to that time." Summing up her feelings on the matter, Macdonald asked "Wouldn't you have thought that... when I wanted that prescription he might have said but you understand that this may impede the production of breast milk?"121 A 1965 article in Chatelaine affirmed that "most doctors do not prescribe it...for nursing mothers-it reduces the milk supply."122 Had she known in advance, Macdonald might not have gone back on the pill while trying to nurse. ${ }^{123}$

\footnotetext{
${ }_{119}^{119}$ Stewart, 8, 17, 12 and 19.

${ }^{120}$ Marks, 209-210; Watkins, 77; Gordon, 332.

${ }^{121}$ Macdonald, 12, 17 and 18. Despite her irritation, Macdonald did not indicate that she switched doctors over this issue.

${ }^{122}$ Mungall, 1965, 49.

${ }^{123}$ Macdonald, 18.
} 
Though it is impossible to know for sure, the failure of her doctor to share relevant information with her may have been influenced both by the lack of medical consensus on the significance of side effects as well as the ongoing debate surrounding how much to share with patients on this topic.

Jones also encountered difficulty in getting clear information from doctors about her side effects. Again, this demonstrates that doctors themselves were often unsure of or confused about the pill's safety. While her gynecologist told her when he prescribed the pill that headaches could be a problem, especially since she'd always had migraines, he later dismissed the possibility when she returned and complained about them. A new gynecologist, Dr. C., whom she began seeing during her second pregnancy, in 1972 or 1973, gave more credence to the idea that the pill was causing or perhaps exacerbating her migraines. ${ }^{124}$ Richards also had doctors misdiagnose her migraines. Though, as mentioned above, a doctor would eventually advise Richards to stop taking the pill because her migraines were worsening, the first doctors she dealt with in regard to this side effect were not as helpful. She returned to her family doctor, who had initially prescribed the pill, with terrible migraines but he not only failed to make the connection to the pill but did not seem to recognize the symptoms at all and, because she had pain behind her eyes, sent her to an eye doctor. The specialist found nothing wrong with her eyes and also failed to diagnose the problem as migraines. Lacking any medical information, Richards thought 'I didn't have this problem before I took the pill and now I do so I'm going to stop taking it. And the doctor just laughed at me and he said...[he had] never known anyone to go off it unless they wanted to get pregnant." ${ }^{, 25}$ Finally, Edwards

\footnotetext{
124 Jones, 5, 8-9, 13 and 14.

${ }^{125}$ Richards, 21-22, 7-9, 7. She would go back on pill after this first time though.
} 
met two doctors, a gynecologist and a GP, who did not seem to realize the pill could cause mood disruptions. Though she was certain, after her first time on the pill, that it was responsible for her depression and low libido, she chose to return to it twice more. Ultimately, even without medical confirmation, she decided to stop taking the pill because of her side effects. ${ }^{126}$ Therefore, Jones, Edwards and Richards encountered doctors who did not recognize their problems as pill-related, testifying again to the uneven and contested nature of medical knowledge on the pill. In the face of this confusion, women, like Richards and Edwards, had to make their own judgments about their health.

As discussed above, Clarke probably had one of the worst experiences with doctors during her first time on the pill from 1967-1968. Four doctors (two family doctors and two urologists) failed to connect her bladder control issues to the pill. Their reasons for doing so are not entirely clear. When asked, Clarke allows that at least one of the family doctors may have simply been unaware that the pill could cause such problems. ${ }^{127}$ This ignorance may, in turn, have reflected the lack of medical consensus on side effects in the 1960s. However, not all doctors were unhelpful merely because they lacked pertinent information. Clarke explained that one urologist's reactions to her side effects occurred because he lacked empathy and had little interest in her case. As a group, the doctors she encountered tended to classify her problems as psychologically rooted. Clarke believed them and worried that she did have some deep-seeded issue. ${ }^{128}$ Thus, in the short term, Clarke had to cope not only with the physical discomfort and

\footnotetext{
${ }^{126}$ Edwards, 13, 15, 22-24, 26, 35-36. It is interesting to note that Edwards' gynecologist, as discussed on page 21 , was more aware that the pill could interfere with the return of fertility. ${ }_{127}$ Clarke, 10 and 12.

${ }^{128}$ Ibid. Perhaps the doctors were remiss because, as discussed in note 68 , Clarke was experiencing side effects that did not seem to be common or widely reported in the 1960 s.
} 
inconvenience of her side effect, but she also had to grapple with the insinuation she was somehow mentally unbalanced. Reflecting on her experience Clarke remembered

saying to the doctor...well I got married, I moved to Ottawa, got a new job, well you're just...like a mental wreck kind of thing...it really was a difficult time ahh and as I look back on it...I mean what it did for me is to make sure my own daughter was much more informed, much more confident about umm this is your body and you have the right to...ask questions...Because I would have said, things were great, I've married a man who loves me, umm we know how to enjoy life ahh, you know, we're happy together...I mean what's the problem? And the doctor saying, oh it's...sort of deep in your psyche...you can't handle this or you've got problems, you miss your mother. ${ }^{129}$

Clarke reflected that it was very disempowering to have to question her mental health in this manner. However, at the time she trusted medical authority. She went off the pill to get pregnant and about six months later read in the newspaper that that particular brand of pill was being recalled for that and other side effects. She felt "like copying it and sending it to these...[doctors] and saying...it was not in my head, it was a side effect of this particular brand of pill." 130 Other women, like Clarke, who had their side effects minimized or labeled as psychosomatic, also began to be more critical of medical authority. ${ }^{131}$ Some of them would, as discussed in Chapter 1, go on to participate in the women's health movement of the 1970s.

Thus, as we have seen, most women did discuss their side effects with a doctor and, in doing so, encountered a variety of responses. Some doctors were not helpful, particularly when they did not believe or did not know the birth-control pill could cause the symptoms in question. This medical incredulity was especially upsetting for Clarke who, based on their expertise, began to question her own body and psyche. Other doctors

\footnotetext{
${ }^{129}$ Clarke, 11.

${ }^{130}$ Ibid., 25, 12, 10, 29, 10.

${ }^{131}$ Marks, 210.
} 
were better informed, especially about the more common side effects, and did try to help women. They did this by simply providing information, switching the dose or brand of pill or, if all else failed, advising the women to get off the pill.

While some women were quite satisfied with their medical care, the testimony shows that many were assertive in managing their own side effects. They would defy medical advice to both stay on the pill and go off of it. Though Clarke retained at first a more traditional confidence in medical authority, her experience with the pill's side effects caused her to consider the profession more critically. She therefore demonstrates the process through which a compliant patient might become an active health-care consumer.

However, then as now, women did not just rely on their doctors for support in dealing with side effects. They would also turn to friends, family and their husbands (or fiancés). Male partners, like doctors, responded in a variety of ways. While some appeared to be indifferent to or uninvolved with the management of side effects, and perhaps contraception in general, most took a much more active interest in their wives' pill use. This suggests that Kate Fisher's claim that even after the arrival of the pill, men may have "continued to play significant roles within new forms of relationship, in which birth control was openly negotiated by partners who saw contraception as a matter of joint concern," ${ }^{132}$ also applies to the Canadian context.

Many women remembered that their husbands were aware of and worried about the side effects they experienced. Sometimes husbands provided an important sounding board for concerns. Clarke recalled that she spoke to her husband about her bladder

${ }^{132}$ Kate Fisher, Birth Control, Sex, and Marriage in Britain, 1918-1960 (Oxford: Oxford University Press, 2006), 241. 
issues but, in their case, neither of them knew that the pill was the cause. Because several doctors suggested her problems were psychosomatic, Clarke would discuss with her husband what her "mental barriers" might be. ${ }^{133}$ Other women, and consequently their husbands, knew more definitely that problems were caused by the pill. Jones' husband, for example, was concerned when she suffered from migraines during her time on the pill. When she had a headache, she would have to go lie in a quiet, dark room and he was upset to see her in that state. ${ }^{134}$ Wood's husband was also troubled by her side effects. She thinks she discussed her irritability and sadness with her husband and, though he was supportive, he was also overwhelmed and confused by her extreme reaction to the pill. She felt he was naturally affected by her mood during her year and a half on the pill and that he was happy when she went off and got an IUD. ${ }^{135}$

Many other husbands, knowing or believing the pill was responsible for physical or mental upsets in their wives, were supportive of the decision to discontinue or not resume the pill. ${ }^{136}$ An American study by Dr. Frederick Ziegler, a psychiatrist, and Dr. David Rodgers, a psychologist, cited in Seaman in 1969, actually found that when women were more dominant in certain household duties, they would stay on the pill despite side effects whereas "the father-knows-best families go off the pill." ${ }^{, 137}$ This suggests perhaps that in some marriages, characterized by more traditional gender roles, the husband retained a controlling and protective interest in birth control. Though their general relationship dynamic is unknown, Koch's husband may have been quite instrumental in her decision-making process regarding contraception. She was on the pill

\footnotetext{
${ }^{133}$ Clarke, 10 and 12.

${ }^{134}$ Jones, 15.

${ }^{135}$ Wood, 6,7 and 13.

${ }^{136}$ Walsh, 7; Beck, 13, 15-16 and 23.

${ }^{137}$ Seaman, 60-61. For information on this study, see Appendix 2.
} 
for about a year but went off because of persistent bleeding. Her husband commented at the time that the pill was "an effective contraceptive because I kept bleeding all the time, it...wasn't conducive to good sexual relations." 138

When asked, other women suggested their husbands were less involved or sympathetic about any side effects they suffered while on the pill. Harrison, for example, said her husband was not really part of decisions regarding contraception. While aware of her increasing blood pressure and migraines, he was happy she was on the pill because then "he didn't have to do anything.", 139 Morrison also mentioned to her husband that she thought her bloating, tender breast and decreased sexual desire may have been connected to the pill. However, he wanted her to take the pill as he valued its effectiveness and they were both motivated to avoid another pregnancy. ${ }^{140}$

Morrison's husband was not the only husband to promote the pill as birth control. According to Barbara Seaman, many "husbands, in effect, pressure their wives to stay on the pill, often without being aware of it." ${ }^{, 141}$ This seemed to be the case for both Richards and Stewart whose husbands particularly valued the security and reliability of the pill.

Both men were eager to prevent more pregnancies and, consequently, were more invested in continuing with the pill, despite their wives' troubling side effects. As Stewart struggled with the pill, she did tell her husband about the headaches, irritability and leg pains. Over perhaps a two-year period, Stewart would go on and off the pill, each time

\footnotetext{
${ }^{138}$ Koch, 17 and 12. Jack Batten, "Is There a Male Conspiracy against the Pill?" Chatelaine 42, 7 (July 1969), 17,39-41. In this article, Batten accuses husbands of opposing birth-control pills and significantly contributing to their wives' decisions to discontinue pill use. He suggests this attitude may be because the pill, by removing worry over pregnancy, makes women more sexually interested and sometimes assertive which not all husbands enjoy or welcome. Though an interesting idea, husbands did not really seem to actively assume this role in my sample.

${ }^{139}$ Harrison, 17.

${ }^{140}$ Morrison, 17-19, 20.

${ }^{141}$ Seaman, 59.
} 
hoping the side effects would diminish. When they didn't, she would tell her husband she was going off and they would use condoms. After having two children close together, her husband in particular felt their family was complete and "he was afraid to get any more children so he'd let me suffer for awhile [with side effects]." While Stewart's husband was fine with using condoms as birth control, "he liked me to go back on...[the pills] once in awhile so he could be more sure of things." Ultimately, when the pills proved intolerable for her, they returned to condoms and then he was quite willing to get a vasectomy in $1970 .{ }^{142}$ Richards also went on the pill multiple times, even though she experienced migraines on it. While her husband was aware of her headaches, he also wanted her to keep trying the pill because it was reliable. ${ }^{143}$ Therefore, husbands could obviously influence their wives to stay on the pill as well as go off it. Either way, the pill, though a female-controlled method, did not completely exclude most husbands from contraceptive decision-making.

In addition to their husbands, women could also turn to their female friends and relatives to commiserate about pill side effects. ${ }^{144}$ While some women think they may have done so, ${ }^{145}$ others had more definite memories of conversations. Stewart, for example, discussed the pill with her mother-in-law, her sister and her friends. Her mother-in-law, observing her fume with irritation one day while trying to hang drapes, commented that "you've never been like this, you get off the damn pills." Stewart thought she may have followed this advice. She also remembered discussing side effects with her friends and hearing that they also had headaches and mood disruptions. In

\footnotetext{
${ }^{142}$ Stewart, 7-10, 11-13 and 15.

${ }^{143}$ Richards, 11 and 23.

${ }^{144}$ Tone, 234. Elizabeth Linden, interviewed by Tone, remembered having such discussions during her ten years on the pill.

${ }_{145}$ Richards, 10; Koch, 16-17; Stevens.
} 
particular, Stewart recalled that her sister found the pill "bothered her nerves." ${ }^{146}$ Like Stewart, Beck at least gained possible reassurance and validation from discussing side effects with other women. She heard that, like her, some friends experienced weight gain while on the pill. ${ }^{147}$

While some women availed themselves of the support of friends and family when coping with side effects, others never broached the subject at all. Clarke stated that, while she did remember women discussing the pill in general, she never raised the topic of her bladder control issues with friends. In her case, this may have been because of the sensitive nature of her complaint as well as the fact that she did not connect it to the pill until later and that she did not have many close friends nearby, having moved to a new city after her wedding. ${ }^{148}$ Wood added that, while she knew other friends were on the pill, she never talked about her experiences as she was "almost embarrassed or ashamed to...[be] having the feelings that I was having so I didn't talk about them..".149 Other women with a range of side effects asserted that matters such as birth control were not openly discussed, even among close friends or family. ${ }^{150}$ In her work on Britain in the first half of the twentieth century, Fisher found that women similarly did not discuss contraception with each other. She said "Most birth control knowledge was tainted by its association with sexual intercourse."151 Even though the pill could be taken at a time divorced from sexual activity, perhaps some Canadian women into the 1960s continued to feel this way. Therefore, while friends and family members could enlighten women

\footnotetext{
${ }^{146}$ Stewart, 10-11, 14.

${ }^{147}$ Beck, 20-21.

${ }^{148}$ Clarke, 6, 12, 4 and 11 .

${ }^{149}$ Wood, 7.

${ }^{150}$ Thompson, 17, 18 and 27; Morrison, 13-14, 19; Edwards, 11 and 30.

${ }^{151}$ Fisher, 60-64.
} 
about the pill, as I discussed in Chapter 2, and be important players in women's management of their side effects, even to the extent of urging them to give up the pill, it was by no means assured that they would adopt this role.

\section{Conclusion}

This chapter has demonstrated the complexities of married women's experiences with and responses to the pill's side effects. Women suffered a range of side effects from mild nausea and weight gain to debilitating headaches and even blood clots. Among those who experienced side effects, it is amazing how many doggedly persisted in the use of the pill despite disruptive problems, particularly migraines. Their determination speaks perhaps both to the appeal of the pill as an effective contraceptive and to the unpalatable nature of other birth-control methods, topics discussed in the previous chapter. Those who continued to have health problems even after discontinuing the pill demonstrate that this supposedly problem-free contraceptive came with a price.

When they did suffer side effects, many women turned to their doctors, friends, and husbands. They often found support in these relationships as they navigated pill use. Doctors could help in this process by adjusting the dose or brand of pill. However, some women reported that their doctors did not suggest this to them or did not always seem to even know about all the possible side effects of the pill. This confusion and even ignorance reflected the ongoing debate within the medical profession about the safety of the pill. Women's interactions with their doctors also demonstrate how the pill, which required a prescription and check-ups, encouraged women to become much more actively engaged in their own healthcare. In managing side effects, they would challenge doctors 
to take their problems seriously, sometimes ignore medical advice to go off the pill and, when necessary, come to their own decisions about staying on.

Generally, husbands are remembered as supportive figures but, on occasion, they seemed to influence their wives to stay on the pill, despite side effects, because they wanted the reassurance of such reliable birth control. In the vast majority of cases, husbands did not seem to be disinterested parties who, with the advent of the femalecontrolled pill, no longer had a say in contraceptive decisions. Friends and female family members could pool information on side effects, provide comparative experiences and cautionary tales and even, on occasion, more actively urge a woman to give up the pill.

The next chapter will continue to discuss side effects by analyzing what women heard on this topic from friends, family members or the media. Once alerted to possible problems, women had to decide what to do with this information. 


\section{Chapter 5-Hearing About Side Effects}

As the previous chapter demonstrated, not all women who went on the birthcontrol pill in the 1960s had side effects, serious or otherwise. However, did they know or discover that they were possible and, if so, how did they obtain this information? In Chapter 3, I discussed what, if any, information regarding side effects was conveyed by doctors during the initial or subsequent appointments. This next section will focus more on what women heard outside of the doctor's office, namely from friends, family or the media. While some pill users claimed reports of side effects only emerged much later, in the 1970s or 1980s, others insisted side effects were understood and discussed from the start. When and if they did hear about them, how did Canadian women on the pill respond? Did they discontinue the contraceptive? This chapter will seek to answer these questions.

\section{Friends and Family}

As demonstrated in previous chapters, friends and family members could play a pivotal role in the dissemination of information about the pill and its side effects. I have already described how women may or may not have taken their problems with the pill to their friends. But did these same friends report problems of their own? If so, how did women, with or without their own side effects, respond to these complaints? What purpose did discussions with friends who, unlike husbands, might also be on the pill, serve? In brief, female friends could share information on side effects, give positive reviews of the pill, provide a comparison against which a woman could judge her own experience or even furnish cautionary tales that might influence a woman to go off the pill. 
When asked about any memory of complaints from their friends regarding the pill, some women simply reiterated that it was not a topic they ever remember discussing, in some cases because they considered it too intimate. ${ }^{\prime}$ Other women did discuss the pill amongst themselves but don't recall any specific mention of side effects. ${ }^{2}$ However, friends could pool information about potential side effects, particularly if the topic had not been broached by the prescribing doctor. If women did discuss the pill, they remembered that their friends experienced a continuum of side effects, as they did. Sometimes memories of these conversations were vague and non-specific. ${ }^{3}$ For example, Stevens remembered someone suggesting that being on the pill was similar to being pregnant and Williams thought she recalled people wondering if their headaches or bloating were due to the pill. ${ }^{4}$

Other pill users recalled more specific and potentially troubling side effects, namely headaches and vision problems, which caused friends to discontinue the pill. ${ }^{5}$ While these stories could have provoked anxiety among pill-users, sometimes friends' experiences with the pill could also be used to strengthen positive impressions of the

\footnotetext{
${ }^{1}$ Interview with Evelyn Scott, December 12, 2009; Interview with Linda Johnson, July 17, 2009; Interview with Catherine Smith, July 9, 2009, 13-14; Interview with Caroline Mason, July 29, 2009, 3 and 6; Interview with Katherine Quinn, August 14, 2009, 17; Interview with Jane Lynch, October 6, 2009, 31; Interview with Beverley Brooks, October 19, 2009, 8; Interview with Anne Ryan, October 27, 2009, 15 ; Interview with Hazel Evans, December 1; 2009, 7; Interview with Deborah Campbell, February 9, 2010, 13; Interview with Caroline Morrison, March 9, 2010, 19; Interview with Emma Edwards, April 12, 2010, 11 and 30.

${ }^{2}$ Interview with Olivia Taylor, August 6, 2009, 8-9; Interview with Elizabeth Kennedy, November 10, 2009, 7; Interview with Beth Reid, November 18, 2009, 21 and 26; Interview with Cora Stefánsson, November 23, 2009, 4-6; Interview with Claire Macdonald, March 11, 2010, 5-6, 9.

${ }^{3}$ Interview with Mary Ramsey, October 29, 2009, 13.

${ }^{4}$ Interview with Lydia Stevens, November 20, 2009, 8; Interview with Lucy Williams, October 8, 2009, 16-17. It is worth noting that Stevens lived in the United States from 1967-1968 and in England and Europe in the mid-1970s. She was on the pill for at least some of her time in these other countries so it is possible that conversations about the pill may have been with women who were not Canadian. ${ }^{3}$ Interview with Cynthia Young, February 8, 2010, 8 and 18; Interview with Emily Wood, July 6, 2009, 5 and 14. Constance Mungall, "The Pill and Its Side Effects Today," Chatelaine 39, 11 (November 1966), 119. Though none of my informants had this particular problem, a 1966 article in Chatelaine does discuss a young Toronto woman who temporarily lost the vision in her right eye after eighteen months on OrthoNovum. Her condition was caused by a blood clot and resolved itself when she went off the pill.
} 
contraceptive. For instance, a few women recalled that their friends did not seem to have any significant side effects. Meyer, for example, who had no side effects herself, stated "I didn't have any friends that were having any problems with the pill. I had no reason to

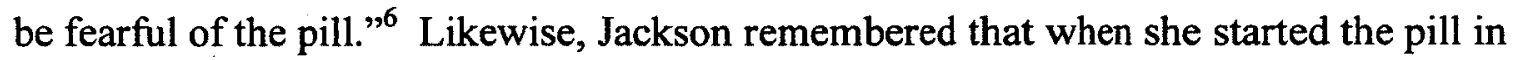
1968, her friends had no major side effects with the pill and "thought this was great. It was easy, it was effective."7

Other women also stated that their friends did not suffer to the same extent as they did while on the pill. While it is possible that their side effects were actually much worse, it also could be that their friends were cast as more fortunate in order to emphasize the extent of their own difficulties. Richards, who had migraines and some problems with her mood on the pill, added that "I don't think any of my friends who were using it were having as much trouble with it...I think it affected me psychologically more than it did them." Stewart remembered that some in her circle were bothered by the pill while others were not. Though Stewart asserted that headaches and leg aches were quite common among the women she knew, she reported that only she and her sister noticed significant mood changes. ${ }^{9}$ Jones also confirmed that, among her friends, she was the one with the more disruptive side effects. While friends might have had nausea, they did not have the migraines that she experienced. ${ }^{10}$ Therefore, while these women may have been the most afflicted with side effects in their circle, friends could also be remembered as relatively more fortunate in order to underline the severity of their own experiences.

\footnotetext{
${ }^{6}$ Interview with Judy Meyer, October 8, 2009, 16.

${ }^{7}$ Interview with Ellen Jackson, October 23, 2009, 3-4 and 6. Jackson adds later in the interview that most of her friends experienced a little weight gain with the pill at first, 31 .

${ }^{8}$ Interview with Alice Richards, December 7, 2009, 10.

${ }^{9}$ Interview with Eileen Stewart, August 18, 2009, 11, 14 and 18.

${ }^{10}$ Interview with Mary Jones, December 3, 2009, 16.
} 
As discussed in Chapter 4, strokes and blood clots were associated with pill use. Cases were reported in the pages of the Canadian Medical Association Journal, Barbara Seaman's 1969 book and newspapers like The Toronto Star. ${ }^{11}$ Many of the women I interviewed had friends or acquaintances who had strokes. In most cases, these stories were recalled in vivid detail even if they were not close friends. They may have been circulated as cautionary tales for those on the pill. Murray recounted that in 1965, before she went on the pill, the daughter of someone her mother worked with had a stroke. This woman had just had a baby and had been on the pill. She had to learn to speak and walk and could not care for her baby. ${ }^{12}$ In this case, one wonders if the pill was really implicated in the stroke since the woman would have, one assumes, been off it throughout her pregnancy. However, it is important that Murray remembers this stroke in connection to the pill.

In other cases, the pill's role seemed to be clearer in both blood clots and deaths. When in her early twenties, Carter remembered vividly that a co-worker, who had been on the pill for five years, developed a blood clot and almost died. It was understood at the time that the problem was due to the pill. ${ }^{13}$ Similarly, during her time on the pill, Shevchenko had a friend who was a heavy smoker and had a stroke while on the pill. She thought at the time there was a connection between the pill and the stroke. ${ }^{14}$ Even more seriously, Harrison knew a woman who died in her early twenties from a stroke

\footnotetext{
"See for example, R.S. McWilliam, "Thrombophlebitis Following the Use of Norethynodrel (Enovid)," Canadian Medical Association Journal 88, 20 (May 18, 1963), 1032-1033; L.A. Edwards, M.D. et. al., "Axillary Vein Thrombosis and Pulmonary Embolism Possibly Due to Oral Contraception," Canadian Medical Association Journal 100, 2 (January 11, 1969), 78-80; Barbara Seaman, The Doctors' Case Against the Pill (New York: Peter H. Wyden, Inc., 1969), Chapters 6 and 7; Hyman Solomon, "“"6 Die, Warn Against Birth Control Pill," The Toronto Star, August 8, 1962, 42.

${ }^{12}$ Interview with Rose Murray, October 28, 2009, 12-13.

${ }^{13}$ Interview with Ellen Carter, February 12, 2010, 16.

${ }^{14}$ Interview with Betty Shevchenko, November 9 and 10, 2009, 11 and 18.
} 
which was believed to have been caused by the pill. ${ }^{15}$ Edwards and Lowe, two sisters interviewed separately for this thesis, both remember how Lowe's friend as well as a cousin suffered strokes due to the pill. ${ }^{16}$ Both were apparently smokers and had the strokes during the same six-month period around $1973 .{ }^{17}$ Ultimately, their cousin was left with no peripheral vision at all and Lowe's friend had her foot affected and now wears a brace. ${ }^{18}$

Thus, for women on the pill their friends' experiences with side effects served a number of functions. First, they could simply provide additional information about the multitude of potential problems. Second, friends, who had no side effects, could lend credence to the assertion that the pill was trouble-free and, in this way, provide reassurance. Third, women could use their friends, who had fewer or no problems, to emphasize the exceptionally difficult struggle they had with the pill. Finally, on the flip side of this, when other women did have rare and dangerous side effects, such as blood clots, their stories were remembered vividly and possibly served as cautionary tales, a point I will return to in the next section.

The Role of the Media

Before turning to an analysis of media as a source of information on the pill's side effects, it is interesting to note that, for some women, worries about the pill were filtered through the lens of the widely publicized thalidomide tragedy. While Junod and Marks, quoted above, say that the arrival of the "thalidomide" babies effectively distracted from early reports of problems with the pill, Marks acknowledges in her book that the fears

\footnotetext{
${ }^{15}$ Interview with Cindy Harrison, January 25, 2010, 19.

${ }^{16}$ Edwards, 31-32; Interview with Isabelle Lowe, April 27, 2010, 18 and 24.

${ }^{17}$ Edwards, 32; Lowe, 18 and 24.

${ }^{18}$ Lowe, 26.
} 
prompted by thalidomide permeated the discussion regarding the pill's side effects. Indeed, "For most women, thalidomide came to epitomize the potential and unknown dangers posed by any drug used in pregnancy." ${ }^{\prime 19}$ Certainly testimony from Canadian women about the pill is often haunted by the specter of thalidomide. For instance, Stefánsson did not want to get pregnant for at least six months after going off the pill in case the developing fetus could somehow be adversely affected. ${ }^{20}$ Intriguingly, Stefánsson connected this concern back to her own mother's reproductive experiences and suggested that her caution about the pill was because her mother was pregnant in the mid-1950s and almost took thalidomide. However, it is perhaps most interesting that Stefánsson's mother could not possibly have taken thalidomide in the mid-1950s as the drug was not developed until 1957 and was only sold in Canada between April of 1961 and March of 1962. Carter shared Stefánsson's caution about getting pregnant right after pill use and, like Stefánsson, referred to thalidomide as contributing to this attitude. ${ }^{21}$ Thus, one can see that women internalized the message, learned through the thalidomide crisis, that a fetus could potentially be impacted by a medication.

Fears about subsequent children may have been further stimulated by medical research on the pill itself. The 1970 special committee, while saying "there is well documented evidence that pregnancies following the use of OCs do not result in an increase in fetal abnormalities," also reported research on miscarried fetuses which had discovered a significantly elevated rate of triploidy, a chromosomal defect, among those

\footnotetext{
${ }^{19}$ Suzanne White Junod and Lara Marks, "Women's Trials: The Approval of the First Oral Contraceptive Pill in the United States and Great Britain," Journal of the History of Medicine and Allied Sciences 57, 2 (April 2002), 154 and 120; Lara V. Marks, Sexual Chemistry: A History of the Contraceptive Pill (New Haven: Yale University Press, 2001), 138.

${ }^{20}$ Stefánsson, 4 and 11.

${ }^{21}$ Carter, 25 and 26.
} 
conceived within six months after the pill had been discontinued. ${ }^{22}$ The committee's second report, in 1975, confirmed that if a woman was on the pill during the six months before conceiving, she might face increased chances of fetal abnormalities which would lead to miscarriage. Though it was apparently not included in the patient insert used in the early 1970 s, the committee did recommend that "after discontinuing oral contraceptives, the patient should await the resumption of normal ovulatory cycles before attempting to become pregnant." ${ }^{, 23}$ This advice was repeated in the 1978 committee report which explained again that women who got pregnant before their natural cycles resumed "may have a higher incidence of congenital abnormalities in their offspring."24 The possibility of any problems with subsequent pregnancies or children, if this news reached the ears of pill users, could have been particularly upsetting in light of the thalidomide tragedy.

Nevertheless, despite the influence of thalidomide on women in the 1960s, it is important to note that not everyone was affected by these events in a similar or predictable way. Macdonald, a former public servant, mused that "I marvel in retrospect...particularly...having been in Health Canada when the thalidomide experience hit the nation...[that] we took on faith...a, the efficacy and $b$, the safety of...[the birthcontrol] pill. ${ }^{, 25}$ In this chapter, I will show that, as with thalidomide, women also remembered and reacted very differently to news regarding the pill.

\footnotetext{
${ }^{22}$ Report of The Special Committee appointed by The Minister of National Health and Welfare to Advise The Food and Drug Directorate on all Aspects of the Safety and Efficacy of Oral Contraceptives Marketed in Canada, October 1970, Rx Bulletin, Special Issue, December, 1970, 42 and 34.

${ }^{23}$ Report of the Special Committee Appointed by The Minister of National Health and Welfare to Advise the Health Protection Branch on All Aspects of the Safety and Efficacy of Oral Contraceptives Marketed in Canada, Second Report, February 1975, Rx Bulletin Volume 6, Supplement 1 (1975), 3, 43-45.

${ }^{24}$ Report of The Special Advisory Committee on Reproductive Physiology to The Health Protection Branch, March 1978, 6.

${ }^{25}$ Macdonald, 6.
} 
Media articles, as Siegel Watkins explains in her book on the pill in the United States, "by narrating women's stories about their experiences...reduced the isolation of individuals' ordeals and created a sense of shared experience among pill users." Thus, the media, like discussions with friends, provided an opportunity for women to connect the problems they were experiencing to the pill and realize they were not alone in their struggles. Additionally, even those who had no side effects might read the reports and start to consider the risks associated with the pill. ${ }^{26}$

Discussing what women may have heard about the pill's side effects in the media is important in demonstrating what potential knowledge women could bring to their contraceptive decision-making but also challenging, given the often difficult task of remembering where and when one heard certain information. In her 2001 book on contraception, Andrea Tone says "We do not have an accurate count of how many women knew about the controversy [over the pill's safety in the 1960s]; but we can reasonably assume that many, perhaps most, were aware that taking oral contraceptives posed certain health risks, even if they were uninformed about their scope or severity." Tone goes on to say that, as well as information from doctors and friends, American women could read about the advantages and disadvantages of the pill in publications such as Redbook, The Saturday Evening Post, Good Housekeeping, Ebony and Ladies' Home Journal. ${ }^{27}$ Many of these publications were also popular with Canadian readers in the $1960 \mathrm{~s}^{28}$ However, is Tone correct in assuming that the majority of women were aware

\footnotetext{
${ }^{26}$ Elizabeth Siegel Watkins, On the Pill: A Social History of Oral Contraceptives 1950-1970 (Baltimore: Johns Hopkins University Press, 1998), 102.

${ }^{27}$ Andrea Tone, Devices and Desires: A History of Contraceptives in America (New York: Hill and Wang, 2001 ), 244-5.

${ }^{28}$ Valerie Korinek, Roughing It in the Suburbs: Reading Chatelaine Magazine in the Fifties and Sixties (Toronto: University of Toronto Press, 2000), 59.
} 
of the health drawbacks of the pill? What do Canadian women who first tried the pill in the 1960s say when asked about the media's discussion of side effects? Though American historians, particularly Siegel Watkins, have discussed the importance of the media in disseminating information about the pill and its side effects, there has been little analysis on the Canadian context to answer this question. ${ }^{29}$ Therefore, my interviews can offer some unique insight. In this matter, as in so many other things, the testimony is not monolithic. While some women's memories are precise, others retain more vague impressions of media coverage on this topic. Some women insist that publicity about the pill and its side effects was rampant even in the early 1960 s, whereas others are equally sure that side effects were not discussed in the media until decades later. Somewhere between these two extreme positions lays the majority of women who know they heard about side effects in newspapers, magazines, radio or TV but are not always clear about which medium may have been responsible or when they heard it.

A minority of women in my sample asserted that the side effects or dangers of the pill were discussed and acknowledged in the media even in the $1960 \mathrm{~s}$. While some were less certain or explicit about the exact nature of these concerns, ${ }^{30}$ other women recall more specifically which problems were discussed in the media. ${ }^{31}$ For instance, Quinn asserted that, as a university student in the early $1960 \mathrm{~s}$, the increased risks of stroke and blood clots were understood and upfront right from the start in debates on campus and

\footnotetext{
${ }^{29}$ See also, Marks and Tone.

${ }^{30}$ Scott, 5-6 and 9; Murray, 6-7 and 9; Lowe, 5 and 11-12; Meyer, 16.

${ }^{31}$ An analysis of Chatelaine magazine seems to confirm that the pill's side effects were fairly well-known even in the early 1960s. Articles on the topic appeared throughout the decade. An article from November of 1961, for example, mentions nausea, headaches, dizziness and breakthrough bleeding. A 1966 article provides an in-depth and comprehensive analysis of possible side effects including nausea, dizziness, headaches, weight gain, breast discomfort, cancer, blood clots, eye disorders, liver dysfunction, diabetes and epilepsy, depression, and delayed fertility. Lawrence Galton, "Here's Health," Chatelaine 34, 8 (August 1961), 26; Ron Kenyon, "The Pill Nobody Talks About," Chatelaine 34, 11 (November 1961), 64 and Mungall, 1966, 33 and 117-120.
} 
possibly in sources like Chatelaine magazine. ${ }^{32}$ Wood was on the pill in 1967 , for about a year, and remembered hearing or reading reports of people, like her friend mentioned above, who had problems with their eyesight as well as bloating while on the pill. ${ }^{33}$ Other side effects that women possibly gleaned from media coverage in the 1960s included nausea, decreased libido, headaches, weight gain, sore breasts, problems with subsequent babies and post-pill infertility. ${ }^{34}$

A few women reflected that they heard one should not stay on the pill too long. ${ }^{35}$ This idea may have been circulating in the media very early as a 1961 article in Chatelaine magazine, for example, did say that the manufacturers of Enovid, G.D. Searle, advised women to avoid being on the pill for longer than two years without a break. ${ }^{36}$ The 1970 special committee report to the Food and Drug Directorate affirmed that women, who had not yet had children and had been on the pill for around two years, should discontinue it for a short time so that natural hormone cycles could be re-

\footnotetext{
${ }^{32}$ Quinn, 2. Mungall, 1965, 49; Mungall, 1966, 33 and 118. Though not in the early 1960s, Mungall does comment in 1965 that "Most [doctors] do not prescribe...[the pill] for women with a history of bloodclots, liver ailments and certain cancers," demonstrating the existence of a public discussion regarding these contraindications. The 1966 article also mentioned the possibility of blood circulation problems.

${ }^{33}$ Wood, 14.

${ }^{34}$ Interview with Susan Walsh, November 24, 2009, 5; Interview with Elizabeth Thompson, June 11, 2009, 22; Jones, 22; Interview with Diane Galli, December 8, 2009, 10; Interview with Annie Beck, November 6, 2009, 13; Stevens, 13-14. Galli, though not specifying media, thought she knew from her own reading, prior to starting the pill in 1966, that it could cause problems like weight gain and sore breasts. Information on side effects did seem to be available in the media. For example, a 1967 health column in Chatelaine commented that the pill might cause headaches in women who had an existing predisposition to migraines. See "What's New in Health," Chatelaine 40, 9 (September 1967), 14. Stevens did not specify where she heard that the pill could make it harder to get pregnant after going off. She added that, in 1967, she did not know about any possible connection between the pill and blood clots. Stevens was living in the United States when she went off the pill for the first time in 1967 so she may also have been exposed to American media reports.

${ }^{35}$ Walsh, 4; Interview with Eva Green, June 23, 2009, 12. Green went on the pill in 1966 and then spent a number of years in the United States so she may have been exposed to both American and Canadian media discussions concerning the pill. Green also reflected that there was little publicity surrounding the pill when compared to thalidomide and "my friends and I were just glad that we never took that because that was right around the time when we were all pregnant, some of us anyway." This comment is interesting in light of the fact that thalidomide was only for sale in Canada for a few months in the early 1960s. Green did not go on the pill until 1966 and did not have her first child until 1969, however, she associated thalidomide with her childbearing years. Thus, here again we see the pervasive influence of thalidomide. ${ }^{36}$ Kenyon, 64.
} 
established. However, by 1975 , the committee seemed to say there was no reason for such a break from pill use. ${ }^{37}$ As was discussed in more detail in Chapter 3, Thompson understood, even before talking to her doctor, that women should not stay on the pill after age forty. ${ }^{38}$

Therefore, some pill users clearly recalled that side effects were understood and discussed in mainstream media even as early as the 1960s. This group of women might argue, then, that those who took the pill and consumed such media should have been under no illusions about the risks involved, even if their doctors were less than forthcoming. However, more women interviewed for this thesis claimed that there was little information or media coverage on risks or side effects when they began taking the pill in the 1960s. This may have been because they preferred not to think they had ignored or missed such reports. In fact, some emphasized instead the positive nature of media coverage. Smith, for instance, started the pill in 1962 and did not remember hearing or reading at that time any media reports about side effects. More specifically, she did not recall ever hearing about blood clots or cancer in connection to the pill when she started it. On the contrary, she thought she "had read enough in the press...it had been tested so I knew I wasn't a guinea pig." ${ }^{39}$ Like Smith, Mason did not remember any negative publicity about the pill's side effects when she was on it, from 1966-1969. In fact, she also found the newspaper coverage reassuring when she started in its presentation of the pill as safe and effective..$^{40}$ Macdonald agreed that newspaper coverage of the pill, when she first heard about it in the early 1960s, was glowing and

\footnotetext{
${ }^{37}$ Report of The Special Committee, 1970, 38; Report of the Special Committee, 1975, 2.

${ }^{38}$ Thompson, 17.

${ }^{39}$ Smith, 13-14 and 19.

${ }^{40}$ Mason, 6 and 16.
} 
that "the culture of risks around drugs...didn't exist. If it was on the market, it was probably very safe., ${ }^{, 41}$ Thus, some women remember that the media emphasized the pill's safety, rather than its dangers, in the 1960s.

Nevertheless, many women I spoke to recalled that, over time, side effects became much more widely discussed in the media. A 1969 article in Chatelaine magazine seemed to confirm this impression and reflected on the "black bulletins from gynecologists, medical journals, ministers of health, and various symposia of 'experts' warning that the pill might be a contributing factor to an increase among women of blood clotting, cancer of the cervix, strokes, diabetes and jaundice, not to mention depression, irritability, decreased libido, and in one spectacularly ridiculous case, dandruff., ${ }^{, 42}$ The same year, Barbara Seaman's book The Doctors' Case Against the Pill was published. Using interviews with women, doctors and medical literature, it linked the pill to numerous side effects, listed at the start of this chapter, as well as to "potentially fatal blood clots, haemorrhage, strokes, heart disease and, possibly, cancer of the cervix, breast and uterus." Seaman's book, with its "plea for the need for informed consent among pill takers led United States Senator Gaylord Nelson to call Senate hearings devoted to pill safety between January and March 1970." These hearings were widely covered by the media. ${ }^{43}$ Canadian women were not immune to these and other reports. Indeed, "In a nationwide poll released shortly after the Senate hearings ended, 56 per cent of Canadian adult women surveyed considered the birth control pill an effective means of

\footnotetext{
${ }^{41}$ Macdonald, 32. At some point, Macdonald did become aware of more serious side effects like blood clots but she is not sure when or if she was still on the pill, 26.

42 Jack Batten, "Is There a Male Conspiracy against the Pill?" Chatelaine 42, 7 (July 1969), 39.

${ }^{43}$ Christabelle Sethna, "A Bitter Pill: Second Wave Feminist Critiques of Oral Contraception," in Canada: Confederation to the Present, eds. Bob Hesketh and Chris Hackett (Edmonton: Chinook Multimedia Inc., 2001), http://chinookmultimedia.com/poccd/registered/web_papers/case_studies5.php
} 
contraception. Yet $\mathbf{4 0}$ per cent of them claimed that the pill posed a danger to health, while another 30 per cent said they were unsure."44 Confirming a sense of unease, Dr. T.M. Roulston, head of the Department of Obstetrics and Gynecology at the University of Manitoba, referenced the Senate hearings and tried to reassure women in a 1970 article in The Globe and Mail. He said "We regret the alarm caused to women across Canada by recent reports emanating from Washington [D.C.] on [the] side effects of the pill."45 Speaking for the Family Planning Federation of Canada, Roulston went on to say that "the benefits to women in preventing unwanted pregnancies by using the pill...far outweigh the risks of side effects, provided the advice is given under medical supervision." $" 46$

Women in my sample did express an awareness of the increasing number of media reports. Though Lowe thought there was some concern about the pill in the media when she started in about 1967 , she emphasized that the available information increased with time and, by 1969 , she was hearing more which concerned her, likely in newspapers, magazines, etc. ${ }^{47}$ As well as general impressions, several women in my sample recalled hearing about the pill and blood clots/strokes though they were a little vague about when and where they heard these reports. ${ }^{48}$ For instance, Reid did hear about an association between blood clots, smoking and the pill but was not sure if this was when she was still

\footnotetext{
${ }^{44}$ Sethna, 2001; Canadian Gallup Poll, March 1967, \#323 and Canadian Gallup Poll, May 1970, \#341. By comparing Gallup Polls from 1967 and 1970, one can discern a shift in Canadian public opinion, possibly also related to media reports. In $1967,53.8 \%$ of respondents felt the pill could be used without threatening a person's health. Three years later, that number had dropped to $42.2 \%$.

${ }^{45}$ Cited in Sethna, 2001.

46 "Benefits of the Pill Underplayed: Doctor," Globe and Mail, January 26, 1970, 12.

${ }^{47}$ Lowe, 6, 11, 17, 18, 21.

${ }^{48}$ Stewart, 19-20; Interview with Susan Brown, August 7, 2009, 21-22; Taylor, 7-9; Interview with Claire Moore, November 17, 2009, 24; Interview with Yvonne Wilkins, September 30, 2009, 16 and 28; Interview with Olivia Klein, October 20, 2009, 21 and 23; Lowe, 25. Moore adds that she did not hear about cancer when she was on the pill from 1969-1973.
} 
on the pill, between $1967-1970$, or when she was considering birth-control options after completing her family in $1972 .{ }^{49}$ A few other women were able to provide a more precise date for their increasing knowledge about the pill and blood clots/strokes. ${ }^{50}$ Johnson, for instance, was actually put on the pill from approximately 1961-1962 because she had developed a blood clot in her leg after the birth of her first child and was told not to get pregnant again for at least a year. One assumes her doctor did not know about the connection between the pill and blood clots then but, by 1964, Johnson thought she may have heard about this in the news and, consequently, did not go back on the pill after her second child was born. ${ }^{51}$

Other possible problems, according to the women's testimony, seemed to be discussed more publicly as time went on. ${ }^{52}$ For instance, as mentioned above, some women stressed that they were aware from the start of their pill use that they should only be on it for a limited time. For others, this knowledge came during their years on the pill. This may have been because they had heard about side effects. ${ }^{53}$ Also some women began to hear of cancer associated with pill use. ${ }^{54}$

\footnotetext{
${ }^{49}$ Reid, 27.

${ }^{50}$ Young, 12-13; Ryan, 14-15.

${ }^{51}$ Johnson, 7-9.

${ }^{52}$ Edwards, 8, 10-12, 30-31. Edwards implied initially that information connecting the pill to mood disruptions was available, possibly in newspapers, during or shortly after her first time on it (1965-1967). However, she then later clarified that did not hear of side effects in the media in general or read about this particular problem until the 1970s. She added she was most definitely off the pill when she heard reports concerning blood clots.

${ }^{53}$ Evans, 9-10 and 15-16; Quinn, 2 and 10. Evans was in Germany for some of the time she was on the pill and she is a little unclear about where she lived when she started to hear that it might be a bad idea to stay on the pill for extended periods. However, it was back in Canada that a doctor seemed to articulate a similar concern and proposed she take a break from the pill, prompting her to go off after five or six years. This idea of having time off from the pill was promoted in the 1970 special committee report, as discussed above.

${ }^{54}$ Interview with Julia Hall, June 29, 2009, 7; Klein, 20-21. Mungall, 1965, 49. As a potential source of information for Canadian women, this 1965 article mentioned that doctors would not prescribe the pill for women with a history of certain cancers. Mungall, 1966, 118. A 1966 article in Chatelaine magazine did discuss in more detail the possible connection between the pill and cancer. Klein confirmed that when she went off the pill in about 1966, after her supply was stolen in Trinidad, she had been hearing such reports
} 
The experiences of two women demonstrate clearly how public knowledge about the pill was evolving very rapidly, even in the 1960s. First, as I will discuss below, Wilson felt that generally side effects were not discussed when she was on the pill in the 1960s and 1970s. However, she did read, possibly in the newspaper, after the birth of her daughter in 1967 , that breast-feeding might not be a good idea while taking the pill. She thought this may have been a concern about hormones passing to the baby through breast milk. She did not have this information when she had nursed her first child, in 1965 , while on the pill, and it bothered her enough to go off the pill for the nine months she breast-fed. ${ }^{55}$ Her experience, therefore, further suggests an evolution in the dissemination of knowledge about the pill.

Finally, Clarke's experience confirms that knowledge about the pill was evolving in the 1960s. She suffered from bladder control issues while on the pill from 1967-1968, and never heard that this side effect was possible until about six months after she went off of it. She then recalled vividly that she read in the newspaper that this particular brand was being taken off the market because of this and other side effects. ${ }^{56}$ Therefore, many women, like Clarke, followed media reports and learned more as time went on. Though they would not suggest such information was readily accessible from the start of their pill use, their recollections seem to confirm that such useful coverage increased over time.

Nevertheless, some women stress that they do not remember any significant media reports of side effects until several years or decades had passed at which point they Chatelaine or other publications in Trinidad.

${ }^{55}$ Interview with Margaret Wilson, August 12, 2009, 15, 12-13 and 28-29.

${ }^{56}$ Interview with Cheryl Clarke, November 12, 2009, 13, 10 and 29. 
may or may not have gone off the pill. ${ }^{57}$ This response can be more surprising depending on when and how long a woman was on the pill. At one end of the continuum, Walsh only took the pill for a year, from 1969-1970, and did not remember any reports of blood clots associated with the pill when she was on it. ${ }^{58}$ Campbell was also on the pill for a short time, only about a month in 1964, and thought she heard more about side effects like blood clots later on. ${ }^{59}$ It is not surprising that these women, who were only on the pill for a short time, did not recall hearing about side effects while taking it.

Other women, however, were on the pill for longer periods and still assert they did not hear about side effects in the media (or at all) during their time on the pill. ${ }^{60}$ Wilson, for instance, asserted that there was little information on side effects while she was on the pill in the 1960s and 1970s. Further, she did not think there was any discussion of blood clots specifically until about twenty years ago. ${ }^{61}$ Brooks also claimed she did not hear about blood clots while she was on the pill from 1969 to 1974 and generally did not recall reading about the pill in the news. ${ }^{62}$ Jackson would concur that information on side effects was not available when it could have been most useful for her. She maintained that she only heard about the pill's association with blood clots and strokes after she had her own stroke in 1973. Then she began to hear reports in the media

\footnotetext{
${ }^{57}$ Interview with Jane Arsenault, March 2, 2010, 5, 15 and 31. For example, Arsenault asserted she heard about an association between the pill and blood clots, but not until later during her time on the pill. She took the pill, on and off, from 1966 and 1973.

${ }^{58}$ Walsh, 9.

${ }^{59}$ Campbell, 20.

${ }^{60}$ Kennedy, 13 and 25-26; Jones, 22 and 16 . Jones, as mentioned above, did hear about headaches from sources like newspapers before starting the pill but specifies that blood clots were not discussed in the media when she took the pill.

${ }^{61}$ Wilson, 15.

${ }^{62}$ Brooks, 19-20.
} 
and from other people regarding blood clots. Even later on, she heard that smoking could contribute to blood clot issues. ${ }^{63}$

Anderson and Morrison had a long history of pill use, extending to or even after 1980. Anderson said she did not hear about blood clots or other problems in the 1960 s but, by the 1980 s, she had become more concerned and decided to go off the pill. ${ }^{64}$ Morrison also had the impression that she heard about an association between the pill and blood clots, though she was not sure of the source, later in her time on the pill. ${ }^{65}$

As a caveat to this discussion, it is important to note that women may have paid heed to media reports to varying degrees. For example, Watson, who was on the pill from 1962 to approximately 1969 , thought she might have heard about side effects in the media but never gave the issue much thought. ${ }^{66}$ Though on and off the pill over a much longer time, from 1969-1983, Stefánsson echoed this sentiment. She also did not remember hearing about blood clots or other alarming side effects. However, she commented as well that, as she never suffered from any side effects, any publicity may not have resonated with her. ${ }^{67}$ Williams concurred that she did not recall any media reports on side effects until many years after stopping the pill in 1970 but that she may have simply not been very interested before that. ${ }^{68}$

Ultimately, then, women who took the pill in the 1960s have different impressions and memories of media coverage of side effects. While some say it was clearly presented

\footnotetext{
${ }^{63}$ Jackson; 29-31; Galli, 5, $11-15,16-17$; Edwards, 12, 22, 24, 26 and 29. Galli and Edwards agreed that smoking, as particularly problematic for pill-users, was not widely discussed or known when they were on it, on and off, from 1968-1978 and about 1965-1970 respectively. As discussed in Chapter 3, warnings about smoking did not appear in a patient insert until late in the 1970s.

${ }^{64}$ Interview with Heather Anderson, December 3, 2009, 8-9.

${ }^{65}$ Morrison, 20.

${ }^{66}$ Interview with Jean Watson, November 3, 2009, 19.

${ }^{67}$ Stefánsson, $11-12$ and 14.

${ }^{68}$ Williams, 23.
} 
even in the early 1960 s, others suggest that they became more aware of alarming reports as the decade wore on. Still others insist that media reports were not common until later in the 1970s or even the 1980s. One wonders how much memory is affected here by a desire to believe one did not ignore available evidence suggesting the pill had potential risks. In addition, women, coming off the pill or considering doing so, may have used media reports on the disadvantages of the pill to bolster their own choice.

\section{How Did Women Respond to Reports of Side Effects?}

So not all women remember hearing about side effects while on the pill. If they did, how did they respond when friends or the media described potentially lifethreatening consequences to pill use? Did they decide to go off the pill? One can gain more insight into these complex questions by looking at the reactions of American women to the Nelson Senate hearings on the pill. As mentioned above, these hearings were also covered by the Canadian media and presented a variety of concerns about the pill's safety. ${ }^{69}$ Given the subject matter, it is not surprising that an American Gallup Poll, published in February 1970 "found that 18 percent of the eight and a half million women with pill prescriptions had stopped taking the pills in recent months, and another 23 percent were considering stopping. One-third of those who had quit or thought about quitting directly attributed their recent or imminent abandonment of oral contraceptives to the Nelson hearings; another one-fourth cited side effects-experienced personally or by friends-as the reason for their doubts about the pill." Confirming something of a

\footnotetext{
${ }^{69}$ For some examples of this coverage, see "Strong reason to link the Pill with cancer U.S. Senators told," Toronto Daily Star, January 14, 1970, 80; Terrance Wills, "Chromosome defects tied to use of pill," Globe and Mail, January 15, 1970, W7; "Banned for chicken fattener, hormone still being used in the pill," Globe and Mail, January 16, 1970, 9; "Charge The Pill is marketed without enough testing," Toronto Daily Star, January 21, 1970, 70; "Doctors argue over Pill dangers," Toronto Daily Star, January 22, 1970, 34. The headlines are hardly reassuring.
} 
stampede away from the pill, the Planned Parenthood clinic in Detroit reported, for January 14-February 13, increases in requests for diaphragms, IUDs, tubal ligations and vasectomies as women went off the pill. ${ }^{70}$ Thus, women clearly did respond to reports of side effects by jettisoning the pill. ${ }^{71}$

However, it is important to look beyond this immediate response to see that it was somewhat knee-jerk and temporary. In April of the same year, another Gallup Poll found that $13 \%$ of women who had discontinued the pill had decided to take it again and $26 \%$ were thinking of doing so. Ultimately, "after a brief drop, prescription rates rebounded, and the number of users peaked in 1973 at approximately ten million.,72

In her 1969 book, Barbara Seaman had asked, particularly in light of media reports, "Why...do intelligent women, aware of at least some of the dangers and complications connected with the pill, persist in taking it?"73 For those who did stay on the pill, how did they reconcile the possible risks with continued pill use? A twenty-nineyear old housewife from Toronto cited in Chatelaine the same year explained the dilemma in these terms: "The trouble is that you hear every sickness imaginable blamed on the damned things...you wouldn't believe the things I've heard people say the pill caused-headaches, laziness, overweight problems, swollen feet, and then all the serious diseases like cancer. What it all boils down to is that you simply don't know what to believe or what the medical facts really are. ${ }^{.74}$ As might be expected, there was a range of responses. Seaman reported that the women she spoke to cited the benefits of the pill,

\footnotetext{
${ }^{70}$ Watkins, 115-116.

${ }^{71} \mathrm{Ibid} ., 100$. The 1970 National Fertility Study confirmed the drop-out rate for pill users increased in the late 1960 s. The authors speculated that this phenomenon was due to "anxiety about serious health implications generated by responsible medical experts and sometimes exaggerated publicity."

72 Tone, 249.

${ }^{73}$ Seaman, 48 .

${ }^{74}$ Cited in Batten, 40.
} 
including better complexions, larger breasts, effectiveness and more sexual spontaneity. Particularly, "Some women say that...they know the risks of the pill, but that they are willing to accept them for the sake of the spontaneity it allows them in their sex life." 75 In the same fashion, in my sample, some women disregarded or minimized reports of side effects while others emphasized factors which they felt lessened the risks for them (e.g., age, weight, non-smoker, conversations with their doctors). Nevertheless, another significant group decided to stop taking the pill because of what they heard from friends or in the media.

Some women remembered learning about side effects from friends or in the media but were simply not concerned enough to change their behaviour. Meyer was so anxious to avoid another pregnancy that, though she did hear something about side effects while on the pill, she also felt "if they had said...I'm going to shorten my life by five years, well hell I'm only twenty-five, that's okay...I'll still have a nice life." ${ }^{.76}$ Taylor, a smoker, also heard about several side effects, including the risks associated with pill use and smoking. However, the reports in the media did not bother her enough to either quit smoking or discontinue pill use. ${ }^{77}$ Likewise, Stewart, who suffered from leg aches and headaches while on the pill, thought she read at some point in newspapers about the pill and blood clots but did not stop taking the pill because of the reports. She explained that "when my legs would ache, I guess I would be a little afraid of...[blood clots]...but you'd still keep taking the stupid things...because you just...want to have no more children and how else

\footnotetext{
${ }^{75}$ Seaman, 49-55.

${ }^{76}$ Meyer, 16-17 and 13.

${ }^{77}$ Taylor, 9-10.
} 
are you going to really prevent it, other than condoms or not doing it at all?"78

Shevchenko also heard in 1963 or 1964 "stories about other people on the pill who were smokers and they were having strokes. And of course I think that scared me." However, Shevchenko went off the pill more because of her own side effects. ${ }^{79}$ Finally, Lynch became aware that it might be a good idea to come off the pill after five years. However, for her, "that's when I really dragged my feet because I was terrified if I went off, I would get pregnant and I was willing to risk the side effects." 80

Other women heard about side effects but alluded to, or more explicitly emphasized, that they themselves were not at risk for a variety of reasons. In other

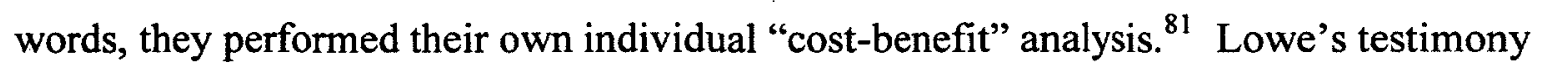
represents a good example of how this process might work and involve the medical profession. She said that she only became concerned about side effects in 1969 , two years after she started on the pill. She discussed the risks with two different doctors, both general practitioners, in 1969 and 1970, the second of whom was more helpful, and also did her own reading on the pill. She concluded she was not in the risk groups being described (smokers, family history of stroke, etc.) and "decided on balance, I still wanted

\footnotetext{
${ }^{78}$ Stewart, 20. Stewart's testimony is not entirely clear here. While she says she did worry about the reports while on the pill, she then seems to contradict this somewhat by stating she was not sure when she read about blood clots and may, in fact, have not been on the pill at the time.

${ }^{79}$ Shevchenko, 11 and 19.

${ }^{80}$ Lynch, 37, 16 and 21 . To provide context to these sentiments, it is important to note that Lynch suffered from debilitating migraines during her two pregnancies.

${ }^{81}$ Watkins, 3. In her study of the pill in the United States, Watkins confirms that "Women's contraceptive choices in the late 1960 s involved a difficult risk-benefit calculation: the benefit of a highly effective contraceptive versus the risk of potentially fatal complications, or the benefit of a barrier contraceptive with no side effects...versus a higher risk of pregnancy."
} 
to stay on the pill cause it was still very important for me not to conceive at that point...but I became increasingly worried about it. ${ }^{, 82}$

Women, like Lowe, did turn to their doctors to help them weigh the risks and benefits of the pill. However, as discussed above, doctors themselves had not reached a consensus on these questions. Additionally, as Lowe discovered, some doctors were more helpful and forthcoming about the risks associated with the pill than others who believed concerns were exaggerated and were irritated by the insistent questions of their female patients. Expressing some of this frustration, an obstetrician, who was part of a 1967 McCall's-American College of Obstetricians and Gynecologists survey, stated in a McCall's article that "Some women just aren't comfortable on oral contraceptives. These are the women who make the phone calls that drive us crazy." Doctors with this sort of attitude might consider women who asked a lot of questions about side effects "difficult." $" 83$

Sometimes age was mentioned as a factor protecting women from the most troubling outcomes of pill use. ${ }^{84}$ Wilkins, for example, took the pill from 1962-1973 and explained that she was not concerned about side effects in the 1960s because "I was younger so you don't ever think that you're going to get older. And you don't ever think

\footnotetext{
${ }^{82}$ Lowe, $4,11,15,16$ and $20-22$. Lowe also added that she had no problems herself. In the interview, Lowe explained that she wished to postpone children so she could work as a lawyer. She may have particularly wished to avoid pregnancy in 1969 and 1970 because she was still establishing her career. In the summer of 1969 , she had graduated from law school and would begin her year of articling that fall. ${ }^{83}$ Alice Lake, "The Pill," McCall's, November 1967, 169. Quoted in Watkins, 97, 101-102 and note 93, page 156. For this survey, conducted by McCall's and the American College of Obstetricians and Gynecologists (ACOG), all the 8,500 fellows of the ACOG were asked to fill out questionnaires concerning the birth-control pill. Ultimately, close to 7,000 did so. See Appendix 2 on this and other surveys. ${ }^{84}$ Clarke, 29.
} 
it's going to happen to you." She only began to worry more in the early 1970 s when she was in her late twenties. ${ }^{85}$

Women, like Lowe, also associated smoking with an increased risk of serious problems on the pill and, consequently, felt they were safer if they were non-smokers. For instance, Young was on the pill for a long time, from 1965 into perhaps the early 1980s, and became increasingly troubled by reports of side effects. However, she reasoned at the time "I wasn't ever a smoker, I wasn't overweight...smoking was a big thing...they did warn you about that."

Women who heard reports of serious side effects alluded to other factors to explain why they did not worry about being on the pill. These included no awareness of having high blood pressure, no history of blood clots and possibly not being on the pill precisely when they heard. ${ }^{87}$ Reid, for instance, heard about an association between blood clots, smoking and the pill. She was concerned about this as her father had a history of phlebitis but, upon reflection, she was not sure if she knew about these risks when she was still on the pill, between 1967-1970, or only heard later when she was considering birth-control options after completing her family in $1972 .{ }^{88}$ Obviously, if she did not know about these risks when on the pill, she would not have had to justify her continued pill use.

The variety of reasons mentioned suggests that pill users were anxious to construct boundaries between themselves and those who suffered rare and serious side

\footnotetext{
${ }^{85}$ Wilkins, 41.

${ }^{86}$ Young, 13.

${ }^{87}$ Murray, 12-13 and 15-16; Morrison, 20. Morrison said she knew when she was on the pill about a connection between the pill and blood clots but commented that people with a history of blood clots should not take the pill.

${ }^{88}$ Reid, 27.
} 
effects. However, Edwards explicitly acknowledged the artificiality of these barriers when she discussed how two women she knew had strokes on the pill. She said that if she was still on it, she did not think these events influenced her decision to go off as "I'd never had any trouble with blood clots or anything but, of course, I don't think these women did either."${ }^{, 89}$

Despite these efforts to mitigate or disregard the risks associated with the pill, some women were happy to stop taking it or chose not to go back on partly because of what they heard regarding side effects, including cancer and blood clots. ${ }^{90}$ Other women had an even more active response to media coverage of the pill. Wilson, for instance, chose to discontinue pill use while she was nursing her daughter in 1967 because she heard that this might be a bad idea. ${ }^{91}$ Beck also chose to go off the pill for a certain period of time because of something she had heard. In her case, it was that the pill might adversely affect a developing fetus so she went off six months before conceiving her third child in $1968 .^{92}$ Stefánsson agreed with Beck and went off the pill about six months before conceiving her children in 1974,1976 and $1979 .{ }^{93}$

Other women went off the pill more permanently because of troubling reports. ${ }^{94}$ For instance, a thirty-two-year old woman, cited in Chatelaine magazine, said "I went back to my diaphragm after I'd been on the pill for three years...It's stupid-I didn't have any problems with my pills, but my husband kept showing me articles about how dangerous they could be, and after a while the whole thing began to get to me. I mean,

\footnotetext{
${ }^{89}$ Edwards, 30 and 32 . Edwards was also not sure if she was coming to the end of her time on the pill (in 1970 ) or was already off it when these events occurred.

${ }_{90}$ Sethna, 2001; Hall, 7; Brown, 21-22; Meyer, 16 and 17; Quinn, 10; Kennedy, 16-17.

${ }^{91}$ Wilson, 12-13 and 29.

${ }^{92}$ Beck, 13.

${ }^{93}$ Stefánsson, 4.

${ }^{94}$ Watkins, 99-100.
} 
what if the articles are right?"95 Mrs. R.T., interviewed by historian Lara V. Marks for her book on the pill, "eventually gave up the contraceptive because of the growing publicity about adverse reactions to the drug and the fears she began to have about what it could do to her health in the long term."96 Some women in my sample made similar decisions. Evans also, while not sure what she heard specifically, went off the pill in about 1972 after five or six years because she began to understand that women could have problems after taking the pill for a long time. She then used condoms until she was ready to have children and never went back on the pill. ${ }^{97}$ Lowe, after deciding to stay on the pill in $1969 / 1970$, went off the pill in about 1973 . While her immediate motivation was to get pregnant, she had been hearing reports about strokes which troubled her. She decided she would definitely not go back on the pill in the future. This decision was probably affirmed for her when a cousin and a friend who were on the pill had strokes around this time. ${ }^{98}$ Anderson was on the pill for a much longer period, from 1965 into the 1980 s, but also went off because of reports of blood clots. In her case, she first discussed her concerns with a doctor in the 1980s who said she would probably be better off on the pill. Consequently, she stayed on for a few more years but then did go off, in part, because a friend's daughter had a stroke while on the pill. ${ }^{99}$

\section{Conclusion}

Women who did not themselves suffer side effects while on the pill could certainly hear about them in the media or from friends. Many women report this was the

\footnotetext{
${ }^{95}$ Batten, 40.

${ }^{96}$ Marks, 212. Mrs. R.T.'s nationality is not provided but, given Marks' particular interest in the United States and Britain, one could safely assume she was from one of these countries.

${ }^{97}$ Evans, 9-12. See note 53.

${ }^{98}$ Lowe, 24-26.

${ }^{99}$ Anderson, 8-9 and 18.
} 
case though it is sometimes difficult to remember what they heard and when. Stories of side effects did trouble some women but not always enough to go off the pill. As we have seen in this chapter, the decision-making process regarding contraception was complex, involving a variety of factors. Some women, like Lynch and Meyer, may have been willing to accept the possibility of serious problems because they feared another. pregnancy even more. Others emphasized that they were not personally at risk because of factors such as age, smoking or medical history. Ultimately, however, not all women were reassured about the pill. They would choose to go off because of the reports of side effects.

Through its side effects, the pill, more than barrier methods of contraception, had an impact well beyond the immediacy of sex. Chapter 6 will continue to explore the influence of the pill on the lives of married, Canadian women who first took it in the 1960s. 


\section{Chapter 6-The Impact of the Pill}

I was always tense and found my self scolding or punishing the children for things that I used to laugh about. Naturally our happy go lucky home soon became one with very few laughs in it. Since I started the use of this pill I have found that I can once more relax and enjoy my family. As a result of this our home is once more a place where our friends like to come, because as a chum of mine said 'Even the house seems happy.'

This is how a twenty-four-year old married mother of four described her experience on the pill in a letter to Chatelaine magazine in March of 1962. She explained that another pregnancy and birth would have put her life in physical jeopardy. According to her, the worry over this possibility influenced her interactions with her children. Once on the pill, her mood and the entire atmosphere of her home shifted. This letter demonstrates one way that the pill could profoundly affect a married woman's life.

In previous chapters, I looked at how the pill's side effects, either personally experienced or heard about, impacted the lives of married, Canadian women who started the pill in the 1960s. I have shown how the pill was unique in its ability to affect lives, beyond sex and fertility, due in part to its systemic nature and side effects. While very important, side effects represent only a part of the pill's impact. This chapter will continue to examine the multifaceted nature of the pill's influences on female lives by concentrating first on the fact that almost since its introduction, the pill has been connected to a "sexual revolution." What was its role in this phenomenon? To what extent was there a sexual revolution among married people compared to the single population? What was the nature of this transformation and when did it occur? To help

\footnotetext{
${ }^{1}$ Letter by Mrs. M. Mulark, Sudbury, Ontario, to Chatelaine, March 13, 1962, Archives of Ontario, Reference Code F138, Barcode B255348, F-4-3-A, Box 215, file February 1962 (1 of 2).
} 
answer these questions, I will consider the testimony of those who lived through the tumultuous period.

I will then discuss the pill's impact upon family size, sexuality and work. This analysis will support the argument, developed in the previous section, that the pill did have a significant influence, perhaps even a revolutionary one, on the lives of married women. I will conclude with an examination of the interplay between religion and the pill. As members of a religion that condemned the pill, and all artificial contraception, Catholic women sometimes found themselves in a difficult position when they went on the pill. Additionally, Christian Science, a religion born of the nineteenth century, was credited as promoting in some women skepticism towards modern medicine and pharmaceuticals, including the pill.

In focusing on these particular areas to describe the pill's impact, I am guided by what my interviewees underlined as important or significant. There are potentially other ways in which the pill affected married (or engaged) women that I will not discuss. For example, it would be interesting to know if the pill, with its reputation for efficacy, influenced some Canadian women to marry earlier than they might have otherwise.

\section{A Sexual Revolution?}

The "sexual revolution" of the 1960s is often associated with and even attributed to the birth-control pill. ${ }^{2}$ According to Canadian historian Doug Owram, the sexual revolution "encompassed many changes in social and sexual behaviour but centred on the

\footnotetext{
${ }^{2}$ For more on the pill's connection to changing social values and behaviour in England, see Hera Cook, The Long Sexual Revolution: English Women, Sex and Contraception 1800-1975 (Oxford: Oxford University Press, 2004), Chapters 12,13 and 15.
} 
collapse of social authority surrounding premarital chastity for women." ${ }^{33}$ Indeed, in Canada, as well as the United States, "In the early sixties, the 'sexual revolution' was used to describe the suspected impact of the newly invented birth control pill on the behavior of white, middle-class, female college students." ${ }^{4}$ Below I will discuss in detail the pill's effect on sexual behaviour. This particular topic has been the subject of much historiographical debate. Now, I wish to briefly explore changing sexual values, which underpinned any shifts in behaviour, before turning to an examination of how individual women, my interviewees, understand the significant social changes occurring in the 1960s.

In $1965,22 \%$ of married, Canadian women in a study of one hundred believed that the pill would cause a decline in sexual morals. ${ }^{5}$ From the mid-1960s to the mid1970s, Canadian sexual values were undergoing significant changes. By the early 1960 s, the idea of sin, once upheld by religion, was losing its relevance, many Canadians were condemning censorship in general and sex was increasingly seen as natural, though girls were still urged to remain sexually pure. In this decade, "Sexual activity, as such, was no longer...condemned. Instead, society judged when sex was appropriate and when it was not." In participating in these sort of evaluations, young people of the 1960 s particularly considered the consequences of sexually-transmitted diseases, pregnancy or lingering

\footnotetext{
${ }^{3}$ Doug Owram, Born at the Right Time: A History of the Baby Boom Generation (Toronto: University of Toronto Press, 1996), 249.

${ }^{4}$ David Allyn, Make Love, Not War: The Sexual Revolution: An Unfettered History (New York: Little, Brown and Company, 2000), 4; Christabelle Sethna, "The University of Toronto Health Service, Oral Contraception, and Student Demand for Birth Control, 1960-1970," Historical Studies in Education 17, 2 (2005), 268.

${ }^{5}$ C.A. Douglas Ringrose, "The Emotional Responses of Married Women Receiving Oral Contraceptives," Canadian Medical Association Journal 92, 23 (June 5, 1965), 1208. Of these 22, 6 particularly said this would occur "if the tablets were available to single women, or juveniles, or without prescription." See Appendix 2 for more information on this study.
} 
social criticism. Penicillin and the Pill, amongst other things, mitigated these concerns and, consequently, there was a "redefinition of appropriate sexual morality."

Many interviewees, who lived through this period, do associate the pill with a "sexual revolution." It is worth noting that these types of claims are probably much easier to make in retrospect. Seventy-two married Canadian women, as part of a 1965 study, published in the Canadian Medical Association Journal, seemed less convinced about the pill's social impact and asserted that it would not lead to a decline in sexual morals. Some of them (17) "considered that no deterioration would result because doctors controlled distribution of the drug." This affirms a possible common impression, discussed in Chapter 3, that physicians would only prescribe the pill to married or engaged women. ${ }^{8}$

The women I interviewed, unlike those in Ringrose's study, had the benefit of hindsight, having witnessed how social changes unfolded (or not) in the 1960s and 1970s. Their perspectives, like all those who participate in oral history projects, are, therefore, necessarily informed by the passage of time as well as their own experiences during these years. Decades later, what does the "sexual revolution" mean to them and how was the pill involved? As part of this phenomenon, the pill is often credited with averting unwanted pregnancies, reducing the worry associated with such possible events,

\footnotetext{
${ }^{6}$ Owram, 249, 261-264, 269-270.

${ }^{7}$ Interview with Eva Green, June 23, 2009, 12; Email correspondence from Ruth Wright, July, 2009, 3 ; Interview with Caroline Mason, July 29, 2009, 17; Interview with Katherine Quinn, August 14, 2009, 20; Interview with Eileen Stewart, August 18, 2009, 27; Interview with Jane Lynch, October 6, 2009, 36; Interview with Judy Meyer, October 8, 2009, 19; Interview with Olivia Klein, October 20, 2009, 41; Interview with Ellen Jackson, October 23, 2009, 35; Interview with Anne Ryan, October 27, 2009, 19; Interview with Rose Murray, October 28, 2009, 25; Interview with Jean Watson, November 3, 2009, 23; Interview with Charlotte Dawson, November 5, 2009, 20; Interview with Betty Shevchenko, November 9 and 10, 2009, 23; Interview with Cora Stefánsson, November 23, 2009, 16; Interview with Vivian Koch, January 21, 2010, 23; Interview with Cynthia Young, February 8, 2010, 22; Interview with Jane Arsenault, March 2, 2010, 28; Interview with Emma Edwards, April 12, 2010, 41; Interview with Lydia Stevens, November 20, 2009, 22.

${ }^{8}$ Ringrose, 1208.
} 
enhancing sexual freedom, especially for women, and providing a straightforward method of birth control..$^{9}$ It has even been labeled as a catalyst or, at least, a large part of the social upheaval. ${ }^{10}$ Clarke, for one, said the birth-control pill came to symbolize for her resistance to patriarchal rules which had dictated female roles. ${ }^{11}$ However, others are more cautious in giving the pill such a defining role and articulate a more complex interpretation, suggesting additional factors were also at play in the dramatic social upheaval of the period including the admission of women into professional careers which promoted more equal interactions with men and evolving attitudes towards marriage and divorce. ${ }^{12}$ These trends predated and were not necessarily a consequence of the pill. While they still acknowledge that the contraceptive was important, Carter questioned, at least when she first heard about it, if the pill deserved to be considered revolutionary at all since people were clearly already using other forms of birth control to successfully restrict their family size. ${ }^{13}$ Thus, even women who lived through the dramatic changes of the 1960s do not agree on the precise role and relative importance of the pill in the socalled sexual revolution.

\footnotetext{
${ }_{9}^{9}$ Lynch, 36; Meyer, 13 and 19; Jackson, 35; Dawson, 20; Stefánsson, 16-17; Interview with Eleanor Doyle, November 30, 2009, 15; Interview with Mary Jones, December 3, 2009, 20; Interview with Diane Galli, December 8, 2009, 17; Koch, 23-24; Interview with Cindy Harrison, January 25, 2010, 23; Interview with Deborah Campbell, February 9, 2010, 22; Interview with Claire Macdonald, March 11, 2010, 30.

${ }^{10}$ For example, Macdonald, 30.

${ }^{11}$ Interview with Cheryl Clarke, November 12, 2009, 26.

${ }^{12}$ Wright, email, 3-4; Interview with Elizabeth Kennedy, November 10, 2009, 23-24; Doyle, 14-15.

${ }^{13}$ Ringrose, 1208; Interview with Ellen Carter, February 12, 2010, 7-8, 29. Carter said she ultimately concluded that the pill was considered significant for family planning because, though other methods did exist, it was easier to use, more reliable, and allowed spontaneity. Two women in Ringrose's study likewise questioned the impact of the pill, in their case on sexual morals, given the existence of other birth control.
} 
In addition, many interviewees particularly associate the pill with changes in the lives of single women. ${ }^{14}$ They speculate that the pill promoted sexual freedom before marriage and even promiscuity, and not everyone thought these were positive developments. ${ }^{15}$ As Quinn explained, "every technology has an upside and a downside and so the upside of it, for married people, would be the opportunity to space your family and to be responsible about your choices and the downside might be that it might encourage promiscuity and so on."16 Women I interviewed, as well as possibly those in Ringrose's study, also emphasized that the pill would have impacted unmarried women by decreasing the dread of an unplanned pregnancy and its accompanying horrors (i.e. social stigma, adoption, etc.). ${ }^{17}$ In her book on the pill, which focuses on the United States and Britain, historian Lara V. Marks confirms that "the oral contraceptive provided a vital release from the age-old torment of possible pregnancy. Given the social and financial difficulties many single women experienced on having a baby, the possibility of pregnancy provoked substantial fear."18 A desire to alleviate this concern may have attracted unmarried Canadian women to the pill. "Joan," for instance, a single, university student, profiled in the University of Toronto's student newspaper in 1967, went on the pill following a pregnancy scare. ${ }^{19}$ My interviewees affirm that fear of pregnancy was pervasive among single women. As Wright explained, "we were all trained that if we

\footnotetext{
${ }^{14}$ Interview with Susan Walsh, November 24, 2009, 13; Klein, 41 and 47-48; Green, 12. Suggesting that she was particularly thinking about single people, Green said that she "could see how...[the pill] would free women and their boyfriends or whatever to become sexually active...without risk of children."

${ }^{15}$ Young, 22; Mason, 17; Stewart, 27-28. Mason and Stewart seem to connect the sexual revolution to sexually-transmitted diseases (or at least the spread thereof).

${ }^{16}$ Quinn, 20.

${ }^{17}$ Interview with Margaret Wilson, August 12, 2009, 21; Young, 22. Ringrose, 1208. Six, of the one hundred married women, who participated in Ringrose's study felt that pill would trigger an erosion of sexual morals because it removed the fear of pregnancy.

${ }^{18}$ Lara V. Marks, Sexual Chemistry: A History of the Contraceptive Pill (New Haven: Yale University Press, 2001), 203.

${ }^{19}$ Sethna, 2005, 281.
} 
had sex even once, we would immediately get pregnant and ruin our lives if we weren't married. .20

However, despite impressions of dramatic social changes, it is important not to present the "sexual revolution" as complete or inclusive in the 1960s. Its transformative power was uneven, sometimes not penetrating all groups of society simultaneously. ${ }^{21}$ For instance, Walker reflected that, even with the pill, she and her friends did not feel they had liberal sexual freedom in the $1960 \mathrm{~s}^{22}$ In addition, while it may have prevented unwanted pregnancy and the associated worry about such a possibility, Smith also reflected that the new contraceptive did not really alter human sexuality. She had thought that perhaps it would diminish sex as a consuming, driving force in people's lives but this did not seem to occur. ${ }^{23}$ Finally, as mentioned above, the term "sexual revolution" was also used specifically in the early 1960s to describe the impact of the pill on white, female college students, most of whom were probably unmarried. But even in this case, historians continue to fiercely debate both the role of the pill and the larger issue of actual changes in sexual behaviour among single women. ${ }^{24}$ First, premarital sex seemed to increase before the pill was widely available. ${ }^{25}$ Additionally, several historians have demonstrated and several of my interviewees recall that single women had restricted

\footnotetext{
${ }^{20}$ Wright, email, 3.

${ }^{21}$ Interview with Annie Beck, November 6, 2009, 26; Interview with Hazel Evans, December 1, 2009, 13. A few women emphasized that their friends, their generation or even their region of the country did not experience the pill as part of a sexual revolution. Evans even felt that, in Nova Scotia, the sexual revolution was non-existent.

${ }_{22}^{23}$ Interview with Joan Walker, October 15, 2009, 23-24.

${ }^{23}$ Interview with Catherine Smith, July 9, 2009, 20.

${ }^{24}$ Sethna, 2005, 268-269; Elaine Tyler May, American and the Pill: $A$ History of Promise, Peril, and Liberation (New York: Basic Books, 2010), 71, 79-82.

${ }^{25}$ Christabelle Sethna, "A Bitter Pill: Second Wave Feminist Critiques of Oral Contraception," in Canada: Confederation to the Present, eds. Bob Hesketh and Chris Hackett (Edmonton: Chinook Multimedia Inc., 2001), http://chinookmultimedia.com/poccd/registered/web papers/case studies5.php. Sethna points out that the number of single mothers jumped between the years 1962 and 1967, suggesting that more unmarried women were having sex.
} 
access to the pill in the 1960 s, making it unlikely that the pill alone could be responsible for changes in their behaviour. ${ }^{26}$ In her study of the pill in the United States, from 1950 to 1970 , Watkins explains that "The pill did indeed revolutionize birth control, and radical changes in sexual attitudes and conduct did take place, particularly among young people, but no one ever established a connection between these two phenomena."27

If the pill did not necessarily trigger a sexual revolution among single people in the 1960 s, what about those who were married? Historians have considered this question in the American and British contexts. Drawing on the work of demographer Michael Murphy, Hera Cook argues that the decline in British fertility in the 1970s was largely due to the pill. Looking specifically at the years 1970 and 1976, Murphy found that the number of conceptions among married couples dropped by $30 \%$. His study confirmed there was no significant increase in the number of couples using some form of birth control but, "what did change between 1970 and 1976 were the proportions of women in the first five years of marriage using the pill as contraception." For Murphy, it would seem the pill was so influential in these trends because of its enhanced efficacy. ${ }^{28}$ American studies from 1965 and 1970 showed that the pill was supplanting other methods, like the diaphragm and the condom. Indeed, "according to these national surveys...oral contraceptives were the predominant method of birth control among married Americans in the 1960s. ${ }^{29}$ My interviews confirm, as discussed in Chapter 2, that many Canadian women similarly jettisoned other contraception in favour of the

\footnotetext{
${ }^{26}$ Owram, 267; Sethna, 2001; Sethna, 2005, 291; May, 72; Cook, 274-275 and 279.

${ }^{27}$ Elizabeth Siegel Watkins, On the Pill: A Social History of Oral Contraceptives 1950-1970 (Baltimore: Johns Hopkins University Press, 1998), 55.

${ }^{28}$ Cook, 268-270.

${ }^{29}$ Watkins, 61-62.
} 
pill. ${ }^{30}$ Historian Elizabeth Siegel Watkins concludes in her study of the United States that a contraceptive revolution, sparked by the pill, did occur among the married population. ${ }^{31}$ May agrees that the pill precipitated a contraceptive revolution and stated that "Unquestionably, the pill had its greatest impact within marriage. The long-term benefits for married women were profound. The ability to plan and space the birth of children allowed them to take advantage of educational and professional opportunities that unexpected pregnancies precluded. ${ }^{\text {32 }}$

Canadian women I interviewed concur that the pill created revolutionary changes in the lives of married women. ${ }^{33}$ In particular, they emphasize that it allowed married women to space, plan or limit their pregnancies. ${ }^{34}$ As Morrison said, the pill freed the married woman "from having a child that... would suddenly totally change her whole life and forever...it gave women freedom finally to make decisions that affected their lives." ${ }^{, 35}$ In turn, Klein felt that the ability to decide when to have children was important in enabling women to excel in their careers. ${ }^{36}$ Edwards echoed this sentiment somewhat when she said that, with the pill, "you didn't have to worry about having too many children and you could spend more of your adult life doing something else besides taking care of children., ${ }^{, 37}$ The pill also impacted marital sexuality, as will be discussed more below. Wilkins said that before the introduction of the pill, there were [married] men apologizing to women for having sexual urges, men apologizing to women if they didn't withdraw in time, couples really worried because if they had any more kids...they couldn't afford to take

\footnotetext{
${ }^{30}$ Chapter 2, 7-14.

${ }^{31}$ Watkins, 2, 53 and 61-63. Watkins distinguishes this revolution from the sexual revolution.

${ }^{32}$ May, 4 and 79.

${ }^{33}$ Stewart, 30; Klein, $41-42$ and 47.

${ }^{34}$ Murray, 25-26; Campbell, 22-23.

${ }^{35}$ Interview with Caroline Morrison, March 9, 2010, 27-28.

${ }^{36}$ Klein, 41-42.

${ }^{37}$ Edwards, 41.
} 
care of them, couples concerned and terrified that... [the woman] whose health was at risk if they got pregnant...would die and I mean, you cannot emphasize enough and I cannot strongly emphasize enough to you what it was like before the pill. ${ }^{38}$

With all these possible concerns, some couples were afraid to even have sex. ${ }^{39}$ Jones concurred that some women had been, before the pill, inhibited during sex because they feared the possibility of a pregnancy. ${ }^{40}$ Finally, some women also suggest that the pill might have been transformative in the lives of married women because it could or did facilitate extramarital affairs. ${ }^{41}$

Therefore, if the pill's impact on single people is by no means certain or clear, both historians and pill-users agree that the pill did facilitate revolutionary changes in the lives of married women. The next sections will explore these transformations in more detail, focusing on sexuality, careers, family size and religion.

The Pill: A Boon to Sexuality?

This section will explore the complex question of the pill's ramifications for married women's sexuality. I will address, first, how it may have enhanced spontaneity, sexual freedom and even desire before discussing women who found the pill actually undermined their sexual experience. Finally, I will include the testimony of those who, despite its reputation for effecting radical change, recalled no significant transformation in their sex lives because of the pill.

\footnotetext{
${ }^{38}$ Interview with Yvonne Wilkins, September 30, 2009, 29-30.

${ }^{39}$ Ibid., 30-31.

${ }^{40}$ Jones, $20-21$.

${ }^{41}$ Watson, 23; Young, 22; Arsenault, 28; Wilson, 21. In this situation, Wilson seems to imply that the pill would have more effectively prevented the birth of a child who did not resemble one's husband. See also Ringrose, 1207 and 1209. In Ringrose's intriguing study of 100 married women taking Ortho-Novum $2 \mathrm{mg}$, "One woman in five (22\%) predicted an increase in premarital and extramarital sexual relations as a result of tablet-induced infertility."
} 
The new contraceptive was appealing to many women, as discussed in Chapter 2, because, it was not only very reliable, but it was also divorced from the act of sexual intercourse which allowed a more spontaneous and pleasurable sex life. ${ }^{42}$ In sum Highly effective, the pill eliminated women's anxiety about an unwanted pregnancy. Neat in appearance and simple to take, the pill eased women's concerns over the use of female-dependent barrier methods that were often messy and complicated. And because the pill was a coitus-independent method of contraception, it permitted women the liberty of engaging in spontaneous lovemaking that could progress uninterrupted toward coitus. ${ }^{43}$

Public speculation on the impact of the birth-control pill on sexuality has frequently focused upon single women. Indeed, as I outlined earlier in the chapter, the term "sexual revolution," as narrowly defined in the early 1960s, was applied to a particular group of women, university students, who were much more likely to be single. Often, perhaps because they did not need to fight as much for access to birth control, as outlined in Chapter 3, married women's experiences have remained more private. Additionally, since married women's sexual activity and reproduction is condoned and often approved by society, some may assume that they felt relatively little or no anxiety about the possibility of pregnancy, particularly in comparison to single women. ${ }^{44}$ However, in the 1960s this was simply not the case. In fact, testimony indicates that, for many, the pill did indeed have a significant effect on their sex lives. Ringrose's study of one hundred

\footnotetext{
${ }^{42}$ Marks, 193-194; May, 1, 57 and 147; Watkins, 54; James Reed, From Private Vice to Public Virtue: The Birth Control Movement and American Society since 1830 (New York: Basic Books, 1978), 311.

${ }^{43}$ Sethna, 2001.

${ }^{44}$ Interview with Isabelle Lowe, April 27, 2010, 9, 32-34. In our interview, Lowe, who started on the pill as a single woman, advanced a similar opinion. She asserted that, though the pill would have been useful to married women, their sex lives were both more predictable and more acceptable. Therefore, the pill, in her view, had a much greater significance for single women in decreasing their anxiety about premarital sex and providing a simple contraceptive.
} 
married women taking the pill found that "Fifty-three per cent reported improved...[sexual enjoyment] while $4 \%$ noted the opposite effect. ${ }^{\text {}}{ }^{45}$

Many Canadian married women interviewed for this thesis who had used other birth-control methods confirmed that the pill brought a spontaneity and freedom to their sex lives. ${ }^{46}$ Some agreed this was the case when asked specifically, while others mentioned this advantage more independently and emphatically. ${ }^{47}$ Hall, for example, who had also previously used a diaphragm for several years, stated that "[the pill meant] if you wanted...to have sex spontaneously, you didn't have to rush to the bathroom and put in a diaphragm so it really relaxed it a bit. ${ }^{, 48}$ Clearly, the diaphragm could diminish spontaneity, which was valued by many women on the pill. ${ }^{49}$ Other methods, such as rhythm, could also inhibit sexuality in this way. ${ }^{50}$

Pill users with no or little previous birth control experience also believed, though lacking the direct comparison, that the pill allowed them greater sexual spontaneity and freedom. ${ }^{51}$ For instance, Wright commented that "We had none of the worries of getting pregnant before we were ready, and so we felt free to have sex as desired." ${ }^{52}$ Clarke explained further that, with the pill, there was "no did we run out of condoms or is there a diaphragm? Umm, is this going to be reliable or not? I mean there was...that freedom and confidence that you didn't...provided you followed the rules and took them every

\footnotetext{
${ }^{45}$ Ringrose, 1207 and 1209.

${ }^{46}$ Lynch, 12, 20, 22, 24-25 and 32; Dawson, 5-13, 22-23; Arsenault, 5 and 27; Klein, 22-24, 27, 40-41; Smith, $2,4,5,11$ and 18 .

${ }^{47}$ Meyer, 5, 9-11, 21; Morrison, 9 and 25; Interview with Beverley Brooks, October 19, 2009, 4, 6 and 17.

${ }^{48}$ Interview with Julia Hall, June 29, 2009, 1, 21 and 14.

${ }^{49}$ Carter, 3, 4, 6, 20-22; Barbara Seaman, The Doctors' Case Against the Pill (New York: Peter H. Wyden, Inc., 1969), 56-58.

${ }^{50}$ Galli, 5, 7 and 19.

${ }^{51}$ Interview with Susan Brown, August 7, 2009, 3 and 9, Follow-up Interview, December 11, 2009, 3; Brooks, 17; Clarke, 22; Watson, 6-8 and 10; Interview with Beth Reid, November 18, 2009, 5-6, 22; Evans, 2-3, 5, and 13-14; Macdonald, 17 and 28; Quinn, 4, 8-10, 18. In Quinn's case, she compared the pill favourably in this regard to her subsequent use of the diaphragm.

${ }^{52}$ Wright, email, 3; Interview with Ruth Wright, July 8, 2009, 2.
} 
day, you didn't have to think about it again." ${ }^{, 53}$ Therefore, many married women valued the pill because of its real or perceived ability to facilitate a spontaneous sex life. This advantage did not cease to matter simply because they were married and demonstrates one way the pill had an impact on marital sexuality.

The freedom to have sex where and when desired, with little planning or preparation involved, could improve sex for married couples. However, not all women limited their sexual contact to their husbands. As mentioned above, some wondered whether the pill would facilitate sex outside of marriage. If a single woman accessed the pill, she might find it sexually liberating. For instance, Lowe credited the contraceptive with allowing her sexual experience to happen when she was not yet engaged. ${ }^{54}$

However, this is only one individual and historians need to explore further the connection between the pill and increasing rates of premarital sex. Within marriage, Barbara Seaman wrote in 1969 that "the pill apparently does not cause promiscuity to any extent." She based her conclusion on Drs. David Rodgers and Frederick Ziegler of The Cleveland Clinic who reported women taking the birth-control pill actually had fewer extramarital affairs than women whose husbands had had vasectomies. However, she did not clarify if, with the advent of two such reliable methods of contraception, more women were indeed pursuing such relationships. ${ }^{55}$ In my sample, it was clear that the pill could increase a woman's sexual freedom outside of marriage. Claire Moore, who started taking the pill in about 1968 after completing her family of four, felt that she did take

\footnotetext{
${ }^{53}$ Clarke, 21.

${ }^{54}$ Lowe, 4, 9, 14, 27-31, 32-34. However, later in the interview, Lowe elaborated that, if the pill had not been available, she "would have tried to get a diaphragm or insisted on condoms." After the birth of her first child, she did have a diaphragm and did not think this method significantly impacted her sex life. At this time, she had the impression the diaphragm was quite reliable and that she was in a better position to handle an unplanned pregnancy anyway.

${ }^{55}$ Seaman, 132-133.
} 
advantage of the freedom afforded by the pill to pursue an extramarital affair in the late 1960 s and early 1970 s. $^{56}$ She said that the pill liberated her to explore her sexuality outside of marriage. ${ }^{57}$. Thus, it seems the pill could, as it did for Moore, promote sexual expression for married women, though not necessarily with their husbands.

For some women, the pill also impacted female sexuality by increasing sexual desire. If Barbara Seaman said in her book that only "one to two per cent of pillusers...have experienced an increase in sex drive and a new ability to reach climax," other sources suggest the numbers were higher..$^{58}$ For example, the 1965 Ringrose study of married women found that twenty-two percent of women on the pill reported increased sexual desire. ${ }^{59}$ Wood, even if she experienced troubling psychological side effects on the pill, actually thought the pill may have contributed to her enjoyment of sex. ${ }^{60}$ While not experiencing an increased libido per se, the pill did apparently alter, perhaps positively, the sexual dynamic between Meyer and her husband. She said that "I became a nicer wife. I was far more accepting of my husband when he wanted sex and I didn't." ${ }^{, 61}$

Furthermore, as well as the opportunity for spontaneity, discussed in Chapter 2, the pill also appealed to many married women because it effectively removed or reduced the fear of pregnancy. This in itself could have a positive impact on sexual experience. ${ }^{62}$

\footnotetext{
${ }^{56}$ Interview with Claire Moore, November 17, 2009, 1, 2, 14, 15 and 19-20.

${ }^{57}$ Ibid., 29-30.

${ }^{58}$ Seaman, 130-131. Seaman, perhaps because of her overarching interest in revealing the negative and troubling aspects of pill use, seemed rather dismissive of this potential upside. She said it "is not all moonlight and roses and pulsating excitement," as some of these women developed persistent sexual cravings which turned them into nymphomaniacs.

${ }^{59}$ Ringrose, 1208.

${ }^{60}$ Interview with Emily Wood, July 6, 2009, 4, 13-15.

${ }^{61}$ Meyer, 23.

${ }^{62}$ Marks, 192, 194-195; Interview with Penelope Dobos, July 7, 2009, 7; Wilson, 20; Wilkins, 30; Klein, 40; Ryan, 14; Harrison, 22-23; Macdonald, 29; Interview with Heather Anderson, December 3, 2009, 11 -
} 
While the consequences of an unintended pregnancy for married women were perhaps not as catastrophic as for single women, it is worth noting that the former may have had sex more regularly and, therefore, were exposed to an increased risk of pregnancy. Jones explained that "I think...[the pill] probably made for a more relaxed relationship with my husband...because you're not thinking; oh my God, I'm going to get pregnant so you have a much more relaxed sex life." ${ }^{, 63}$ When asked about the pill's impact on sexuality, some women also describe a general feeling of relief or relaxation which could be connected to the decreased risk of pregnancy but also the convenience of the pill. ${ }^{64}$ Ramsey, for one, explained it was a "feeling of relief...that was one thing I didn't have to think about anymore." 65

If many married women reported an improvement in their sexual experience because of the pill which could enhance spontaneity, increase desire, mitigate concerns over pregnancy and even allow them to seek sexual gratification outside the marriage, it is also important to note that some women experienced a decline in libido or sexual enjoyment while on the pill. The possible connection of this phenomenon with the pill was reported in Barbara Seaman's 1969 book. One married woman, cited there, described herself as "sexually apathetic" on the pill. She had little or no interest in sex with her husband; another reported that she was unable to have orgasms while on the pill. Seaman noted further that, deprived of any pretense to avoid sex, many women were

\footnotetext{
12. However, Anderson added that even before the pill, she did not worry that much about getting pregnant.

${ }^{63}$ Jones, 17-18; Marks, 192. In her book, which focuses on the United States and Britain, Marks also argues that this near perfect efficacy totally altered expectations of birth control. People were now less likely to accept that pregnancy was always possible if you were sexually active, no matter what birth control you used. Instead, they "began to measure the efficacy of other contraceptives against the standard set by the pill."

${ }^{64}$ Murray, 25; Watson, 23.

${ }^{65}$ Interview with Mary Ramsey, October 29, 2009, 15.
} 
beginning to feel "The excitement, the sense of oneness, that satisfaction that she used to find in sex slowly disappears as it becomes just another chore like counting the laundry. .66

My interviews confirmed that the pill could have a detrimental effect on female sexuality for a number of reasons. Several women, representing about eight percent of my sample; stated that the pill seemed to diminish their sexual desire or libido. ${ }^{67}$ Klein, though concurring that the pill made her more relaxed about sex, felt that the persistent absence of desire she experienced even contributed to the disintegration of her first marriage. ${ }^{68}$ In the Ringrose study, discussed above, thirteen percent of women on the pill said they had experienced a decrease in desire. ${ }^{69}$ To partly explain this correlation, Barbara Seaman's book suggested that, for some women, the removal of the possibility of pregnancy, occasioned by the pill, could actually adversely affect sexual enjoyment. She explained "Psychiatrists suspect that this loss [of sexual excitement] comes about because the risk of pregnancy may itself be titillating to some.",70 In my interviews, Richards seemed to hint that this may have been a factor in her experience on the pill. ${ }^{71}$ Thus, while the pill could enhance sexuality for some married women by increasing libido, it could also have the opposite effect.

\footnotetext{
${ }^{66}$ Seaman, 127-128, 130-132; Jack Batten, "Is There A Male Conspiracy against The Pill?" Chatelaine 42, 7 (July 1969), 41. Though beyond the scope of my research, a 1969 article in Chatelaine magazine also suggested that the pill could have an adverse effect on male sexuality. According to Dr. M.J. Meldman, a Chicago psychiatrist, "many husbands see the pill- with its power to release their wives from pregnancy fears and thus to encourage them into more relaxed and even aggressive activities in bed- as a terrifying threat to their own sense of masculinity." On this subject, see also Marks, 198.

${ }^{67}$ Interview with Elizabeth Thompson, June 11, 2009, 22; Klein, 13, 15 and 23; Edwards, 19, 22, 40-41; Morrison, 17-18, 25; Marks, 194.

${ }^{68}$ Klein, 13, 15, 23 and 40 . However, as mentioned above, Klein did not find this to be an issue with her second husband.

${ }^{69}$ Ringrose, 1208.

${ }^{70}$ Seaman, 133.

${ }^{71}$ Interview with Alice Richards, December 7, 2009, 9, 25 and 26.
} 
For other women, the pill's side effects made sex thoroughly unappetizing or even logistically impossible. First, the pill could cause vaginal dryness in a small number of women which made sex difficult. ${ }^{72}$ Barbara Seaman's book is the only existing source to discuss this problem, confirming perhaps that it was not that common. Pamela R., a twenty-three-year old married woman, cited in Seaman's book, experienced both a loss of sexual desire and vaginal dryness on the second pill she tried. In her words, "I started having real pain during sex. My vagina wasn't moist enough. It wouldn't expand. I was very dry, no matter how much Ron would stimulate me. When he entered me, I would get a burning sensation and sometimes I would scream at him to stop. I was frightened. And I felt that I just wanted to get away from sex." Pamela switched to a diaphragm after talking to her doctor. ${ }^{73}$ One of my interviewees reported a comparable experience. Mason said that, on the pill, she did suffer from vaginal dryness which made sex painful. Even if this problem persisted when she went off the pill, she associated it, at least by the time of our interview, with the contraceptive. ${ }^{74}$

A married woman's sex life could also be disrupted by side effects that did not directly affect sexual activity. ${ }^{75}$ In retrospect, Kennedy reflected that the fatigue she seemed to experience on the pill may have had an effect on her sex life, though she agreed the pill also made her less concerned about getting pregnant. ${ }^{76}$ Stewart's side effects, including headaches, leg aches and mood changes, were more extreme, and the

\footnotetext{
${ }^{72}$ Seaman, 131. Seaman suggested that only about two or three percent of women on the pill reported this problem and it usually ceased once they discontinued the pill. ${ }_{73}^{73}$ Ibid., 143-144.

${ }^{74}$ Mason, 5 and 14-15. Mason said at the time she did not connect this problem to the pill. Since it did not resolve after she went off, it in unclear exactly how she knew it was a side effect.

${ }^{75}$ Ringrose, 1208. In his study, Ringrose noted that, of the 13 women who reported a diminished libido on the pill, almost half suffered other side effects including weight gain, skin discoloration, fatigue and nervousness. Though he does not suggest this, it is possible that these problems had an adverse effect on their sex drives.

${ }^{76}$ Kennedy, 10, 17, 19-20.
} 
pill totally removed her desire for sex, as she reported "I couldn't stand anything, I was in such a bad mood, I didn't feel loveable, I didn't feel loved, I didn't feel nothing (sic)." Stewart added that she wanted sex more often when not on the pill. ${ }^{77}$ Campbell, on the pill for only a short time because of faintness, dizziness and fatigue, was quite sure it had a negative effect on her sex life. She recalled "I was thinking it would work as...a birth control because there was no way I was going to have intercourse feeling like that...And I mean if you're about to vomit, I don't think you're very appealing." ${ }^{, 78}$ Koch's husband apparently made a similar observation. He commented at the time, perhaps with a certain ironic humour, that the pill was most definitely an effective means of contraception because it caused Koch to experience persistent bleeding which, as one could imagine, hampered their sexual relationship. ${ }^{79}$ Thus, women who experienced significant or sexual side effects found that the pill, rather than liberating them in the bedroom, diminished or quashed their sex lives.

Before concluding this section, it is also important to note that it was possible for the pill to have no significant impact on sexuality. For example, Dr. Ringrose's study of one hundred women on the pill found that, while twenty-two percent reported more sexual desire than before the pill and thirteen percent reported less, the majority (55\%) actually experienced no difference. ${ }^{80}$ Likewise, a number of women I spoke with did not think or were not sure, when I asked specifically about it, that the pill had any significant impact on their sex lives. ${ }^{81}$ In Scott's case, this may have been because she only took the

\footnotetext{
${ }^{77}$ Stewart, 7-9, 14 and 17.

${ }_{78}^{78}$ Campbell, 11,12 and 19.

${ }^{79} \mathrm{Koch}, 12,21-22$.

${ }^{80}$ Ringrose, 1208.

${ }^{81}$ Beck, 18 and 20; Shevchenko, 22 and 25; Walsh, 12; Stefánsson, 16; Doyle, 11; Interview with Evelyn Scott, December 12, 2009, 6 and 16; Young, 21. Later in the interview, Beck volunteered that the pill was "less intrusive in our sex life." When asked, a couple of these women agreed that the pill might have
} 
pill for six to eight months. She agreed that the pill may have been sexually freeing for her but she did not have any vivid recollections of this given that she was only on it for a short time. ${ }^{82}$

Other factors could also explain why the pill was not as important to some women's sexuality as it was to others. While acknowledging the pill did facilitate spontaneity, when asked directly about its impact on her sex life, Reid pointed to a wider social context saying "I don't think the pill had...as much an impact as sort of the whole women's movement where women took more control over their own sexuality and the acknowledgment that they were sexual human beings. That they could have orgasms and if they weren't, there'd better be some conversation about why not." She hinted that the pill may have allowed the discussion to shift to other crucial facets of female sexuality ${ }^{83}$

Ultimately, then the pill's impact on the sexuality of married women was significant but complex. While for many it could enhance their experience, by decreasing fear of pregnancy and increasing spontaneity, desire and even the freedom to look outside the marriage, the pill, for a significant number in my sample, could also sabotage marital sexuality with its side effects, including fatigue, vaginal dryness and loss of sexual desire. The fact that ten women, out of fifty-three, reported some sort of detrimental effect on their sex lives because of the pill is significant and suggests once again the need to look beyond the stereotype of the pill as the "Great Emancipator."

enhanced spontaneity or diminished a fear of pregnancy. However, these factors were apparently not as consequential for them as for other women.

${ }^{82}$ Scott, 6 and 16.

${ }^{83}$ Reid, 22 and 21 . This is a very interesting consideration of the influence of the women's movement on understandings of female sexuality. As discussed in Chapter 2, it was unusual, at least in my sample, for women to refer to second-wave feminism in their discussions of the pill. 
Whether exerting a positive or negative influence, my analysis has also demonstrated the many changes the pill affected in the bedrooms of married, Canadian couples.

\section{Family Size}

In her book on British couples, most of whom married in the 1930s, Kate Fisher finds these individuals did not adopt a family planning mentality in which they "discussed the issue and made calculated and firm decisions either to have a child or to avoid one." On the contrary, except for some in the middle class, they "rejected what they saw as the overly deterministic approach to life adopted by modern society, and saw a calculative attitude towards such unpredictable variables as pregnancy and childbirth as detracting from the mystery and magic of reproduction." Indeed, they denied having any firm sense regarding how many children they might have wanted and stressed, instead, that babies "just came." McLaren and McLaren, in their book on Canadian contraception, do find evidence that some Canadians in the 1930s "wanted birth control information so they could plan their families in a purposeful manner." However, perhaps confirming Fisher's finding, these women, who wrote to Marie Stopes, were primarily middle-class. ${ }^{85}$

After World War Two, the Canadian government, maintaining a role it had adopted during the conflict, was very involved in planning society and the economy with such measures as family allowances, first passed in 1945. According to polls, “a majority [of Canadians], impressed with the efficiency with which the wartime economy was regimented and the transition from a surfeit of workers to a labour shortage, also wanted

\footnotetext{
${ }^{84}$ Kate Fisher, Birth Control, Sex, and Marriage in Britain, 1918-1960 (Oxford: Oxford University Press, 2006), 4, 76-78, 91 and 104.

${ }^{85}$ Angus McLaren and Arlene Tigar McLaren, The Bedroom and The State: The Changing Practices and Politics of Contraception and Abortion in Canada, 1880-1980 (Toronto: McClelland and Stewart, 1986), 26 and 28.
} 
a planned economy for Canada in peacetime. ${ }^{, 86}$ Possibly reflecting this new enthusiasm for planning, the majority of postwar parents, at least by the 1960 s, embraced the idea that families and children should likewise be the product of careful consideration. Brenda Appleby, in her book on the legalization of birth control, argues that Protestant churches in Canada, by the mid-1960s, had also adopted the idea of "responsible parenthood." This concept "called spouses to fulfil their parental duties and be willing to be held accountable for them. Their most basic duty was to plan their families with regard to the number of children and frequency of childbearing in accordance with the family's needs and means." Further, "Each child had a right to be wanted and cared for., 87

Thus, there were potentially several sources for the family planning rhetoric which, as I will show below, was clearly circulating in Canada by the $1960 \mathrm{~s}^{88}$ Most of my interviewees, from various socioeconomic situations, in response to questions about discussing family size or children with their fiancés or husbands, indicated a degree of planning. ${ }^{89}$ For instance, Taylor, married in 1967, said "We talked about having children and I said I wanted a big family and he didn't really think he wanted a very large family

\footnotetext{
${ }^{86}$ Dominique Marshall, The Social Origins of the Welfare State: Québec Families, Compulsory Education, and Family Allowances, 1940-1955, trans. Nicola Doone Danby (Waterloo: Wilfrid Laurier University Press, 2006), 1 and 19-21; Alvin Finkel, Social Policy and Practice in Canada: A History (Waterloo: Wilfrid Laurier University Press, 2006), 125-126.

${ }^{87}$ Brenda Margaret Appleby, Responsible Parenthood: Decriminalizing Contraception in Canada (Toronto: University of Toronto Press, 1999), 7 and 158.

${ }^{88}$ Carter, 6-7. As part of her answer on a question regarding what she first heard about the pill, Carter implied that the phrase "family planning" was ubiquitous.

${ }^{89}$ Thompson, 14; Green, 8; Hall, 5-6; Dobos, 4; Interview with Linda Johnson, July 17, 2009, 5; Mason, 2; Brown, 7; Quinn, 13; Interview with Lucy Williams, October 8, 2009, 9; Brooks, 9; Klein, 11 and 29; Murray, 9; Beck, 6; Clarke, 7; Moore, 7; Reid, 15; Stevens, 5; Walsh, 4; Doyle, 3; Evans, 5; Jones, 11 ; Richards, 6; Macdonald, 10; Harrison, 21; Lowe, 16 and 37; Smith, 6; Carter, 13; Galli, 4. Smith, Klein, Carter and Galli at least talked with their fiancés or husbands about not wanting to get pregnant immediately. With her second husband, Klein said they initially discussed having a large family.
} 
so we...compromised and had two." 90 However, a significant few, the vast majority of whom married before 1960 , did not report such discussions. ${ }^{91}$ Stewart, for example, said, when asked if they talked about how many children they wanted before marriage, "No, we never did, we never did...It just happened."92 Wilkins echoes this sentiment saying that "a lot of people... [did not talk about how many children they wanted because] there wasn't a lot of control over it." 93 Among those who did not discuss the topic with their husbands, I would consider three, or $27 \%$, of the women working-class. This compares to $13.8 \%$ in the group that did have conservations about family size or children. ${ }^{94}$ These findings could suggest that, though more research is needed to flush out any connections, attitudes towards family planning may have been linked to socioeconomic status in Canada, as they were in Britain in the 1930s. Additionally, based on my sample, beliefs seemed to be evolving. Perhaps, prior to 1960 , it was less common for couples to have, and communicate to each other, firm expectations about children or family size. Campbell, for example, when asked if she and her husband had discussed, prior to their marriage in 1959 , "whether you might want children in the future or how many you might want?" replied "we both felt we wanted children. And I don't think we settled on a particular number." In this way, some women in my sample were similar to the British couples Fisher interviewed. However, after this date, it seemed that more young people, either when engaged or married, began to have these thoughts and conversations.

\footnotetext{
${ }^{90}$ Interview with Olivia Taylor, August 6, 2009, 3-4.

${ }^{91}$ Lynch, 12; Ramsey, 4; Dawson, 10-11; Anderson, 4; Koch, 5 and 10; Shevchenko, 3-4; Wilson, 6; Scott, 4. However, Wilson did say that, while they did not discuss family size prior to marriage, she and her husband did talk about wanting a child quickly. Scott added that, though generally questions involving children were not raised before their marriage, she may have informed her future husband of her desire to eventually adopt a child.

92 Stewart, 3.

${ }^{93}$ Wilkins, 12.

${ }^{94}$ See Appendix 1 for more background information on interviewees.

${ }^{95}$ Campbell, 8.
} 
Following a 1966 panel discussion involving six Canadian married couples, for Chatelaine magazine, chairman Dr. Benjamin Schlesinger, associate professor of Social Work at the University of Toronto, declared "Family planning, child spacing, and contraception have become the most popular family topics in 1966 . There is an awareness that family planning is beneficial to modern marriages and every indication that the revolution of the pill has invaded most Canadian households...[The pill has] freed many couples from fear, anxiety, and emotional and physical worries, to plan for children in a meaningful way." ${ }^{, 96}$ Thus, Dr. Schlesinger very much implicated the pill in family planning in the 1960s. The desire and need to plan one's life, including family, certainly seemed to be central to many marriages in the 1960s. Illustrating this phenomenon, Phyllis Holman, panel participant and aged twenty-six with no children, said "we believe in contraception. All our plans have been very definite and carefully adhered to. They become nebulous next year. We're leaving our plans past that point to see how we feel about being tied down. We've talked about having four or five- and I'm going to be twenty-seven this summer- so I'd like to have them soon."

Married women were the intended beneficiaries of the pill. ${ }^{98}$ Expectations were high, among many segments of society, that the pill could facilitate family planning, creating happier families, as well as neutralizing the "population explosion." the hopes pinned on the pill were expressed in an unpublished letter to Chatelaine. The writer, a married woman from British Columbia, fervently wanted the pill to be available

\footnotetext{
${ }^{96}$ Mildred Istona, "Is There a Young Marriage Revolution? Part 2," Chatelaine 39, 12 (December 1966), 40 and 64.

${ }^{97}$ Ibid., 40 and 57.

${ }^{98}$ Christabelle Sethna, " 'Chastity Outmoded!': The Ubyssey, Sex, and the Single Girl, 1960-1970," in Creating Postwar Canada: Community, Diversity, and Dissent, 1945-75, edited by Magda Fahrni and Robert Rutherdale (Vancouver: UBC Press, 2008), 293.

${ }^{99}$ Watkins, 1; May, 2-3.
} 
to everyone, not to fight overpopulation but to ensure, echoing the Protestant concept of responsible parenthood, that "every baby born would be wanted." She acknowledged that if this did happen "perhaps there wouldn't be so many babies born." 100 Rather than focusing on sexual liberation, married women "tended to emphasize the pill's promise of family planning and marital happiness."101 And, for many, it seemed to deliver.

In the 1960s, the increasing use of the pill was associated in public debates with a drop in the Canadian birth rate. ${ }^{102}$ While the Canadian birth rate had started to decrease in 1958 , the pill did facilitate family planning in several ways. ${ }^{103}$ First, women in my sample stressed that it helped them postpone childbearing until the ideal time. ${ }^{104}$. For example, Brown, who took the pill for about three years when first married, explained "I think it gave us control over when we had family and whether we had family...I think that's a very freeing thing...the ability to make decisions for yourself has some really positive things to be said for it as opposed to maybe...not feeling ready and suddenly you're dealing with a baby and hoping you do get emotionally and financially and every other way ready after the pregnancy begins." 105 Kennedy, who took the pill for approximately the first three years of her marriage, concurred emphatically that, without it, she may have had her children sooner. She confirmed there would have been accidents and that she might have run out of foam, as she later did when she got pregnant

\footnotetext{
${ }^{100}$ Letter by Mrs. Hazel McBride, Prince Rupert, B.C., to Chatelaine, January 22, 1962, Archives of Ontario, Reference Code F138, Barcode B255348, F-4-3-A, Box 215, file January 1962 (1 of 2).

${ }^{101}$ May, 59.

${ }^{102}$ Constance Mungall, "The Pill and Its Side Effects Today," Chatelaine 39, 11 (November 1966), 117; Constance Mungall, "The Birthrate's Down: What Happens Next?" Chatelaine 40, 4 (April 1967), 29 and 92. In her 1967 article, Mungall seemed to perpetuate this belief, stating twice that the pill was responsible for the decline in birthrate and family size. She only acknowledges on the last page of her article that the birthrate actually started to decrease in the late 1950 s, well before the pill was available. She explains that economists connect this phenomenon to other factors such as the emancipation of women and materialism.

${ }^{103}$ McLaren and McLaren, 133-134.

${ }^{104}$ Quinn, 18.

${ }^{105}$ Brown, 3-4, 10 and 17.
} 
(not unhappily) with her second child. ${ }^{106}$ Ryan and Murray, who both waited several years to start their families, also agreed that they might have had their children sooner without the pill. ${ }^{107}$

Women also appreciated that the pill allowed them to space their pregnancies and to make more deliberate decisions about additional children. ${ }^{108}$ Stefánsson, for instance, while hinting that she could have possibly used another method, said, with the pill, "when we decided to have children, we could decide when to have children and we decided and we had two and then I can remember looking at them one day and thinking, we're not finished yet...and then we got pregnant and then I looked at the kids and I thought we're all together...this is it...and I think then we could say stop and a lot of women, two generations ago, couldn't say stop, this is enough, I've had enough children."109 Clarke, while also thinking they probably would have just used another method to prevent a larger family, did suggest that the pill was helpful in providing more certain control over family size. Clarke had a much younger sister whose arrival was something of a shock to their parents. She said "I didn't want to repeat that kind of an experience so I really wanted to feel that these were the...children we really wanted knowing full well that we would welcome another child if it happened but I wanted it to be our choice and not an accident so I felt that first the pill and then the vasectomy would really ensure us that that wouldn't...or was very unlikely to happen."110 Thus, married women often emphasized that the pill provided a sense of security and control over determining final family size.

\footnotetext{
${ }^{106}$ Kennedy, 5, 8, 13-15 and 20.

${ }^{107}$ Ryan, 3, 9, 13, 16 and 17.

${ }^{108}$ Doyle, 13; Macdonald, 27-28; Quinn, 4, 8-10, 18-20. However, Quinn did not think her family would have been bigger without the pill.

${ }^{109}$ Stefánsson, 16-17.

${ }^{110}$ Clarke, 1 and 30.
} 
In addition, many women asserted or agreed that they would have had larger families without the pill. Seaman discussed an American housewife, Claudia L., who seemed to have the impression that all other methods carried a more significant risk of pregnancy. ${ }^{111}$ Harrison, mother of two, thought she absolutely would have had more children without the pill as her husband would not consider condoms or a vasectomy and she was told that her tipped uterus meant a diaphragm was not a good option for her. In making these kind of assertions, some women emphasized that they seemed to conceive easily. ${ }^{112}$ As Arsenault said, "I probably would have ended up with like six or seven kids...Cause every time I went off it, I got pregnant...I got pregnant really quick." ${ }^{113}$ This claim was particularly persuasive in women who had had unplanned pregnancies while using other methods. Lynch, for example, got pregnant three times relying on withdrawal and then a diaphragm. When asked if the pill impacted her family size, she succinctly replied, "Yes. God knows what it would have been without." 114 Richards, a mother of four, also alluded to her reproductive record when discussing the pill's impact on her family size. She affirmed that, without the pill, she might have had more children, which would have been detrimental to her marriage, and that she did get pregnant while relying on spermicidal gel. ${ }^{115}$ Therefore, married women who went on the pill in the $1960 \mathrm{~s} \mathrm{did}$ feel that the new contraceptive allowed them to avoid, often undesired, larger families.

\footnotetext{
${ }^{111}$ Seaman, 54-55.

${ }^{112}$ Thompson, 25; Wilson, 20-21; Ramsey, 15; Anderson, 11; Galli, 13-15 and 19; Harrison, 4, 11 and 20; Morrison, 25-26; Meyer, 21; Watson, 21-22; Jones, 17-18. Some of these women, like Meyer, Watson, Anderson, Jones and Galli qualified their responses or seemed a little more tentative. For example, Meyer affirmed she "very likely" could have had many more children without the pill. Jones thought one more child might have been possible without the pill.

${ }^{113}$ Arsenault, 26.

${ }^{114}$ Lynch, 3, 12, 20, 22, 24-25 and 41.

${ }^{115}$ Richards, $16-17$ and 25.
} 
While many women were happy that the pill reduced their fertility, Wright, who struggled with infertility after going off the pill and only had one child in 1982, after trying to conceive for eight years, speculated that it might have had an unexpected consequence on her reproductive life. She said:

I have wondered if I would have gotten pregnant more easily and been able to have more than one child if I had never gone on the pill. With 20-20 hindsight, I can now say that if I had believed that the pill could cause infertility or difficulties getting pregnant, I wouldn't have used it. But...I don't remember any warnings about the pill impacting fertility. ${ }^{16}$

For Jackson, the pill also had a surprising and adverse impact on her family size. After the birth of her son, she resumed pill use but suffered a stroke thirteen months later. She was told immediately not to have any more children and she followed this advice.

Though Jackson and her husband were ultimately not disappointed to only have one child, this was obviously not the outcome they would have envisioned when she went on the pill. ${ }^{117}$ Thus, while many married women lauded the pill's impact on their fertility, a few others, like Jackson and Wright, found it had perhaps too large a role in determining their final family size and, in effect, deprived them of the very control it was supposed to provide.

Nevertheless, some women stated that the pill had no large role in governing their family size or planning. ${ }^{118}$ They often said they would have utilized another method to

\footnotetext{
${ }^{116}$ Wright, email, 2 and 3 and interview, 7.

117 Jackson, 14-22 and 28.

${ }^{118}$ Hall, 14; Beck, 26; Evans, 17; Edwards, 41; Lowe, 34; Walsh, 6, 8 and 11; Williams, 11-12 and 26. Once off the pill, Walsh did agree that her first child came along sooner than planned but she does not explicitly suggest a role for the pill in this event. Williams' answer is a bit confusing. At first, she insists the pill did impact her family size but then clarifies that, in her mind, the pill and the IUD are the same thing. I think here she is referring to them as two effective methods of birth control. However, her answer then is not really personal since, when she tried an IUD, before the pill, it fell out.
} 
achieve the same results. ${ }^{119}$ For example, Reid did not even think she would have had children sooner without the pill. When asked, she replied no "Because we knew what...kind of a lifestyle we wanted and I had no intention of raising kids in an apartment or under a huge debt load." ${ }^{\text {"120 }}$ Reid's choice of words is interesting. Other sources hint that these sort of goals around home, money and family may have been particularly important to this generation. Though, as mentioned on page 230, Claudia L. expressed doubt in other methods, she also expressed a sense of clear lifestyle priorities. In explaining why she wished to stay on the pill for another few years, Claudia said by then "our country house will be paid off and so will our boat. Steve and I were depression babies. We both came from families that had high standards, but no money. We've always had to work hard for everything. Now we feel entitled to the pleasures of life."121 Phyllis Holman, the twenty-six old married woman with no children who took part in the 1966 Chatelaine panel, confirmed the pill was facilitating different, and perhaps not always simple, choices for people. She said "there's a tendency to get greedy in these years of inflation, and you think 'Gee, I'll work one more month-that's five hundred dollars- and we can have this and this.' I think families are going to be smaller, and some people are going to put them off much longer than they should. ${ }^{122}$

Such lifestyle considerations were clearly important to Reid. If the pill had been unavailable, Reid felt she would have simply employed another birth-control method to

\footnotetext{
${ }^{119}$ Moore, 1 and 29; Edwards, 41; Koch, 15, 17-19 and 22. Edwards did allow the pill probably made the spacing of her family easier. Initially, Koch, who conceived easily and was on the pill for approximately a year, thought she would have gotten pregnant again during that time if not for the pill but then mused that she never got pregnant subsequently while using an IUD for about fifteen years.

${ }_{120}$ Reid, 23-24.

${ }^{121}$ Seaman, 55.

${ }^{122}$ Istona, 40 and 57.
} 
postpone her childbearing. ${ }^{123}$ Carter, who was only on the pill for nine months, likewise thought that, rather than getting pregnant sooner, she would have just used another method and pointed out that she did not get pregnant immediately after discontinuing the pill. ${ }^{124}$ Thus, it is important not to oversimplify the pill's effects. While the pill could be revolutionary in facilitating family planning for married couples, some women did not see it as crucial in this area.

So it seems that the pill could facilitate family planning for many married couples in the 1960s and 1970s. As they had and completed their families, were they at all influenced by the discourse of population control? As discussed in Chapter 1, this rhetoric was increasingly part of public discussion in the late 1960s. Though historians of the pill analyze its development and dissemination, they have not attempted to track its influences by speaking directly to women who had children in this decade. When I did so, I discovered that some of them are not sure if they even heard about population control in the $1960 \mathrm{~s} .{ }^{125}$ Had they heard, they might not have been bothered by the discussion anyway. Wright explained that population control sentiment was likely something she was cognizant of when she was on the pill from 1969 to 1973 but that she “did want four kids and I didn't really...perceive that I was abusing the world by doing that." 126 Therefore, the population control message may not have reached all married women in the 1960s and, if it did, some may have been indifferent to it.

Nevertheless, the public discussion of population control had an influence on the private feelings of some of the interviewees regarding their family size. Richards, who

\footnotetext{
${ }^{123}$ Reid, 23-24.

${ }^{124}$ Carter, 3, 16-17, 27 and 28.

${ }^{125}$ Thompson, 15 and 26; Scott, 15.

${ }^{126}$ Wright, 7, 2, 6, 8-9 and email, 2.
} 
got pregnant quite quickly after her wedding and had the first of four children in 1965, recalled that someone said, in reference to her pregnancy, "talk about population explosion." When having her family, Richards was aware of what she referred to as "social pressure" to avoid large families. However, she reasoned that "as the years went by and I realized that most of my friends that I went through high school with weren't having kids...some of them had no kids and many of them had one kid and I thought, oh well, it all averages out so I've got four." 127 Beck, likewise the mother of four children, also heard about population control concerns. Specifically, Beck remembered that the widely-discussed rhetoric urged people to have smaller families, preferably just two children (or fewer) to replace the parents, because there were insufficient resources to feed the growing world population. Despite these admonishments, Beck, like Richards, found a way to justify her decision to have four children. In her case, she rationalized that, since she and her husband had no siblings, they were still not contributing to overpopulation. She added that, after three children, they did reflect on population control concerns and even considered adoption but decided ultimately to have a fourth. However, they thought they had "maybe overdone it because there was the thing about population explosion...so three months after I was pregnant with...[the fourth child], my husband had a vasectomy." 128 Thus, population control rhetoric had the potential to influence how people in the 1960s thought about their family size and even the decisions they made in this regard.

Beyond the Bedroom Door: The Specter of Pregnancy, The Marital Dynamic, and

\section{Female Careers}

\footnotetext{
${ }^{127}$ Richards, 6, 12, 13, 17 and 26-27.

${ }^{128}$ Beck, 1, 4, 10, 16-18.
} 
"[The pill] gave me a life I never had." 129

"The pill makes for better economic conditions, happier people, and there'll be less battered-baby syndrome.,"130

These two quotations demonstrate the immense impact attributed by married Canadian women to the birth-control pill, both in retrospect and in the 1960s. Because of its profound impact on sexuality and reproduction, women felt the pill influenced their lives beyond the confines of the bedroom. Fear of pregnancy often stalked them throughout their days, not just during sex itself. The pill could remove or reduce this worry in general. ${ }^{131}$ Describing this situation, Wilson said

I mean I felt such a relief that I didn't have to worry about an unwanted pregnancy. It was a real concern, you know, every month I'd think am I going to get my period, am I going to get my period? Even though he was taking some precautions, such as they were. You know...it was a constant worry...the calendar would be marked and...I'd think, oh, dear...oh-oh, I'm late, why am I late? So it was a very big deal. ${ }^{132}$

Meyer echoed this sentiment. She explained that, before the pill, "Every morning you'd get up and if you were supposed to have your period and you didn't...and you have to look after your children, you have to make them breakfast and all you can do is sweat and think oh my god, oh my god, oh my god." ${ }^{133}$ Moore may have had even more reason to fear an unexpected pregnancy. She affirmed that the pill freed her from the worry of getting pregnant first in her troubled marriage and then subsequently during her extramarital affair. ${ }^{134}$

\footnotetext{
${ }^{129}$ Wilkins, 19.

${ }^{130}$ Judy Lowe, quoted in "Is There a Young Marriage Revolution? Part 2," 57.

${ }^{131}$ Taylor, 13; Wilkins, 28-29; Meyer, 13-14; Reid, 233; Stefánsson, 16; Morrison, 29.

${ }^{132}$ Wilson, 20 .

${ }^{133}$ Meyer, 23.

${ }^{134}$ Moore, 17 and 23-24.
} 
The pill could also affect the relationship between a husband and wife. Dr. E.T. Tyler, medical director of the Planned Parenthood Centre of Los Angeles, interviewed in 1964 on CBC radio, credited the pill with saving marriages by improving sex. ${ }^{135}$ However, its impact on couples was sometimes more complex. Wood, who took the pill as a newly-wed and suffered mood disturbances, reflected that she was lucky her husband was understanding and that her difficulties with the pill may have taught them about the vicissitudes of marriage. ${ }^{136}$ Additionally, some women, once they experienced an entirely female-controlled method of contraception, began to act more independently outside the bedroom. ${ }^{137}$ For instance, Wilkins claimed that her husband used sex to control her and, after the birth of three children, "I didn't want to be pregnant again, I didn't want to go through that. I couldn't cope with what I had...when I didn't have to worry about it again, I was more assertive with him who was extremely controlling. I think he didn't want me to have the pill because it meant he couldn't control me anymore." 138 Two years after starting the pill, Wilkins left her husband. ${ }^{139}$ Klein also asserted that the pill gave her a sense of control in her life, affecting both her career decisions as well as her willingness to leave her first husband when their marriage was not working. ${ }^{140}$ Thus, for some women, the pill escaped the confines of the bedroom, influencing their non-sexual interactions with their husbands in positive and negative ways.

\footnotetext{
135 "Praising the Pill," CBC Radio's Assignment, hosted by Jim McLean, broadcast date May 4, 1964, CBC Digital Archives, http://archives.cbc.ca/health/reproductive_issues/topics/572.

${ }^{136}$ Wood, 3-4 and 14.

${ }^{137}$ Marks, 196-197.

${ }^{138}$ Wilkins, 9, 14, 19 and 28-29.

${ }^{139}$ Ibid., 20 and 22.

${ }^{140}$ Klein, 40.
} 
As suggested by Klein, the pill, by providing very reliable birth control, could have an effect on a young woman's career or income. The 1960s witnessed an increase in the number of Canadian women continuing to work after marriage. ${ }^{141}$ While it became more common for married women to remain in the workforce, mothers, particularly with young children, were still expected by many people, including employers, to stay at home. According to a 1960 Canadian Gallup Poll, "only 5 per cent of women and 4 per cent of men thought a woman with younger children should take a job."142 This attitude could be reflected in hiring practices. Klein, who first started the pill before her 1964 wedding, remembered that during one job interview for a teaching position, she was asked point bank if she was on the pill. She confirmed that she was. ${ }^{143}$ One wonders if this intrusive question was posed because the interview panel was trying to exclude women who might get pregnant, either on purpose or by accident. Their question is also intriguing because it suggests that perhaps even middle-aged men saw the pill as more popular or more effective. Otherwise, why not just ask about birth control in general? Many of the women I interviewed did continue to work after marriage, though some still quit at this time. For those who did not and went on the pill when engaged, did it contribute to their ability to continue pursuing a career or simply work outside the home? In some cases, it seems clear, at least according to the women involved, that it did

${ }^{141}$ Byron G. Spencer and Dennis C. Featherstone, "Married Women in Canada's Labour Force," in Marriage, Family and Society: Canadian Perspectives, edited by S. Parvez Wakil (Toronto: Butterworth \& Co. Limited, 1975), 342-343. Though the numbers had been steadily increasing since at least 1931, there was a more dramatic upswing between 1961 and 1971 when married women's participation in the work force climbed from 22 to $33 \%$.

${ }^{142}$ Owram, 253 and 369, note 14; Nancy Zukewich Ghalan, "Attitudes Toward Women, Work and Family," Canadian Social Trends (Autumn 1997), 14 and 16. Over twenty years later, in 1982, four out of ten Canadians shared this view. Ghalan confirms that, even in 1995, traditional ideas about women's roles could persist. For example, the General Social Survey found that $59 \%$ of men and $51 \%$ of women "agreed or strongly agreed that a pre-school child is likely to suffer if both parents are employed."

${ }^{143}$ Klein, 3-4, 8-9 and 16-17. This interview would have taken place in the summer of 1964 . 
because it effectively delayed the arrival of children. ${ }^{144}$ Almost all the women in my sample did want children eventually and would have them, but many wanted to postpone children for a number of reasons, including a desire to strengthen their relationship with their husbands. ${ }^{145}$ However, there were also women who spoke of a need, sometimes in addition to relationship factors, to establish themselves in careers or take advantage of having two salaries.

Many women explained that they wished to postpone children because they wanted to begin or further their careers. Sometimes, the pill's role in facilitating this choice could be inferred ${ }^{146}$ while other times it was made quite explicitly. ${ }^{147}$ For instance, when asked why she decided to try the pill, Wright replied that "I wanted surefire contraception when we were first married because I wanted to build my career." Also contributing to her decision to not have children immediately, was the fact that her husband required another year to complete his education, making her the sole breadwinner during that time. ${ }^{148}$ Both Galli and her husband were also completing their educations and she said if "we didn't want to have children and study at the same time cause we didn't think it...would be fair [to the children]...let's go and pick something that works." ${ }^{149}$ Wood, a teacher, affirmed that she started the pill, right before her wedding in 1967 , because, with her career just beginning and her husband traveling a lot in his work,

\footnotetext{
${ }^{144}$ Marks, 192. Marks affirms that, with the pill, "women, particularly those from the middle-class, could delay having children until it was convenient, and more successfully combine a family with a career."

${ }^{145}$ For example, Edwards, 4-5.

${ }^{146}$ Isabelle Lowe, 16-17 and 27.

${ }^{147}$ Macdonald, 10 and 13-14; Stevens, 3-6. Stevens explained that for her, a civil servant, and her peers going on the pill made sense, in part, because they had promising careers and would, therefore, not want children immediately. She also said that she did not really consider other methods.

${ }^{148}$ Wright, 3 and email, 2.

${ }^{149}$ Galli, 2-4, 13 and 6.
} 
she did not want children right away. ${ }^{150}$ Finally, Klein also felt the pill impacted her career choices because it allowed her to feel she could go to Trinidad as a married teacher with the Canadian University Services Overseas (CUSO). She explained that it was not appealing to her to start her family in Trinidad. ${ }^{151}$

As well as career goals, some women, who went on the pill in preparation for marriage, explained that, prior to having children, they also wished to achieve a certain lifestyle, often including a house or savings. ${ }^{152}$ Again, this demonstrates that many couples in the 1960s were very interested in planning their lives and families, perhaps much more so than in previous decades. The pill may have, for some people, played a significant role in this process. Brown, for example, said she went on the pill to delay children and that they "waited for financial reasons and we bought a house and we had good jobs and had saved some money...before we had kids." ${ }^{153}$

Sometimes pill users intimated that, rather than being eager to build their careers, they and their husbands simply could not afford to have children right away. As mentioned above, quite often in the 1960s, a married women, if she had continued to work, was expected to quit her job when pregnant. ${ }^{154}$ This likely outcome was especially alarming for women who were, like Wright, the only breadwinner. Klein, discussed above, found herself in this situation and got the pill from her family doctor in 1964 . Though he expressed reservations about prescribing it for her, as discussed in Chapter 3,

\footnotetext{
${ }^{150}$ Wood, 2, 3 and 5.

${ }_{152}^{151}$ Klein, 12, 40, 8.

152 Jones, 3 and 7; Stevens, 4-6 and 12.

${ }^{153}$ Brown, 7.

${ }^{154}$ Certainly several of my informants, including Klein, Stefánsson and Macdonald, had this impression. Macdonald said that it was "not the done thing in any way, shape or form for a married woman to have a child and continue to work."
} 
she replied that "I've got to keep this husband in school for a year."155 Her answer indicates that she very much saw the pill, which appealed to her because of its efficacy and convenience, as crucial to their plans regarding family. ${ }^{156}$ She did not seem to consider that other methods might also have delayed children and allowed her to continue working while her husband finished his education. Similarly, Taylor, who also did she not want a family right away, partly because of financial concerns, said the pill "seemed to be the easiest way, the most convenient way to prevent having a family immediately." 157 Though others did not explicitly credit the pill with their ability to delay children in circumstances were finances were tight, they often did say that they were attracted to it or valued it because it was very effective. ${ }^{158}$ Clarke elaborated that this efficacy was important to them as they "got married with no money...there was no way we could afford to have a child."159 Thus, many married women who started the pill in the 1960s perceived that it facilitated their decision to postpone children so they, amongst other things, could establish their careers or save money.

The pill could also profoundly affect a woman's career after children arrived. Indeed, it allowed many to continue working or return to work after they had children. As Marks explained, women on the pill "could also plan with greater confidence when and how to have children, deciding, for instance, to have longer spaces between births, or confining their childbearing years to a restricted set period to limit the expense of childcare and time spent away from work." Some married women in the 1960s found

\footnotetext{
${ }^{155}$ Klein, 7-9.

${ }^{156}$ Ibid., 10.

${ }^{157}$ Taylor, 4.

${ }^{158}$ Mason, 4-5; Carter, 9 and 13; Clarke, 4, 7-8. Clarke also emphasized that, unlike other methods, the pill did not intrude on sexual activity. Mason is unique in that, when discussing her desire to postpone children, she explicitly compares herself to someone who did not, it seems, plan or limit their family. She said her "oldest brother had eight children and they were always poor."

${ }^{159}$ Clarke, 7.
} 
that getting pregnant, particularly if it was unexpected, had significant effects on their careers and incomes. Once they had the pill, it allowed them to have more control over their working lives. Lynch, for example, lost her job as a service representative at Bell because she was so sick during her first pregnancy. When she was not too unwell, she then did payroll and other tasks in her husband's service station. After the birth of her second child in 1959 and a miscarriage in 1962, Lynch went on the pill and found it facilitated her more active role in the family business. She said,

I'm not sure...[my husband] was all that happy, he would liked to have had more children. It was a little bit of a source of disagreement at times, why don't you stop taking the pill? But, by this time, I was much more involved in the business and for me to stop and have another baby, and all that that entails, would have presented some hardship there. So, I think on one hand he wanted more children, on the other hand, he knew we were partners in this business and he needed me. You know, even at that time, I was taking the girls, little ones to the service station and they would colour and do things while I was dealing with customers or paying bills or whatever. So it wasn't in my scheme to do this again. ${ }^{160}$

Meyer, an interior designer, also found that the pill allowed her the freedom to work outside the home. She said, "once my kids were in school and I was fulltime in the business, the pill was my...lifeline to life...It was my guarantee that nothing was going to upset my life now." Meyer credited the pill with allowing her to practice her profession. When speaking about her life, Meyer seems to very much understand it in terms of her career, underscoring the latter's importance. ${ }^{161}$ Morrison also felt the pill impacted her career path. After her second child was born in 1965, she and her husband agreed that they should not have any more as both of them needed to work outside the home.

\footnotetext{
${ }^{160}$ Lynch, 3, 4, 8, 9, 15-16, 20, 22, 25 and 28. Lynch's comments provide insight into the potential role of women in family-run businesses. While she had the freedom to bring her children to work, with no fear of reprisals, there were limits to her flexibility, particularly in regard to having more children, as she was needed in the business which sustained the whole family.

${ }^{161}$ Meyer, 1-4, 18 and 21.
} 
Morrison went on the pill and thinks, without it, she would have had more children. As it was, she stayed home with her two children for about four years. ${ }^{162}$ Finally, Watson, who had different jobs connected to the Canadian government, confirmed she was on the pill so she could work outside the home. Watson also hinted that, since some of her jobs required travel, she needed "something that I was pretty sure of." Her meaning is not entirely clear here though she clarified later in the interview that the pill provided a sense of confidence and, when asked, of predictability. ${ }^{163}$ So, the pill did allow Canadian mothers to return to the paid workforce.

The pill also opened the door to higher education for some women. Before getting pregnant and having her only child in 1974, Brooks was working in secretarial jobs she found boring. She had started the pill three months before her wedding in 1969 and speculated that if they had continued to rely on condoms, she probably would have gotten pregnant and never gone to university. ${ }^{164}$ Similarly, Morrison also found herself discontented with secretarial work and decided, with her husband's encouragement, to quit her job and pursue university studies in journalism. She asserted that, without the pill, these choices would not have been possible as she would have had more children to consider. Her improved career prospects gave her additional security when her husband began to have health issues. She said "I wanted to make sure that if something happened to him, if he became very sick and couldn't work or if he died, that I'd be able to support the family...and...give the children opportunities so for me, if I hadn't been on the birth-

\footnotetext{
${ }^{162}$ Morrison, 10-11, 25-26 and 28. One might ask, if she was able to leave the paid workforce for this period of time, why did her husband believe they needed two incomes? Perhaps it had more to do with achieving a certain lifestyle, as discussed on pages 232-233. Morrison does explain that, when she decided to be at home with her children, her husband was working three jobs to cover their expenses.

${ }^{163}$ Watson, 24, 9, 13 and 22.

${ }^{164}$ Brooks, 2, 3, 6, 11 and 17.
} 
control pill, I don't believe...[anyone] in my family would have had the quality of life that we were looking for."

However, the pill could also have a detrimental effect on a woman's ability to work outside the home. Stewart, who had terrible headaches and irritability when on the pill, asserted that it would have been impossible to cope with these side effects while holding down a job. For her, getting off the pill was necessary before she returned to work as a switchboard operator. ${ }^{166}$ Watson, while saying that the pill was important in allowing her to return to work, also commented that the heavier periods she experienced on it were especially problematic when she had to travel for her job. ${ }^{167}$ Jackson, who suffered a stroke from the pill, speculated that her loss of right peripheral vision in both eyes may have limited some of her career options. ${ }^{168}$ In the short-term, she returned to work quickly but at first had trouble seeing as her vision was blurry. Her sister walked her to work since she was advised not to venture out on her own because she would need time to adjust to the change in her vision. After returning to work, the stroke's aftermath continued to affect her in unexpected ways. Jackson had a bad reaction to the anticoagulants she was taking and began to bleed internally. While the problem was corrected, she had to go off work again for a time. ${ }^{169}$

Thus, for both married women and mothers the pill could give them the freedom to pursue their career and educational goals. However, and further complicating the positive image of the pill as contributing to female emancipation in this area, was the fact that, through its side effects, it could actually sabotage or impede career aspirations.

\footnotetext{
${ }^{165}$ Morrison, 28.

${ }^{166}$ Stewart, 7,9 and 19.

${ }^{167}$ Watson, 9, 11 and 14.

${ }^{168}$ Jackson, 16, 21 and 28.

${ }^{169}$ Ibid., 20-24.
} 
Finally, moving well beyond sex, reproduction or even work, the pill probably had the most far-reaching effect on Jackson, impacting her life in ways that continue to this day. Ironically, while the pill liberated some women, for Jackson it curtailed her freedom and independence. In the short term, this loss was rather extreme as she could not leave her house alone. She was also no longer free to have more children, as discussed in the previous section. While she has adjusted to the lack of peripheral vision, she hasn't been able to drive since her stroke. This means that someone else has to provide transportation, a requirement which has sometimes chaffed, particularly since she had a license for five years before the stroke. Jackson said "I think driving was probably the biggest thing. You know, I would want to go someplace and the car would be sitting there and I couldn't take it. To this day...if I'm going grocery shopping or anything...my husband is driving me, taking me where I want to go."170

The pill had a potentially huge impact on a married woman's sexuality and fertility. However, this contraceptive's influence extended well beyond the bedroom, influencing a woman's career, education, and marital dynamic. This chapter will conclude with an examination of the pill's particular impact on those with connections to Catholicism or Christian Science. Historians of contraception, include McLaren and McLaren, Sethna and May, have studied the Catholic's Church reaction to the pill and the ensuing debate within the Church. However, in the Canadian context, only Gervais and Gauvreau have used interviews to probe how individual Catholics responded to the challenge posed by the pill. To my knowledge, no one has looked at the interplay between the pill and Christian Science.

Religion: The Battle within the Catholic Church

${ }^{170}$ Jackson, 23, 25 and 28. 
'Bless me, Father, for I have sinned...' With these words, I open my confession to my priest. I then proceed to tell him all my sins - all except one, that is. That one I cannot tell him for if I did, he would be unable to give me absolution for my sins; unless, of course, I can promise him that I will never break that law of the church again, and that I cannot do. For you see, I know I will commit that sin over and over again, and I will go right on committing it year after year. I can't help it. I just cannot go on having one pregnancy after another. ${ }^{171}$

With these words, written in a 1968 Chatelaine article, a married Catholic woman begins her discussion of how she came to use birth control, in contravention of Church doctrine. Though she was not on the pill at the time, this excerpt speaks to the dilemma and possible anguish experienced by Catholic women over the use of contraception in the 1960s.

While Anglicanism and the United Church of Canada had reversed their traditional opposition to artificial contraceptives in the 1930s, the Roman Catholic Church had not. ${ }^{172}$ For hundreds of years, it had upheld the position of theologian Clement of Alexandria who asserted, in the second century, that "To have coition other than to procreate children is to do injury to nature." Using very similar language, Pope Pius XI affirmed in his 1930 encyclical, Casti connubii, the church's disapproval of birth control. However, the encyclical did state that sex during non-fertile periods was permissible and many Catholics interpreted this, perhaps a little generously, as approval of the rhythm method. ${ }^{173}$ Indeed, by the 1930s, the Church did permit Catholics, many of whom were in favour of birth control, to avoid conception by using this method. ${ }^{174}$ However, to be successful, it does require regular abstinence and meticulous attention to

\footnotetext{
${ }^{171}$ Joan O'Donnell (assumed name), "A Catholic Mother Answers the Pope," Chatelaine 41, 11 (November 1968), 26.

${ }^{7}$ Appleby, 8, 124-125 and 142.

${ }^{173}$ Cited in Marks, 217; Marks, 217; Appleby, 164-166; Diane Gervais and Danielle Gauvreau, "Women, Priests, and Physicians: Family Limitation in Quebec," Journal of Interdisciplinary History 34, 2 (Autumn 2003), 300.

${ }^{174}$ McLaren and McLaren, 131.
} 
the woman's fertility cycle. Therefore, it is not surprising that the problem of birth control remained unresolved for many Catholics into the 1950s and 1960s. In their article on family limitation among Francophone Catholics in Quebec from 1940-1970, Gervais and Gauvreau comment that the decision to use any birth control, other than rhythm, often involved a great deal of guilt for practicing Catholics. ${ }^{175}$ Indeed, "Canadian Catholic spouses found themselves in a moral dilemma, torn between the physical desire that they felt for one another, their desire to limit the size of their families, and their desire to live in a proper Christian way." 176

The Catholic Church continued to wrestle with the issue of family planning throughout the 1960s. Priests were not unsympathetic to the anguish of their parishioners. Particularly after the start of the Vatican II Council in 1962, many within the Church began to reconsider birth control. Individual priests could find themselves almost as conflicted as Catholic women. Reflecting the lack of consensus on this issue, and even before the introduction of the pill, clerical attitudes and behaviours in the arena of family planning varied considerably. ${ }^{177}$

In 1957, the Church did approve the use of the birth-control pill as a treatment for irregular periods or other gynecological problems. ${ }^{178}$ This could provide Catholic women with a legitimate reason (some would say excuse) for taking something that had contraceptive properties. ${ }^{179}$ However, some Catholics, notably pill developer Dr. John

\footnotetext{
${ }^{175}$ Gervais and Gauvreau, 305.

${ }^{176}$ Ibid., 303-304.

${ }^{177}$ Ibid., 306-307 and 313.

${ }^{178}$ Loretta McLaughlin, The Pill, John Rock, and the Church: The Biography of a Revolution (Toronto: Little, Brown and Company, 1982), 154.

${ }^{179}$ O'Donnell, 26. O'Donnell was desperate to avoid further pregnancies but, as a Catholic woman, struggled over her decision to use birth control. She said that the Church did permit the use of the pill to regulate periods and she did take it, ostensibly for this purpose, but had to go off when she had bleeding between periods.
} 
Rock, asserted that the pill represented a solution to the Catholic conundrum on contraception. ${ }^{180}$ Rock explained that the pill worked by using hormones to simulate a woman's regular cycle. ${ }^{181}$ Therefore, he hoped that the Vatican would recognize the pill as a natural form of birth control. ${ }^{182}$ In the 1960 s, many lay Catholics seemed to agree with Rock, or at least were simply willing to ignore Church teachings. For example, in the United States the "proportion of Catholic women between the ages of 18 and 39 who use methods of contraception other than rhythm... increased from 30 percent in 1955 to 68 percent in 1970."183 A 1962 sociological study in Montreal, cited in Chatelaine magazine, found that in a sample of eighty Catholic families, " 30 percent admitted to having used contraceptive devices." Three years later, the research director of an unnamed drug company, stated that over $50 \%$ of married Catholics in Montreal now used these products. ${ }^{184}$ A 1966 survey of Canadian Catholics found six in ten thought the Catholic Church "would eventually approve of an artificial method of birth control such as the pill." 185

While some, therefore, argued that the pill was unique in mimicking natural cycles, other Catholics also pointed out that it added to their dilemma about using birth control as it had to be taken daily, making it difficult for them to receive absolution after

\footnotetext{
${ }^{180}$ Sethna, 2001.

${ }^{181} \mathrm{Ibid}$. For more on Rock's rationale see his book John Rock, The Time Has Come: A Catholic Doctor's Proposals to End the Battle over Birth Control (New York: Alfred A. Knopf, 1963).

${ }^{182}$ Sethna, 2001.

${ }^{183}$ Charles F. Westoff and Norman B. Ryder, The Contraceptive Revolution (Princeton: Princeton University Press, 1977), 23.

${ }^{184}$ Constance Mungall, "Birth Control in Canada Today," Chatelaine 38, 4 (April 1965), 49.

${ }^{185}$ Sethna, 2005, 286; Letter by Dorothy A.M. Hanrath, Dundas, Ontario, "Catholics and Birth Control," Chatelaine 42, 2 (January 1969), 76. Of course, not all Canadian Catholics agreed with the need for artificial contraception and made their views known in a variety of forums. One example is in a letter published in Chatelaine magazine in which Dorothy Hanrath, a self-identified Catholic mother, reflecting on the article by a Catholic woman, cited at the start of this section, said "Rhythm comes not easy for us either, but we have been able to space them enough to give them our patience and time, and it made me love and admire my husband all the more."
} 
each use. As explained by an English Catholic convert, Dr. Anne Biezanak, mother of seven children, "If you're using a condom or something like that, you hold your breath, dash off to church, confess, and get communion, and then sigh and fall back again into your sinful way of living."

Perhaps because of its reformist spirit, "Vatican II led many to believe that the Church's position on contraception might be relaxed." 187 Adding fuel to this speculation, in 1963, Pope John XXIII created the Pontifical Commission for the Study of Population, Family and Births. ${ }^{188}$ The commission came to include lay Catholics, both men and women, and it worked to consider the Church's position on birth control. ${ }^{189}$ In 1967 , the commission issued its final report which stated that couples had "a right to limit the size of their families and to select the contraceptive method most suited to their needs."190 However, disregarding this assertion, Pope Paul VI chose in his 1968 encyclical, Humanae Vitae, to simply affirm again that the only acceptable form of birth control for Catholics was the rhythm method. ${ }^{191}$ In reaching this decision, he concluded that he did not "really...[have] the power to change a doctrine that had been maintained so long." 192 This stance upset many Catholics and thousands left the church because of it. ${ }^{193}$ One suspects even more found themselves disenchanted or simply in disagreement with Church leadership. In Canada, a "near majority of Canadian Catholics rejected the

\footnotetext{
${ }^{186}$ Quoted in Marks, 219.

${ }^{187}$ May, 123-124.

${ }^{188}$ Edward Stourton, Absolute Truth: The Catholic Church in the World Today (London: Penguin Group, 1998), 43-44; May, 124.

${ }^{189}$ Stourton, 43-50; McLaughlin, 172 and 175.

${ }^{190}$ Marks, 226-227, 327, note 58.

191 Ibid., 227; Allyn, 108; Robert Jütte, Contraception: A History, trans. Vicky Russell (Cambridge: Polity Press, 2008), 189; Andrea Tone, Devices and Desires: A History of Contraceptives in America (New York: Hill and Wang, 2001), 237.

${ }_{192}$ Marks, 227.

${ }^{193}$ Stourton, 58.
} 
Vatican's 1968 confirmation of the church's ban on artificial methods of birth control; 71 per cent of those polled claimed that it was possible to use artificial methods of birth control and still remain good Catholics." 194 This high number should not cause one to overlook the possibility of anguish or guilt experienced by individual, Catholic women which I uncovered in my interviews and will discuss below. A hint of the turmoil caused by the Pope's pronouncement was also evident in a CBC Television Special broadcast August 18, 1968. A panel of Catholic priests was convened at the University of Toronto and fielded questions from the audience. One woman wondered where "the dignity of women comes into a set-up where...[for] a majority of women, rhythm is completely physiologically or medically unacceptable and these women are being told, either lead a celibate life or be some sort of child-bearing machine." One panelist, not clearly identified by name, replied that the Pope's encyclical was being misunderstood and was not suggesting either strict celibacy or continual pregnancies but instead was simply saying that the Catholic Church must continue to consider the issue. When pressed by the woman and the moderator, Barry Callaghan, about where this left individual Catholic women with many children, the panelist rather obliquely mused that "if she has five children, I imagine that she has faced countless situations in which she doesn't know what the right thing to do is and she has to take a deep breath and do her best with no assurances whatever that it's the right thing." Obviously, this sort of answer would not satisfy all Catholic women. Another woman in the crowd self-identified as a loyal Catholic but said "the Pope has simply lost all relevance" for her as she made her own

\footnotetext{
${ }^{194}$ Sethna, 2001.
} 
decisions. ${ }^{195}$ She was not the only Catholic, as I will discuss below, to use birth control, in defiance of the Pope's encyclical. ${ }^{196}$ A 1971 survey of married women in Halifax found that Catholics and Protestants employed contraception in roughly equal numbers. Furthermore, among those who did so, over $60 \%$ of Catholics took the pill, confirming that "many Roman Catholics...find the pill acceptable, despite the continued opposition by the Church to chemical or mechanical contraception." 197

There were also signs that the clergy was not wholly satisfied with the Church's stance on birth control, as affirmed in the Pope's encyclical. Indeed, internationally, "within a day of the encyclical's publication, huge numbers of Catholic priests and members of their congregations started to protest by walking out publicly from Mass."198 Within Canada, the seventeen retired priests interviewed by Gervais and Gauvreau did not, for the most part, dispute the document. However, they said that they had expected the Pope to approve the pill at this time and were genuinely taken aback when he did not. ${ }^{199}$ Additionally, a group of Canadian bishops issued a statement in 1968 in response to Humanae Vitae. This document expressed their position but also provided guidance to priests and confessors. While the bishops called for a moratorium on any public statements against the Pope's encyclical, they also said that parishioners who attempted to follow the Church's teachings but could not "may be safely assured that whoever

195 "The birth control pill sparks religious furor," CBC Television Special, broadcast August 18, 1968, CBC . Digital Archives, http://www.cbc.ca/archives/categories/health/reproductive-issues/the-birth-controlpill/the-pill-sparks-religious-furor.html

${ }^{196}$ Jütte, 191; Tone, 237.

${ }^{197}$ Virginia K. Elahi, "A Family Planning Survey in Halifax, Nova Scotia," Canadian Journal of Public Health, 64 (November/December 1973), 516-518. See Appendix 2 for more on this survey. ${ }_{198}$ Marks, 229.

${ }^{199}$ Gauvreau and Gervais, 299-300, 306 and 313. These individuals were all Catholic, Francophone and based in the Montral area between 1940 and 1970 . 
honestly chooses that course which seems right to him does so in good conscience."200 Therefore, despite proclamations of loyalty to the Pope, this statement actually freed individual Catholics to make their own decisions about birth control.

Thus, pill use had a potentially unique impact on married Canadian women who were Catholic. My fifty-three interviews included nine women who were practicing Catholics in the 1960 s or 1970 s, while taking the pill. They all came to terms with the Church's position on birth control in a variety of ways. As alluded to in the above discussion, both guilt and quiet (or more vocal) defiance were evident in Catholic women's interaction with the pill. While some struggled over the moral dilemma of disobeying the Church, others seemed less conflicted. Sometimes their reaction may have been mitigated by the ability to obtain some form of approval or reassurance from a priest or a Catholic doctor.

Like the woman who confronted the panel of Catholic priests in 1968, some pill users did not seem to need, or at least did not seek out, religious validation, of their choices. Dobos, for instance, was raised Catholic and continued to go to church after her marriage in 1969 and when her children were young. Though taking the pill from about 1969-1976, on and off, she was not really disconcerted by the Church's stance on birth control and said she simply made her own decisions in this regard. She added that she probably went to Confession during this time in her life but likely never raised the issue of birth control with a priest. ${ }^{201}$ Similarly, Galli, a lifelong Catholic, started the pill in 1968, before her wedding. She got it from a Catholic obstetrician/gynecologist who did

200 "Statement of Canadian Bishops on the Encyclical Humanae Vitae," in Population Issues in Canada, edited by Carl F. Grindstaff, Craig L. Boydell and Paul C. Whitehead (Toronto: Holt, Rinehart and Winston of Canada, Limited, 1971), 19-24.

${ }^{201}$ Dobos, 1, 2, 4 and 8. 
not object to it. ${ }^{202}$ Though she took the pill on and off over about ten years, she did not think she ever discussed it with a priest, saying she considered it her business and not a sin. She added that, while in the past, "it was felt to be a good Catholic you have to...produce every year or every year and a half," she did not share this view. ${ }^{203}$

Unlike Galli, Jones did see the use of the pill as a sin. Consequently, she felt a little more guilty about it but "my feelings were so strong about not getting pregnant, that I just decided...I always say I'm not a very good Catholic...I don't follow all the rules." Thus, despite some nagging feelings, she never felt compelled to discuss the matter with a priest. During her years on the pill, which spanned 1966 to about 1974, with some interruptions, she attended Church regularly and whenever she did go to Confession, she simply omitted any mention of the pill. ${ }^{204}$ Thus, despite a little more ambivalence about her choice, Jones, like Galli and Dobos, never felt so conflicted that she needed to seek out religious absolution or reassurance.

Other women wrestled more over their decision to use the pill for birth control and found it complicated their religious experience. In a 1968 editorial in Chatelaine magazine, following the Pope's encyclical, Doris Anderson lamented that "The tragedy is that individual devout Catholics may feel in conscience that they have to go against the ruling of the highest authority of the church...and that the greatest hardship of all will undoubtedly fall on those countries and those people least able to bear the burden of large numbers of children." 205 As Anderson speculated, some women did choose to use the pill

\footnotetext{
${ }^{202}$ Galli, 14-15. However, this same doctor would not perform a tubal ligation when she wanted one in about 1978. He instead referred her to another doctor who performed the surgery. This time, Galli believed that his actions were motivated by his Catholicism as well as the fact that she only had one child. ${ }^{203}$ Ibid., 1, 5, 10-13, 15, 16-17.

${ }^{204}$ Jones, 5, 6, 7-9, 14-15

${ }^{205}$ Editorial, "The Pope and the Pill," Chatelaine 41, 11 (November 1968), 1.
} 
rather than adhere rigidly to Church teachings. However, this choice was not without emotional upheaval or even anguish. This struggle was manifested in the testimony of Wilson, a woman who became Catholic when she married in 1963. Catholicism was the religion of her husband and one assumes she joined this Church primarily for that reason. She also added, however, that she had "always felt drawn to the Catholic Church."206 After the birth of her first child in 1965, she started the pill and was on it, with a few interruptions, until the mid-1970s. ${ }^{207}$ She said she did take her children to Mass but felt guilty about using the pill and "I think that's why I got away from going to church after a while because I felt as if I was committing a mortal sin...but, at the same time...we couldn't afford to have a baby every year." While also mentioning that it was challenging when her children were young to get to Mass since she did not drive, Wilson reflected that she could not participate in Communion, which she saw as a major component of the service, or Confession because of the pill. Embarrassed, she never discussed the issue with a priest but felt confident they would agree she should not be on the pill. Wilson struggled with this moral dilemma and, ultimately, it was a factor in diminishing her Church attendance during this time in her life. ${ }^{208}$ Therefore, while other women were able to reconcile their pill use and their religion without speaking to a priest, Wilson remained silent for other reasons. Ultimately, she resolved her inner turmoil by distancing herself from the Church.

Though Wilson was certain her priest would have discouraged use of the pill, this proved to not always be the case. In fact, women who spoke to members of the clergy received a variety of responses. Sometimes, they did encounter disapproval. When a

\footnotetext{
${ }^{206}$ Wilson, 2; Follow-Up Interview with Margaret Wilson, December 11, 2009, 30.

${ }^{207}$ Wilson, 2, 6-7, 11-14.

${ }^{208}$ Follow-Up with Wilson, 30-32.
} 
priest visited Arsenault after the birth of her son in 1966 and she stated that she did not intend to have any more children immediately, he replied that he hoped she was not employing birth control. Undaunted, Arsenault responded by asking him to leave. Subsequently, she was denied absolution during Confession because of the pill. As she was initially quite distressed, Arsenault's sister tried to comfort her by suggesting that they go to a different church where the priest would give absolution. ${ }^{209}$ This intriguing idea suggests, as do the interviews conducted by Gervais and Gauvreau, that some priests, like their parishioners, did not adhere rigidly to Church doctrine. ${ }^{210}$ Arsenault followed her sister's advice and did get absolution at this second church but ultimately, while she continued to go to Mass regularly, she dispensed with Confession. She explained that "I knew I wasn't committing a sin. I thought it was more sinful to have a pack of kids you couldn't look after."211 Therefore, while she did not move away from the Church to the same extent as Wilson, it would seem that the differences of opinion over the pill did diminish Arsenault's participation in one religious activity.

Thus, though Arsenault received religious censure for her family planning decisions, she also found a priest who had no problem giving her absolution. This demonstrates the variety of responses to the pill even within the Catholic Church. ${ }^{212}$ As Thompson stated, "the Church...really did not...want people using birth control. And then

\footnotetext{
${ }^{209}$ Arsenault, 3 and 11-13. Arsenault was not sure if this was the same priest who visited her home that then denied her absolution. She did think it was likely both encounters were connected to the same church. ${ }^{210}$ Gervais and Gauvreau, 299 and 306. In their sample of seventeen former priests, Gervais and Gauvreau found that "None claimed to have denied anyone absolution [because of contraceptive use]."

${ }^{211}$ Arsenault, 13 and 11. Gervais and Gauvreau, 313. Gervais and Gauvreau confirm in their article on family limitation in Quebec from 1940 to 1970 that, like Arsenault, "some women 'shopped around' for a confessor who would not refuse them absolution."

${ }^{212}$ Gervais and Gauvreau, 306. This finding was confirmed by Gervais and Gauvreau in their interviews with Catholic priests.
} 
again it depended on what priest and what church you were talking to." ${ }^{\text {213 }}$ Thus, like Arsenault, women could encounter more or less sympathetic members of the clergy. Often, positive discussions with a priest or even the approval of a Catholic doctor could mitigate any sense of religious transgression.

Ecclesiastical reassurance was particularly important to Morrison. After the birth of her second child in 1965, she realized that birth control might be necessary as she needed to be able to work outside the home. Despite the reality of her situation, she still felt quite guilty being on the pill. When she did go to Confession, she would simply not mention it. At some point between 1970-1975, when she had been on the pill for several years, she talked to her parish priest. She explained that she was on the pill and did not want any more children. The priest was understanding and said he saw no reason for her to feel guilty. Though Morrison was reassured by this conversation, she still kept the importance of his opinion in perspective. She said I needed "someone from the Church to tell me they thought it was okay. Although if he told me it wasn't okay, I would have ignored it anyway."214 This comment is interesting and suggests that, even though she was more conflicted about the pill, Morrison was prepared, like Arsenault, to defy ecclesiastical authority if necessary. Morrison also commented that another priest might have responded much more negatively to her pill use. ${ }^{215}$ This again points to the disparity of opinion within the Catholic Church.

Thompson, though perhaps less conflicted than Morrison, still sought out a priest. She told him that, while she wanted more children in the future, her doctor had suggested she take a break from child-bearing and go on the pill after the birth of two children in

\footnotetext{
${ }^{213}$ Thompson, 16.

${ }_{215}^{214}$ Morrison, 5, 10, 12, 14, 15, 23 and 24.

${ }^{215}$ Ibid., 15.
} 
seventeen months. She said the priest, while reiterating the Church's view, was reassuring. Like other women, Thompson felt that she could remain a Catholic without adhering to all the Church's positions. ${ }^{216}$ Klein, who used the pill in the 1960 s and 1970s, was also unconcerned about pill use. She converted to Catholicism because this was the faith of her husband and "I thought religion should be important to the kids and I couldn't see the problem of becoming Catholic."217 Wilson and Klein, though both converts, had very different perspectives on birth control. When she approached a priest to discuss having her son baptized, he "reached over and took my arm and he said, now you know you have to give this baby his chance at childhood. No more babies for two years." ${ }^{218}$ The priest's choice of words is interesting and perhaps reflected both the rhetoric of responsible parenthood and that of children's rights. The latter, though not used very often in my interviews, was circulating in the 1970s. Though the concept predated the twentieth century, by this time, "a new emphasis evolved on allowing children the freedom to develop as individuals and on validating their experiences, just as women were attempting to do through second-wave feminism. ${ }^{, 219}$ Here, Klein's priest is emphasizing the right of her son to have a childhood, an idea dating back to Romanticism. ${ }^{220}$ He seems to use this argument to couch what Klein interpreted as his more implicit endorsement of birth control. ${ }^{221}$ Thus, while some priests were not shy about condemning birth control, others appeared to be more sympathetic to Catholic women's difficult choices in this matter.

\footnotetext{
${ }^{216}$ Thompson, 15-16, 20.

${ }^{217}$ Klein, 34-35.

${ }^{218}$ Ibid.

${ }^{219}$ Hugh Cunningham, The Invention of Childhood (London: BBC Books, 2006), 224; Jessica Haynes, "The Legacy of Scientific Motherhood: Doctors and Child-Rearing Advice in the 1960s and 1970s in English Canada," (Master's Thesis, Department of History, Carleton University, 2007), 64.

${ }^{220}$ Cunningham, 224.

${ }^{221}$ Klein, 35 .
} 
Sometimes, medical clearance seemed to be sufficient for both priests and women. Moore, who started the pill in about 1968, after having four children, did once broach the topic during Confession. The priest simply replied that if her doctor advised it, ostensibly in her case to regulate her periods, there was no problem. Moore confirmed that "Even Catholics were using...[the pill]...as long as you had your doctor's...advice that you needed it." Though she did not feel using the pill was sinful, she must have still appreciated the priest's validation of her actions. ${ }^{222}$ The story of Julie Macauley, related in Barbara Seaman's book, displayed a similar dynamic between the doctor, the priest and the pill user. Macauley, a young Catholic mother with five daughters, was put on the pill by her doctor to make her periods more regular. After informing the doctor that she was Catholic, he said she should discuss the matter with a priest before he would prescribe it. According to her husband, Macauley

went to.Monsignor O'Hara...who was our pastor at the time and talked with him. He said that it was a strictly medical matter. If [the doctor] was giving it to her for some condition that he felt was necessary from a medical standpoint, why, then, she was justified in taking it. Julie called the doctor back after she had seen the priest and the doctor phoned the prescription to the drugstore so we could pick it up. ${ }^{223}$

Before leaving the topic of the pill and Catholicism, I wanted to briefly discuss the role of the Catholic husband in their wife's contraceptive decision-making. It is, of course, not a given that Catholic spouses would agree on this topic which, as we have seen, could be very divisive. This seems to be the case for Molly, a Catholic mother of

\footnotetext{
${ }^{222}$ Moore, 10, 12, 14, 15-16, 28, 30-31. Despite this apparent need for Church support, Moore concurred later in the interview that her decision to use the pill partly reflected a change in her own views on birth control. When she was having her family, she respected the Catholic Church's prohibition on birth control. However, by 1968 , she felt their opposition to the pill was wrong. In about 1971 or 1972, Moore stopped going to church entirely in part because she felt her lifestyle, which included taking the pill and pursuing an extramarital affair, made her feel hypocritical in church.

${ }^{223}$ Seaman, $9,71,74-76$. Seaman said that she disguised names in her book to protect privacy.
} 
eight, who hid her use of the pill from her husband because he opposed birth control on religious grounds. ${ }^{224}$ She explained

Win says that if God meant for us to have 14 or 16 children, then we should go ahead and have them...On the other hand, I believe this is a matter of personal conscience and that it would not be a sin to practice birth control. I give my eight children so much love and attention...I don't believe that I could take proper care of them if I had more. And I can't believe that God would send me to hell for taking measures to insure that I can continue to take proper care of the children I already have. ${ }^{225}$

While this example shows disagreement between a Catholic husband and wife, the women I spoke to remember that their husbands had no religious qualms about the pill, or at least did not voice them. ${ }^{226}$ Moore explained that, for her husband, it was not an issue "if your doctor was a good Catholic doctor and recommended it."227 Interestingly, this apparent lack of inner conflict occurred even if their wives were struggling to reconcile pill use with Catholicism. ${ }^{228}$

As this chapter has shown, the pill had an extensive impact on the lives of married women, influencing their sexuality, careers and family sizes. For Catholic women, the pill could also change the way they understood and practiced their religion. While many were able to reconcile their pill use, sometimes after supportive consultations with a priest, others had more difficulty and responded by sacrificing parts of their religious experience, such as Confession. It is interesting to note that no one in my sample resolved their inner turmoil by going off the pill, suggesting both the importance attached

\footnotetext{
${ }^{224}$ Seaman, 63-64.

${ }^{225}$ Ibid., 63.

${ }^{226}$ Wilson, 31; Jones, 6; Galli, 6; Arsenault, 20.

${ }^{227}$ Moore, 27.

${ }^{228}$ For example, Wilson, 30-32.
} 
to the pill as birth control and, perhaps, the diminishing power of religion in the second half of the twentieth century. ${ }^{229}$

\section{Religion: The Lingering Unease in Christian Science}

The 1960 s were not the first or only time that people in Western countries expressed dissatisfaction with and skepticism of modern medicine. In the 1860 s and 1870s, Mary Baker Eddy, an American, developed Christian Science which posited that the body and illness were simply material illusions, created by the mind. Real healing, under the guidance of a Christian Scientist practitioner, occurred when an individual came to accept these truths. Given these ideas, it is not surprising that Christian Science, under Eddy, initially positioned itself in opposition to medical care. However, in the twentieth century it became more flexible, permitting such things as blood transfusions and hearing aids. Eddy, towards the end of her life, also "sanctioned the use of painkillers for bouts of intense pain, even though she had claimed in 1884 that medicine 'only weaken[s] your power to heal through mind.",230

It was perhaps inevitable that Christian Science would quickly cross the border. Indeed,

late-Victorian Canada was hospitable to its spread. Nervous ailments and anxieties over personal health were growing faster than physicians' ability to deal with them, and a widespread preoccupation with societal or racial health ensured that any promise that humanity might evolve to a higher state of consciousness was apt to gain a hearing. Debate over the nature of mind had been going on for decades within the medical profession, and the controversy widened as the public took a growing interest in such

\footnotetext{
${ }^{229}$ However, given my focus on women's experiences with the pill, I did not speak to those who never tried the contraceptive because of religious objections. Further research into this group would be interesting. ${ }^{230}$ Patricia Jasen, "Mind, Medicine, and the Christian Science Controversy in Canada, 1888-1910," Journal of Canadian Studies 32, 4 (Winter 1997/1998), http://lion.chadwyck.com.proxy.library.carleton.ca/searchFulltext.do?id=R04235844\&divLevel=0 \& area=a bell\&forward=critref $\mathrm{ft}$; Rennie B. Schoepflin, Christian Science on Trial: Religious Healing in America (Baltimore: The Johns Hopkins University Press, 2003), 6, 28, 29, 66, 80, 192-193.
} 
topics as hypnotism, the unconscious and the nature of psychic phenomena. $^{231}$

Christian Science appealed especially to women and gained the most followers in Ontario, particularly in Toronto. By 1901, the Canadian Census listed 2,619 Christian Scientists and "by 1911 that number had doubled, and had nearly tripled again by 1921 for a total of 13,856, of whom 56 per cent were women."232 Christian Science remained a presence in Canada into the 1950 s and 1960 s, with almost 20,000 adherents in $1961 .^{233}$

Into the twentieth century, Christian Scientists still tried to minimize medical interventions into their lives. Thus, this religion could potentially influence women's relationships with modern medicine and pharmaceuticals, including the pill. In my interviews, I found that Kennedy's grandmother was a Christian Scientist and Kennedy regularly went to this church as a child. She mentioned that her decision not to go back on the pill after the birth of her son may have been influenced in part by Christian Science which imparted to her the message that one should not meddle unnecessarily with one's body. ${ }^{234}$ Like Kennedy, Lowe was exposed to Christian Science in childhood and was raised in this religion by her mother. As a child, Lowe was taught to be cautious about the use of medication. She felt this wariness may have seeped into her perception of the pill even though she did not become a Christian Scientist as an adult. ${ }^{235}$ In contrast, Lowe's sister, Edwards, did not feel Christian Science beliefs influenced her choice of birth control at all. ${ }^{236}$ This once again suggests that women, even those raised

\footnotetext{
231 Jasen.

${ }^{232}$ Ibid.; Rosemary R. Hicks, "Religion and Remedies Reunited: Rethinking Christian Science," Journal of Feminist Studies in Religion (September 2004), 51.

${ }^{233}$ Religious Denominations in Canada (Ottawa: Queen's Printer, 1965), 11-6.

${ }^{234}$ Kennedy, 2 and 15-17.

235 Isabelle Lowe, 1, 6 and 38.

${ }^{236}$ Edwards, 1 and 38.
} 
in the same families, can internalize different religious messages which may or may not affect their views of the pill.

\section{Conclusion}

Was the pill revolutionary or not? This chapter has attempted to answer this complex question, particularly as it relates to married women in Canada. Ultimately, the pill could have a deeply transformative (and positive) impact on the lives of Canadian women, improving their sex lives, furthering their careers and allowing them to determine their family sizes. As Lara Marks said in her book on the pill, which focuses on the United States and Britain, "The ability to plan the size of families enabled couples to devote themselves to other priorities such as education, the pursuit of a woman's career, and material acquisitions, without foregoing sexual intercourse." ${ }^{237}$ However, there is a darker underside to this story. For all the women who were happy with the pill, there were also those who found its side effects ruined sex, limited job options and, in one case at least, autonomously curtailed family size. These troubling aspects of pill use complicate its image as a positive force in the lives of married women, as do the stories of those who say the pill had no significant impact on family size, sexuality, etc.

Clearly, religion could be a factor in pill use. The pill had an important impact on the way Catholic women approached their religion. Whether they went on the pill with apparently no sense of conflict, avoided the topic with religious authorities or spoke openly with a priest who was helpful, they all acted in contravention of Church doctrine by taking the pill. Women adopted a variety of strategies to negotiate this reality. Though less influential, Christian Science, even in the 1960s, was cited as affecting

${ }^{237}$ Marks, 192. 
women's attitudes towards taking the pill, perhaps inculcating in them a layer of suspicion regarding this contraceptive medication. 


\section{Chapter 7-Conclusion}

This thesis has explored the impact of the birth-control pill on English-Canadian women who started taking it in the 1960s when married or engaged. I initially chose this topic when I realized that no one had written about the experiences of English-Canadian women on the pill, with the exception of Christabelle Sethna who looks primarily at single women and their struggles to get the pill through universities. The other main source on the history of contraception in Canada, by McLaren and McLaren, also focuses on the public level. The main actors in McLaren and McLaren's work are doctors, eugenicists, activists and the state. The voices of men and women, particularly in the second half of the twentieth century, are not prominent. In contrast, my analysis is at the level of intimate, private social relations and individual choices. This approach is much more similar to Fisher's and, except for a limited glimpse provided by Gervais and Gauvreau in their article on family limitation in Quebec from 1940 to 1970, has not been used before in the Canadian context. It has allowed me to explore in depth, as other studies have not, the complexities surrounding married Canadian women's experiences with the pill, including their interactions with doctors, the role of their husbands in contraception, and the impact of the new contraceptive on family size and marital sexuality.

The testimony of married women, primarily from the middle-class, demonstrated that pill use was neither straightforward nor necessarily positive in the 1960s and 1970s. I also hope my thesis contributes to the recent work on postwar Canadian society, which is beginning to look beyond the experiences of the most visible baby boomers. The women I interviewed were not hippies or radicals. Nor were they amongst the group of 
unattached girls whose sexual morality was at the centre of public debates about the pill at the time, and has remained at the centre of the historiography since then. As young mothers in the 1960s and 1970s, they experienced the period differently. Their struggles and triumphs with reproductive control represent an important part of the story of Canadian culture, society and politics in the 1960s and 1970s.

This thesis was organized to track a woman's journey on the pill. The oral interviews, unlike other sources used by Sethna, McLaren and McLaren, allowed me to gather information about a woman's entire experience. Chapter 2 analyzes some of the factors involved in a woman's decision to take the pill, including learning about it and finding it appealing. Unlike other contraception, the pill was a medication and, as such, knowledge about it might normally have been restricted to the medical community. However, this proved to be impossible. In the process, because of the widespread use of the drug, the larger history of people's relationships to their doctors, and their conceptions of medications, would be changed significantly. For this, my conclusions represent a contribution to the history of women and medicine.

The fifty-three women interviewed heard about the pill from friends, family members, their work and education as well as the media. Once word of the pill reached a woman, it is not surprising that she found it appealing. The pill had a reputation for effectiveness and convenience, and these factors held sway with women who had had unpleasant experiences using other contraception as well as those who simply knew of them. Particularly those pill users who had suffered an unplanned pregnancy while relying on withdrawal, condoms, spermicides, or diaphragms were very interested in the new contraceptive. Beyond their initial enthusiasm for it, the experiences of this first 
generation of pill users prove definitively that contraception before the pill's arrival left much to be desired. Finally, a woman's decision to try the pill more often than not involved their husband or fiancé. Though some apparently remained more aloof from the field of contraception, others were remembered as very much engaged: sometimes the couple reached the decision jointly, sometimes husbands suggested the pill themselves or even opposed the idea. Whatever the case, they certainly did not appear to have left these decisions entirely in the hands of women, confirming Kate Fisher's speculation that, with the pill, birth control may have become a joint responsibility.

Once a woman decided to take the pill, usually with the support and approval of her male partner, some might assume that getting it would be quite easy. After all, married women were expected to have sex and, by the 1960 s, to try to limit their families in some way. Moreover, proponents of the pill had overwhelmingly presented it as a means destined for married women. Chapter 3 demonstrates, nevertheless, that, while testimony confirms the impression that single women had more trouble than married ones in accessing the pill, impediments were still possible for those who were married or engaged. Waiting until they could approach a doctor sporting a shiny engagement ring increased their chances of getting a prescription but even with this significant piece of jewelry, there was no guarantee. At least one of the doctors made a woman wait until closer to her wedding, possibly because of moral or religious objections to premarital sex. Additionally, a ring did not assuage the concerns that some physicians had about the medical safety of the pill. Age and income could also play a role in the ease with which a woman accessed the pill: a few of the married women I encountered did find, particularly at certain times in their lives, that the pill was beyond their financial means. 
Chapters 3, 4 and 5 all explore in some depth the relationship between the doctor and the pill user at specific times in a woman's life cycle. Most significantly, the examination of such interactions demonstrates not only how this dynamic was changing, a process observed by many historians, but also how intimate histories of pill use were contributing to those shifts. Perhaps driven by its reputation for ease of use and effectiveness, many women were becoming more assertive by asking their doctors for a specific medication. Sometimes, they even persisted when doctors themselves were uncertain. Others encountered pill advocates in the doctor's office and again showed agency, this time by resisting the medical advice to try the pill. However, in the 1960s, there were also instances of the perpetuation of a more traditional doctor-patient dynamic in which women were content to follow the doctors' recommendations. Thus, my analysis demonstrates that the pill, though capable of substantially altering the doctorpatient dynamic, did not do so absolutely in the 1960s.

Chapter 3 also explores the medical care of women on the pill. At a time when the medical community's uncertainties over the side effects of the new contraceptive were high, women received varying amounts of information when getting on the pill. Some doctors were more forthcoming than others. Somewhat alarmingly, doctors were not universally conscientious in performing physical examinations when initially prescribing the pill, an act which by the standards of the time would have been prudent, given that the pill worked systemically in the body. Canadian doctors also differed in the extent to which they carried out check-ups on women taking the pill. Such lack of medical attention often added to a woman's unpleasant experience with side effects. 
Indeed, in contrast with the simplicity of contemporary and current myths about the liberating impact of the pill, side effects were a huge component of a woman's experience with the contraceptive in the 1960s and 1970s. Unfortunately for many interviewees, they were common, demonstrating that the pill was by no means a perfect contraceptive. Side effects ranged from annoying to life-threatening. As women navigated these problems, they relied on the support of friends, husbands and doctors. If doctors had the power to reduce or even eliminate side effects by recommending a different brand or dose, not all physicians offered these options, another sign that women received varying levels of care. Doctors could also help a woman plagued by side effects by advising her to go off the pill. While this happened to a number of women, others found members of the medical profession unhelpful, particularly if they did not seem to be aware of the possibility of certain side effects.

In managing their side effects, women again showed agency in a number of different ways. A few interviewees chose not to report side effects, possibly fearing a doctor's judgment. Some went off the pill without medical endorsement, while others clung to the contraceptive when doctors suggested it was causing problems for them. For this first generation of women and doctors in contact with the pill, these interactions could constitute a mutually beneficial process of learning in which participants had access to different forms of knowledge and shared what they gleaned with one another. Husbands also helped their wives manage side effects. They were often remembered as troubled by serious issues and supportive of decisions to discontinue the pill. However, one or two so valued the contraceptive that they encouraged their wives to stay on despite disruptive side effects. 
Obviously, side effects that were so unpleasant as to make sex unpalatable or impossible cancelled out any benefit of the pill as a contraceptive. The pill is also only very effective if taken regularly. Chapter 3 looks at whether or not women had difficulty remembering to take the pill every day. While some do not report this as an issue, others found it to be a problem. This again complicates the idea that the pill represented a universal solution to family planning.

Chapter 6 examines the broader impacts of the pill on married, Canadian women, beyond the strict domains of health and reproduction. Ultimately, I argue it could have profound consequences for them, shaping their experiences of sexuality, their family sizes, their careers and, for some, their religious practices. In regard to religion, historians looking at the American and British contexts have found that the pill caused tension between Catholics and the institutional church. Canadians, including individual women, priests and even bishops, were part of this turmoil and had to, in some cases, redefine their relationship with the Church and its doctrine. Generally, while some interviewees remembered the pill as a benign force which transformed their lives, for others it was a more sinister presence, bringing with it physical discomfort and mental anguish. These problems were often no less because the women in question were married.

Several important themes run through all the chapters of the thesis. First, there is the question of women's agency in dealing with the medical profession. Though my thesis is not systematically comparative and I did not read all the relevant Western literature, based on what I have reviewed, in this area English-Canadian women seem to belong to a broader history of Western English experiences. Like their British, American 
and Quebec counterparts, many English-Canadian women, as evidenced by my research, were quite comfortable assuming a more assertive role with their doctors by asking for the pill. They also sought out, as Watkins in particular found in the United States, medical opinion and help regarding side effects. While placing trust in doctors to solve any issues or address any concerns, Canadian women in my sample also challenged medical authority by making their own decisions about the pill. Marks, whose book focuses primarily on Britain and the United States, confirms such moments of defiance. Thus, Canadian women, like others in Western countries, were not hapless victims of a domineering medical profession. Even in the absence of the detailed patient insert given to pill users in Canada today, they were still able to make choices regarding contraception. Therefore, as Mitchinson points out in her work on medicine and Canadian women in the first half of the twentieth century, the constraints placed upon a woman's ability to exert agency did not mean she was completely powerless.

The issue of side effects is also an important component of this thesis. Half way through the period covered by this study, American journalist Barbara Seaman, in her influential 1969 book entitled The Doctors' Case Against the Pill, attributed an extensive and diverse number of problems to the new contraceptive. One might be tempted to view her list, which drew on testimony from women around the world, with a certain skepticism. However, my interviews confirm that Canadian women did indeed suffer numerous side effects, including weight gain, yeast infections, migraines, depression and even stroke, all of which were mentioned in Seaman's book. It would appear Seaman was right to highlight the occurrence and seriousness of side effects. My interviews 
confirm further that they could have a detrimental impact on women's lives and certainly tarnish the image of the pill as the "Great Emancipator."

Finally, the question of contraceptive responsibility appears at many different moments during a woman's experience on the pill. This aspect of my research sheds an interesting light on the larger history of Canadian marital relations which is not well documented. Kate Fisher's social and cultural history of British couples demonstrates persuasively that, for at least the first half of the twentieth century, contraception was something that British men managed. In contrast, the existing evidence for the Canadian couples has so far been conflicting. For instance, McLaren and McLaren state that "withdrawal was the most widely used method of contraception...until at least the 1930s," indicating a strong degree of male involvement; but the Canadian letters to birth-control advocate Marie Stopes they discuss were written largely by women. ${ }^{1}$ Does this mean that Canadian spouses in the 1930s shared the responsibility for contraception? Further research is needed to answer this question.

Christabelle Sethna asserts methods like the pill brought contraception into the female domain. And indeed my analysis demonstrates that, on the whole, women who initially tried the pill in the 1960 s did seem to accept birth control as their responsibility. However, many husbands and fiancés were, as Kate Fisher speculated, involved in decisions about contraception. They could have a voice in selecting the pill and in managing its side effects. Though beyond the scope of my dissertation, they might have later on agreed or volunteered to have a vasectomy, indicating that they most certainly did not abandon the birth-control field to their wives.

\footnotetext{
${ }^{1}$ Angus McLaren and Arlene Tigar McLaren, The Bedroom and The State: The Changing Practices and Politics of Contraception and Abortion in Canada, 1880-1980 (Toronto: McClelland and Stewart, 1986), 18 and 24-28.
} 
The subject of surgical sterilization, which became increasingly popular in the 1970s and 1980s, is one area that deserves further research in Canada. As McLaren and McLaren reflect in the second edition of their path-breaking book, seventeen years after its publication in 1986, "In the 1980s the married or cohabiting, once they achieved a desired family size, increasingly accepted sterilization as the simplest and safest way to avoid pregnancy." Certainly, many of the women I interviewed, or their partners, chose to have surgery to permanently end their fertility. The selection of this birth-control option often involved interactions between husbands, wives and doctors which are fascinating for further discussions of contraceptive responsibility. For instance, some husbands volunteered to get vasectomies while others were urged to by their wives. Once the decision had been made, medical authorities intervened in very interesting ways. Two women I spoke to were quite indignant that, before they could get tubal ligations in the 1970s, their husbands were required to sign a consent form. Though this appears at first glance to represent a blatant assertion of patriarchal authority over the female body, it is interesting to note that another woman I interviewed said her signature was necessary prior to her husband's vasectomy. Perhaps doctors were encouraged by law or professional guidelines to ensure that both parties agreed to these procedures, which were very hard to reverse. Other doctors were openly resistant to doing sterilizations. One woman in my sample, the mother of six children, was told that a panel of doctors had carefully considered her case and agreed she could have a tubal ligation provided she also had her appendix removed. Her husband objected to this condition and had a vasectomy instead. The availability and popularity of surgical contraception has

\footnotetext{
${ }^{2}$ Angus McLaren and Arlene Tigar McLaren, The Bedroom and the State: The Changing Practices and Politics of Contraception and Abortion in Canada, 1880-1997 Second Edition (Oxford: Oxford University Press, 1997), 141.
} 
likely had a significant influence on Canadian marriages. I would particularly suggest oral history, which proved to be so rewarding and rich in my work, as a source for this project.

There are certainly many other topics or areas to be explored which would contribute to the history of Canadian sexuality and contraception. As well as sterilization, it would now be interesting to analyze the contraceptive experiences of a later generation of married women in light of what I have discovered about the lives of the pill pioneers. Did they have more or better options? Quite a few women in my sample, often after the pill, experimented with intrauterine devices (IUDs). McLaren and McLaren say that "in North America the oral contraceptive, by the mid-1970s, was already viewed with increased wariness by the married, associated as it was with increased incidences of cancer and blood clotting."3 Certainly, Chapter 5 of this thesis confirms that married women, who started the pill in the 1960 s, were aware of such reports. But what about their younger counterparts? Did they choose to go on the pill for the same reasons? If not, what other methods were used? What new data informed their decisions? How did the experience of older women they knew contribute to their deliberations regarding birth-control options? Though McLaren and McLaren in the second edition of their book, as well as Sethna in her 2001 article, provide insight into some of these questions, further research is needed.

Both Mary Louise Adams and Christabelle Sethna discuss sexual education in Ontario in the postwar period but they focus on the school system. It would be interesting to explore the familial and generational transmission of such knowledge. My interviewees, usually in response to questions, discussed how they learned about sex and

\footnotetext{
${ }^{3}$ McLaren and McLaren, 1997, 140.
} 
birth control as young girls and women. Often, though not always, their mothers played an important role in these stories while formal education appeared to be less significant. In turn, once my interviewees had children of their own, they (and their husbands) may have informed the next generation. Though this is purely speculative, I wonder if the pill, which made the public discussion of contraception much easier, also facilitated private conversations between parents and children surrounding birth control. After all, the pill, unlike condoms or a diaphragm, could be discussed with less or even no reference to sexual intercourse.

Through the work of Sethna, McLaren and McLaren as well as Appleby's book on the legalization of birth control, we have learned something about contraception at the institutional level of religion, the state, the university and the medical profession. While my analysis offers a new and necessary window into the private realm of pill users, it would be interesting to explore further how the pill may have impacted public life in Canada. For instance, did the experiences of women, detailed in this thesis, influence the Canadian government to establish the special committee on oral contraceptives? How did the pill, taken every day over potentially long periods of time by healthy women, alter both the drug industry and the medical profession? As I discuss, both were compelled to accept patient inserts for the pill. Did this then become standard practice for other medications? If so, when? Finally, how did the pill affect the institution of marriage in ways I do not explore? For instance, did its use contribute to the rise in divorce occurring in the same period?

In addition to these larger topics, there are more specific areas which are not covered in my thesis. I limited my study to English Canada and the testimony of French- 
Canadian women, married or otherwise, regarding the pill's impact, would, I am sure, be very revealing. While Gervais and Gauvreau offer some interesting insight into the French-Canadian experience, their analysis is limited to Montreal and includes the testimony of only eight women. Though Sethna's articles are informative and provocative, single women await their own thesis or book which would look beyond the university campus. As my sample includes more middle-class women, the stories of working-class women also deserve further exploration. Finally, my thesis focuses on women and so anything about the role of the man in pill use is very much filtered through female eyes. Future study involving both partners could be informative, especially on the subject of sterilization.

I wish to conclude with a brief note on methodology. I did not originally conceive of this project as an oral history. However, I quickly realized that sources capturing married, Canadian women's experiences on the pill simply did not exist, at least not in the number and depth I required. In her work on single women, Christabelle Sethna draws a lot on student publications, like campus newspapers and McGill University's Birth Control Handbook. Married women have not left the same sort of record. Their voices were perhaps most preserved in printed issues of Chatelaine magazine as well as letters to the periodical which I used as much as possible. However, the magazine constituted a public forum in which women might not always have been comfortable expressing their private contraceptive experiences. Ultimately, I concluded the best way to gain insight into birth-control practices and experiences was to speak directly to women. 
The interviews I conducted yielded rich and intriguing testimony. However, like any source, the method is not perfect. The interviewer sometimes has to deal with testimony that is uncertain, contradictory and incomplete. Additionally, as I mentioned particularly in Chapter 5 in regard to reports of side effects, it was sometimes difficult for people to separate what they knew in the 1960s and 1970s from what they knew later. Interpretations of events are often influenced by subsequent history, both personal and collective. For example, the woman who suffered bladder control issues with the pill did not know it was the cause until after she was off of it. Once she heard about this side effect, she presumably felt much more antagonistic towards the doctors who had dismissed her as psychologically troubled. As a group, my informants, from the vantage point of 2009 and 2010, seemed to express an implicit awareness that side effects were very publicly discussed at some point, though not necessarily during their time on the pill. Regardless of when they became aware of this information, it might have altered how they reflected upon their interactions with the contraceptive and the medical profession. These additional layers of interpretation make the testimony more interesting and dynamic, as oral historians have been arguing since the 1970s.

Beginning in the 1960 s, the pill was trumpeted in the media as the "Great Emancipator," which would free women. This myth continues to circulate in contemporary Canadian society. Without diminishing the pill's potential as a liberator of women, my thesis complicates this image. Given the diverse experiences of women who took the pill, one wonders why it is still often hailed as the "Great Emancipator." Perhaps it is simply because the pill pioneers in Canada, those women who were the first to try the new contraceptive, have been hesitant to speak of the pill's impact on their 
lives, particularly if it contradicts the larger social narrative. Another explanation may be that, looking back on the twentieth century, a period of great disruption and moral uncertainty, contemporary society wants to see at least some unequivocal positive outcomes, and so, clings to the pill as a symbol of the triumph of medical science, progress, and female liberation. While it did represent all of these things, this thesis has shown its real impact on women was much more nuanced, interesting and multidimensional. 
Appendix 1

Interviewees

\begin{tabular}{|c|c|c|c|c|c|c|c|}
\hline Name & $\begin{array}{l}\text { Year } \\
\text { of } \\
\text { Birth }\end{array}$ & $\begin{array}{l}\text { Occupation (when } \\
\text { on pill) }\end{array}$ & $\begin{array}{l}\text { Ethnic } \\
\text { Background }\end{array}$ & $\begin{array}{l}\text { Religion } \\
\text { (when on } \\
\text { pill) }\end{array}$ & $\begin{array}{l}\text { Region } \\
\text { (when on } \\
\text { pill) }\end{array}$ & $\begin{array}{l}\text { Years } \\
\text { on Pilli }\end{array}$ & Side Effects \\
\hline $\begin{array}{l}\text { Heather } \\
\text { Anderson }\end{array}$ & 1942 & $\begin{array}{l}\text { Various jobs in } \\
\text { retail and a } \\
\text { restaurant from } \\
\text { maybe } 1959-1970 . \\
\text { After } 1970 \text { worked } \\
\text { in motel then got } \\
\text { into real estate. }\end{array}$ & $\begin{array}{l}\text { Scottish and } \\
\text { Irish }\end{array}$ & $\begin{array}{l}\text { Anglican } \\
\text { (lapsed) }\end{array}$ & $\begin{array}{l}\text { Ontario } \\
\text { N.B. }\end{array}$ & $\begin{array}{l}1965- \\
1980 \mathrm{~s}\end{array}$ & None \\
\hline $\begin{array}{l}\text { Jane } \\
\text { Arsenault }\end{array}$ & 1945 & $\begin{array}{l}\text { Homemaker and } \\
\text { part-time in various } \\
\text { clerical/ } \\
\text { secretarial jobs }\end{array}$ & Acadian & Catholic & $\begin{array}{l}\text { N.B. } \\
\text { Ontario } \\
\text { Alberta }\end{array}$ & $\begin{array}{l}1966- \\
69 \\
1970-3\end{array}$ & $\begin{array}{l}\text { None, periods } \\
\text { got } \\
\text { lighter }\end{array}$ \\
\hline Annie Beck & 1935 & Homemaker & $\begin{array}{l}\text { German, } \\
\text { French } \\
\text { (from } \\
\text { Rhineland } \\
\text { area) }\end{array}$ & Anglican & $\begin{array}{l}\text { N.S. } \\
\text { Ontario }\end{array}$ & $1965-8$ & $\begin{array}{l}\text { Weight gain, } \\
\text { mood, lighter } \\
\text { periods, } \\
\text { felt off }\end{array}$ \\
\hline $\begin{array}{l}\text { Beverley } \\
\text { Brooks }\end{array}$ & 1948 & Secretarial & $\begin{array}{l}\text { Irish, French } \\
\text { Canadian } \\
\text { and British }\end{array}$ & None & Ontario & $\begin{array}{l}1969- \\
74\end{array}$ & $\begin{array}{l}\text { Possible anxiety, } \\
\text { morning sickness, } \\
\text { yeast infections, } \\
\text { tender breasts }\end{array}$ \\
\hline $\begin{array}{l}\text { Susan } \\
\text { Brown }\end{array}$ & 1944 & Nurse Teacherii' & $\begin{array}{l}\text { Irish, } \\
\text { English, } \\
\text { Scottish }\end{array}$ & $\begin{array}{l}\text { Anglican } \\
\text { then } \\
\text { United }\end{array}$ & Ontario & $\begin{array}{l}1966- \\
69, \\
\text { again } \\
\text { later }\end{array}$ & $\begin{array}{l}\text { Bloating, } \\
\text { possibly mood } \\
\text { and headaches } \\
\text { a little worse } \\
\text { initially, } \\
\text { possible } \\
\text { weight gain }\end{array}$ \\
\hline $\begin{array}{l}\text { Deborah } \\
\text { Campbell }\end{array}$ & 1940 & Homemaker & $\begin{array}{l}\text { Scottish, } \\
\text { possibly } \\
\text { some Irish }\end{array}$ & United & Ontario & $\begin{array}{l}1964 \\
\text { maybe } \\
\text { for a } \\
\text { month }\end{array}$ & $\begin{array}{l}\text { Dizzy, } \\
\text { faint, } \\
\text { very tired }\end{array}$ \\
\hline Ellen Carter & 1947 & $\begin{array}{l}\text { Office clerk (at least } \\
\text { some of this time) }\end{array}$ & $\begin{array}{l}\text { U.K., } \\
\text { Sweden }\end{array}$ & Anglican & Ontario & $1967-8$ & $\begin{array}{l}\text { Lighter periods, } \\
\text { possibly a } \\
\text { little bloating }\end{array}$ \\
\hline $\begin{array}{l}\text { Cheryl } \\
\text { Clarke }\end{array}$ & 1946 & $\begin{array}{l}\text { Job with } \\
\text { government } \\
\text { (menial) for brief } \\
\text { period then } \\
\text { homemaker and } \\
\text { volunteer }\end{array}$ & English & Anglican & Ontario & $\begin{array}{l}1967- \\
68, \\
1969- \\
70, \\
1971- \\
1979 \\
\end{array}$ & $\begin{array}{l}\text { Bladder } \\
\text { control issues }\end{array}$ \\
\hline $\begin{array}{l}\text { Charlotte } \\
\text { Dawson }\end{array}$ & 1918 & $\begin{array}{l}\text { Social Worker/ } \\
\text { Home-makeriv }\end{array}$ & $\begin{array}{l}\text { Scottish, } \\
\text { English, } \\
\text { Irish }\end{array}$ & Anglican & Ontario & $\begin{array}{l}1 \text { year } \\
\text { (btw } \\
1962- \\
65)\end{array}$ & Migraines \\
\hline $\begin{array}{l}\text { Penelope } \\
\text { Dobos }\end{array}$ & 1945 & $\begin{array}{l}\text { Clinical Dietician } \\
\text { (at least from } 1969 \\
\text { to mid-1970s) }\end{array}$ & Hungarian & Catholic & Ontario & $\begin{array}{l}1969- \\
72 \\
1973- \\
1976\end{array}$ & $\begin{array}{l}\text { Bloating, } \\
\text { maybe } \\
\text { heavier bleeding }\end{array}$ \\
\hline
\end{tabular}




\begin{tabular}{|c|c|c|c|c|c|c|c|}
\hline $\begin{array}{l}\text { Penelope } \\
\text { Dobos } \\
\text { (Cont.) }\end{array}$ & & & & & & $\begin{array}{l}\text { little } \\
\text { bit } \\
\text { after } \\
\text { baby } \\
\text { born in } \\
1976\end{array}$ & \\
\hline $\begin{array}{l}\text { Eleanor } \\
\text { Doyle }\end{array}$ & 1940 & $\begin{array}{l}\text { Homemaker and } \\
\text { worked in plant } \\
\text { shops, first part- } \\
\text { time }\end{array}$ & $\begin{array}{l}\text { Irish, } \\
\text { Scottish, } \\
\text { possibly } \\
\text { some } \\
\text { Pennsyl- } \\
\text { vania Dutch }\end{array}$ & Anglican & Ontario & $\begin{array}{l}1964- \\
67 \\
1968- \\
74\end{array}$ & $\begin{array}{l}\text { Periods more } \\
\text { regular and shorter, } \\
\text { sensitive breasts, } \\
\text { blood clot scare } \\
\text { in } 1974\end{array}$ \\
\hline $\begin{array}{l}\text { Emma } \\
\text { Edwards }\end{array}$ & 1943 & $\begin{array}{l}\text { Worked for Bell as } \\
\text { computer } \\
\text { programmer then } \\
\text { homemaker after } \\
1968\end{array}$ & $\begin{array}{l}\text { English, } \\
\text { French- } \\
\text { Canadian, } \\
\text { English (via } \\
\text { US) } \\
\end{array}$ & $\begin{array}{l}\text { CS } \\
\text { (lapsed) }\end{array}$ & $\begin{array}{l}\text { Quebec } \\
\text { Ontario }\end{array}$ & $\begin{array}{l}1965- \\
67 \\
1968- \\
69 \\
1970 \\
\end{array}$ & $\begin{array}{l}\text { Regulated periods, } \\
\text { mood, decreased } \\
\text { libido, delayed } \\
\text { ovulation }\end{array}$ \\
\hline Hazel Evans & 1948 & $\begin{array}{l}\text { Receptionist and } \\
\text { always piano } \\
\text { teacher (occupation } \\
\text { in Ontario from } \\
1969-72 \text { unclear) }\end{array}$ & $\begin{array}{l}\text { English } \\
\text { (father but } \\
\text { his parents } \\
\text { from } \\
\text { Wales), } \\
\text { Irish, } \\
\text { Scottish }\end{array}$ & $\begin{array}{l}\text { Baptist } \\
\text { (lapsed) }\end{array}$ & $\begin{array}{l}\text { N.S. } \\
\text { Germany } \\
\text { Ontario }\end{array}$ & $\begin{array}{l}1966- \\
72\end{array}$ & None \\
\hline Diane Galli & 1941 & $\begin{array}{l}\text { Student and } \\
\text { graduate student } \\
\text { (part-time), nurse } \\
\text { teacher, nurse (had } \\
\text { various jobs both } \\
\text { part- and fulltime in } \\
\text { nursing and nursing } \\
\text { education fields } \\
\text { after child born in } \\
\text { 1975) }\end{array}$ & $\begin{array}{l}\text { British and } \\
\text { Swiss }\end{array}$ & Catholic & $\begin{array}{l}\text { Ontario } \\
\text { Quebec }\end{array}$ & $\begin{array}{l}1968- \\
1973, \\
1973- \\
74 \\
1975-8\end{array}$ & $\begin{array}{l}\text { Lighter periods, } \\
\text { ovaries shrunk }\end{array}$ \\
\hline Eva Green & 1942 & Teacher & $\begin{array}{l}\text { Channel } \\
\text { Islands, } \\
\text { Scotland, } \\
\text { Britain }\end{array}$ & $\begin{array}{l}\text { Un- } \\
\text { known }\end{array}$ & USA & $\begin{array}{l}1966- \\
68, \\
\text { after } \\
1971 \\
\text { and } \\
\text { before } \\
1975 \\
\end{array}$ & $\begin{array}{l}\text { Vomiting } \\
\text { at first }\end{array}$ \\
\hline Julia Hall & 1938 & $\begin{array}{l}\text { Teacher, Graduate } \\
\text { Student, } \\
\text { Township } \\
\text { Councillor }\end{array}$ & $\begin{array}{l}\text { United } \\
\text { Kingdom } \\
\text { (Loyalists) }\end{array}$ & Anglican & Ontario & $\begin{array}{l}1964- \\
68 \text { (on } \\
\text { and } \\
\text { off) }\end{array}$ & None \\
\hline $\begin{array}{l}\text { Cindy } \\
\text { Harrison }\end{array}$ & 1947 & $\begin{array}{l}\text { Homemaker (some } \\
\text { of time), worked in } \\
\text { parents' store, } \\
\text { taught hairdressing, } \\
\text { ran home daycarev }\end{array}$ & $\begin{array}{l}\text { German, } \\
\text { English, } \\
\text { Scottish, } \\
\text { Welsh (birth } \\
\text { mother } \\
\text { British Isles) } \\
\end{array}$ & Baptist & $\begin{array}{l}\text { N.B. } \\
\text { Ontario }\end{array}$ & $\begin{array}{l}1967- \\
68, \\
1968- \\
1970 \\
1971-5\end{array}$ & $\begin{array}{l}\text { Blood pressure } \\
\text { increased over time, } \\
\text { later bloating and } \\
\text { migraines }\end{array}$ \\
\hline $\begin{array}{l}\text { Ellen } \\
\text { Jackson }\end{array}$ & 1950 & $\begin{array}{l}\text { Clerical/Ad- } \\
\text { ministration }\end{array}$ & $\begin{array}{l}\text { Scottish and } \\
\text { English }\end{array}$ & $\begin{array}{l}\text { Anglican } \\
\text { (lapsed) }\end{array}$ & Ontario & $\begin{array}{l}1968- \\
71 \\
1972-3\end{array}$ & $\begin{array}{l}\text { Yeast infections, } \\
\text { some weight gain } \\
\text { and then stroke }\end{array}$ \\
\hline
\end{tabular}




\begin{tabular}{|c|c|c|c|c|c|c|c|}
\hline $\begin{array}{l}\text { Linda } \\
\text { Johnson }\end{array}$ & 1938 & $\begin{array}{l}\text { Homemaker also in } \\
\text { voluntary sector }\end{array}$ & $\begin{array}{l}\text { English, } \\
\text { Irish, } \\
\text { Scottish, } \\
\text { maybe some } \\
\text { German }\end{array}$ & United & Manitoba & $1961-2$ & None \\
\hline Mary Jones & 1946 & $\begin{array}{l}\text { Customer Service } \\
\text { Rep at Bell, then } \\
\text { homemaker and } \\
\text { part-time at Bell } \\
\text { doing various jobs }\end{array}$ & $\begin{array}{l}\text { Irish, French } \\
\text { Canadian, } \\
\text { Scottish }\end{array}$ & Catholic & Ontario & $\begin{array}{l}1966- \\
71 \\
1972 \\
1973\end{array}$ & $\begin{array}{l}\text { Headache, small } \\
\text { weight gain, helped } \\
\text { control heavy } \\
\text { periods }\end{array}$ \\
\hline $\begin{array}{l}\text { Elizabeth } \\
\text { Kennedy }\end{array}$ & 1944 & $\begin{array}{l}\text { Archivist (for most } \\
\text { of period at least) }\end{array}$ & $\begin{array}{l}\text { Some Irish } \\
\text { and likely } \\
\text { British Isles }\end{array}$ & $\begin{array}{l}\text { None } \\
\text { (some } \\
\text { CS as } \\
\text { child) }\end{array}$ & Ontario & $\begin{array}{l}1967- \\
70\end{array}$ & $\begin{array}{l}\text { Tired, } \\
\text { periods more } \\
\text { regular }\end{array}$ \\
\hline Olivia Klein & 1942 & Teacher & $\begin{array}{l}\text { German and } \\
\text { English }\end{array}$ & $\begin{array}{l}\begin{array}{l}\text { Lutheran } \\
\text { (growing }\end{array} \\
\text { up), } \\
\text { became } \\
\text { Catholic } \\
\text { later }\end{array}$ & $\begin{array}{l}\text { Ontario } \\
\text { Trinidad }\end{array}$ & $\begin{array}{l}1964- \\
66 \\
1970 \\
74\end{array}$ & $\begin{array}{l}\text { Loss of sexual } \\
\text { desire, } \\
\text { maybe irritable, } \\
\text { some bloating, } \\
\text { possibly yeast } \\
\text { infections and } \\
\text { cervical erosion, } \\
\text { acne }\end{array}$ \\
\hline Vivian Koch & 1931 & $\begin{array}{l}\text { Homemaker and } \\
\text { student } \mathrm{t}^{\mathrm{vi}}\end{array}$ & $\begin{array}{l}\text { German and } \\
\text { Austrian }\end{array}$ & $\begin{array}{l}\text { Un- } \\
\text { known }\end{array}$ & Ontario & $1961-2$ & Bleeding \\
\hline $\begin{array}{l}\text { Isabelle } \\
\text { Lowe }\end{array}$ & 1945 & $\begin{array}{l}\text { Law student and } \\
\text { then lawyer }\end{array}$ & $\begin{array}{l}\text { English, } \\
\text { French- } \\
\text { Canadian, } \\
\text { British (via } \\
\text { US) }\end{array}$ & $\begin{array}{l}\text { CS } \\
\text { (lapsed) }\end{array}$ & Ontario & $\begin{array}{l}1967- \\
74\end{array}$ & $\begin{array}{l}\text { Lighter periods, } \\
\text { uneasy about pill }\end{array}$ \\
\hline Jane Lynch & 1938 & $\begin{array}{l}\text { Worked in service } \\
\text { station with } \\
\text { husband }\end{array}$ & $\begin{array}{l}\text { Irish and } \\
\text { Scottish }\end{array}$ & United & Ontario & $\begin{array}{l}1962- \\
70\end{array}$ & $\begin{array}{l}\text { None, } \\
\text { regulated periods } \\
\text { and decreased } \\
\text { migraines }\end{array}$ \\
\hline $\begin{array}{l}\text { Claire } \\
\text { Macdonald }\end{array}$ & 1938 & $\begin{array}{l}\text { Public servant and } \\
\text { then homemaker }\end{array}$ & Scottish & $\begin{array}{l}\text { Pres. } \\
\text { (lapsed) }\end{array}$ & Ontario & $\begin{array}{l}1963- \\
1966, \\
1967- \\
68, \\
1969- \\
1971\end{array}$ & $\begin{array}{l}\text { Possibly decreased } \\
\text { milk supply, } \\
\text { regulated periods }\end{array}$ \\
\hline $\begin{array}{l}\text { Caroline } \\
\text { Mason }\end{array}$ & 1944 & Secretary & English & Anglican & Ontario & $\begin{array}{l}1966- \\
1969, \\
\text { again } \\
\text { later }\end{array}$ & $\begin{array}{l}\text { Vaginal dryness, } \\
\text { post-pill } \\
\text { painful periods }\end{array}$ \\
\hline Judy Meyer & 1935 & $\begin{array}{l}\text { Homemaker and } \\
\text { Designer }\end{array}$ & $\begin{array}{l}\text { Polish and } \\
\text { Germanic }\end{array}$ & None & Ontario & $\begin{array}{l}1960 \\
\text { (app.)- } \\
1965 \\
\text { or } \\
1966 \\
\end{array}$ & $\begin{array}{l}\text { None, helped } \\
\text { regulate cycles }\end{array}$ \\
\hline $\begin{array}{l}\text { Claire } \\
\text { Moore }\end{array}$ & 1937 & $\begin{array}{l}\text { Part-time student, } \\
\text { administration } \\
\text { officer with } \\
\text { government }^{\text {vii }} \\
\end{array}$ & $\begin{array}{l}\text { French and } \\
\text { Irish }\end{array}$ & Catholic & Ontario & $\begin{array}{l}1969- \\
73\end{array}$ & $\begin{array}{l}\text { Bloating, } \\
\text { regulated periods }\end{array}$ \\
\hline
\end{tabular}




\begin{tabular}{|c|c|c|c|c|c|c|c|}
\hline $\begin{array}{l}\text { Caroline } \\
\text { Morrison }\end{array}$ & 1938 & $\begin{array}{l}\text { Homemaker and } \\
\text { secretary, later } \\
\text { student (initially } \\
\text { part time) } \\
\end{array}$ & $\begin{array}{l}\text { Scottish and } \\
\text { Irish }\end{array}$ & Catholic & Ontario & $\begin{array}{l}1965- \\
1980\end{array}$ & $\begin{array}{l}\text { Possibly bloating, } \\
\text { sensitive breasts, } \\
\text { less desire }\end{array}$ \\
\hline $\begin{array}{l}\text { Rose } \\
\text { Murray }\end{array}$ & 1945 & Teacher & $\begin{array}{l}\text { Irish and } \\
\text { Scottish }\end{array}$ & $\begin{array}{l}\text { Pres. } \\
\text { then } \\
\text { Unitarian }\end{array}$ & Ontario & $\begin{array}{l}1966- \\
70\end{array}$ & $\begin{array}{l}\text { Possibly tender } \\
\text { breasts, very } \\
\text { irregular periods } \\
\text { post-pill }\end{array}$ \\
\hline $\begin{array}{l}\text { Katherine } \\
\text { Quinn }\end{array}$ & 1941 & $\begin{array}{l}\text { Teacher in Christian } \\
\text { education, } \\
\text { homemaker after } \\
\text { marriage }\end{array}$ & $\begin{array}{l}\text { Irish and } \\
\text { Scottish }\end{array}$ & Anglican & Manitoba & $\begin{array}{l}1967, \\
1971- \\
1975 / \\
1976 \\
\end{array}$ & None \\
\hline $\begin{array}{l}\text { Mary } \\
\text { Ramsey }\end{array}$ & 1933 & $\begin{array}{l}\text { Teacher and } \\
\text { Homemaker }\end{array}$ & $\begin{array}{l}\text { Irish, } \\
\text { Scottish, } \\
\text { German, } \\
\text { English and } \\
\text { possibly } \\
\text { Native }\end{array}$ & Anglican & Ontario & $\begin{array}{l}1967- \\
80\end{array}$ & $\begin{array}{l}\text { None, } \\
\text { pill made } \\
\text { periods regular }\end{array}$ \\
\hline Beth Reid & 1944 & Teacher & $\begin{array}{l}\text { Scottish, } \\
\text { Spanish, } \\
\text { possibly } \\
\text { Irish }\end{array}$ & $\begin{array}{l}\text { Pres. } \\
\text { then } \\
\text { United }\end{array}$ & Ontario & $\begin{array}{l}1967- \\
70\end{array}$ & $\begin{array}{l}\text { Migraines, } \\
\text { maybe cysts } \\
\text { in breasts }\end{array}$ \\
\hline $\begin{array}{l}\text { Alice } \\
\text { Richards }\end{array}$ & 1941 & $\begin{array}{l}\text { Piano teacher and } \\
\text { Homemaker }\end{array}$ & $\begin{array}{l}\text { French } \\
\text { Canadian, } \\
\text { English }\end{array}$ & $\begin{array}{l}\text { United, } \\
\text { Anglican } \\
\text { Prot. }\end{array}$ & $\begin{array}{l}\text { Ontario } \\
\text { Quebec }\end{array}$ & $\begin{array}{l}1965- \\
66, \\
1967- \\
68, \\
1969, \\
1974 \\
\text { for a } \\
\text { couple } \\
\text { years } \\
\end{array}$ & $\begin{array}{l}\text { Bloating, felt } \\
\text { sluggish, mood, } \\
\text { migraines, periods } \\
\text { somewhat lighter }\end{array}$ \\
\hline Anne Ryan & 1944 & $\begin{array}{l}\text { Welfare Worker (at } \\
\text { least some of } \\
\text { period) }\end{array}$ & $\begin{array}{l}\text { Irish and } \\
\text { Anglo- } \\
\text { Saxon } \\
\text { (possibly } \\
\text { some } \\
\text { German) }\end{array}$ & None & Ontario & $\begin{array}{l}1966- \\
72\end{array}$ & Migraine headaches \\
\hline Evelyn Scott & 1936 & Homemaker & Scottish & None & Ontario & 1965 & $\begin{array}{l}\text { Uneasy about } \\
\text { taking pill but } \\
\text { no specific } \\
\text { side effects }\end{array}$ \\
\hline $\begin{array}{l}\text { Betty } \\
\text { Shevchenko }\end{array}$ & 1927 & Homemaker & Ukrainian & United & $\begin{array}{l}\text { England } \\
\text { B.C. }\end{array}$ & $1961-5$ & $\begin{array}{l}\text { Weight retention, } \\
\text { dizzy, possibly } \\
\text { less energy }\end{array}$ \\
\hline $\begin{array}{l}\text { Catherine } \\
\text { Smith }\end{array}$ & 1936 & $\begin{array}{l}\text { Homemaker } \\
\text { later reading teacher }\end{array}$ & Unsure & United & $\begin{array}{l}\text { B.C. } \\
\text { Ontario }\end{array}$ & $\begin{array}{l}1962- \\
1976\end{array}$ & None \\
\hline $\begin{array}{l}\text { Cora } \\
\text { Stefánsson }\end{array}$ & 1946 & $\begin{array}{l}\text { Teacher (some time } \\
\text { off when children } \\
\text { born) }\end{array}$ & Icelandic & None & $\begin{array}{l}\text { B.C. } \\
\text { Ontario }\end{array}$ & $\begin{array}{l}1969- \\
74, \\
1975- \\
1976, \\
1977- \\
79, \\
1980-3\end{array}$ & None \\
\hline
\end{tabular}




\begin{tabular}{|c|c|c|c|c|c|c|c|}
\hline $\begin{array}{l}\text { Lydia } \\
\text { Stevens }\end{array}$ & 1941 & $\begin{array}{l}\text { Civil servant, then } \\
\text { Homemaker and } \\
\text { student in } 1980 \text { s }\end{array}$ & $\begin{array}{l}\text { American } \\
\text { and } \\
\text { Pennsyl- } \\
\text { vania Dutch }\end{array}$ & $\begin{array}{l}\text { Catholic } \\
\text { (lapsed) }\end{array}$ & $\begin{array}{l}\text { Ontario } \\
\text { U.S. } \\
\text { England }\end{array}$ & $\begin{array}{l}1964- \\
67, \\
1975- \\
76, \\
1977- \\
81 \\
\end{array}$ & $\begin{array}{l}\text { Bloating, } \\
\text { weight gain, } \\
\text { headaches, } \\
\text { nausea, did regulate } \\
\text { periods, post-pill } \\
\text { infertility }\end{array}$ \\
\hline $\begin{array}{l}\text { Eileen } \\
\text { Stewart }\end{array}$ & 1934 & Homemaker & Scottish & Prot. & Ontario & $\begin{array}{l}\text { On } \\
\text { and off } \\
\text { for } 2 \\
\text { years } \\
\text { in } \\
\text { early } \\
1960 \mathrm{~s}\end{array}$ & $\begin{array}{l}\text { Headache, } \\
\text { leg aches, mood }\end{array}$ \\
\hline $\begin{array}{l}\text { Olivia } \\
\text { Taylor }\end{array}$ & 1944 & $\begin{array}{l}\text { Clerical, later } \\
\text { homemaker }\end{array}$ & $\begin{array}{l}\text { British Isles } \\
\text { (likely), } \\
\text { German (via } \\
\text { US) }\end{array}$ & $\begin{array}{l}\text { Anglican } \\
\text { and } \\
\text { United }\end{array}$ & Ontario & $\begin{array}{l}1966- \\
70, \\
\text { also } \\
\text { later }\end{array}$ & Amenorrhea \\
\hline $\begin{array}{l}\text { Elizabeth } \\
\text { Thompson }\end{array}$ & 1939 & Homemaker & $\begin{array}{l}\text { Welsh, } \\
\text { English, } \\
\text { Irish } \\
\end{array}$ & Catholic & Ontario & $\begin{array}{l}1967- \\
72 \\
1972-9 \\
\end{array}$ & Decreased libido \\
\hline Joan Walker & 1946 & $\begin{array}{l}\text { Key Punch } \\
\text { Operator }\end{array}$ & $\begin{array}{l}\text { English and } \\
\text { Scottish }\end{array}$ & Anglican & $\begin{array}{l}\text { Quebec } \\
\text { Ontario }\end{array}$ & $\begin{array}{l}1967- \\
1978\end{array}$ & Maybe bloating \\
\hline Susan Walsh & 1947. & Student & $\begin{array}{l}\text { German (via } \\
\text { US), Irish, } \\
\text { Scottish } \\
\end{array}$ & $\begin{array}{l}\begin{array}{l}\text { United } \\
\text { (lapsed) }\end{array}\end{array}$ & $\begin{array}{l}\text { Alberta } \\
\text { Ontario }\end{array}$ & $\begin{array}{l}1969- \\
70\end{array}$ & $\begin{array}{l}\text { Bloating, } \\
\text { headaches }\end{array}$ \\
\hline Jean Watson & 1926 & $\begin{array}{l}\text { Various jobs for } \\
\text { government }\end{array}$ & $\begin{array}{l}\text { American } \\
\text { (possibly } \\
\text { from } \\
\text { England } \\
\text { originally), } \\
\text { Scottish, } \\
\text { Irish } \\
\end{array}$ & $\begin{array}{l}\text { Catholic } \\
\text { (lapsed) }\end{array}$ & Ontario & $\begin{array}{l}1962- \\
1969\end{array}$ & $\begin{array}{l}\text { Heavier periods, } \\
\text { maybe bloating }\end{array}$ \\
\hline $\begin{array}{l}\text { Yvonne } \\
\text { Wilkins }\end{array}$ & 1942 & $\begin{array}{l}\text { Homemaker then } \\
\text { Clerical }\end{array}$ & Unsure & None & B.C. & $\begin{array}{l}1962- \\
1973 \\
\end{array}$ & None \\
\hline $\begin{array}{l}\text { Lucy } \\
\text { Williams }\end{array}$ & 1935 & $\begin{array}{l}\text { Homemaker and } \\
\text { then Librarian }\end{array}$ & $\begin{array}{l}\text { English and } \\
\text { American }\end{array}$ & United & Ontario & $\begin{array}{l}1962- \\
65, \\
\text { then } \\
\text { again } \\
\text { later }\end{array}$ & None \\
\hline $\begin{array}{l}\text { Margaret } \\
\text { Wilson }\end{array}$ & 1944 & $\begin{array}{l}\text { Homemaker (on and } \\
\text { off), Cashier, Letter } \\
\text { carrier }\end{array}$ & Scottish & Catholic & Ontario & $\begin{array}{l}1965- \\
1966, \\
1967- \\
1976 \\
\text { (off } \\
\text { for } \\
\text { short } \\
\text { time in } \\
1967 \text { ) }\end{array}$ & $\begin{array}{l}\text { Nausea } \\
\text { at first }\end{array}$ \\
\hline Emily Wood & 1944 & Teacher & $\begin{array}{l}\text { English and } \\
\text { Australian }\end{array}$ & $\begin{array}{l}\text { Prot. (not } \\
\text { obser- } \\
\text { vant) }\end{array}$ & B.C. & $1967-8$ & $\begin{array}{l}\text { Mood, possibly } \\
\text { increased libido, } \\
\text { bloating }\end{array}$ \\
\hline
\end{tabular}




\begin{tabular}{|l|l|l|l|l|l|l|l|}
\hline Ruth Wright & 1948 & $\begin{array}{l}\text { Programmer } \\
\text { Systems Analyst, } \\
\text { Accounting } \\
\text { Manager (btw 1969- } \\
1982)\end{array}$ & $\begin{array}{l}\text { Mostly } \\
\text { United } \\
\text { Kingdom } \\
\text { (including } \\
\text { some } \\
\text { Loyalists) }\end{array}$ & Anglican & Ontario & $\begin{array}{l}\text { 1969- } \\
1973\end{array}$ & $\begin{array}{l}\text { Pain with periods, } \\
\text { post-pill cramping } \\
\text { with ovulation }\end{array}$ \\
\hline $\begin{array}{l}\text { Cynthia } \\
\text { Young }\end{array}$ & 1943 & $\begin{array}{l}\text { Various jobs from } \\
\text { 1964-1980s } \\
\text { including, teacher, } \\
\text { student, and } \\
\text { recreation activity } \\
\text { director at seniors' } \\
\text { home }\end{array}$ & $\begin{array}{l}\text { Scottish } \\
\text { (likely), } \\
\text { possibly } \\
\text { German }\end{array}$ & Anglican & Ontario & $\begin{array}{l}1965 \\
\text { to } \\
\text { about } \\
1978, \\
\text { again } \\
\text { for a } \\
\text { short } \\
\text { period }\end{array}$ & $\begin{array}{l}\text { Possible weight } \\
\text { periods sometimes }\end{array}$ \\
\hline
\end{tabular}

' Some dates are approximate based on the best recollections of informants or my own deductions from their testimony.

ii Arsenault did not provide a clear description of all the work she did but the majority seemed to be in these fields.

iii This was her occupation for at least some of the time she was on the pill.

iv Dawson was at home with her children until 1965. However, given her uncertainty about when exactly she was on the pill, it is hard to know if she was working outside the home or not when she took it.

"Harrison's testimony is a little unclear in regard to whether she taught hairdressing or worked in her parents' store after the birth of her daughter in 1968. She also did not say explicitly that she worked in this store when engaged to be married and just starting on the pill but this seems likely.

${ }^{v i}$ Koch was only on the pill for about a year, beginning in 1961, so it is not clear if she was still on when she started university in September of 1962.

vii It is not entirely clear when Moore started working for the government.

viii Morrison entered university as a journalism student in about 1975 . Though she does not detail it, I assume she got work in this field though it is not clear if she was off the pill by the time she finished her degree.

${ }^{i x}$ Walker went back to work in 1967 , after her baby died of SIDS. She did not say exactly what she did from then until about 1970 but it was likely clerical. 
Nhy

国

Carleton

U N I ER SITY

Canada's Capital University
Carteton University Research Office

Sth Floor Tory Building

1125 Colonel By Drive

Ottawa, ON K1S 5 B6 Canada

Tel: (613) 520-2516

Fax: (613) 520-2521

muw.carleton.ca/cu/research/curo/

\section{Ethics Clearance Form}

This is to certify that the Carleton University Research Ethics Board has examined the application for ethical clearance. The REB found the research project to meet appropriate ethical standards as outlined in the Tri-Council Policy Statement: Ethical Conduct for Research Involving Humans and, the Carteton University Policies and Procedures for the Ethical Conduct of Research.

o. New clearance

$X$ Renewal of original clearance

Date of clearance

Researcher.

Status

Department

Supervisor

Title of project
24 August 2009

Jessica Haynes

Ph.D. student

Department of History

Professor Dominique Marshall

The Impact of the Birth-Control PIII on Married Women In EnglishCanada, 1960-1970

Ethics approval expires on: 31 May 2010

All researchers are governed by the following conditions:

Annual Status Report: You are required to submit an Annual Status Report to either renew clearance or close the file. Failure to submit the Annual Status Report will result in the immediate suspension of the project. Funded projects will have accounts suspended until the report is submitted and approved.

Changes to the project: Any changes to the project must be submitted to the Carleton University Research Ethics Committee for approval. All changes must be approved prior to the continuance of the research.

Adverse events: Should any participant suffer adversely from their participation in the project you are required to report the matter to the Carleton University Research Ethics Committee. You must submit a written record of the event and indicate what steps you have taken to resolve the situation.

Suspension or termination of clearance: Failure to conduct the research in accordance with the principles of the Tri-Council Policy Statement: Ethical Conduct for Research Involving Humans and the Carleton University Policies and Procedures for the Ethical Conduct of Research may result in the suspension or termination of the research project.

Lesîle J. Mačbonald-Hicks

Research Ethics Committee Coordinator

For the Chair of the Carleton University Research Ethics Committee

Prof. Antonio Gualtieri 


\section{Appendix 2 \\ List of Surveys and Studies Consulted on the Pill and Contraception, 1962-1993, Principally focused on Canada, Britain, England, Wales and the United States}

1962

A sociological study conducted in Montreal which revealed information about the birthcontrol practices of eighty Catholic families, cited in Constance Mungall, "Birth Control in Canada Today," Chatelaine, April 1965, Volume 38, 4, p. 49.

$\underline{1963}$

Morris P. Wearing, "The Use of Norethindrone ( $2 \mathrm{mg})$ with Mestranol $(0.1 \mathrm{mg})$ in Fertility Control: A Preliminary Report," Canadian Medical Association Journal 89, 6 (August 10, 1963), 239-241.

This study, which started in January of 1962, followed 62 patients taking OrthoNovum 2mg.

1964

K.M. Crocker, M.D. and W.D. Stitt, M.D., "Ovulation Inhibitors," Canadian Medical Association Journal, March 21, 1964, 90, 12, 713-716.

This study involved 185 women, ranging in age from 19 to 44, and taking OrthoNovum.

$\underline{1965}$

C.A. Douglas Ringrose, "The Emotional Responses of Married Women Receiving Oral Contraceptives," Canadian Medical Association Journal, June 5, 1965, 92, 1207-1209.

For this study, Ringrose sent questionnaires to one hundred married women on norethindrone $2 \mathrm{mg}$. with mestranol $0.1 \mathrm{mg}$.

A study in England and Wales involving 6,300 married women which discussed women's role in contraception, original source M. Woolf, Family Intentions (London, 1971).

A study of 5,600 women which included information on forgetting the pill, original source Leslie Aldridge Westoff and Charles F. Westoff, From Now to Zero: Fertility, Contraception and Abortion in America (Boston, 1971).

1966

"Clinical Aspects of Oral Gestogens: Report of a WHO Scientific Group," World Health Organization Technical Report Series, No. 326 (Geneva: World Health Organization, 1966).

This report included recommendations about examinations when initially prescribing the pill as well as the frequency of check-ups. 
1967 McCall's-American College of Obstetricians and Gynecologists Survey, original source "A Report on the Questionnaire 'Survey of Experience with Oral Contraceptive Pills"' (October 1967), 1-6, pill survey folder, Records of the American College of Obstetricians and Gynecologists.

This survey, conducted by McCall's and the American College of Obstetricians and Gynecologists (ACOG), asked the 8,500 fellows of the ACOG about the birth-control pill. Ultimately, close to 7,000 participated in the survey. One of them, an obstetrician, is quoted in the November 1967 issue of McCall's which I refer to in Chapter 5.

1967-1968 British survey of working-class women, which discussed the continuing popularity of male methods of birth control, original source E. Draper, Birth Control in the Modern World (Harmondsworth, $2^{\text {nd }}$ edition, 1972).

1967-1968 survey of family planning services in Ann Cartwright, Parents and Family Planning Services (1970), 239.

This survey revealed information about the percentage of doctors who give physical examinations when offering advice on birth control.

1967-1970 British investigation, original source A. Cartwright, Parents and Family Planning Services (1970).

This study found information on medical examinations performed when prescribing the pill.

Letter by P.E. Hoogewerf, "Migraine and Oral Contraceptives," Canadian Medical Association Journal 97, 16 (October 14, 1967), 978-979.

Doctor Hoogewerf wrote to the $C M A J$ about three women who developed migraines while on the pill. He explained they had no previous history and that their symptoms went away when the contraceptive was discontinued.

$\underline{1968}$

Letter by Martin S. Kazdan, "Migraine and Oral Contraceptives," Canadian Medical Association Journal 98, 3 (January 20, 1968), 175.

In response to Dr. Hoogewerf's letter, Dr. Kazdan wrote to the $C M A J$ in regard to a thirty-one-year-old woman who, after two years on Ortho-Novum, started to get migraine symptoms. Like the patients of Hoogewerf, she had no previous history of such problems.

$\underline{1969}$

Letter by Michael J. Brindle, M.D. and I. Nigel Henderson, "Vascular Occlusion of the Colon Associated with Oral Contraception," Canadian Medical Association Journal, 100, 14 (April 12, 1969): 681-2.

In this letter, Brindle and Henderson describe the case of Mrs. D.Q., on Enovid, who developed an unusual colon condition. The writers speculate about the role of the contraceptive pill. 
$\underline{1970}$

Report of The Special Committee appointed by The Minister of National Health and Welfare to Advise The Food and Drug Directorate on all Aspects of the Safety and Efficacy of Oral Contraceptives Marketed in Canada, October 1970, Rx Bulletin, Special Issue, December, 1970.

This committee was created in January of 1970 to make recommendations to the Food and Drug Directorate regarding the safety and effectiveness of the pill. Dr. R.A.H. Kinch, an obstetrician/gynecologist, served as chair. The report discussed a range of side effects and made recommendations regarding patient selection and care. It also called for a short patient insert to be included with the pill.

National Fertility Study, original source Charles F. Westoff and Norman B. Ryder, The Contraceptive Revolution (Princeton: Princeton University Press, 1977).

This book by Westoff and Ryder published the results of the 1970 National Fertility Study which was the final of four studies done on American fertility. The others were conducted in 1955, 1960 and 1965. Each one involved only women.

1973

Virginia K. Elahi, "A Family Planning Survey in Halifax, Nova Scotia," Canadian Journal of Public Health, 64 (November/December 1973): 515-520.

The purpose of this survey, conducted in Halifax in April to June of 1971, was to gather information about family planning knowledge and practices. For this purpose, three hundred women, ranging in age from 15 to 44 , were interviewed. Respondents were from range of socioeconomic backgrounds and included Catholics and Protestants. The most relevant information for my thesis concerned the pill and population control.

$\underline{1975}$

Report of the Special Committee Appointed by The Minister of National Health and Welfare to Advise the Health Protection Branch on All Aspects of the Safety and Efficacy of Oral Contraceptives Marketed in Canada, Second Report, February 1975, Rx Bulletin Volume 6, Supplement 1 (1975).

This second report by the special committee, now expanded to include two female physicians, discussed side effects and patient care.

$\underline{1978}$

Report of The Special Advisory Committee on Reproductive Physiology to The Health Protection Branch (Ottawa: The Branch, 1978).

By 1978, the original special committee on oral contraceptives, had been renamed. It produced a third report on the pill.

Probable Dates

(Mid 1960s) Study by Dr. William G. Francis, gynecologist at the Grace Hospital in Toronto, cited in Constance Mungall, "Birth Control in Canada Today," Chatelaine, April 1965, 38, 4, pp. 18, 20, 48-49. 
Dr. Francis' study involved 150 women who reported a range of side effects, including more regular periods, depression, and fatigue.

(Late 1960s) Study by Britain's Medical Research Council, cited in Earl Damude, "What's New: Health," Chatelaine, April 1968, 41, 4, p. 18.

This study included information on the incidence of depression among pill users.

(Late 1960s) Study by Drs. Ziegler and Rodgers, original source unknown

This study was discussed by Barbara Seaman in her 1969 book. She does not provide dates for it but does identify Dr. Frederick Ziegler as a psychiatrist and Dr. David Rodgers as a psychologist. Both were from the department of psychiatry at the Cleveland Clinic. They concluded that, as discussed in Chapter 4 , marital roles influenced whether or not a woman who experienced side effects stayed on the pill.

1993

Michael Murphy, "The Contraceptive Pill and Women's Employment as Factors in Fertility Change in Britain, 1963-1980," Population Studies 47 (1993)

Historian Hera Cook credits Murphy's work with showing that the birth-control pill did cause a drop in fertility in Britain. 
Bibliography

Interviews (Listed by Pseudonyms)

Heather Anderson, December 3, 2009

Jane Arsenault, March 2, 2010

Annie Beck, November 6, 2009

Beverley Brooks, October 19, 2009

Susan Brown, August 7, 2009 and December 11, 2009

Deborah Campbell, February 9, 2010

Ellen Carter, February 12, 2010

Cheryl Clarke, November 12, 2009

Charlotte Dawson, November 5, 2009

Penelope Dobos, July 7, 2009

Eleanor Doyle, November 30, 2009

Emma Edwards, April 12, 2010

Hazel Evans, December 1, 2009

Diane Galli, December 8, 2009

Eva Green, June 23, 2009

Julia Hall, June 29, 2009 and January 5, 2010

Cindy Harrison, January 25, 2010

Ellen Jackson, October 23, 2009

Linda Johnson, July 17, 2009

Mary Jones, December 3, 2009

Elizabeth Kennedy, November 10, 2009

Olivia Klein, October 20, 2009

Vivian Koch, January 21, 2010

Isabelle Lowe, April 27, 2010

Jane Lynch, October 6, 2009

Claire Macdonald, March 11, 2010

Caroline Mason, July 29, 2009

Judy Meyer, October 8, 2009

Claire Moore, November 17, 2009

Caroline Morrison, March 9, 2010

Rose Murray, October 28, 2009

Katherine Quinn, August 14, 2009

Mary Ramsey, October 29, 2009

Beth Reid, November 18, 2009

Alice Richards, December 7, 2009

Anne Ryan, October 27, 2009

Evelyn Scott, December 12, 2009 and January 6, 2010

Betty Shevchenko, November 9 and 10, 2009

Catherine Smith, July 9, 2000

Cora Stefánsson, November 23, 2009

Lydia Stevens, November 20, 2009

Eileen Stewart, August 18, 2009

Olivia Taylor, August 6, 2009 
Elizabeth Thompson, June 11, 2009 and November 30, 2009

Joan Walker, October 15, 2009

Susan Walsh, November 24, 2009

Jean Watson, November 3, 2009

Yvonne Wilkins, September 30, 2009 and January 11, 2010

Lucy Williams, October 8, 2009

Margaret Wilson, August 12, 2009 and December 11, 2009.

Emily Wood, July 6, 2009

Ruth Wright, Email correspondence July 2009, Interview July 8, 2009

Cynthia Young, February 8, 2010

Other Primary Sources

Anglin, Gerald. "The Pill That Could Shake the World." Chatelaine 26, 10 (October 1953): 17, 99-103.

"An Increasing Number of People Favor Birth Control." Gallup Report, February 13, 1965, 1-2.

"Association News Special Supplement: The Canadian Medical Association comments on the Food and Drug Committee Report 'Hazards of the Oral Contraceptive."'

Canadian Medical Association Journal, 103, 13 (December 19, 1970): 1415-1422.

A Vancouver Woman's Health Booklet. Press Gang Publishers, 1972.

"Banned for chicken fattener, hormone still being used in the pill." Globe and Mail, January 16, 1970, 9.

Batten, Jack. "Is There a Male Conspiracy against The Pill?" Chatelaine 42, 7 (July 1969): 17, 39-41.

"Benefits of the Pill Underplayed: Doctor." Globe and Mail, January 26, 1970, 12.

Canadian Gallup Poll, March 1960, \#281.

Canadian Gallup Poll, March 1967, \#323.

Canadian Gallup Poll, May 1970, \#341.

Canadian Gallup Poll, June 1975, \#377.

"Canadian Medical News-Health Minister Announces: Seven-doctor Committee Studies Safety of Oral Contraceptives." Canadian Medical Association Journal 102, 3 (February 14, 1970): 236.

"Charge The Pill is marketed without enough testing." Toronto Daily Star, January 21, 1970,70 . 
Clayton, Deidra. "The rising cost of birth control pills." The Financial Post, December $30,1978,16$.

"Clinical Aspects of Oral Gestogens: Report of a WHO Scientific Group." World Health Organization Technical Report Series, No. 326. Geneva: World Health Organization, 1966.

Crocker, K.M, M.D. and W.D. Stitt, M.D. “Ovulation Inhibitors.” Canadian Medical Association Journal 90, 12 (March 21, 1964): 713-716.

Damude, Earl. "What's New: Health." Chatelaine 41, 4 (April 1968): 18.

"Doctors argue over Pill dangers." Toronto Daily Star, January 22, 1970, 34.

Editoral. "Oral Contraception and Thromboembolic Disease." Canadian Medical Association Journal 98, 23 (June 8, 1968): 1117-1118.

Editorial. "The Pope and the Pill." Chatelaine 41, 11 (November 1968), 1.

Edwards, L.A., M.D. et. al. "Axillary Vein Thrombosis and Pulmonary Embolism Possibly Due to Oral Contraception." Canadian Medical Association Journal 100, 2 (January 11, 1969), 78-80.

Elahi, Virginia K. “A Family Planning Survey in Halifax, Nova Scotia." Canadian Journal of Public Health 64 (November/December 1973): 515-520.

Galton, Lawrence. "Here's Health: A versatile drug for menstrual disorders." Chatelaine 34, 8 (August 1961): 26.

"Hazards of the Oral Contraceptive," Medical News Special Supplement. Canadian Medical Association Journal 102 (May 30, 1970): 1193-1207.

"Is Pre-Marital Sex Right or Wrong? Split Opinions Among Young: Old Object." Gallup Report, April 11, 1970, 1-2.

Istona, Mildred. "Is There a Young Marriage Revolution? Part 1." Chatelaine 39, 11 (November 1966): 44, 45, 112, 114 and 115.

Istona, Mildred. "Is There a Young Marriage Revolution? Part 2." Chatelaine 39, 12 (December 1966): 40, 57, 58, 60, 62 and 64.

Letter by Doris Anderson, editor, Chatelaine, in response to Mrs. Higgins, November 17, 1961, Archives of Ontario, Reference Code F138, Barcode B255348, F-4-3-A, Box 215, file February 1962 ( 2 of 2). 
Letter by Joan Bird, Nova Scotia, Chatelaine 42, 9 (September 1969): 124.

Letter by Brindle, Michael J., M.D. and I. Nigel Henderson. "Vascular Occlusion of the Colon Associated with Oral Contraception." Canadian Medical Association Journal 100, 14 (April 12, 1969): 681-2.

Letter by Mrs. Mae Douglas, Edmonton, Alberta, to Chatelaine, April 24, 1962, Archives of Ontario, Reference Code F138, Barcode B255331, F4-4-b, Box 219, interior Box 442, file DA-DE, 1962.

Letter by Dorothy A.M. Hanrath, Dundas, Ontario, "Catholics and Birth Control," Chatelaine 42, 2 (January 1969): 76.

Letter by Mrs. D. Harrison. "Pregnant For Spite?" Chatelaine 38, 8 (August 1965): 68.

Letter by Mrs. E.M. Higgins, Willowdale, Ontario, to Chatelaine, November 1, 1961, Archives of Ontario, Reference Code F138, Barcode B255348, F-4-3-A, Box 215, file February 1962 (2 of 2).

Letter by P.E. Hoogewerf. "Migraine and Oral Contraceptives." Canadian Medical Association Journal 97, 16 (October 14, 1967): 978-979.

Letter by Martin S. Kazdan. "Migraine and Oral Contraceptives." Canadian Medical Association Journal 98, 3 (January 20, 1968): 175.

Letter by Mrs. Hazel McBride, Prince Rupert, B.C., to Chatelaine, January 22, 1962, Archives of Ontario, Reference Code F138, Barcode B255348, F-4-3-A, Box 215, file January 1962 ( 1 of 2).

Letter by Mrs. M. Mulark, Sudbury, Ontario, to Chatelaine, March 13, 1962, Archives of Ontario, Reference Code F138, Barcode B255348, F-4-3-A, Box 215, file February 1962 (1 of 2 ).

Letter by Mrs. Grant Murray, Harriston, Ontario, to Chatelaine, March 2, 1962, Archives of Ontario, Reference Code F138, Barcode B255348, F-4-3-A, Box 215, file February 1962 (1 of 2).

Letter by Mrs. D. Robinson, Scarborough, Ontario, to Chatelaine, January 27, 1962, Archives of Ontario, Reference Code F138, Barcode B255334, F-4-4-b, Box 220, interior Box 445, file RA-RZ.

Light, Linda and Nancy Kleiber. Caring for Ourselves: An Alternative Structure for Health Care. 1978.

"Looking Back on the Birth Control Movement." Close-Up, CBC Television Show, broadcast November 11, 1962, interviewer George Reynold, 
http://www.cbc.ca/archives/categories/health/reproductive-issues/the-birth-controlpill/looking-back.html

Marshall, Douglas. "The Surprising Social Revolution We've Started with The Pill." Maclean's March 1967: 20, 21, 70 and 71.

McWilliam, R.S. "Thrombophlebitis Following the Use of Norethynodrel (Enovid)." Canadian Medical Association Journal 88, 20 (May 18, 1963), 1032-1033.

Mungall, Constance. "Birth Control in Canada Today." Chatelaine 38, 4 (April 1965): $18,20,48$ and 49.

Mungall, Constance. "The Birthrate's Down: What Happens Next?" Chatelaine 40, 4 (April 1967), 29, 88, 90 and 92.

Mungall, Constance. "The Pill and Its Side Effects Today." Chatelaine 39, 11 (November 1966): 33 and 117-120.

O'Donnell, Joan (assumed name). "A Catholic Mother Answers the Pope." Chatelaine 41, 11 (November 1968): 26, 95-96.

Ottawa Women's Centre. Ottawa Women's Resource Handbook, 1976. University of Ottawa Archives, Canadian Women's Movement Archives Fonds, Box 91.

"Praising the Pill," CBC Radio's Assignment, hosted by Jim McLean, broadcast date May 4, 1964, CBC Digital Archives, http://archives.cbc.ca/health/reproductive_issues/topics/572.

Report of The Special Advisory Committee on Reproductive Physiology to The Health Protection Branch. Ottawa: The Branch, 1978.

Report of The Special Committee appointed by The Minister of National Health and Welfare to Advise The Food and Drug Directorate on all Aspects of the Safety and Efficacy of Oral Contraceptives Marketed in Canada, October 1970. In Rx Bulletin, Special Issue, December, 1970.

Report of the Special Committee Appointed by The Minister of National Health and Welfare to Advise the Health Protection Branch on All Aspects of the Safety and Efficacy of Oral Contraceptives Marketed in Canada, Second Report, February 1975. In Rx Bulletin Volume 6, Supplement 1 (1975).

Ringrose, C.A. Douglas. "The Emotional Responses of Married Women Receiving Oral Contraceptives." Canadian Medical Association Journal 92, 23 (June 5, 1965): 12071209. 
Rock, John. The Time Has Come: A Catholic Doctor's Proposals to End the Battle over Birth Control. New York: Alfred A. Knopf, 1963.

"Statement of Canadian Bishops on the Encyclical Humanae Vitae." In Population Issues in Canada, eds. Carl F. Grindstaff, Craig L. Boydell and Paul C. Whitehead, 1924. Toronto: Holt, Rinehart and Winston of Canada, Limited, 1971.

Seaman, Barbara. The Doctors' Case Against the Pill. New York: Peter H. Wyden, Inc., 1969.

Solomon, Hyman. "6 Die, Warn Against Birth Control Pill." The Toronto Star, August 8, 1962, 42.

"Strong reason to link the Pill with cancer U.S. Senators told." Toronto Daily Star, January 14, 1970, 80.

"The birth control pill sparks religious furor." CBC Television Special, broadcast August 18, 1968, CBC Digital Archives, http://www.cbc.ca/archives/categories/health/reproductive-issues/the-birth-controlpill/the-pill-sparks-religious-furor.html

"The Magic Pill." This Hour has Seven Days, CBC Television Show, broadcast October 11, 1964, The CBC Digital Archives, http://archives.cbc.ca/health/reproductive issues/clips/2956/

Wearing, Morris P. "The Use of Norethindrone $(2 \mathrm{mg})$ with Mestranol $(0.1 \mathrm{mg})$ in Fertility Control: A Preliminary Report." Canadian Medical Association Journal 89, 6 (August 10, 1963): 239-241.

Westoff, Charles F. and Norman B. Ryder. The Contraceptive Revolution. Princeton: Princeton University Press, 1977.

"What's New in Health," Chatelaine 40, 9 (September 1967), 14.

"What's New in Health: Who Forgets the Pill?" Chatelaine 38, 5 (May 1965): 16.

"Why the pill isn't the answer," The Last Word is Yours, Chatelaine 35, 2 (February 1962): 92.

Wills, Terrance. "Chromosome defects tied to use of pill." Globe and Mail, January 15, . 1970, W7.

Secondary Sources

Adams, Mary Louise. The Trouble with Normal: Postwar Youth and the Making of Heterosexuality. Toronto: University of Toronto Press, 1997. 
Allyn, David. Make Love, Not War: The Sexual Revolution: An Unfettered History. New York: Routledge, 2001.

Annau, Catherine. "Promoting Prophylactics: The Birth Control Society of Hamilton's Very Public Profile." Ontario History LXXXX, 1 (Spring 1998): 49-67.

Appleby, Brenda. Responsible Parenthood: Decriminalizing Contraception in Canada. Toronto: University of Toronto Press, 1999.

Asbell, Bernard. The Pill: A Biography of the Drug that Changed the World. New York: Random House, 1995.

Barber, Marilyn. "Hearing Women's Voices: Female Migration to Canada in the Early Twentieth Century." Oral History 33, 1 (2005): 68-76.

Boutin, Raymond. "A History of the Family Planning Movement in Canada," 16-29. In Family Planning and Social Work. Ottawa: Health and Welfare Canada, 1976.

Brandt, Allan M. and Martha Gardner. "The Golden Age of Medicine?". In Medicine in the Twentieth Century, eds. Roger Cooter and John Pickstone, 21-37. Amsterdam: Harwood Academic Publishers, 2000.

Clow, Barbara. “ 'An Illness of Nine Months' Duration': Pregnancy and Thalidomide Use in Canada and the United States." In Women, Health, and Nation: Canada and the United States since.1945, eds. Georgina Feldberg et. al., 45-66. Kingston: McGillQueen's University Press, 2003.

Connelly, Matthew. Fatal Misconception: The Struggle to Control World Population. Cambridge: Belknap Press of Harvard University, 2008.

Cook, Hera. The Long Sexual Revolution: English Women, Sex and Contraception 18001975. Oxford: Oxford University Press, 2004.

Creating Postwar Canada: Community, Diversity, and Dissent, 1945-1975, eds. Magda Fahrni and Robert Rutherdale. Vancouver: UBC Press, 2008.

Cunningham, Hugh. The Invention of Childhood. London: BBC Books, 2006.

Dove, Stephen. "The Reconstruction of Pharmacist Authority in British Columbia: 19651968." Master's Thesis, Department of History, University of Victoria, 2010.

Doyle, Marie-Paule. "Serena Canada: Twenty Years of Family Planning Action," 30-39. In Family Planning and Social Work. Ottawa: Health and Welfare Canada, 1976.

Dreifus, Claudia. "Introduction." In Seizing Our Bodies: The Politics of Women's Health, ed. Claudia Dreifus, xvii-xxxi. New York: Vintage Books, 1977. 
Duffin, Jacalyn. History of Medicine: A Scandalously Short Introduction. Toronto: University of Toronto Press, 1999.

Finkel, Alvin. Social Policy and Practice in Canada: A History. Waterloo: Wilfrid Laurier University Press, 2006.

Fisher, Kate. " 'She was quite satisfied with the arrangements I made', Gender and Birth Control in Britain, 1920-1950." Past and Present 169 (2000): 161-193.

Fisher, Kate. Birth Control, Sex, and Marriage in Britain, 1918-1960. Oxford: Oxford University Press, 2006.

Ghalan, Nancy Zukewich. "Attitudes Toward Women, Work and Family." Canadian Social Trends (Autumn 1997): 13-17.

Gervais, Diane and Danielle Gauvreau. "Women, Priests, and Physicians: Family Limitation in Quebec, 1940-1970." Journal of Interdisciplinary History 34, 2 (2003): 293-314.

Gleason, Mona. Normalizing the Ideal: Psychology, Schooling, and the Family in Postwar Canada. Toronto: University of Toronto Press, 1999.

Goodman, Jordan. "Pharmaceutical Industry." In Medicine in the Twentieth Century, eds. Roger Cooter and John Pickstone, 141-154. Amsterdam: Harwood Academic Publishers, 2000.

Gordon, Linda. The Moral Property of Women: A History of Birth Control Politics in America. Chicago: University of Illinois Press, 2007.

Gordon, Linda. Woman's Body, Woman' Right: A Social History of Birth Control in America. New York: Grossman Publishers, 1976.

Gossel, Patricia Peck. "Packaging the Pill." In Manifesting Medicine: Bodies and Machines, eds. Robert Bud, Bernard Finn, and Helmuth Trischler, 105-121. Amsterdam: Harwood Academic, 1999.

Haynes, Jessica. "Help for All Parents? Child-Rearing Advice in English Canada in the 1960s and 1970s." Histoire Sociale/Social History 44,l (May 2011): 53-82.

Haynes, Jessica. "The Legacy of Scientific Motherhood: Doctors and Child-Rearing Advice in the 1960s and 1970s in English Canada." Master's Thesis, Department of History, Carleton University, 2007.

Hicks, Rosemary R. "Religion and Remedies Reunited: Rethinking Christian Science." Journal of Feminist Studies in Religion (September 2004): 25-58. 
Historical Statistics of Canada: Section A-Population and Migration, Table A125-163 Origins of the population, census dates, 1871-1971, Statistics Canada website, http://www5.statcan.gc.ca/access acces/archive.action?]=eng\&loc=A125 163-eng.csv.

Jasen, Patricia. "Mind, Medicine, and the Christian Science Controversy in Canada, 1888-1910." Journal of Canadian Studies 32, 4 (Winter 1997/1998), http://lion.chadwyck.com.proxy.library.carleton.ca/searchFulltext.do?id=R04235844\&di vLevel $=0$ \&area $=$ abell \& forward $=$ critref $\mathrm{ft}$.

Jobling, Paul. "Playing Safe: The Politics of Pleasure and Gender in the Promotion of Condoms in Britain, 1970-1982." Journal of Design History 10, 1 (1997): 53-70.

Junod, Suzanne White and Lara Marks. "Women's Trials: The Approval of the First Oral Contraceptive Pill in the United States and Great Britain." Journal of the History of Medicine and Allied Sciences 57, 2 (April 2002): 117-160.

Jütte, Robert. Contraception: A History. Trans. Vicky Russell. Cambridge: Polity Press, 2008.

Kline, Wendy. Building a Better Race: Gender, Sexuality and Eugenics from the Turn of the Twentieth Century to the Baby Boom. Berkeley: University of California Press, 2001.

Kluchin, Rebecca M. Fit to Be Tied: Sterilization and Reproductive Rights in America, 1950-1980. New Brunswick: Rutgers University Press, 2009.

Korinek, Valerie. Roughing It in the Suburbs: Reading Chatelaine Magazine in the Fifties and Sixties. Toronto: University of Toronto Press, 2000.

Kostash, Myrna. Long Way From Home: The Stories of the Sixties Generation in Canada. Toronto: James Lorimier, 1980.

Lee, Raymond M. Doing Research on Sensitive Topics. London: Sage Publications, 1993.

Lexchin, Joel. "Pharmacare: Equity, Efficiency, and Effectiveness-We've Waited Long Enough." In Medicare: Facts, Myths, Problems \& Promise, eds. Bruce Campbell and Greg Marchildon, 262-267. Toronto: James Lorimer and Company Ltd., 2007.

Marchildon, Greg. "Federal Pharmacare: Prescription for an Ailing Federation." In Medicare: Facts, Myths, Problems \& Promise, eds. Bruce Campbell and Greg Marchildon, 268-284. Toronto: James Lorimer and Company Ltd., 2007.

Marks, Lara. Sexual Chemistry: A History of the Contraceptive Pill. New Haven: Yale University Press, 2001. 
Marshall, Dominique. The Social Origins of the Welfare State: Québec Families, Compulsory Education, and Family Allowances, 1940-1955. Trans. Nicola Doone Danby. Waterloo: Wilfrid Laurier University Press, 2006.

May, Elaine Tyler. America and The Pill: A History of Promise, Peril, and Liberation. New York: Basic Books, 2010.

McDonnell, Kathleen. "The Women's Health Movement in Canada: New Directions." Canadian Dimension 13, 7 (May 1979): 30-32.

McLaren, Angus. A History of Contraception: From Antiquity to the Present Day. Oxford: B. Blackwell, 1990.

McLaren, Angus and Arlene Tigar McLaren. The Bedroom and the State: The Changing Practices and Politics of Contraception and Abortion in Canada, 1880-1980. Toronto: McClelland and Stewart, 1986.

McLaren, Angus and Arlene Tigar McLaren. The Bedroom and the State: The Changing Practices and Politics of Contraception and Abortion in Canada, 1880-1997. Second Edition. Oxford: Oxford University Press, 1997.

McLaren, Angus. Our Own Master Race: Eugenics in Canada, 1885-1945. Toronto: McClelland and Stewart, 1990.

McLaughlin, Loretta. The Pill, John Rock, and the Church: The Biography of a Revolution. Toronto: Little, Brown and Company, 1982.

Minister, Kristina. “A Feminist Framework for the Oral History Interview." In Women's Words: The Feminist Practice of Oral History, eds. Sherna Berger Gluck and Daphne Patai, 27-41. New York: Routledge, 1991.

Mitchinson, Wendy. "Agency, Diversity, and Constraints: Women and Their Physicians, Canada, 1850-1950." In The Politics of Women's Health: Exploring Agency and Autonomy by The Feminist Health Care Ethics Research Network, 122-149. Philadelphia: Temple University Press, 1998.

Mitchinson, Wendy. "Problematic Bodies and Agency: Women Patients in Canada, 1900-1950." In On The Case: Explorations in Social History, eds. Franca Iacovetta and Wendy Mitchinson, 266-286. Toronto: University of Toronto Press, 1998.

Mitchinson, Wendy. The Nature of Their Bodies: Women and Their Doctors in Victorian Canada. Toronto: University of Toronto Press, 1991.

Morrow, Marina. "Our Bodies, Ourselves in Context: Reflections on the Women's Health Movement in Canada." In Women's Health in Canada: Critical Perspectives on 
Theory and Policy, eds. Marina Morrow, Olena Hankivsky and Colleen Varcoe, 33-63. Toronto: University of Toronto Press, 2007.

New World Coming: The Sixties and the Shaping of Global Consciousness, eds. Karen Dubinsky, Catherine Krull, Susan Lord, Sean Mills and Scott Rutherford. Toronto: Between the Lines, 2009.

Owram, Doug. Born at the Right Time: A History of the Baby Boom Generation. Toronto: University of Toronto Press, 1996.

Pearson, Glen J. "Evolution in the practice of pharmacy-not a revolution!" Canadian Medical Association Journal, 176, 9 (April 24, 2007), http://www.cmaj.ca/content/176/9/1295.full\#ref-1.

Portelli, Alessandro. "What Makes Oral History Different." Reprinted in The Oral History Reader Second Edition, eds. Robert Perks and Alistair Thomson, 32-42. New York: Routledge, 2006.

Religious Denominations in Canada. Ottawa: Queen's Printer, 1965.

Revie, Linda. "More Than Just Boots! The Eugenic and Commercial Concerns behind A.R. Kaufman's Birth Controlling Activities." Canadian Bulletin of Medical History 23, 1 (2006): 119-143.

Ritchie, Donald A. Doing Oral History: A Practical Guide. Oxford: Oxford University Press, 2003.

Ruzek, Sheryl Burt. The Women's Health Movement: Feminist Alternative to Medical Control. New York: Praeger Publishers, 1978.

Saks, Mike. "Medicine and the Counter Culture." In Medicine in the Twentieth Century, eds. Roger Cooter and John Pickstone, 113-123. Amsterdam: Harwood Academic Publishers, 2000.

Sangster, Joan. "Telling Our Stories: Feminist Debates and the Use of Oral History." Women's History Review 3, 1 (1994): 5-28.

Schoen, Johanna. Choice and Coercion: Birth Control, Sterilization, and Abortion in Public Health and Welfare. Chapel Hill: The University of North Carolina Press, 2005.

Schoepflin, Rennie B. Christian Science on Trial: Religious Healing in America. Baltimore: The Johns Hopkins University Press, 2003.

Sethna, Christabelle. "A Bitter Pill: Second Wave Feminist Critiques of Oral Contraception." Canada: Confederation to the Present. Eds. Bob Hesketh and Chris Hackett. Edmonton: Chinook Multimedia Inc., 2001. 
Sethna, Christabelle. " 'Chastity Outmoded!' The Ubyssey, Sex, and the Single Girl, 1960-1970." In Creating Postwar Canada: Community, Diversity, and Dissent, 19451975, eds. Magda Fahrni and Robert Rutherdale, 289-314. Vancouver: UBC Press, 2008.

Sethna, Christabelle. "The Evolution of the Birth Control Handbook: From Student PeerEducation Manual to Feminist Self-Empowerment Text, 1968-1975." Canadian Bulletin of Medical History 23, 1 (2006): 89-117.

Sethna, Christabelle. "The University of Toronto Health Service, Oral Contraception, and Student Demand for Birth Control, 1960-1970." Historical Studies in Education 17, 2 (2005): 265-292.

Sethna, Christabelle. “'WE WANT FACTS NOT MORALS!' Unwed Motherhood, High School Women's Liberation and the Second Wave Feminist Reproductive Rights Campaign." In Ontario Since Confederation: A Reader, eds. Edgar-André Montigny and Lori Chambers, 409-428. Toronto: University of Toronto Press, 2000.

Soderstrom, Lee. The Canadian Health System. London: Croom Helm Ltd., 1978.

Spencer, Byron G. and Dennis C. Featherstone. "Married Women in Canada's Labour Force." In Marriage, Family and Society: Canadian Perspectives, ed. S. Parvez Wakil, 341-358. Toronto: Butterworth \& Co. Limited, 1975.

Stephens, Trent and Rock Brynner. Dark Remedy: The Impact of Thalidomide and Its Revival as a Vital Measure. Cambridge: Perseus Publishing, 2001.

Stern, Alexandra. Eugenic Nation: Faults and Frontiers of Better Breeding in Modern America. Berkeley: University of California Press, 2005.

Stourton, Edward. Absolute Truth: The Catholic Church in the World Today. London: Penguin Group, 1998.

Strong-Boag, Veronica. "Home Dreams: Women and the Suburban Experiment in Canada, 1945-60." Canadian Historical Review 72, 4 (1991): 471-504.

Summerfield, Penny. Reconstructing Women's Wartime Lives: Discourse and Subjectivity in Oral Histories of the Second World War. Manchester: Manchester University Press, 1989.

The Insight Team of the Sunday Times. Suffer the Children: The Story of Thalidomide. London: André Deutsch Limited, 1979.

The Oral History Reader Second Edition, eds. Robert Perks and Alistair Thomson. New York: Routledge, 2006. 
The Sixties: Passion, Politics, and Style, ed. Dimitry Anastakis. Montreal and Kingston: McGill-Queen's University Press, 2008.

Tone, Andrea. Devices and Desires: A History of Contraceptives in America. New York: Hill and Wang, 2001.

Tone, Andrea. "Making Room for Rubbers: Gender, Technology and Birth Control before the Pill." History and Technology 18, 1 (2002): 51-76.

Vayda, Eugene and Raisa B. Deber. "The Canadian Health-Care System: A Developmental Overview." In Canadian Health Care and the State: A Century of Evolution, ed. C. David Naylor, 125-140. Montreal and Kingston: McGill-Queen's University Press, 1992.

Watkins, Elizabeth Siegel. On the Pill: A Social History of Oral Contraceptives 1950-70. Baltimore: The Johns Hopkins University Press, 1998.

Yow, Valerie Raleigh. Recording Oral History: A Guide for the Humanities and Social Sciences. New York: Altamira Press, 2005. 